\title{
PoLA/CFPiP/PCS/PSLD/PSD/PSH guidelines on diagnosis and therapy of lipid disorders in Poland 2021
}

\author{
Maciej Banach (Chairperson) ${ }^{1,2,3}$, Paweł Burchardt ${ }^{4,5}$, Krzysztof Chlebus ${ }^{6}$, Piotr Dobrowolski ${ }^{7}$, \\ Dariusz Dudek ${ }^{8}$, Krzysztof Dyrbuśs ${ }^{9}$, Mariusz Gąsior ${ }^{9}$, Piotr Jankowski ${ }^{10,11}$, Jacek Jóźwiak ${ }^{12}$, \\ Longina Kłosiewicz-Latoszek ${ }^{13}$, Irina Kowalska ${ }^{14}$, Maciej Małecki ${ }^{15}$, Aleksander Prejbisz ${ }^{7}$, \\ Michał Rakowski ${ }^{16}$, Jacek Rysz ${ }^{17}$, Bogdan Solnica ${ }^{18}$, Dariusz Sitkiewicz ${ }^{19}$, Grażyna Sygitowicz ${ }^{19}$, \\ Grażyna Sypniewska ${ }^{20}$, Tomasz Tomasik ${ }^{21}$, Adam Windak ${ }^{21}$, Dorota Zozulińska-Ziółkiewicz²2, \\ Barbara Cybulska (Co-Chairperson) ${ }^{13}$
}

\author{
${ }^{1}$ Department of Preventive Cardiology and Lipidology, Medical University of Lodz, \\ Lodz, Poland \\ ${ }^{2}$ Cardiovascular Research Center, University of Zielona Gora, Zielona Gora, Poland \\ ${ }^{3}$ Department of Cardiology and Congenital Diseases of Adults, Polish Mother's \\ Memorial Hospital Research Institute (PMMHRI) in Lodz, Lodz, Poland \\ ${ }^{4}$ Department of Hypertensiology, Angiology, and Internal Medicine, \\ K. Marcinkowski Poznan University of Medical Science, Poznan, Poland \\ ${ }^{5}$ Department of Cardiology, Cardiovascular Unit, J. Strus Hospital, Poznan, Poland \\ ${ }^{6}$ First Department and Chair of Cardiology, Medical University of Gdansk, Gdansk, \\ Poland \\ ${ }^{7}$ Department of Hypertension, National Institute of Cardiology, Warsaw, Poland \\ ${ }^{8}$ Institute of Cardiology, Jagiellonian University Medical College, Krakow, Poland \\ ${ }^{9} 3^{\text {rd }}$ Department of Cardiology, Faculty of Medical Sciences in Zabrze, Medical \\ University of Silesia, Katowice, Poland; Silesian Center for Heart Diseases in Zabrze, \\ Poland \\ ${ }^{10}$ Department of Internal Medicine and Geriatric Cardiology, Centre of Postgraduate \\ Medical Education, Warsaw, Poland \\ ${ }^{11}$ Department of Cardiology and Arterial Hypertension, Institute of Cardiology, \\ Jagiellonian University Medical College, Krakow, Poland \\ ${ }^{12}$ Department of Family Medicine and Public Health, Institute of Medical Sciences, \\ Faculty of Medicine, University of Opole, Opole, Poland \\ ${ }^{13}$ National Institute of Public Health NIH - National Research Institute, Warsaw, \\ Poland \\ ${ }^{14}$ Department of Internal Medicine and Metabolic Diseases, Medical University \\ of Bialystok, Bialystok, Poland \\ ${ }^{15}$ Department and Chair of Metabolic Diseases, Jagiellonian University Medical \\ College, Krakow, Poland \\ ${ }^{16}$ Department of Molecular Biophysics, Institute of Biophysics, Faculty of Biology \\ and Environmental Protection, University of Lodz, Lodz, Poland \\ ${ }^{17}$ Chair of Nephrology, Arterial Hypertension, and Family Medicine, Medical University \\ of Lodz, Lodz, Poland \\ ${ }^{18}$ Chair of Clinical Biochemistry, Jagiellonian University Medical College, Krakow, \\ Poland \\ ${ }^{19}$ Department of Clinical Chemistry and Laboratory Diagnostics, Medical University \\ of Warsaw, Warsaw, Poland \\ ${ }^{20}$ Department of Laboratory Medicine, L. Rydygier Medical College in Bydgoszcz, \\ Nicolaus Copernicus University in Torun, Poland \\ ${ }^{21}$ Chair of Family Medicine, Jagiellonian University Medical College, Krakow, Poland \\ ${ }^{22}$ Department and Chair of Internal Medicine and Diabetology, K. Marcinkowski \\ Poznan University of Medical Sciences, Poznan, Poland
}

Submitted: 20 October 2021, Accepted: 3 November 2021

Online publication: 8 November 2021

Arch Med Sci 2021; 17 (6): 1447-1547

DOI: https://doi.org/10.5114/aoms/141941

Copyright (c) 2021 Termedia \& Banach
Corresponding author: Prof. Maciej Banach MD, PhD, FNLA, FAHA, FESC Department of Preventive Cardiology and Lipidology Medical University of Lodz Rzgowska 281/289 93-338 Lodz, Poland E-mail: maciej.banach@ umed.lodz.pl 
M. Banach, P. Burchardt, K. Chlebus, P. Dobrowolski, D. Dudek, K. Dyrbuś, M. Gąsior, P. Jankowski, J. Jóźwiak, L. Kłosiewicz-Latoszek I. Kowalska, M. Małecki, A. Prejbisz, M. Rakowski, J. Rysz, B. Solnica, D. Sitkiewicz, G. Sygitowicz, G. Sypniewska, T. Tomasik, A. Windak,

D. Zozulińska-Ziółkiewicz, B. Cybulska

\section{TABLE OF CONTENTS}

LIST OF ABBREVIATIONS

1. Preamble. Why do we need new guidelines in 2021? .................................................................. 1452

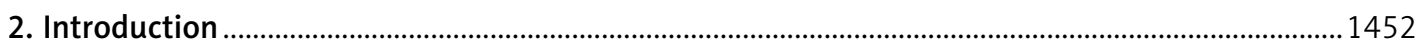

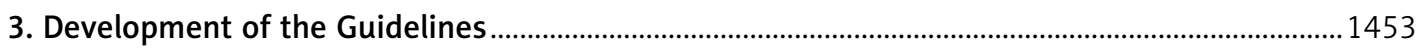

4. Epidemiology of lipid disorders in Poland......................................................................................... 1454

5. Lipid disorders as a cardiovascular risk factor ................................................................................... 1457

6. Recommendations on lipid profile measurement, its diagnostic significance, and limitations..... 1460

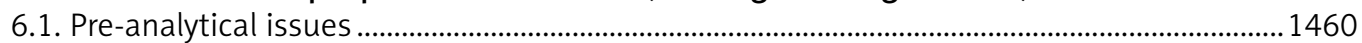

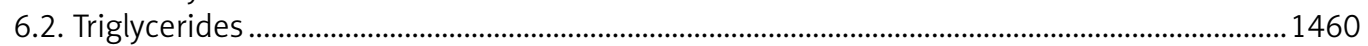

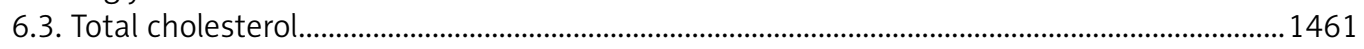

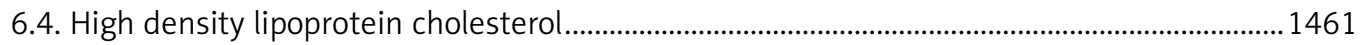

6.5. Low density lipoprotein cholesterol .......................................................................................... 1462

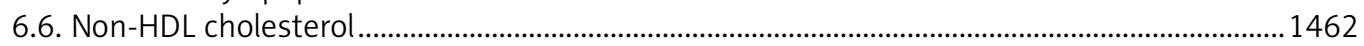

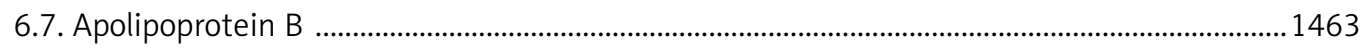

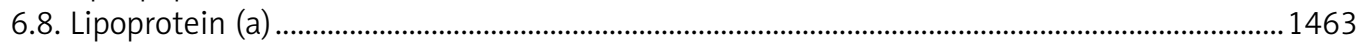

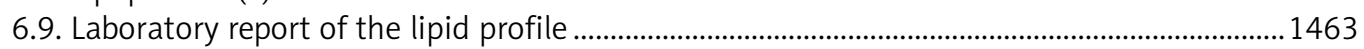

7. Therapy goals of lipid disorders - target values depending on the risk......................................... 1465

8. Non-pharmacological prevention and treatment of lipid disorders .................................................. 1468

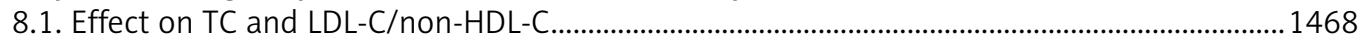

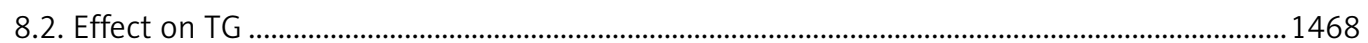

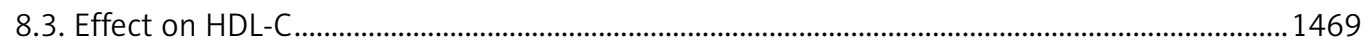

8.4. Significance of nutraceuticals and modified foods .................................................................. 1470

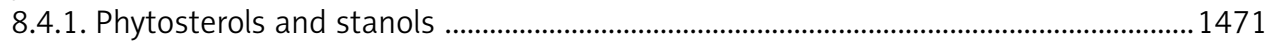

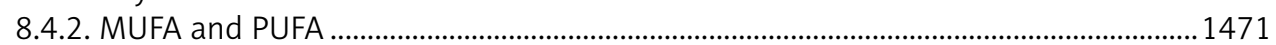

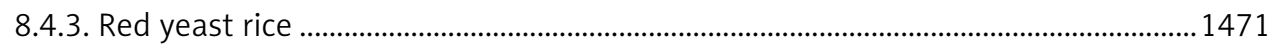

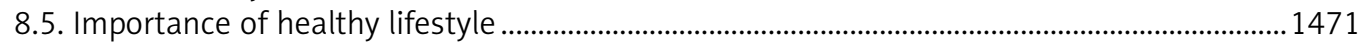

9. Principles of pharmacological treatment of lipid disorders ….......................................................1473

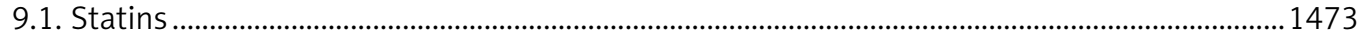

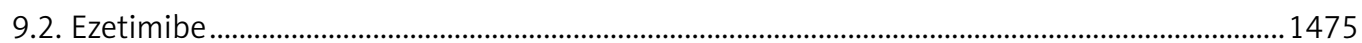

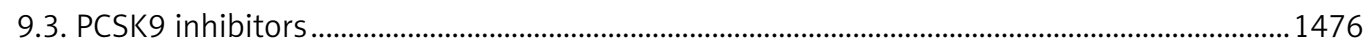

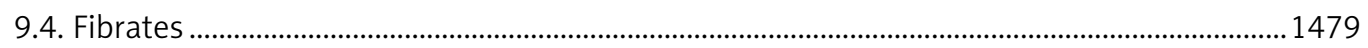

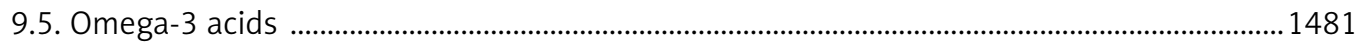

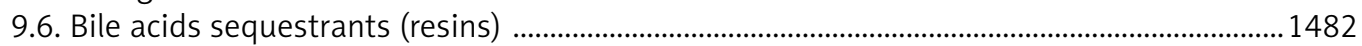

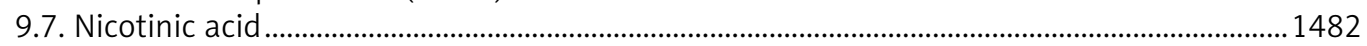

9.8. Combination therapy and guidelines concerning treatment of lipid disorders ................... 1483

9.9. Recommendations on management of hypertriglyceridaemia ..............................................1490

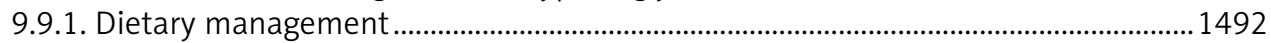

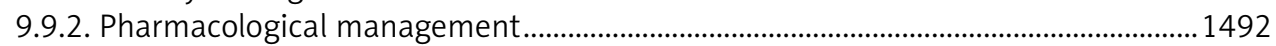

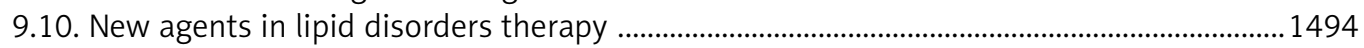

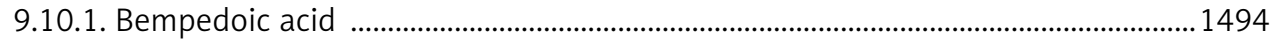

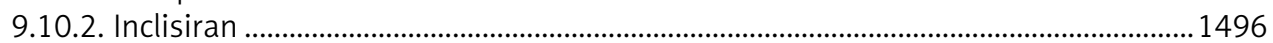

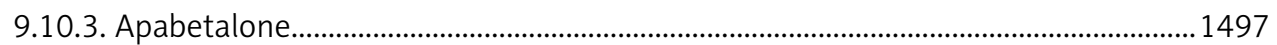

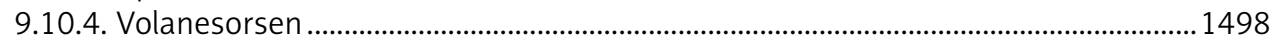

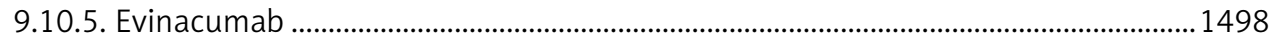

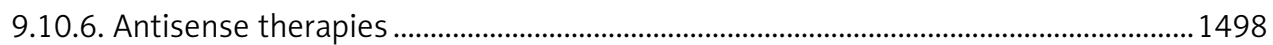

9.11. Management of elevated Lp(a) concentration ......................................................................... 1499

9.12. The importance of antihyperglycaemic agents in treatment of lipid disorders

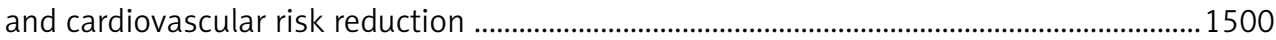

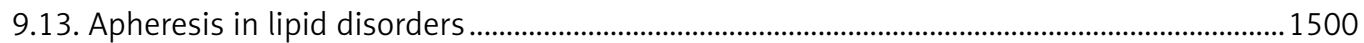

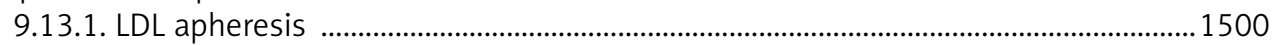

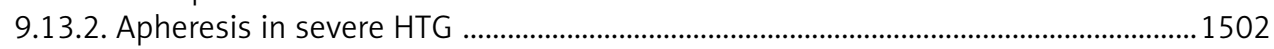

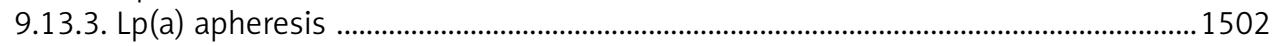


10. Treatment of lipid disorders in specific populations ................................................................. 1502

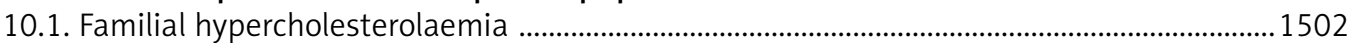

10.2. Prediabetes and diabetes mellitus .................................................................................................. 1504

10.2.1. Lipid disorders in patients with type 2 diabetes ........................................................ 1505

10.2.2. Lipid disorders in patients with type 1 diabetes ........................................................ 1505

10.2.3. Pharmacotherapy of lipid disorders in patients with diabetes................................... 1505

10.3. Arterial hypertension and lipid disorders.............................................................................................1506

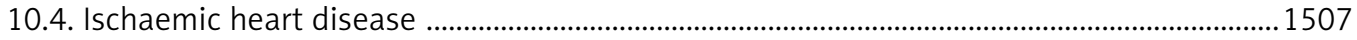

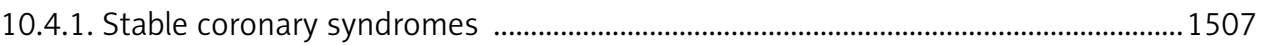

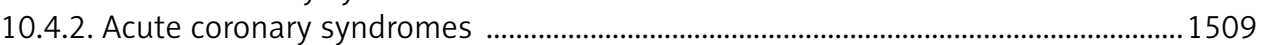

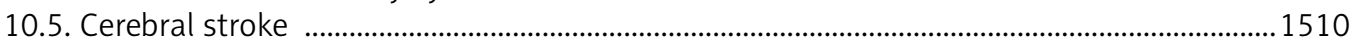

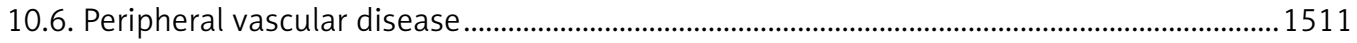

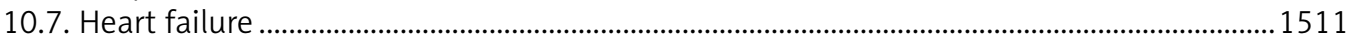

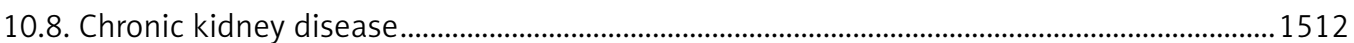

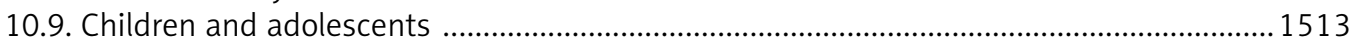

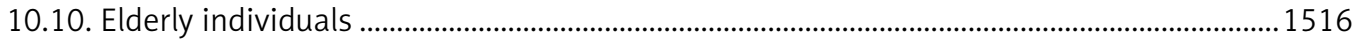

10.11. Autoimmune, rheumatic, and inflammatory diseases .......................................................... 1517

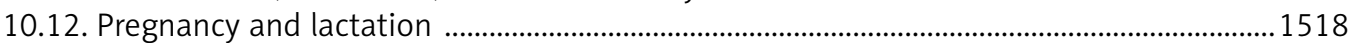

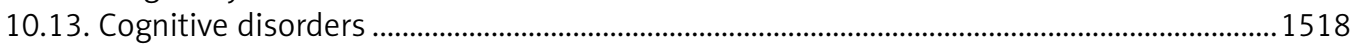

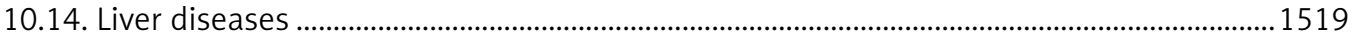

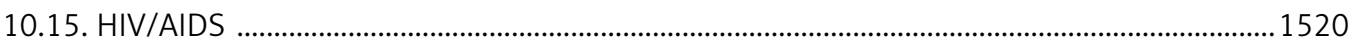

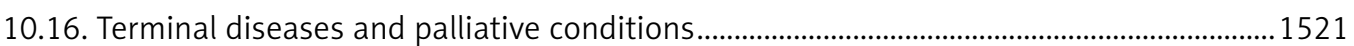

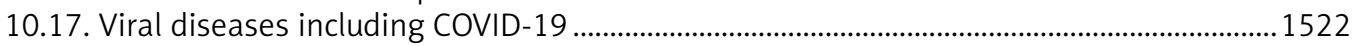

11. Adverse effects associated with treatment of dyslipidaemia/statin intolerance ...................... 1523

12. Recommendations on monitoring lipids and biochemical parameters during treatment

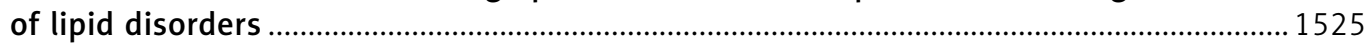

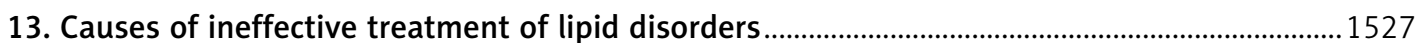

13.1. Efficacy of treatment of dyslipidaemia .......................................................................................1527

13.2. Therapeutic persistence in treatment of dyslipidaemia .......................................................... 1527

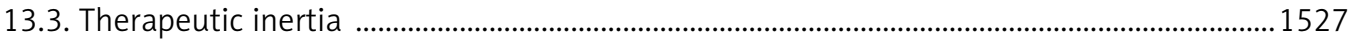

13.4. Causes of ineffective treatment of lipid disorders ................................................................. 1528

13.5. Recommendations on how to improve doctor-patient cooperation and thus the efficacy of lipid-lowering therapy, and effectively fight against anti-statin movements ..................... 1529

14. Organisation of healthcare in lipid disorders in Poland ............................................................... 1529

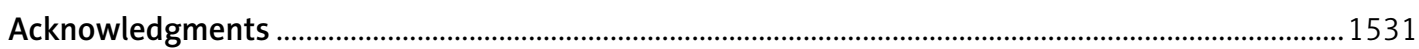

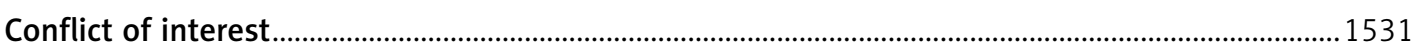

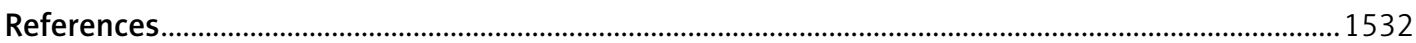

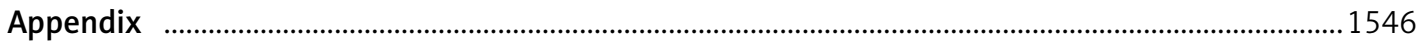


M. Banach, P. Burchardt, K. Chlebus, P. Dobrowolski, D. Dudek, K. Dyrbuś, M. Gąsior, P. Jankowski, J. Jóźwiak, L. Kłosiewicz-Latoszek, I. Kowalska, M. Małecki, A. Prejbisz, M. Rakowski, J. Rysz, B. Solnica, D. Sitkiewicz, G. Sygitowicz, G. Sypniewska, T. Tomasik, A. Windak, D. Zozulińska-Ziółkiewicz, B. Cybulska

\section{LIST OF ABBREVIATIONS}

AACE - American Association of Clinical Endocrinologists

$\mathrm{ABI}$ - ankle brachial index

ACCORD - Action to Control Cardiovascular Risk in Diabetes

$\mathrm{ACL}$ - adenosine triphosphate citrate lyase

ACS - acute coronary syndrome

AIM-HIGH - Atherothrombosis Intervention in Metabolic Syndrome with Low HDL/High Triglycerides: Impact on Global Health Outcomes

ALAT - alanine aminotransferase

ALT - alanine aminotransferase

ANGPTL3 - angiopoietin-like protein 3

AP - acute pancreatitis

Apo(a) - apolipoprotein (a)

apoB - apolipoprotein B

ASCVD - atherosclerotic cardiovascular disease BET - bromodomain and extra-terminal domain BETonMACE - Effect of RVX000222 on Time to Major Adverse Cardiovascular Events in High-Risk T2DM Subjects With CAD

$\mathrm{BMI}$ - body mass index

BPF - Bergamot-derived polyphenolic fraction

BRD4 - bromodomain-containing protein 4

CABG - coronary artery bypass grafting

$C A D$ - coronary artery disease

CETP - cholesterol ester transfer protein

CFPiP - College of Family Physicians in Poland

CHD - coronary heart disease

CHMP - Committee for Medicinal Products for Human Use (European Medicines Agency)

$\mathrm{CK}$ - creatine kinase

CLEAR - Cholesterol Lowering via Bempedoic acid, an ACL-Inhibiting Regimen

$\mathrm{CM}$ - chylomicrons

CNS - central nervous system

COBJwDL - Centralny Ośrodek Badań Jakości

w Diagnostyce Laboratoryjnej (Centre for Quality

Assessment in Laboratory Diagnostics)

COMPASS - A Randomised, Double-Blind, Pla-

cebo-Controlled Phase 3 Study of ISIS 304801

Administered Subcutaneously to Patients with

Hypertriglyceridaemia

CVD - cardiovascular disease

DGAT2 - diacylglycerol O-acyltransferase 2

DHA - docosahexaenoic acid

DPP-4 - dipeptidyl peptidase-4 [inhibitors]

EAS - European Atherosclerosis Society

EBBINGHAUS - Evaluating PCSK9 Binding antiBody Influence oN coGnitive HeAlth in High

cardiovascUlar Risk Subjects

EBM - evidence-based medicine

EFLM - European Federation of Clinical Chemistry and Laboratory Medicine

EFSA - European Food Safety Authority

eGFR - estimated glomerular filtration rate

ELIPSE HoFH - Evinacumab Lipid Studies in
Patients with Homozygous Familial Hypercholesterolaemia

EMA - European Medicines Agency

EPA - icosapent ethyl

ESC - European Society of Cardiology

EVACS - Evolocumab in Acute Coronary Syndrome

EVAPORATE - Effect of Vascepa on Improving Coronary Atherosclerosis in People with High Triglycerides Taking Statin Therapy

EVOPACS - EVOlocumab for Early Reduction of LDL-cholesterol Levels in Patients with Acute Coronary Syndromes

FCS - familial chylomicronaemia syndrome

FDA - US Food and Drug Administration

FFA - free fatty acids

$\mathrm{FH}$ - familial hypercholesterolaemia

FHS - Framingham Heart Study

FIELD - the Fenofibrate Intervention and Event

Lowering in Diabetes

FOURIER - Further Cardiovascular Outcomes

Research with PCSK9 Inhibition in Subjects with Elevated Risk

GBD - global burden of disease

GISSI-HF - Effect of rosuvastatin in patients with chronic heart failure

GLAR - German Lipoprotein Apheresis Registry

GLP-1 - glucagon-like peptide 1 [receptor]

HAART - highly active antiretroviral therapy

HBV - hepatitis B virus

HCV - hepatitis C virus

$\mathrm{HDL}$ - high density lipoprotein

$\mathrm{HeFH}$ - heterozygous familial hypercholesterolae-

mia

HMG-CoA - hydroxy 3-methylglutaryl-CoA [reductase]

HoFH - homozygous familial hypercholesterolae-

mia

HPS - Heart Protection Study

HPS2-THRIVE - Treatment of HDL to Reduce the

Incidence of Vascular Events

$\mathrm{HR}$ - hazard ratio

hSCRP - high-sensitivity CRP

HTG - hypertriglyceridaemia

IDL - intermediate density lipoprotein

ILEP - International Lipid Expert Panel

IMPROVE-IT - Improved Reduction of Outcomes:

Vytorin Efficacy International Trial

KIV-2 - kringle IV type 2 domain

KOS-Zawat - Kompleksowa Opieka Specjalistyczna dla osób po przebytym Zawale serca (Comprehensive Coordinated Care After Myocardial Infarction)

$L D L$ - low density lipoprotein

LDLR - LDL receptors

Lp(a) - lipoprotein (a)

$\mathrm{LPL}$ - lipoprotein lipase

MACE - major adverse cardiovascular events 
$\mathrm{MCl}$ - mild cognitive impairment

MCS - multifactorial or polygenic chylomicronaemia

MCT - medium-chain triglycerides

MUFA - monounsaturated fatty acids

NAFLD - non-alcoholic fatty liver disease

$\mathrm{NASH}$ - non-alcoholic steatotic hepatitis

NATPOL - Ogólnopolskie Badanie Rozpowszechnienia Czynników Ryzyka Chorób Układu Krążenia (Polish Nationwide Study on Prevalence of Cardiovascular Risk Factors)

NCD-RisC - Non-Communicable Disease Risk Factor Collaboration

NCEP - [US] National Cholesterol Education

Program

NCEP-ATP III - National Cholesterol Education

Program - Adult Treatment Panel III

NHF - National Health Fund

NNRTI - non-nucleoside reverse transcriptase

inhibitor

NNT - number needed to treat

NPC1L1 - Niemann-Pick C1 like 1 protein (a sterol transporter)

Odyssey OUTCOMES - Evaluation of Cardiovascular Outcomes After an Acute Coronary Syndrome During Treatment with Alirocumab

PAD - peripheral artery disease

$\mathrm{PBC}$ - primary biliary cirrhosis

$\mathrm{PCl}$ - percutaneous coronary intervention

PCS - Polish Cardiac Society

PCSK9 - subtilisin/kexin type 9 proprotein con-

vertase

$\mathrm{PHC}$ - primary health care

PoLA - Polish Lipid Association

PSD - Polish Society of Diabetology

PSLD - Polish Society of Laboratory Diagnostics

PSH - Polish Society of Hypertension

PPAR - peroxisome proliferator-activated recep-

tors

PPAR- $\alpha$ - peroxisome proliferator activated $\alpha$

receptors (transcription factors)

PROMINENT - Pemafibrate to Reduce Cardio-

vascular OutcoMes by Reducing Triglycerides IN patiENts with diabetes

PUFA - polyunsaturated fatty acids

REDUCE-IT - the Reduction of Cardiovascular

Events with Icosapent Ethyl - Intervention Trial

RISC - RNA-induced silencing complex

RNAi - RNA interference

$\mathrm{R} R$ - relative risk

SAMS - statin-associated muscle symptoms

SCORE - systematic coronary risk evaluation

SdLDL - small dense LDL

SFA - saturated fatty acids

SGLT2 - sodium-glucose cotransporter

SMPT - system for monitoring of therapeutic

programmes

SPES - Southern Poland Epidemiological Survey
STRENGHT - A Long-Term Outcomes Study to Assess STatin Residual Risk Reduction with EpaNova in HiGh Cardiovascular Risk PatienTs with Hypertriglyceridaemia

T1DM - type 1 diabetes mellitus

T2DM - type 2 diabetes mellitus

TAUSSIG - Trial Assessing Long Term USe of PCSK9 Inhibition in Subjects with Genetic LDL Disorders

TC - total cholesterol

TERCET - Tertiary Cardiological cEnTer Registry

TESLA - PCSK9 with evolocumab in homozygous familial hypercholesterolaemia

TG - triglycerides

TIA - transient ischaemic attack

TRL - TG-rich lipoproteins

ULN - upper limit of normal

VCU-AlirocRT - Virginia Commonwealth University Alirocumab Response Trial

VITAL - The VITamin D and OmegA-3 TriaL

VLDL - very low-density lipoprotein

WHO - World Health Organisation

WOBASZ - Wieloośrodkowe Ogólnopolskie

Badanie Stanu Zdrowia Ludności (Multicenter Nationwide Study of Population Health in Poland) 
M. Banach, P. Burchardt, K. Chlebus, P. Dobrowolski, D. Dudek, K. Dyrbuś, M. Gąsior, P. Jankowski, J. Jóźwiak, L. Kłosiewicz-Latoszek, I. Kowalska, M. Małecki, A. Prejbisz, M. Rakowski, J. Rysz, B. Solnica, D. Sitkiewicz, G. Sygitowicz, G. Sypniewska, T. Tomasik, A. Windak, D. Zozulińska-Ziółkiewicz, B. Cybulska

\section{PREAMBLE. WHY DO WE NEED NEW GUIDELINES IN 2021?}

Despite 30 years (simvastatin was approved for clinical use by the FDA in 1991 [1]) of experts', societies', and patient organisations' efforts, lipid disorders still comprise a diagnostic and, before all, therapeutic challenge. This applies to adequate risk assessment in patients, introduction of appropriate treatment, problems with patient compliance, as well as to problems with so important non-pharmacological treatment - diet, body mass reduction, or regular exercise [2]. The significance of therapeutic inertia, either in the form of inadequate therapy (usually the lack of intensive statin treatment or, even less likely, combination therapy) or evident errors such as dose reduction or cessation of treatment following achievement of the therapeutic target, also cannot be diminished. That is why in Poland there are still nearly 20 million individuals with hypercholesterolaemia, most of them are unaware of their condition [3]; that is why only ca. $5 \%$ of patients with familial hypercholesterolaemia out of predicted as much as 140,000 have been diagnosed; that is also why other rare cholesterol metabolism disorders are so rarely diagnosed in Poland $[4,5]$.

Let us hope that these guidelines, for the first time being an effect of work of experts representing 6 main scientific societies, as well as the network of Polish Lipid Association (PoLA) lipid centers (currently under development, https:// ptlipid.pl/siec-centrow-lipidowych) (the list of centers is presented in Appendix), being a part of the European Atherosclerosis Society (EAS) lipid centers, certification of lipidologists by PoLA, or the growing number of centers for rare diseases, with a network planned by the Ministry of Health, improvements in coordinated care for patients after myocardial infarction (KOS-Zawał) associated with the need of lipid profile assessment at specific time points, reimbursement of innovative agents (after PCSK9 inhibitors, hopefully also inclisiran, bempedoic acid, evinacumab, and pelacarsen), as well as introduction in Poland of an effective (at least) primary prevention program, will make improvement in relation to these unmet needs in diagnostics and treatment of lipid disorders possible.

Moreover, over the last few years the approach to treatment of patients with a high cardiovascular risk has totally changed from treatment aimed at a specific risk factor (i.e., glucocentricity or lipocentricity) to effective diagnostics, monitoring, and treatment of all risk factors and general cardiovascular risk as well as concomitant diseases, stressing the role of residual risk, and the intensity of the applied therapy. In the case of lipid disorders, intensive lipid-lowering treatment is currently recommended (and not just intensive statin treatment, as it has been for years) in order to achieve in our patients as low concentrations of low density lipoprotein (LDL) cholesterol as possible, according to the rule of "the lower the better", but also to do it as soon as possible ("the earlier the better") and maintain it as long as possible ("the longer the better"), as this gives us a chance to reduce the risk of cardiovascular events even in every other patient $(50-55 \%)[6,7]$.

Taking into consideration immense challenges still present in diagnostics and therapy of lipid disorders, changes in the approach to treatment, including innovative molecules, as well as the most recent results of numerous studies (lipidology and atherosclerosis research are currently the most rapidly developing specialty in medicine), Polish Lipid Association (PoLA), along with College of Family Physicians in Poland (CFPiP), Polish Cardiac Society (PCS), Polish Society of Diabetology (PSD), Polish Society of Laboratory Diagnostics (PSLD), and Polish Society of Hypertension (PSH), decided to prepare comprehensive guidelines concerning management of lipid disorders, with special attention paid to the practical aspect of these guidelines, as we would like to make them an actual tool for everyday work with patients suffering from lipid disorders.

\section{INTRODUCTION}

Although 5 years elapsed since the time of publication of the previous guidelines, lipid metabolism disorders remain the most common and the worst controlled cardiovascular risk factor in Poland [8]. Along with tobacco smoking, type 2 diabetes mellitus, arterial hypertension, improper dietary habits, and insufficient physical activity leading to overweight and obesity, they are the primary modifiable risk factors of atherosclerosis and its most important complications, such as ischaemic heart disease, cerebral stroke, and peripheral artery disease [9].

The results of epidemiological studies performed in our country indicate that their prevalence grows constantly due to spreading of unhealthy dietary habits and sedentary lifestyle resulting in an epidemic of overweight and obesity [10], in which the coronavirus pandemic also played a very detrimental role in the last 2 years. Recent results of large observational studies by NonCommunicable Disease Risk Factor Collaboration (NCD-RisC) indicate that Poland belongs to countries in which the least changes in mean total cholesterol or non-high density lipoprotein (non-HDL) cholesterol concentration may be observed, even with trends indicating their growth in men in subsequent years, which, unfortunately, has translated into a slight decrease or the lack of reduction 
of mortality due to ischaemic heart disease and ischaemic stroke dependent on this risk factor in the years 1990-2017 [11, 12].

Therefore, their control, with particular emphasis on lipid disorders, remains one of the main public health challenges, also in the present context of struggle to improve the health of Poles in the post-pandemic era. To face these challenges, comprehensive preventive activities at the population level are needed, especially those concerning primary prophylaxis, which should be concentrated on selection of high-risk patients, adequate widespread health education, and optimum treatment (including non-pharmacological interventions), to avoid or delay development of ischaemic heart disease, stroke, or peripheral artery disease.

Family physicians, as well as other healthcare professionals (cardiologists, diabetologists, internists, nurses), bear a special responsibility with respect to high-risk patients, i.e., the group to which numerous patients with dyslipidaemia belong. This common, well-organised struggle, with good communication between family physicians and specialists (which is still often missing), should be an element of a wider strategy aimed at reduction of the total cardiovascular risk, and ultimately at reduction of mortality, morbidity, and disability due to cardiovascular disease.

\section{DEVELOPMENT OF THE GUIDELINES}

Members of the Steering Committee who prepared these guidelines were selected and indicated by Polish Lipid Association (PoLA), College of Family Physicians in Poland (CFPiP), Polish Cardiac Society (PCS), Polish Society of Diabetology (PSD),
Polish Society of Laboratory Diagnostics (PSDL), and Polish Society of Hypertension (PSH) as experts in treatment of patients with lipid disorders. The Steering Committee has carefully reviewed published evidence on the management of dyslipidaemia, including its diagnosis, treatment, and prevention, as well as critical evaluation of diagnostic and therapeutic procedures, including benefit-risk assessment and cost-effectiveness indicators. The level of evidence and the strength of recommendations for each intervention were weighed and categorised using widely recognised defined classifications presented in Tables I and II. As these guidelines are intended to be a practical tool, apart from application of the appropriate class and strength of recommendation, each chapter is additionally independently summarised, pointing to the information necessary to remember by physicians and key points of recommendation, in terms of their application in everyday clinical practice.

Experts being members of the Writing Committee submitted the declaration of interest forms regarding all associations that could be perceived as actual or potential sources of conflict of interest (see details at the end of this document). After final approval of their content, the final pre-print version of the guidelines will be published immediately on the webpages of the relevant societies and then, if possible, simultaneously published in the Archives of Medical Science (indicated by PoLA), Lekarz Rodzinny (official journal of CFPiP), Kardiologia Polska (Polish Heart Journal, PCS), Diagnostyka Laboratoryjna (Laboratory Diagnostics, PSDL), Current Topics in Diabetes (PSD), Nadciśnienie Tętnicze $w$ Praktyce (PSH) and additionally

Table I. Classification of recommendations in the guidelines

\begin{tabular}{|c|c|c|}
\hline $\begin{array}{l}\text { Class of } \\
\text { recommendation }\end{array}$ & Definition & Suggestion of use \\
\hline Class I & $\begin{array}{l}\text { There is scientific evidence and/or general agreement that a specific } \\
\text { treatment/procedure is beneficial, useful, and effective }\end{array}$ & $\begin{array}{l}\text { It is recommended/ } \\
\text { It is indicated }\end{array}$ \\
\hline Class II & $\begin{array}{c}\text { Scientific evidence is ambiguous and/or there are conflicting } \\
\text { opinions as to the usefulness/efficacy of a specific treatment/ } \\
\text { procedure }\end{array}$ & \\
\hline Class Ila & $\begin{array}{l}\text { Prevailing evidence/opinions confirm the usefulness/efficacy of } \\
\text { a specific treatment/procedure }\end{array}$ & It should be considered \\
\hline Class IIb & $\begin{array}{c}\text { Evidence/opinions do not sufficiently confirm the usefulness/efficacy } \\
\text { of a specific treatment/procedure }\end{array}$ & It may be considered \\
\hline Class III & $\begin{array}{l}\text { There is scientific evidence and/or general agreement that a specific } \\
\text { treatment/procedure is useless/ineffective, and in certain cases it } \\
\text { may be harmful }\end{array}$ & It is not recommended \\
\hline
\end{tabular}

Table II. Level of evidence

\begin{tabular}{|l|r|}
\hline Level A & Data obtained from multiple randomised clinical trials or meta-analyses \\
\hline Level B & Data obtained from a single randomised clinical trial or large non-randomised trials \\
\hline Level C & A consensus expert opinion and/or data from small trials; retrospective studies, and registries \\
\hline
\end{tabular}


M. Banach, P. Burchardt, K. Chlebus, P. Dobrowolski, D. Dudek, K. Dyrbuś, M. Gąsior, P. Jankowski, J. Jóźwiak, L. Kłosiewicz-Latoszek, I. Kowalska, M. Małecki, A. Prejbisz, M. Rakowski, J. Rysz, B. Solnica, D. Sitkiewicz, G. Sygitowicz, G. Sypniewska, T. Tomasik, A. Windak, D. Zozulińska-Ziółkiewicz, B. Cybulska

Lekarz POZ to reach as many interested parties as possible.

Family physicians and physicians of other specialities involved in the care of patients with lipid disorders are encouraged to take these guidelines into full consideration in clinical evaluation as well as in development and implementation of medical strategies for prevention, diagnostics, or treatment. However, these guidelines do not in any way disclaim the individual responsibility of physicians for making appropriate and accurate decisions, taking into account the condition of a specific patient, and following consultation with the patient and, if necessary, with the patient's caregiver. Healthcare professionals are also responsible for verification of the rules and regulations concerning medicines and devices at the time of their prescription/application.

\section{EPIDEMIOLOGY OF LIPID DISORDERS IN POLAND}

Disorders of lipid metabolism are the most common cardiovascular risk factor; this has also been confirmed in Polish screening studies $[4,10]$. Despite continuous education of physicians and patients and availability of different lipid-lowering therapies, the effectiveness of detection and treatment of dyslipidaemia in Poland remains unsatisfactory. Over the last nearly 40 years, numerous, extensive studies have been conducted in Poland to evaluate the prevalence of dyslipidaemia. A summary of the most important studies concerning lipid disorders, including the method of patient sample selection and the years of their conduction, is presented in Table III.

Depending on the sample selection method, the prevalence of dyslipidaemia in Poland is estimated at $60-80 \%$ of people in the population over 18 years of age [13]. The first data on the prevalence of hyperlipidaemia (the Pol-MONICA study) indicated hypercholesterolaemia in just over $70 \%$ of women and nearly $73 \%$ of men [14]. In that study, the percentage of individuals with the low-density lipoprotein-cholesterol (LDL-C) concentration above the normal range was higher in men (60\%) than in women (53\%) [14]. Decreased HDL-C concentration was observed in nearly $2 \%$ of women and $10 \%$ of men, while elevated triglyceride (TG) concentration was observed in $6 \%$ of women and $21 \%$ of men [14]. In another study (SPES - Southern Poland Epidemiological Survey) hypercholesterolaemia was reported in nearly $56 \%$ of the subjects $(58 \%$ of women and $52 \%$ of men, respectively) [15]. The cited results, however, were not nationwide but restricted to the ex-voivodeships of Warsaw and Tarnobrzeg (the Pol-MONICA study), and Katowice and Bielsko-Biala (the SPES study).

Further data on the prevalence of dyslipidaemia in Poland came from two nationwide studies with random sampling: the NATPOL III PLUS study and the WOBASZ study. The prevalence of hypercholesterolaemia was estimated in the NATPOL study at $59.5 \%$ in men and $62 \%$ in women, while in the WOBASZ study it was $67 \%$ and $64 \%$, respectively $[16,17]$. In the NATPOL study, the observed percentage of patients with the LDL-C concentration above the normal range was almost the same in men and women (55\%) [16]. In the WOBASZ study, elevated LDL-C concentration was observed in $60 \%$ of men and $55 \%$ of women [17]. The proportion of patients with decreased $\mathrm{HDL}-\mathrm{C}$ concentration in the NATPOL study was $17 \%$ and $6 \%$ in men and women, respectively, and in the WOBASZ study, $15 \%$ and $17 \%$, respectively $[16,17]$. The NATPOL study results showed that in Poland hypertriglyceridaemia occurred in $30 \%$ of the subjects, more often in men than women (38\% vs. $23 \%$ ) [16]. In the WOBASZ study, elevated TG concentration was observed in $31 \%$ of men and $20 \%$ of women [17].

Significant prevalence of lipid disorders, estimated according to the US NCEP-ATP III (National Cholesterol Education Program - Adult Treatment Panel III) guidelines, was also observed in the nationwide studies LIPIDOGRAM2003, LIPIDOGRAM2004 and LIPIDOGRAM2006, in which a total number of nearly 49,000 primary health care $(\mathrm{PHC})$ patients were eventually included in the

Table III. Summary of Polish epidemiological studies on dyslipidaemia according to the method of patient sample selection

\begin{tabular}{|c|c|c|c|}
\hline \multicolumn{2}{|c|}{$\begin{array}{l}\text { Studies with random sampling } \\
\text { in the overall population }\end{array}$} & \multicolumn{2}{|c|}{$\begin{array}{l}\text { Studies in active } \\
\text { primary care patients }\end{array}$} \\
\hline Study acronym & Years of conduction & Study acronym & Years of conduction \\
\hline Pol-MONICA & 1984-1993 & SPES & 1997 \\
\hline NATPOL III PLUS & 2002 & POLSCREEN & 2002 \\
\hline WOBASZ & 2003-2005 & LIPIDOGRAM2003 & 2003 \\
\hline NATPOL 2011 & 2011 & LIPIDOGRAM2004 & 2004 \\
\hline \multirow[t]{3}{*}{ WOBASZ II } & $2013-2014$ & LIPIDOGRAM2006 & 2006 \\
\hline & & LIPIDOGRAM 5 LAT & 2004-2010 \\
\hline & & LIPIDOGRAM2015 & $2015-2016$ \\
\hline
\end{tabular}


databases (including LIPIDOGRAM 2015) [18-20]. In the LIPIDOGRAM2003 study, the mean values of lipid profile parameters were: total cholesterol (TC) $-228 \mathrm{mg} / \mathrm{dl}(5.9 \mathrm{mmol} / \mathrm{l}), \mathrm{LDL}-\mathrm{C}-140 \mathrm{mg} / \mathrm{dl}$ (3.6 mmol/l), HDL-C - $57 \mathrm{mg} / \mathrm{dl}(1.5 \mathrm{mmol} / \mathrm{l})$, and TG - $156 \mathrm{mg} / \mathrm{dl}(1.8 \mathrm{mmol} / \mathrm{l})$ [18]. Hypercholesterolaemia $>200 \mathrm{mg} / \mathrm{dl}(>5.2 \mathrm{mmol} / \mathrm{l})$ was reported in $72 \%$ of the subjects, more often in women than in men (76\% vs. $67 \%)$. Elevated LDL-C concentration (according to the normal values accepted at the time) of $>160 \mathrm{mg} / \mathrm{dl}(4.1 \mathrm{mmol} / \mathrm{l})$ occurred in $28 \%$ of the enrolled subjects, more often in women than in men (30\% vs. $24 \%$ ). Decreased $\mathrm{HDL}-\mathrm{C}$ concentration $<40 \mathrm{mg} / \mathrm{dl}(1.0 \mathrm{mmol} / \mathrm{l})$ was observed in $6 \%$ of the subjects, $12 \%$ and $3 \%$ in men and women, respectively, while elevated TG levels > $200 \mathrm{mg} / \mathrm{dl}(2.3 \mathrm{mmol} / \mathrm{l})$ were observed in $22 \%$ of the subjects, more often in men than in women (26\% vs. $19 \%$ ) [18]. Mean values of specific lipid profile parameters and the percentage of abnormal values in subsequent studies LIPIDOGRAM2004 [19] and LIPIDOGRAM2006 [20] - are presented in Figure 1.

In another study, i.e. NATPOL 2011, mean values of lipid profile parameters in men and women, respectively, were: TC - $197.1 \mathrm{mg} / \mathrm{dl}(5.1 \mathrm{mmol} / \mathrm{l})$ and $198.6 \mathrm{mg} / \mathrm{dl}$ (5.1 mmol/l), LDL-C $-123.6 \mathrm{mg} / \mathrm{dl}$ (3.2 $\mathrm{mmol} / \mathrm{l})$ and $123.7 \mathrm{mg} / \mathrm{dl}(3.2 \mathrm{mmol} / \mathrm{l})$, $\mathrm{HDL}-\mathrm{C}-45.8 \mathrm{mg} / \mathrm{dl}(1.2 \mathrm{mmol} / \mathrm{l})$ and $54.1 \mathrm{mg} / \mathrm{dl}$ (1.4 mmol/l), and TG - $140.9 \mathrm{mg} / \mathrm{dl}(1.6 \mathrm{mmol} / \mathrm{l})$ and $104.0 \mathrm{mg} / \mathrm{dl}(1.2 \mathrm{mmol} / \mathrm{l})$. The percentages of subjects with abnormal values were: TC > $190 \mathrm{mg} / \mathrm{dl}(4.9 \mathrm{mmol} / \mathrm{l})-54.3 \%$ (54.3\% of men and $54.4 \%$ of women), LDL-C > $115 \mathrm{mg} / \mathrm{dl}$ $(3.0 \mathrm{mmol} / \mathrm{l})-57.8 \%$ (58.3\% of men and 57.3 of women), HDL-C $<40 \mathrm{mg} / \mathrm{dl}(1.0 \mathrm{mmol} / \mathrm{l})$ in men - 32.5\%, HDL-C $<45 \mathrm{mg} / \mathrm{dl}(1.2 \mathrm{mmol} / \mathrm{l})$ in women $-22 \%$, TG > $150 \mathrm{mg} / \mathrm{dl}(1.7 \mathrm{mmol} / \mathrm{l})-21.1 \%$ (28.4\% of men and $14.0 \%$ of women) [4]. In the WOBASZ II study conducted 2 years later, hypercholesterolaemia was reported in $70.3 \%$ of men and $64.3 \%$ of women aged $>20$ years $(67.1 \%$ of the overall study population), while hypertriglyceridaemia with normal cholesterol concentration was observed in $5.6 \%$ of men and $2.4 \%$ of women [21]. Decreased HDL-C with normal TC and TG concentration was observed in $5.1 \%$ of men and $7.3 \%$ of women. Overall, at least one type of dyslipidaemia was reported in as much as $81.0 \%$ of women and $74.0 \%$ of women. As much as $60.6 \%$ of subjects with hypercholesterolaemia were not aware of this fact, and only $6 \%$ of patients were effectively treated and achieved reference values of lipid profile parameters [21].

In a 5-year nationwide prospective cohort study of LIPIDOGRAM 5-YEARS, conducted in the years 2004-2010 in a population of PHC patients treated for dyslipidaemia $(n=1841)$, the reduction of lipid profile parameter values was inef-

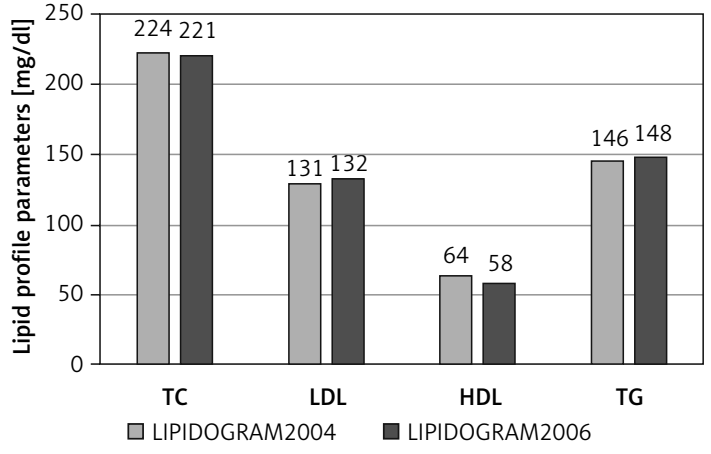

Figure 1. Mean values of lipid profile parameters in the LIPIDOGRAM2004 and LIPIDOGRAM2006 studies

fective in nearly $50 \%$ of individuals with TC and LDL-C concentration above the normal range and in more than $30 \%$ of individuals with elevated TG levels [22-24]; this de facto confirmed the lack of improvement of effectiveness of treatment of lipid disorders observed also in the earlier screening studies of LIPIDOGRAM2004 and LIPIDOGRAM2006 [22-24].

Insufficient control of hypercholesterolaemia was also observed in subsequent studies, including a study in patients hospitalised for ischaemic heart disease followed up in the Krakow Ischaemic Heart Disease Secondary Prevention Programme [25]. The target LDL-C concentration of $<70 \mathrm{mg} / \mathrm{dl}$ $(1.8 \mathrm{mmol} / \mathrm{l})$ was observed in only $28.1 \%$ of patients, while in $71.9 \%, 38.6 \%, 24.4 \%$ and $10.3 \%$, LDL-C was $\geq 70 \mathrm{mg} / \mathrm{dl}(1.8 \mathrm{mmol} / \mathrm{l}), \geq 100 \mathrm{mg} /$ dl $(2.5 \mathrm{mmol} / \mathrm{l}) \geq 115 \mathrm{mg} / \mathrm{dl}(3.0 \mathrm{mmol} / \mathrm{l})$, and $\geq 160 \mathrm{mg} / \mathrm{dl}$ (4.0 mmol/l), respectively [25]. Moreover, what is still a major challenge for physicians and researchers, studies performed in the past twenty years suggest that the percentage of patients with ischaemic heart disease achieving the recommended $L D L$ cholesterol concentration has not significantly changed as compared to the end of the $20^{\text {th }}$ century (regardless of differences with respect to the recommended target LDL-C concentration) [26]. Interestingly, the percentage of patients achieving the target LDL-C concentration among those who declared treatment in $\mathrm{PHC}$ clinics did not differ significantly from the same percentage in patients who declared that their treatment was decided by a physician in a specialist cardiology clinic [26].

In the most recent nationwide study on the prevalence and treatment of dyslipidaemia in primary care patients $(n=13,724)$, i.e., LIPIDOGRAM2015 \& LIPIDOGEN2015, conducted in the years 2015-2016, the results obtained did not indicate any significant improvement in the epidemiological situation concerning lipid disorders in Poland discussed above [10, 27, 28]. The results of the LIPIDOGRAM2015 study showed an elevated total cholesterol level of > $190 \mathrm{mg} / \mathrm{dl}$ 
M. Banach, P. Burchardt, K. Chlebus, P. Dobrowolski, D. Dudek, K. Dyrbuś, M. Gąsior, P. Jankowski, J. Jóźwiak, L. Kłosiewicz-Latoszek, I. Kowalska, M. Małecki, A. Prejbisz, M. Rakowski, J. Rysz, B. Solnica, D. Sitkiewicz, G. Sygitowicz, G. Sypniewska, T. Tomasik, A. Windak, D. Zozulińska-Ziółkiewicz, B. Cybulska

$(4.9 \mathrm{mmol} / \mathrm{l})$ in $58 \%$ of active $\mathrm{PHC}$ patients $>18$ years of age; LDL-C concentration > $115 \mathrm{mg} / \mathrm{dl}$ $(3.0 \mathrm{mmol} / \mathrm{l})$ was observed in $61 \%$ of the subjects, while decreased HDL-C concentration $<40 \mathrm{mg} / \mathrm{dl}$ $(1.0 \mathrm{mmol} / \mathrm{l})$ in men and $<45 \mathrm{mg} / \mathrm{dl}(1.2 \mathrm{mmol} / \mathrm{l})$ in women was observed in $14 \%$ of the subjects $[27,28]$. Elevated TG concentration > $150 \mathrm{mg} / \mathrm{dl}$ $(1.7 \mathrm{mmol} / \mathrm{l})$ was observed in $33 \%$ of patients. Mean values of lipid profile parameters in the overall population as well as in patients treated and not treated due to lipid disorders, depending on the prevalence of cardiovascular disease (CVD), are presented in detail in Table IV [10].

Despite changes in the prevalence of cardiovascular diseases and their risk factors (including lipid disorders) observed in Poland between the year 1990 and 2017, differences between Poland and Western Europe remain very high [29]. In Poland, as in other European countries, there are still discrepancies between the current clinical guidelines (2020) and clinical practice with respect to diagnostics and treatment of lipid disorders - only one in 3 patients in Europe and one in 4 in Poland achieves therapeutic goal; only $18 \%$ of patients in Europe, $17 \%$ in Poland, and only $13 \%$ in Central and Eastern European countries achieve the therapeutic goal for very high-risk patients $(<55 \mathrm{mg} / \mathrm{dl}$ ) $<1.4 \mathrm{mmol} / \mathrm{l})$, not to mention extreme risk patients, of whom less than $10 \%$ achieve their therapeutic goal ( $<40 \mathrm{mg} / \mathrm{dl} /<1 \mathrm{mmol} / \mathrm{l})[30,31]$.

It is also worth mentioning that, according to calculations based on predictions from the studies discussed above, in Poland there may be as many as 140-150 thousand patients with familial hypercholesterolaemia (predicted prevalence of 1 : 250]) [32, 33]. Unfortunately, only less than $5 \%$ of them are diagnosed despite existence of the registries, i.e., the Gdansk registry and the PTL registry, as well as a therapeutic programme for patients with $\mathrm{FH}$ in the context of treatment with PCSK9 inhibitors. Based on the TERCET Registry, it was observed that the prevalence of probable/certain $\mathrm{FH}$ diagnosis and possible $\mathrm{FH}$ diagnosis was $1.2 \%$ and $13.5 \%$, respectively, and in patients with acute coronary syndrome (ACS) $1.6 \%$ and $17.0 \%$, respectively [34]. The 30-day mortality rate was higher in patients with certain and probable $\mathrm{FH}$ diagnosis than in patients without $\mathrm{FH}(8.2 \%$ and $3.8 \%$ vs. $2.0 \%$, respectively). Similar results were observed (using the Propensity Score analysis) for

Table IV. Mean values of lipid profile parameters in patients with cardiovascular disease (CVD) and without CVD in the LIPIDOGRAM2015 study population

\begin{tabular}{|c|c|c|c|c|c|c|c|c|c|}
\hline Parameter & $\begin{array}{c}\text { Overall } \\
\text { population }\end{array}$ & CVD (+) & CVD (-) & Men & CVD (+) & CVD (-) & Women & CVD (+) & CVD (-) \\
\hline \multicolumn{10}{|c|}{ Overall population } \\
\hline$N$ & 13724 & 1965 & 11759 & 5034 & 956 & 4078 & 8690 & 1009 & 7681 \\
\hline $\mathrm{TC}[\mathrm{mg} / \mathrm{dl}]$ & $202 \pm 44$ & $184 \pm 45$ & $206 \pm 43$ & $198 \pm 45$ & $175 \pm 41$ & $203 \pm 44$ & $205 \pm 44$ & $192 \pm 47$ & $207 \pm 43$ \\
\hline $\mathrm{HDL}-\mathrm{C}[\mathrm{mg} / \mathrm{dl}]$ & $55 \pm 15$ & $50 \pm 14$ & $56 \pm 15$ & $48 \pm 13$ & $45 \pm 12$ & $49 \pm 13$ & $59 \pm 15$ & $55 \pm 14$ & $59 \pm 15$ \\
\hline LDL-C [mg/dl] & $129 \pm 41$ & $114 \pm 41$ & $131 \pm 40$ & $127 \pm 40$ & $109 \pm 38$ & $132 \pm 39$ & $129 \pm 41$ & $118 \pm 43$ & $131 \pm 40$ \\
\hline $\begin{array}{l}\text { Non- } \\
{[\mathrm{mg} / \mathrm{C}}\end{array}$ & $148 \pm 42$ & $134 \pm 42$ & $150 \pm 42$ & $150 \pm 44$ & $130 \pm 39$ & $154 \pm 43$ & $146 \pm 41$ & $137 \pm 44$ & $147 \pm 41$ \\
\hline TG $[\mathrm{m}$ & $148 \pm 118$ & $153 \pm 104$ & $147 \pm 121$ & $172 \pm 153$ & $160 \pm 127$ & $174 \pm 158$ & $135 \pm 90$ & $146 \pm 76$ & $133 \pm 92$ \\
\hline \multicolumn{10}{|c|}{ Treated for dyslipidaemia } \\
\hline$N$ & 4703 & 1296 & 3407 & 1899 & 651 & 1248 & 2804 & 645 & 2159 \\
\hline $\mathrm{TC}[\mathrm{mg} / \mathrm{dl}]$ & $192 \pm 47$ & $178 \pm 45$ & $197 \pm 46$ & $186 \pm 46$ & $171 \pm 40$ & $194 \pm 47$ & $196 \pm 47$ & $185 \pm 48$ & $199 \pm 46$ \\
\hline $\mathrm{HDL}-\mathrm{C}[\mathrm{mg} / \mathrm{dl}]$ & $52 \pm 15$ & $49 \pm 14$ & $54 \pm 15$ & $47 \pm 13$ & $44 \pm 12$ & $48 \pm 14$ & $56 \pm 15$ & $54 \pm 14$ & $57 \pm 15$ \\
\hline LDL-C [mg/dl] & $118 \pm 42$ & $108 \pm 40$ & $121 \pm 42$ & $115 \pm 39$ & $105 \pm 36$ & $120 \pm 40$ & $120 \pm 44$ & $110 \pm 43$ & $122 \pm 43$ \\
\hline $\begin{array}{l}\text { Non-HDL-C } \\
{[\mathrm{mg} / \mathrm{dl}]}\end{array}$ & $139 \pm 44$ & $129 \pm 42$ & $143 \pm 45$ & $139 \pm 45$ & $127 \pm 38$ & $146 \pm 47$ & $140 \pm 44$ & $131 \pm 45$ & $142 \pm 44$ \\
\hline TG [mg/dl] & $164 \pm 142$ & $158 \pm 115$ & $167 \pm 150$ & $183 \pm 174$ & $166 \pm 140$ & $192 \pm 189$ & $151 \pm 112$ & $150 \pm 81$ & $152 \pm 120$ \\
\hline \multicolumn{10}{|c|}{ Not treated for dyslipidaemia } \\
\hline$N$ & 9021 & 669 & 8352 & 3135 & 305 & 2830 & 5886 & 364 & 5522 \\
\hline $\mathrm{TC}[\mathrm{mg} / \mathrm{dl}]$ & $208 \pm 42$ & $195 \pm 44$ & $209 \pm 42$ & $205 \pm 43$ & $183 \pm 43$ & $207 \pm 42$ & $210 \pm 41$ & $205 \pm 42$ & $210 \pm 41$ \\
\hline $\mathrm{HDL}-\mathrm{C}[\mathrm{mg} / \mathrm{dl}]$ & $56 \pm 15$ & $52 \pm 13$ & $57 \pm 15$ & $49 \pm 13$ & $46 \pm 11$ & $49 \pm 13$ & $60 \pm 15$ & $57 \pm 13$ & $60 \pm 15$ \\
\hline LDL-C [mg/dl] & $134 \pm 39$ & $125 \pm 40$ & $135 \pm 38$ & $135 \pm 38$ & $119 \pm 40$ & $137 \pm 38$ & $134 \pm 39$ & $131 \pm 39$ & $134 \pm 39$ \\
\hline $\begin{array}{l}\text { Non-HDL-C } \\
{[\mathrm{mg} / \mathrm{dl}]}\end{array}$ & $152 \pm 40$ & $144 \pm 40$ & $152 \pm 40$ & $156 \pm 42$ & $138 \pm 40$ & $158 \pm 41$ & $150 \pm 40$ & $148 \pm 40$ & $150 \pm 40$ \\
\hline $\mathrm{TG}[\mathrm{mg} / \mathrm{dl}]$ & $140 \pm 103$ & $144 \pm 80$ & $140 \pm 105$ & $165 \pm 137$ & $151 \pm 92$ & $166 \pm 141$ & $127 \pm 77$ & $139 \pm 68$ & $126 \pm 77$ \\
\hline
\end{tabular}


all-cause mortality at 36 and 60 months as compared to patients without FH (11.4\% vs. $4.8 \%$ and $19.2 \%$ vs. $7.2 \%$, respectively) [34].

\section{KEY POINTS TO REMEMBER}

- Assuming that in a model practice a family physician takes care for a population of about 2,500 patients, of which adults account for more than $75 \%$, and considering the prevalence of dyslipidaemia in Poland estimated at $60-80 \%$ in individuals over 18 years of age, it can be assumed that each physician has ca. 1100-1500 people with lipid disorders under his/her care, including up to 10 patients with familial hypercholesterolaemia.

- The prevalence of lipid disorders in Poland is still very high as compared to Western European countries, which, considering it is an independent cardiovascular risk factor, poses an immense challenge for the entire healthcare system.

\section{LIPID DISORDERS AS A CARDIOVASCULAR RISK FACTOR}

Some lipoproteins present in the blood (i.e., LDL, lipoprotein (a) (Lp(a)), very low-density lipoprotein
(VLDL) remnants and chylomicron remnants) are involved in all stages of atherogenesis, contributing to development of atherosclerotic cardiovascular disease (ASCVD) [35]. Therefore, lipid disorders in the form of increased plasma/serum concentration of analytes reflecting or associated with elevated atherogenic lipoprotein concentration are long-time recognised cardiovascular risk factors, based on the results of a huge number of experimental, epidemiological, and clinical studies [36].

A key role in the development of ASCVD is attributed to the disorders of low-density lipoprotein metabolism, and LDL-C concentration remains the primary test for detection and diagnosis of this group of lipid disorders (hypercholesterolaemia) and monitoring of lipid-lowering therapy [37]. The diagnostic role of non-HDL cholesterol and apolipoprotein $B(a p o B)$ concentration is similar, although it should be emphasised that non-HDL-C concentration, reflecting the blood level of all atherogenic lipoproteins, is a better predictor of cardiovascular risk than LDL-C concentration [38]. In certain situations, usually associated with metabolic disorders (Section 6), it is recommended to calculate nonHDL-C concentration or to determine the apoB concentration, alternatively or supplementary to LDL-C.

No reference intervals are established for plas$\mathrm{ma} /$ serum LDL-C, non-HDL-C, or apoB concentrations. The interpretation of those results is based on

Table V. Recommended categories of the total cardiovascular risk, modified and completed according to ESC/EAS 2019 recommendations [9] and PSDL/Pola 2020 guidelines [50]. The risk level indicates the presence of at least one of the factors listed in each category

\begin{tabular}{|c|c|}
\hline Extreme & 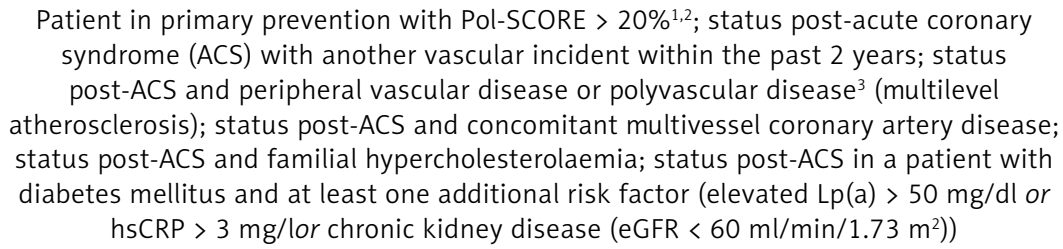 \\
\hline Very high & $\begin{array}{c}\text { Documented cardiovascular disease either clinical or unequivocal on imaging; type } 2 \\
\text { diabetes mellitus with target organ damage } \text { or }^{4} \text { other major risk factors }{ }^{5,6} \text {, early-onset } \\
\text { type } 1 \text { diabetes mellitus lasting }>20 \text { years; chronic kidney disease with eGFR }<30 \mathrm{ml} \\
\text { min } / 1.73 \mathrm{~m}^{2} \text {; familial hypercholesterolaemia with cardiovascular disease or another } \\
\text { major risk factor } \text {; Pol-SCORE risk } \geq 10 \% \text { and } \leq 20 \%\end{array}$ \\
\hline High & 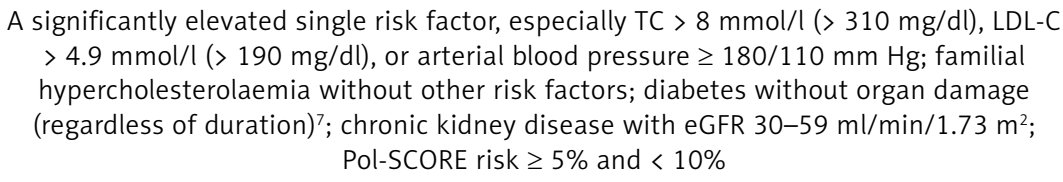 \\
\hline Moderate & Pol-SCORE risk < 5\% \\
\hline Low & Pol-SCORE risk < $1 \%$ \\
\hline
\end{tabular}

${ }^{1}$ E.g. a 65 -year-old woman, smoker, with systolic blood pressure $180 \mathrm{~mm} \mathrm{Hg}$ and total cholesterol concentration $6 \mathrm{mmol} / \mathrm{l}$ (230 mg/dl) or a 60-year-old man with systolic blood pressure $160 \mathrm{~mm} \mathrm{Hg}$ and total cholesterol concentration $7 \mathrm{mmol} / \mathrm{l}$ (270 mg/dl; estimated $L D L-C>190 \mathrm{mg} / \mathrm{dl}$ ); ${ }^{2}$ The same risk is recommended based on the SCORE2 or SCORE-OP based on the recent 2021 ESC Prevention Guidelines; ${ }^{3}$ polyvascular disease (= multilevel atherosclerosis) - the presence of significant atherosclerotic lesions in at least two of three vascular beds, i.e. coronary vessels, cerebral arteries, and/or peripheral arteries; "target organ damage is defined as the presence of microalbuminuria, retinopathy, neuropathy, and/or left ventricular myocardial damage; ${ }^{5}$ "other" means 2 or more; ${ }^{6}$ major risk factors include: age $\geq 65$ years, hypertension, dyslipidaemia, smoking, obesity; 'not applicable to young adults (<35 years of age) with type 1 diabetes lasting $<10$ years. 
M. Banach, P. Burchardt, K. Chlebus, P. Dobrowolski, D. Dudek, K. Dyrbuś, M. Gąsior, P. Jankowski, J. Jóźwiak, L. Kłosiewicz-Latoszek, I. Kowalska, M. Małecki, A. Prejbisz, M. Rakowski, J. Rysz, B. Solnica, D. Sitkiewicz, G. Sygitowicz, G. Sypniewska, T. Tomasik, A. Windak, D. Zozulińska-Ziółkiewicz, B. Cybulska

their assumed target (desired) values, dependent on the total cardiovascular risk (Table V). For LDL-C, these values are lipid-lowering treatment goals.

The results of numerous epidemiological studies have demonstrated an inversely proportional relationship between plasma/serum high density lipoprotein cholesterol (HDL-C) concentration and the incidence of cardiovascular events; therefore, HDL were considered anti-atherogenic lipoproteins, and low HDL-C concentration was considered a cardiovascular risk factor [39, 40]. Studies on mechanisms of anti-atherogenic activity of HDL, mainly reverse cholesterol transport, have also led to the discovery of dysfunctional HDL, developed in inflammatory and/or oxidative stress conditions (as well as a result of glycation and other processes), with limited or nullified anti-atherosclerotic activity, or even with pro-atherosclerotic properties [41]. Furthermore, the results of studies on agents markedly increasing plasma/ serum HDL-C concentration failed to demonstrate their beneficial effect on cardiovascular risk [42]. These observations dispelled the myth of "good cholesterol", and the HDL-C concentration is not used in the assessment of cardiovascular risk, or as a goal of treatment of dyslipidaemia.

Triglycerides (TG) concentration is a significant cardiovascular risk factor. Even in moderate hypertriglyceridaemia (> $1.7 \mathrm{mmol} / /(150 \mathrm{mg} / \mathrm{dl})$ ), being a chronic condition in many individuals with obesity, metabolic syndrome, or diabetes mellitus, intravascular remodelling of LDL particles with formation of small dense LDL (sdLDL) occurs, which may not be reflected by plasma/serum LDL-C concentration. SdLDL particles, readily oxidised and/or glycated, have potent atherogenic activity. Hypertriglyceridaemia accompanied by increased sdLDL fraction and decreased HDL-C plasma/serum concentration is referred to as atherogenic dyslipidaemia $[43,44]$. Since blood sdLDL concentration is not routinely determined, hypertriglyceridaemia remains its main indicator.

Lipoprotein (a) is a recognised independent cardiovascular risk factor, mainly of ischaemic heart disease/myocardial infarction and aortic valve stenosis [45]. Lp(a) has interindividual structural variability, and isoforms occurring in specific individuals are genetically determined and have an indirect effect on plasma/serum concentration of this lipoprotein (Section 6.8). Its elevated concentration associated with a high cardiovascular risk occurs in up to $20 \%$ of the population, up to $30-40 \%$ of patients with atherosclerotic cardiovascular disease, and $30-40 \%$ of individuals with familial hypercholesterolaemia. Elevated values are also observed in pregnant women, which may affect prognosis associated with the risk of preeclampsia, pre-term labour, or low birth weight [45-47].
Atherosclerosis is a polyaetiological condition and, similarly to cardiovascular diseases being its result (ASCVD), depends on many risk factors. In addition to "classical" risk factors of atherosclerosis, known since the time of the Framingham Heart Study (FHS), i.e., dyslipidaemia, tobacco smoking, and arterial hypertension, these include obesity, prediabetes and diabetes mellitus, chronic kidney disease, persistent inflammation, sedentary lifestyle, and many others. According to the principle of primary and secondary prevention of cardiovascular events, i.e., detect and eliminate or control all possible risk factors, these should be identified, and the patient should be classified in the appropriate total cardiovascular risk category (Table $\mathrm{V}$ ). The overall risk determines the management to control its factors, and in dyslipidaemia sets the goals of treatment (Section 7).

A cardiovascular risk assessment tool widely used in primary prevention, especially in the primary care setting, is the Pol-SCORE scale (Figure 2) [48], a modification of the SCORE (systemic coronary risk evaluation) scale developed by the European Society of Cardiology (ESC) experts. It is used to estimate the 10-year risk of cardiovascular death based on the patient's sex, age, systolic blood pressure, smoking status, and plasma/serum total cholesterol concentration. The scale has been developed for people over 40 years of age and should not be used in patients with diabetes and/or chronic kidney disease.

Evaluation of the total cardiovascular risk beyond the SCORE scale (Table $\mathrm{V}$ ) requires extended diagnostics, including detailed clinical assessment, especially of the cardiovascular system, as well as tests concerning the carbohydrate metabolism/diabetes complications, renal function, etc. In the latest ESC/EAS 2019 guidelines [9] on the management of lipid disorders, the concept of extreme risk has been introduced to differentiate the risk among very high-risk patients (being a very heterogeneous group). Based on the results of available studies $[48,49]$, the definition of extreme risk was then extended in the PSDL/ PoLA 2020 guidelines [50], and the current guidelines provide the optimum definition according to evidence-based medicine (EBM). Although achievement of therapeutic goals for this group (< $40 \mathrm{mg} / \mathrm{dl} / 1.0 \mathrm{mmol} / \mathrm{l}$ ) seems very difficult, introduction of this risk category draws attention to the need for intensive lipid-lowering therapy with immediate introduction of combination therapy (Section 9.8) to achieve as low LDL-C concentrations as possible (the lower the better), as soon as possible (the earlier the better). These recommendations also complement and definitely simplify the risk assessment in patients with type 2 diabetes mellitus. 


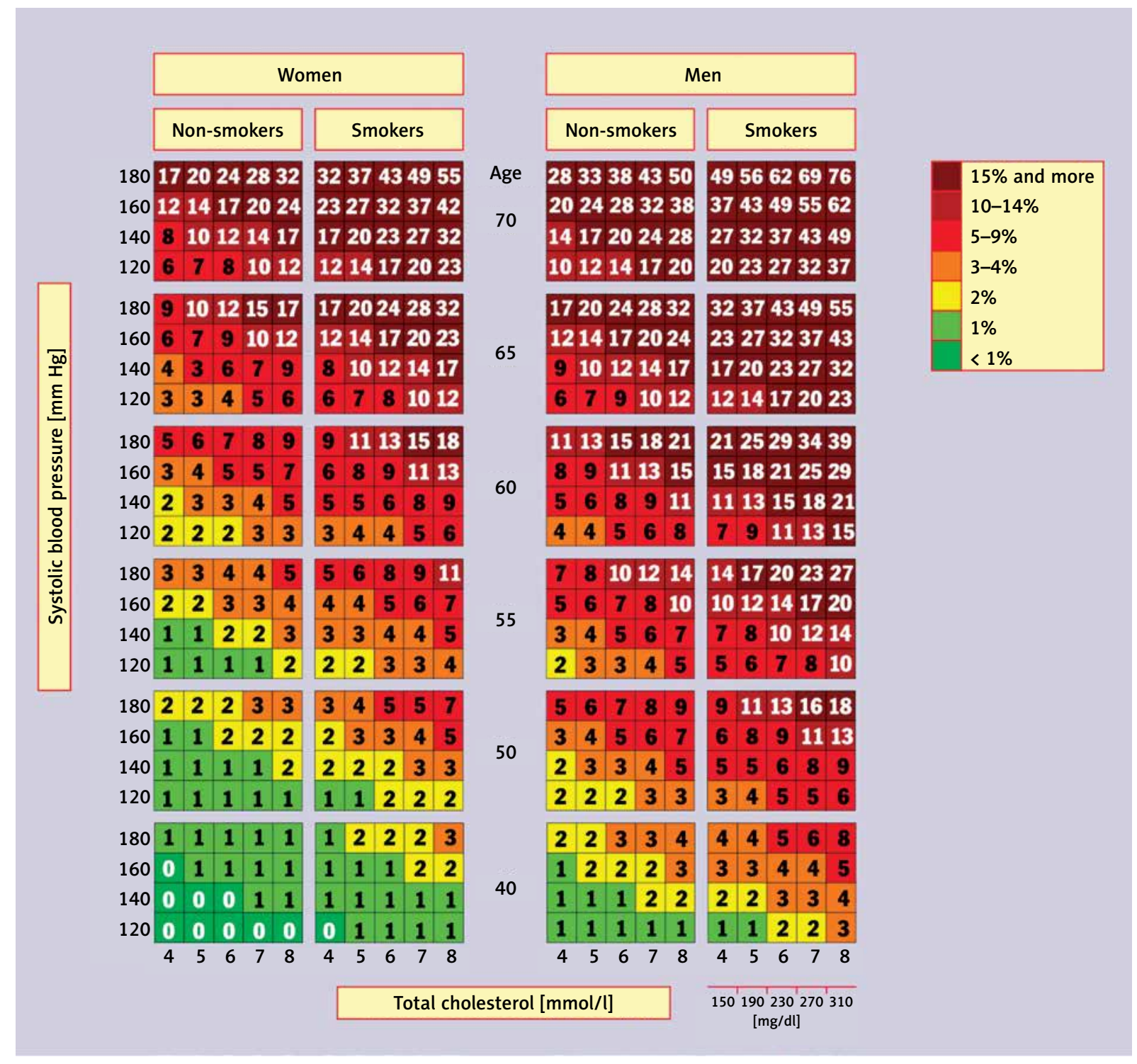

Figure 2. SCORE tables calibrated for the Polish population (Pol-SCORE 2015) [48]. Numbers in the table represent 10-year risk of cardiovascular death

In Table VI conditions associated with a higher cardiovascular risk not included in the Pol-SCORE 2015 table are presented. They should be considered, particularly if the cardiovascular risk assessed using the table is at the border between two categories (e.g., 5\%). In this case, depending on HDL-C concentration or depression, a patient can be assigned to a higher (e.g., in the presence of depression or low HDL-C) or lower (e.g., in the absence of depression or high HDL-C) risk category. The Pol-SCORE tables should be a useful tool for patient education. They make it possible to easily present to the patient to what extent their cardiovascular risk will be reduced after introduction of effective treatment of a specific risk factor [8] (Table VII).
Table VI. Cardiovascular risk factors not taken into account in the Pol-SCORE system $[8,9,48]$

$$
\begin{aligned}
& \text { - Sedentary lifestyle } \\
& \text { - } \text { Psychosocial factors, including: } \\
& \text { - Low socioeconomic status } \\
& \text { - Isolation and low social support } \\
& \text { - Stress at work and in family life } \\
& \text { - Depression (chronic depressed mood) } \\
& \text { - Diseases and conditions associated with an } \\
& \text { increased risk, including: } \\
& \text { - Low HDL-C concentration } \\
& \text { - High triglycerides concentration } \\
& \text { - Certain autoimmune diseases (psoriasis, } \\
& \text { - } \text { reumatoid arthritis) } \\
& \text { - Obstructontal inflammation } \\
& \text { - Family history of premature CVD } \\
& \text { - HIV infection } \\
& \text { - Atrial fibrillation } \\
& \text { - Left ventricular hypertrophy } \\
& \text { - Mental disorders }
\end{aligned}
$$


M. Banach, P. Burchardt, K. Chlebus, P. Dobrowolski, D. Dudek, K. Dyrbuś, M. Gąsior, P. Jankowski, J. Jóźwiak, L. Kłosiewicz-Latoszek, I. Kowalska, M. Małecki, A. Prejbisz, M. Rakowski, J. Rysz, B. Solnica, D. Sitkiewicz, G. Sygitowicz, G. Sypniewska, T. Tomasik, A. Windak,

D. Zozulińska-Ziółkiewicz, B. Cybulska

\section{KEY POINTS TO REMEMBER}

There is a close, independent relationship between cholesterol concentration, mainly nonHDL cholesterol and LDL-C, and development of atherosclerosis and risk of major cardiovascular events. In risk assessment, all cardiovascular risk factors should always be taken into account; when lipid goals have been achieved, these comprise so-called cardiovascular residual risk.

Table VII. Recommendations concerning assessment of cardiovascular risk in patients with lipid disorders

\begin{tabular}{|c|c|c|}
\hline Recommendations & Class & Level \\
\hline $\begin{array}{l}\text { In each patient, overall cardiovascular } \\
\text { risk should be assessed in order to } \\
\text { adequately educate the patient and } \\
\text { to make a decision on the need to } \\
\text { initiate pharmacological treatment of } \\
\text { dyslipidaemia and its intensity, including } \\
\text { the need for the combination therapy. }\end{array}$ & I & $A$ \\
\hline $\begin{array}{l}\text { The Pol-SCORE } 2015^{1} \text {, in which the } \\
\text { 10-year risk of cardiovascular death is } \\
\text { assessed, should be used to evaluate } \\
\text { the overall cardiovascular risk in } \\
\text { individuals in primary prevention. }\end{array}$ & I & A \\
\hline
\end{tabular}

${ }^{1}$ Risk analysis using the Pol-SCORE algorithm and tables is intended for primary prevention in individuals $\geq 40$ years of age, without a history of cardiovascular events, and cannot be used to assess cardiovascular risk e.g., in people with type 2 diabetes or chronic kidney disease (GFR $\left.<60 \mathrm{ml} / \mathrm{min} / 1.73 \mathrm{~m}^{2}\right)$, with direct assignment of such patients to the respective risk categories.

\section{RECOMMENDATIONS ON LIPID PROFILE MEASUREMENT, ITS DIAGNOSTIC SIGNIFICANCE, AND LIMITATIONS}

The lipid profile performed to assess cardiovascular risk consists of assays/calculations of plasma/serum concentration of total cholesterol (TC), HDL cholesterol (HDL-C), LDL cholesterol (LDL-C), triglycerides (TG), and non-HDL cholesterol (non-HDL-C), and, as indicated, apolipoprotein $B(a p o B)$ and lipoprotein (a) (Lp(a)) [8, 35, 51, 52]. The results of these assays (except for $L p(a)$ ) indirectly and approximately reflect the amount of respective lipoproteins in the blood. Of particular importance in laboratory assessment of lipid disorders and the risk of atherosclerosis progression is determination of blood content of atherogenic lipoproteins, i.e., LDL and Lp(a), although the latter is still very rarely determined [35]. Determination of chylomicron remnants (CM) and very low-density lipoprotein (VLDL) remnants with atherogenic activity is not yet used in clinical practice.

\subsection{Pre-analytical issues}

Tests constituting a lipid profile are performed using venous blood plasma/serum. It is consid- ered that lipid profile assessment should be performed in conditions of normal daily activity and diet of a specific patient. Since people are not fasting for about $16 \mathrm{~h}$ a day, blood samples for routine testing do not need to be drawn in fasting conditions $[9,53,54]$. According to the 2016 position of the EAS and the European Federation of Clinical Chemistry and Laboratory Medicine (EFLM), a slight postprandial increase in TG concentration (up to $0.3 \mathrm{mmol} / \mathrm{l}(26 \mathrm{mg} / \mathrm{dl})$ ) does not significantly affect the assessment of lipid profile as compared with the same test in fasting conditions [35]. Small differences in interpretation of the results concern TG concentration, while the results of the LDL-C calculation using the Friedewald formula are consistent. It is recommended to consider repetition of the lipid profile assessment in fasting conditions with non-fasting TG concentration $>5 \mathrm{mmol} / \mathrm{l}(440 \mathrm{mg} / \mathrm{dl})[35,55]$.

The determined lipid concentrations are characterised by intra-subject variability of $5-10 \%$ for TC and > 20\% for TG. In addition to genetic predispositions, variability in TC and TG concentration results from physical activity, diet, including carbohydrate and alcohol content, and smoking. Changes in lipid profile occur during pregnancy, particularly in the third trimester, mainly as an increase in TG (up to 3 times), TC and Lp(a) concentration, to a lesser extent, LDL-C (usually up to $50 \%$ ) and HDL-C [8]. Higher TC and TG concentrations are observed in winter $[51,53,55]$. TC and LDL-C concentration is reduced for several weeks after a cardiovascular event and in chronic inflammation, e.g., in rheumatic diseases (lipid paradox), as well as in the elderly, especially those over 75 years of age $[4,56,57]$.

Cholesterol and triglycerides are components of large molecule lipoproteins; therefore, maintenance of a compression band $>3$ min or standing up for > 30 min before blood sampling may increase their concentration by $10-12 \%$ due to increased blood density, which should be avoided. Serum TC, HDL-C, LDL-C, and TG concentrations are approximately $3 \%$ higher than in plasma. Plas$\mathrm{ma} /$ serum samples can be stored at a temperature of $\sim+4^{\circ} \mathrm{C}$ up to 4 days, while longer storage requires freezing at a temperature of $-70^{\circ} \mathrm{C}$ [35].

\subsection{Triglycerides}

Triglycerides or triacylglycerols (TG) are esters of glycerol (an alcohol) and 3 molecules of fatty acids. TG are largely used as an energy source for the body and constitute the main component of fat cells [58]. They are synthesised endogenously and constitute most of the fat mass of food (exogenous origin - as chylomicron triglycerides) $[58,59]$.

Hypertriglyceridaemia reflects increased concentration of TG-rich lipoproteins, including ath- 
erogenic molecules (VLDL, CM remnants and VLDL remnants) leading to cardiovascular diseases, chronic inflammation, and increased overall mortality [60]. Increased TG concentration coexisting with low HDL-C concentration and high levels of small dense LDL particles is called atherogenic dyslipidaemia. Therefore, TG concentration is essential in the assessment of residual risk, as a high TG concentration even with the target LDL-C concentration significantly and independently increases cardiovascular risk [61-63]. In addition, very high hypertriglyceridaemia is associated with an increased risk of acute pancreatitis.

Plasma/serum TG concentration is measured using enzymatic assays and automated analysers [64]. The acceptable total error of TG measurement, as recommended by the US National Cholesterol Education Program (NCEP), is $\pm 15 \%$, and according to the Centre for Quality Assessment in Laboratory Diagnostics (COBJwDL), $\pm 10 \%$ [50].

\subsection{Total cholesterol}

Cholesterol is obtained from food ( $30 \%)$ or synthesised de novo, mainly in the liver and intestines ( $70 \%)$. The amount of synthesised cholesterol depends on its level in the cells. Cholesterol affects the activity of 3-hydroxy-3-methylglutaryl-CoA (HMG-CoA) reductase by inhibiting its gene expression. The enzyme, HMG-CoA reductase, catalyses the key reaction in this pathway and is the site of action for statins. As the only de novo synthesised steroid, cholesterol is a substrate for the synthesis of steroid hormones, bile acids, and cardiotonic steroids (CTS). Cholesterol also plays an important role as a component of biological membranes, i.e., cytoplasmic and cell organelle membranes. Ca. $70 \%$ of blood cholesterol is transported by LDL; therefore, total cholesterol concentration indirectly and approximately reflects the amount of cholesterol in these plasma lipoproteins [50].

In clinical practice, TC concentration is used to stratify cardiovascular risk using the SCORE scale and to assess the severity of hypercholesterolaemia (suspected familial hypercholesterolaemia) and as the basis for therapeutic decisions in the absence of LDL-C calculation/test results (very rarely at present) $[9,65,66]$. Furthermore, the TC concentration must be known in order to calculate the LDL-C and non-HDL-C concentration. In medical laboratory practice, serum/plasma TC concentration is measured using enzymatic assays and automated analysers [67]. The acceptable total error of TC measurement, as recommended by the NCEP, is $\pm 9 \%$, and according to the COBJWDL $- \pm 8 \%$ [50].

\subsection{High density lipoprotein cholesterol}

High density lipoproteins ( $\mathrm{HDL}$ ) are a heterogeneous group consisting of essentially two lipo- protein fractions of different particle size and density. In physiological conditions, HDL inhibit development of atherosclerosis mainly by their participation in reverse cholesterol transport from tissues, including macrophages in arterial walls, to the liver [68]. In addition, HDL have anti-oxidative activity and inhibit LDL oxidation [69], restore vascular endothelial function, and demonstrate anti-inflammatory and anti-apoptotic effects [70]. Inflammation and oxidative stress as well as glycation lead to changes in particle composition and dysfunctional HDL formation, with the loss of their anti-oxidative and anti-inflammatory properties and limitation of their activity in reverse cholesterol transport [71]. As a result, pro-atherogenic activity is attributed to dysfunctional HDL [71-73]. Laboratory tests used routinely to determine the $\mathrm{HDL}-\mathrm{C}$ concentration in the blood do not make it possible to differentiate fractions (subfractions/ subpopulations) or to assess functionality of these lipoproteins and therefore their role in atherogenesis in the examined patient. Methods of assessment of both heterogeneity and functionality of $\mathrm{HDL}$ are not available for routine laboratory diagnostics [35, 74-76].

Although an inverse relationship between blood HDL-C concentration and the risk of cardiovascular events has been demonstrated repeatedly, studies concerning agents increasing its concentration (i.e., niacin or cholesterol ester transfer protein (CETP) inhibitors) have not yet demonstrated their beneficial effects in terms of cardiovascular risk reduction $[77,78]$. At present, $\mathrm{HDL}-\mathrm{C}$ concentration is not recommended as a target in treatment of dyslipidaemia, a predictor of cardiovascular risk, or in monitoring of lipid disorders. However, HDL-C may be considered as an additional parameter in cardiovascular risk stratification using the SCORE scale. Nevertheless, HDL-C concentration remains an important element of the lipid profile as it is used to calculate LDL-C and non-HDL-C concentration [50].

Although plasma/serum HDL-C concentration brings only indirect information on the HDL blood content, it is still the main parameter in assessment of the number of HDL particles. Direct methods of measurement of the number of HDL particles (HDL-P) and their individual fractions (nuclear magnetic resonance spectrometry, ion mobility analysis, electrophoretic techniques) are not available for routine laboratory diagnostics. In addition, they do not provide sufficient new data to recommend them [50].

In diagnostic laboratories, enzymatic direct (homogenous) methods and automated analysers are commonly used for determination of plasma/serum HDL-C concentration. In these methods, detergents dissolving HDL and adsorptively blocking the access of enzymes to cholesterol 
M. Banach, P. Burchardt, K. Chlebus, P. Dobrowolski, D. Dudek, K. Dyrbuś, M. Gąsior, P. Jankowski, J. Jóźwiak, L. Kłosiewicz-Latoszek, I. Kowalska, M. Małecki, A. Prejbisz, M. Rakowski, J. Rysz, B. Solnica, D. Sitkiewicz, G. Sygitowicz, G. Sypniewska, T. Tomasik, A. Windak, D. Zozulińska-Ziółkiewicz, B. Cybulska

in VLDL and $L D L$ particles are used as reagents [35]. They are standardised and lower accuracy of measurements may be due to the matrix effect (media), e.g., in dyslipidaemias. According to the NCEP recommendations, the acceptable total error for direct HDL-C measurement methods is $\pm 13 \%$ for normolipaemic samples and $-20 \%$ to $+36 \%$ for dyslipidaemic samples. Inaccurate results are mostly observed at $\mathrm{HDL}-\mathrm{C}$ concentrations $<40 \mathrm{mg} / \mathrm{dl}(0.8 \mathrm{mmol} / \mathrm{l})$. According to the COBJWDL, the acceptable error is $\pm 15 \%$ [50].

\subsection{Low density lipoprotein cholesterol}

Cholesterol and its esters account for $40-50 \%$ of weight of the LDL particles that transport them to tissues. Due to the key role of LDL in the process of atherogenesis, the concentration of cholesterol contained in LDL (LDL-C), indirectly reflecting the blood LDL content, reflects significant cardiovascular risk $[35,50]$. Specific LDL-C concentration values are the goal of lipid-lowering therapy. In addition, as it is not necessary to obtain blood samples for lipid profile testing in fasting conditions, the availability of LDL-C calculation/testing is increased [8, 9, 35, 50].

Direct methods of measurement of the number of LDL particles (LDL-P) are also not routinely applied, and in Poland they are actually only of scientific significance. In diagnostic laboratories, LDL-C concentration is usually calculated, but sometimes (although more often in recent years) measured using direct methods. The Friedewald formula is widely used to calculate LDL-C, using the determined TC, HDL-C and TG concentrations, and the assumed TG to VLDL-C ratio [79].

$$
\mathrm{LDL}-\mathrm{C}=\mathrm{TC}-\mathrm{HDL}-\mathrm{C}-\mathrm{TG} / 5 \text { (in } \mathrm{mg} / \mathrm{dl} \text { ) }
$$

or

$$
\mathrm{LDL}-\mathrm{C}=\mathrm{TC}-\mathrm{HDL}-\mathrm{C}-\mathrm{TG} / 2.2(\text { in } \mathrm{mmol} / \mathrm{l})
$$

This formula should not be used for TG concentrations > $4.5 \mathrm{mmol} / \mathrm{l}(400 \mathrm{mg} / \mathrm{dl})$ - in such conditions, the TG/VLDL-C ratio is different from the assumed. The results of calculations using the Friedewald formula are also less accurate if intermediate density lipoproteins (IDL) are present in the plasma as well as in conditions in which the composition of lipoprotein particles is changed (obesity, type 2 diabetes mellitus, metabolic syndrome, kidney, and liver diseases). The Friedewald formula also tends to decrease the results at low $\mathrm{LDL}-\mathrm{C}$ concentrations $<1.8 \mathrm{mmol} / \mathrm{l}(70 \mathrm{mg} / \mathrm{dl})$ and TG concentrations $>1.7 \mathrm{mmol} / \mathrm{l}(150 \mathrm{mg} / \mathrm{dl})$ [80]. The calculated LDL-C concentration is also affected by the sum of errors of measurements used in the formula.
A modification of the Friedewald formula is the Martin and Hopkins formula (2013) [79]:

$$
\mathrm{LDL}-\mathrm{C}=\mathrm{TC}-\mathrm{HDL}-\mathrm{C}-\mathrm{TG} / x(\mathrm{in} \mathrm{mg} / \mathrm{dl})
$$

where $x$ is the TG/VLDL-C ratio based on the concentration of TG and non-HDL-C; these values are available in special tables or online calculators, e.g., www.ldlcalculator.com.

It has been demonstrated that this formula is more accurate than the Friedewald formula for calculation of LDL-C at low concentrations and TG concentration in the range of $2.0-4.5 \mathrm{mmol} / \mathrm{l}$ (175-400 mg/dl), also in non-fasting samples [8082]. The use of the Martin and Hopkins formula is limited by the need to purchase the license. Recently, a new formula for LDL-C calculation has been proposed, which provides more accurate results than both the above. The formula is more complex but compatible with modern laboratory IT systems. The new formula may be used in patients with low LDL-C concentration and those with significant hypertriglyceridaemia, up to $8.8 \mathrm{mmol} / /$ (800 mg/dl) [83]. However, assessment of its practical use in laboratories will require time and further studies.

LDL-C concentration may be measured by enzyme-based direct (homogenous) methods using reagents containing detergents, surfactants, and other blocking components, or dissolving individual lipoprotein fractions, making LDL-C selectively available to the enzymes. The measurements are performed using automated analysers. The acceptable total error of measurement/calculation of LDL-C concentration, as recommended by the NCEP, is \pm 12 [50].

Currently, due to the limitations of the LDL-C concentration calculation described above, it is also recommended to calculate the non-HDL-C concentration or measurement of apoB concentration as an alternative to LDL-C concentration, and not its direct measurement $[9,35]$.

The calculated/measured LDL-C concentration is the sum of LDL-C and Lp(a) cholesterol concentration, which may result in elevated LDL-C concentration. The LDL-C concentration calculated using the Friedewald formula may be corrected for L $(\mathrm{a})$ cholesterol using the Dahlen's modification based on the assumption that cholesterol accounts for $30 \%$ of weight of $L p(a)$ particles $[50,84]$ :

$$
\begin{aligned}
& \mathrm{LDL}-\mathrm{C}_{\text {corr }}= \mathrm{TC}-\mathrm{HDL}-\mathrm{C}-\mathrm{TG} / 5-[\mathrm{Lp}(\mathrm{a}) \times 0.3] \\
&(\text { in } \mathrm{mg} / \mathrm{dl})
\end{aligned}
$$

This adjustment can be made for LDL-C concentrations determined in any other way.

\subsection{Non-HDL cholesterol}

Non-HDL cholesterol (non-HDL-C) concentration reflects the plasma content of all apoB-con- 
taining lipoproteins: LDL, VLDL, IDL, CM, CM remnants, VLDL remnants, and Lp(a), involved in the initiation of atherogenesis, and development and destabilisation of atherosclerotic plaques [85, 86]. As an indicator of atherogenic lipoprotein concentration, non-HDL-C concentration is very important for the assessment of cardiovascular risk and should be a permanent component of the lipid profile. This is of particular diagnostic importance if the accuracy of the LDL-C concentration calculation is limited. According to numerous studies, non-HDL-C concentration is more predictive for cardiovascular risk than LDL-C concentration $[87,88]$.

Non-HDL-C concentration is calculated using the following formula:

$$
\text { Non-HDL-C = TC }- \text { HDL-C (in mmol/l or mg/dl) }
$$

The calculated non-HDL-C concentrations are based on TC concentration calculated or determined using standardised methods and HDL-C concentration also determined by standardised direct methods. Nevertheless, the result of non$\mathrm{HDL}-\mathrm{C}$ concentration calculation is affected by the sum of errors of both measurements.

\subsection{Apolipoprotein B}

Apolipoprotein B (apoB), a component of all lipoproteins except HDL, occurs in two isoforms: apoB 100 present in VLDL, IDL and LDL, and apoB 48 (a fragment of apoB 100) present in CM and their remnants $[9,89]$. Each LDL particle contains one apoB 100 molecule; therefore, the concentration of this apolipoprotein is a measure of the content of LDL particles in plasma/serum and a cardiovascular risk factor equivalent to the LDL-C concentration [90]. Measurement of the apoB concentration should be, in addition to calculation of the non-HDL-C concentration, an alternative to LDL-C calculation when its accuracy is reduced $[9,50]$. Unfortunately, in Poland, apoB is still very rarely measured, which is due to the ongoing debate on the actual added value of this parameter in relation to LDL-C and non-HDL-C, as well as to additional costs of the test.

In laboratory practice, plasma/serum apoB concentration is determined using standardised immunoturbidimetric or immunonephelometric methods and automated analysers. The antibodies used in these methods are directed against apoB 100, although apoB 48 may also be measured using some of them. Possible interference with apoB 48 is marginal, as in the analysed material apoB 100 molecules, almost entirely LDL components, constitute of $>90 \%$ of apoB. The limit of acceptable error for apoB concentration measurement recommended by the NCEP is $\pm 6 \%$ [50].

\subsection{Lipoprotein (a)}

Lipoprotein (a) (Lp(a)) particles are a subpopulation of LDL of similar structure, containing one apoB 100 molecule combined with apolipoprotein (a) $[a p o(a)]$. There is significant inter-individual variability as to molecular weight of $L p(a)$, depending on the number of repetitions of the kringle IV type 2 (KIV-2) domain, ranging from 3 to 40 , genetically determined. This genetically determined $L p(a)$ particle size is inversely proportional to the rate of its synthesis, mainly in the liver, and its plasma/serum concentration $[9,91]$.

In Poland, the concentration of Lp(a) is measured definitely too rarely, and the knowledge about it is still very limited. Therefore, every effort should be made to change it as soon as possible. This is necessary due to a great scientific progress in this field. Today we know that $L p(a)$ is an independent cardiovascular risk factor and that up to $>30 \%$ of patients with familial hypercholesterolaemia and/or acute coronary syndrome may have an elevated $L p(a)$ concentration, often with the desired LDL-C concentration, and there are options for pharmacological reduction of $\mathrm{Lp}(\mathrm{a})$ concentration [45, 92-95]. Therefore, we recommend that plasma/serum Lp(a) concentration should be measured once in every adult individual's life to detect patients with its elevated concentration in whom the cardiovascular risk is high. Specific indications for $L p(a)$ measurement are: premature onset of cardiovascular disease, the lack of expected effect of statin therapy, and the need for better risk stratification in moderate- to high-risk individuals [50].

In diagnostic laboratories, plasma/serum Lp(a) concentration is determined mainly by immunochemical methods, i.e., immunoturbidimetric or immunonephelometric, or various immuno-enzyme methods, including ELISA. These tests may be performed routinely and readily available. Although the methods are standardised, sufficient harmonisation of results has not been achieved; this is considered a consequence of the impact of apo(a) particle size variation on the results of Lp(a) immunochemical assays [84, 96-98]. Therefore, for repeated $L p(a)$ concentration measurements the same method should be applied.

\subsection{Laboratory report of the lipid profile}

The lipid profile includes a set of blood plasma/ serum tests discussed above performed for the diagnosis and monitoring of treatment of dyslipidaemia and to obtain a general picture of cardiovascular risk:

- total cholesterol concentration (TC),

- HDL cholesterol concentration (HDL-C),

- LDL cholesterol concentration (LDL-C),

- non-HDL cholesterol concentration (non-HDL-C),

- triglycerides concentration 
M. Banach, P. Burchardt, K. Chlebus, P. Dobrowolski, D. Dudek, K. Dyrbuś, M. Gąsior, P. Jankowski, J. Jóźwiak, L. Kłosiewicz-Latoszek, I. Kowalska, M. Małecki, A. Prejbisz, M. Rakowski, J. Rysz, B. Solnica, D. Sitkiewicz, G. Sygitowicz, G. Sypniewska, T. Tomasik, A. Windak,

D. Zozulińska-Ziółkiewicz, B. Cybulska

and ordered as indicated:

- apolipoprotein B concentration (apoB),

- lipoprotein (a) concentration (Lp(a)).
In addition to the measured/calculated results, the laboratory lipid profile report (Table VIII) should include information on how the LDL-C con-

Table VIII. Lipid profile - recommended contents of the laboratory report

\begin{tabular}{|c|c|c|c|}
\hline Parameter & $\begin{array}{l}\text { Result } \\
{[\mathrm{mg} / \mathrm{dl}]} \\
{[\mathrm{mmol} / \mathrm{ll}]}\end{array}$ & Target values & Alarm values \\
\hline Total cholesterol (TC) & & $\begin{array}{l}\text { Fasting and non-fasting: }<190 \mathrm{mg} / \mathrm{dl} \\
\qquad(5.0 \mathrm{mmol} / \mathrm{l})\end{array}$ & $\begin{array}{l}>290 \mathrm{mg} / \mathrm{dl}(7.5 \mathrm{mmol} / \mathrm{l})^{1}- \\
\text { suspected heterozygous } \mathrm{FH}\end{array}$ \\
\hline HDL cholesterol (HDL-C) & & $\begin{array}{l}\text { Fasting and non-fasting: }>40 \mathrm{mg} / \mathrm{dl} \\
(1.0 \mathrm{mmol} / \mathrm{l}) \text { for men and }>45 \mathrm{mg} / \mathrm{dl} \\
(1.2 \mathrm{mmol} / \mathrm{l}) \text { for women }\end{array}$ & \\
\hline Triglycerides (TG) & & $\begin{array}{l}\text { Fasting: < } 150 \mathrm{mg} / \mathrm{dl}(1.7 \mathrm{mmol} / \mathrm{l}) ; \text { non- } \\
\text { fasting: }<175 \mathrm{mg} / \mathrm{dl}(2.0 \mathrm{mmol} / \mathrm{l})\end{array}$ & $\begin{array}{l}>880 \mathrm{mg} / \mathrm{dl}(10.0 \mathrm{mmol} / \mathrm{l}) \\
- \text { suspected familial } \\
\text { chylomicronaemia syndrome } \\
\text { (FCS) }\end{array}$ \\
\hline LDL cholesterol (LDL-C) ${ }^{2}$ & & $\begin{array}{l}\text { Fasting and non-fasting; cardiovascular } \\
\text { risk: extreme }<40 \mathrm{mg} / \mathrm{dl}(1 \mathrm{mmol} / \mathrm{l}) \\
\text { very high }<55 \mathrm{mg} / \mathrm{dl}(1.4 \mathrm{mmol} / \mathrm{l}) \\
\text { high }<70 \mathrm{mg} / \mathrm{dl}(1.8 \mathrm{mmol} / \mathrm{l}) \\
\text { moderate }<100 \mathrm{mg} / \mathrm{dl}(2.6 \mathrm{mmol} / \mathrm{l}) \\
\text { low }<115 \mathrm{mg} / \mathrm{dl}(3.0 \mathrm{mmol} / \mathrm{l})\end{array}$ & $\begin{array}{l}>500 \mathrm{mg} / \mathrm{dl}(13 \mathrm{mmol} / \mathrm{l}) \\
\text { - suspected homozygous } \\
\mathrm{FH}(>300 \mathrm{mg} / \mathrm{dl}[8 \mathrm{mmol} / \mathrm{l}] \\
\text { in patients on treatment); } \\
>190 \mathrm{mg} / \mathrm{dl}(5.0 \mathrm{mmol} / \mathrm{l})- \\
\text { suspected heterozygous } \mathrm{FH}\end{array}$ \\
\hline $\begin{array}{l}\text { Non-HDL cholesterol } \\
\text { (non-HDL-C) }\end{array}$ & & $\begin{array}{l}\text { Fasting and non-fasting; cardiovascular } \\
\text { risk: extreme }<70 \mathrm{mg} / \mathrm{dl}(1.8 \mathrm{mmol} / \mathrm{l}) \\
\text { very high }<85 \mathrm{mg} / \mathrm{dl}(2.2 \mathrm{mmol} / \mathrm{l}) \\
\text { high }<100 \mathrm{mg} / \mathrm{dl}(2.6 \mathrm{mmol} / \mathrm{l}) ; \\
\text { moderate }<130 \mathrm{mg} / \mathrm{dl}(3.4 \mathrm{mmol} / \mathrm{l})\end{array}$ & \\
\hline Apolipoprotein B (apoB) & & $\begin{array}{c}\text { Fasting; cardiovascular risk: extreme } \\
<55 \mathrm{mg} / \mathrm{dl}(0.55 \mathrm{~g} / \mathrm{l}) ; \text { very high } \\
<65 \mathrm{mg} / \mathrm{dl}(0.65 \mathrm{~g} / \mathrm{l}) ; \text { high }<80 \mathrm{mg} / \mathrm{dl} \\
(0.8 \mathrm{~g} / \mathrm{l}) ; \text { moderate }<100 \mathrm{mg} / \mathrm{dl}(1.0 \mathrm{~g} / \mathrm{l})\end{array}$ & \\
\hline Lipoprotein (a) [Lp(a)] & & $\begin{array}{l}\text { Fasting and non-fasting: }<30 \mathrm{mg} / \mathrm{dl} \\
(75 \mathrm{nmol} / \mathrm{l})\end{array}$ & $\begin{array}{c}30-50 \mathrm{mg} / \mathrm{dl}(75-125 \mathrm{nmol} / \mathrm{l}) \\
\text { moderate risk; } \\
>50 \mathrm{mg} / \mathrm{dl}(125 \mathrm{nmol} / \mathrm{l}) \text { high } \\
\text { risk; > } 180 \mathrm{mg} / \mathrm{dl} \\
(450 \mathrm{nmol} / \mathrm{l}) \text { very high } \\
\text { cardiovascular risk }\end{array}$ \\
\hline
\end{tabular}

Table IX. Recommendations concerning the lipid profile measurement

Recommendations Class Level

LDL-C concentration is a key lipid parameter determining the cardiovascular risk and defining the goals of lipid-lowering therapy.

TG is a permanent component of the lipid profile. A high TG concentration, as a part of atherogenic dyslipidaemia, increases cardiovascular risk regardless of the achieved target LDL-C.

Non-HDL-C is a permanent component of the lipid profile.

$A p o B$ is a predictor of cardiovascular risk equivalent to LDL-C concentration and it is recommended to be measured primarily in individuals with TG concentration $>4.5 \mathrm{mmol} / \mathrm{l}(400 \mathrm{mg} / \mathrm{dl})$, obesity, diabetes mellitus, metabolic syndrome, and low TC and LDL-C concentration.

Lp(a) concentration should be measured at least once in every adult individual's life.

Measurement of $\mathrm{Lp}(\mathrm{a})$ should be considered in all patients with premature onset of cardiovascular disease, the lack of expected statin therapy effect, and in those with a borderline risk between moderate and high, for better risk stratification.

Measurement of $\mathrm{Lp}(\mathrm{a})$ may be considered in patients with very high cardiovascular risk and atherosclerotic cardiovascular disease, in patients with familial hypercholesterolaemia, and in pregnant women as a prevention of pre-eclampsia or miscarriage, in recurrent pregnancy loss, or intrauterine growth restriction. 
centration was determined, as well as the target (desired) and alarm concentrations of individual analytes [100]. If severe dyslipidaemia is suspected, it should also contain information on the need for an urgent medical consultation in case of LDL-C concentration indicating a possible diagnosis of heterozygous (> $5.0 \mathrm{mmol} / \mathrm{l}, 190 \mathrm{mg} / \mathrm{dl}$ ) or homozygous (> $13.0 \mathrm{mmol} / \mathrm{l}, 500 \mathrm{mg} / \mathrm{dl}$ ) familial hypercholesterolaemia (FH), Lp(a) concentration $>180 \mathrm{mg} / \mathrm{dl}(450 \mathrm{nmol} / \mathrm{l})$ indicating a very high risk of cardiovascular events, or TG concentration $>10.0 \mathrm{mmol} / \mathrm{l}(880 \mathrm{mg} / \mathrm{dl})$ indicating a high risk of acute pancreatitis or suspected familial chylomicronaemia syndrome (FCS) [99]. It is helpful for interpretation and authorisation of the results by laboratory technicians to provide information on the referral form whether the patient is overweight/obese and/or suffers from diabetes, and whether they receive lipid-lowering therapy (Table IX).

\section{KEY POINTS TO REMEMBER}

- The lipid profile includes measurement of serum/plasma concentrations of TG, TC, HDL-C, LDL-C, non-HDL-C, and, as indicated, apoB and $L p(a)$.

- In is not necessary to obtain blood samples for lipid profile testing in fasting conditions; repetition of the tests in fasting conditions should be considered at TG concentration $>5 \mathrm{mmol} / \mathrm{l}$ (440 mg/dl) in non-fasting conditions.

- A high TG concentration even with the target LDL-C concentration attainment significantly increases cardiovascular risk (residual cardiovascular risk).

- HDL-C concentration is not a predictor of cardiovascular risk or a target of lipid-lowering therapy.

- LDL-C concentration is a key lipid parameter determining cardiovascular risk and a target of lipid-lowering therapy.

- LDL-C concentration may be calculated using the Friedewald formula or Martin and Hopkins formula with $\mathrm{TG} \leq 4.5 \mathrm{mmol} / \mathrm{l}$ (400 mg/dl); at low LDL-C concentration $<1.8 \mathrm{mmol} / \mathrm{l}(70 \mathrm{mg} / \mathrm{dl})$ and TG > $2.0 \mathrm{mmol} / \mathrm{l}$ $(175 \mathrm{mg} / \mathrm{dl})$, Martin and Hopkins formula is recommended.

- In individuals with TG concentration $>4.5 \mathrm{mmol} / \mathrm{l}(400 \mathrm{mg} / \mathrm{dl})$, obesity, diabetes mellitus, metabolic syndrome, or low TC and LDL-C concentration, calculation of nonHDL-C or measurement of apoB concentration is recommended.
- It is recommended to calculate non-HDL-C concentration along with calculation/measurement of LDL-C. It is a very important parameter in evaluation of cardiovascular risk; more predictive than LDL-C concentration.

- Plasma/serum Lp(a) concentration should be measured once in every adult individual's life to detect patients with elevated concentration increasing cardiovascular risk, especially those with extremely high $\operatorname{Lp}(\mathrm{a})$ levels $\geq 180 \mathrm{mg} / \mathrm{dl}(\geq 430 \mathrm{nmol} / \mathrm{l})$ and therefore with a very high lifetime risk of ASCVD, approximately equivalent to the risk associated with $\mathrm{HeFH}$.

- The laboratory lipid profile report should include the results of measurements as well as the target (desired) and alarm concentrations of the analytes, and information on the need for urgent medical consultation.

\section{THERAPY GOALS OF LIPID DISORDERS - TARGET VALUES DEPENDING ON THE RISK}

The most important parameter of the lipid profile is LDL cholesterol. This is due to several facts, well-known for a long time. Firstly, epidemiological studies have demonstrated a close relationship between cholesterol concentration and the risk of cardiovascular events, mainly coronary events [8, 9]. Secondly, experimental studies indicate the central role of cholesterol in the pathogenesis of atherosclerosis and its complications [8, 9]. Thirdly, it has been demonstrated that cholesterol present in atherosclerotic plaques is derived from LDL particles [8, 9]. Fourthly, intensive pharmacological reduction of LDL-C concentration results in regression of atherosclerosis [101-103]. Fifthly, reduction of cholesterol concentration is associated with a proportional reduction of the risk of cardiovascular events [104, 105]. For these reasons, reduction of LDL-C concentration is the main (primary) target of lipid-lowering therapy. However, in recent years it has also been unequivocally demonstrated that not only effective reduction of cholesterol concentration according to the rule of "the lower the better" is important, but that achievement of the therapeutic goal for LDL-C as soon as possible, according to the rule of "the earlier the better", and maintaining it as long as possible (= "the longer the better"), is also of critical importance $[2,6,7,106]$.

No LDL cholesterol concentration has been identified below which no further benefits of lipid-lowering therapy can be observed (even for $<20 \mathrm{mg} / \mathrm{dl}$ or $0.5 \mathrm{mmol} / \mathrm{l}$ ) or the risk of adverse effects outweighs the benefit $[6,8,9]$. It is worth 
M. Banach, P. Burchardt, K. Chlebus, P. Dobrowolski, D. Dudek, K. Dyrbuś, M. Gąsior, P. Jankowski, J. Jóźwiak, L. Kłosiewicz-Latoszek, I. Kowalska, M. Małecki, A. Prejbisz, M. Rakowski, J. Rysz, B. Solnica, D. Sitkiewicz, G. Sygitowicz, G. Sypniewska, T. Tomasik, A. Windak, D. Zozulińska-Ziółkiewicz, B. Cybulska

emphasising, as the problem is often a matter of concern, that there is no evidence suggesting any risk of adverse effects, including neurocognitive disorders or haemorrhagic stroke, even for extremely low LDL-C concentrations [107, 108]. Since relative benefits of reduction of LDL-C concentration are largely independent of baseline cholesterol concentration [9, 105], absolute benefits are proportional to the overall cardiovascular risk. Therefore, the target LDL-C concentration depends on baseline cardiovascular risk (Tables $X$ and $\mathrm{XI}$ ). In relation to this, the authors of these guidelines decided to extend the definition of extreme cardiovascular risk in order to highlight the fact that very high-risk patients constitute a very heterogeneous group and with additional risk factors (i.e., higher risk) greater benefits of lipid-lowering interventions may be expected [109]. That is why it is so important to follow the rule of "the lower the better" in these patients and achieve the treatment goal as soon as possible [109]. The first data concerning this problem appeared after the IMPROVE-IT (Improved Reduction of Outcomes: Vytorin Efficacy International Trial) study with simvastatin and ezetimibe [110]; then the definition of extreme risk, still based on expert opinion, was introduced in the guidelines of the American Association of Clinical Endocrinologists (AACE) and the American College of Endocrinology (ACE) guidelines in 2017 [111], while hard clinical data were provided by the results of the FOURIER study for evolocumab and ODYSSEY OUTCOMES study for alirocumab, with a number of sub-analyses [112, 113]. In March 2019, we summarised these results and identified patient groups that obtain the greatest benefit from treatment with PCSK9 inhibitors - assuming that these benefits are greatest for NNT (the number of patients who need to undergo a specific intervention for a defined period to prevent 1 event) < 30 [49], which was eventually partially reflected in September 2019 in the ESC/EAS guidelines [9]. However, these guidelines were surprising as they limited this group to patients with ASCVD and another vascular event in the previous 2 years [9]. Therefore, as soon as in March 2020, in the PTDL/PTL guidelines [50] this definition was extended by 3 other groups, and in the current guidelines, based on a large amount of recent scientific data, two further groups have been added, including patients in primary prevention with Pol-SCORE > 20\% (Tables V and X). However, it seems, particularly in the context of the latest analysis of the TERCET registry, in which we attempted to validate all available definitions and select those risk factors that significantly increase the risk of another myocardial infarction in a 12to 36-month follow-up period, that this definition may still be changed [114].

The concentration of non-HDL cholesterol (a measure of cholesterol concentration in atherogenic lipoproteins, i.e., LDL, VLDL, and so-called remnants) and apolipoprotein B may be secondary goals of therapy, especially in patients with high triglyceride concentration. In these guidelines, we recommend the calculation of non-HDL cholesterol every time the lipid profile is performed. Adjustment of lipid-lowering treatment intensity in order to achieve target concentrations of nonHDL cholesterol (and apolipoprotein B in selected patient groups) may be considered in patients

Table X. Recommended LDL-C concentrations as lipid-lowering treatment goals

\begin{tabular}{|c|c|c|}
\hline Recommendations & Class & Level \\
\hline $\begin{array}{l}\text { In secondary prevention patients with a very high cardiovascular risk, it is recommended to reduce } \\
\text { LDL-C concentration to }<1.4 \mathrm{mmol} / /(<55 \mathrm{mg} / \mathrm{dl}) \text { and by } \geq 50 \% \text { of the baseline value. }\end{array}$ & 1 & A \\
\hline $\begin{array}{l}\text { In primary prevention patients with a very high cardiovascular risk, with or without } \mathrm{FH} \text {, it is } \\
\text { recommended to reduce } \mathrm{LDL}-\mathrm{C} \text { concentration to }<1.4 \mathrm{mmol} / \mathrm{l}(<55 \mathrm{mg} / \mathrm{dl}) \text { and by } \geq 50 \% \text { of the } \\
\text { baseline value. }\end{array}$ & 1 & C \\
\hline $\begin{array}{l}\text { In primary prevention patients with Pol-SCORE }>20 \% O R \text { after an acute coronary syndrome (ACS) } \\
\text { and another vascular incident within the previous } 2 \text { years } O R \text { after an acute coronary syndrome } \\
\text { with peripheral vascular disease or polyvascular disease } O R \text { after an acute coronary syndrome } \\
\text { with multivessel coronary artery disease } O R \text { after an acute coronary syndrome with familial } \\
\text { hypercholesterolaemia } O R \text { after an acute coronary syndrome with diabetes mellitus and at least } \\
\text { one additional risk factor (elevated } \mathrm{Lp}(\mathrm{a})>50 \mathrm{mg} / \mathrm{dl} \text { or } \mathrm{hs} C \mathrm{CRP}>3 \mathrm{mg} / \mathrm{l} \text { or chronic kidney disease } \\
\left.\left(\mathrm{eGFR}<60 \mathrm{ml} / \mathrm{min} / 1.73 \mathrm{~m}^{2}\right)\right) \text {, LDL cholesterol concentration }<1.0 \mathrm{mmol} / \mathrm{l}(<40 \mathrm{mg} / \mathrm{dl}) \text { may be } \\
\text { considered as the target value }{ }^{1} \text {. }\end{array}$ & $\mathrm{Ilb}$ & B \\
\hline $\begin{array}{l}\text { In patients with a high cardiovascular risk, it is recommended to reduce LDL-C concentration to } \\
<1.8 \mathrm{mmol} / /(<70 \mathrm{mg} / \mathrm{dl}) \text { and by } \geq 50 \% \text { of the baseline value. }\end{array}$ & 1 & A \\
\hline $\begin{array}{l}\text { In patients with a moderate cardiovascular risk, reduction of LDL-C concentration to }<2.5 \mathrm{mmol} / \mathrm{l} \\
(<100 \mathrm{mg} / \mathrm{dl}) \text { should be considered. }\end{array}$ & Ila & A \\
\hline $\begin{array}{l}\text { In patients with a low cardiovascular risk, reduction of } L D L-C \text { concentration to }<3.0 \mathrm{mmol} / \mathrm{l} \\
(<115 \mathrm{mg} / \mathrm{dl}) \text { may be considered. }\end{array}$ & $\mathrm{Ilb}$ & A \\
\hline
\end{tabular}

${ }^{1}$ Detailed explanations are provided in the legend of Table $\mathrm{V}$. 


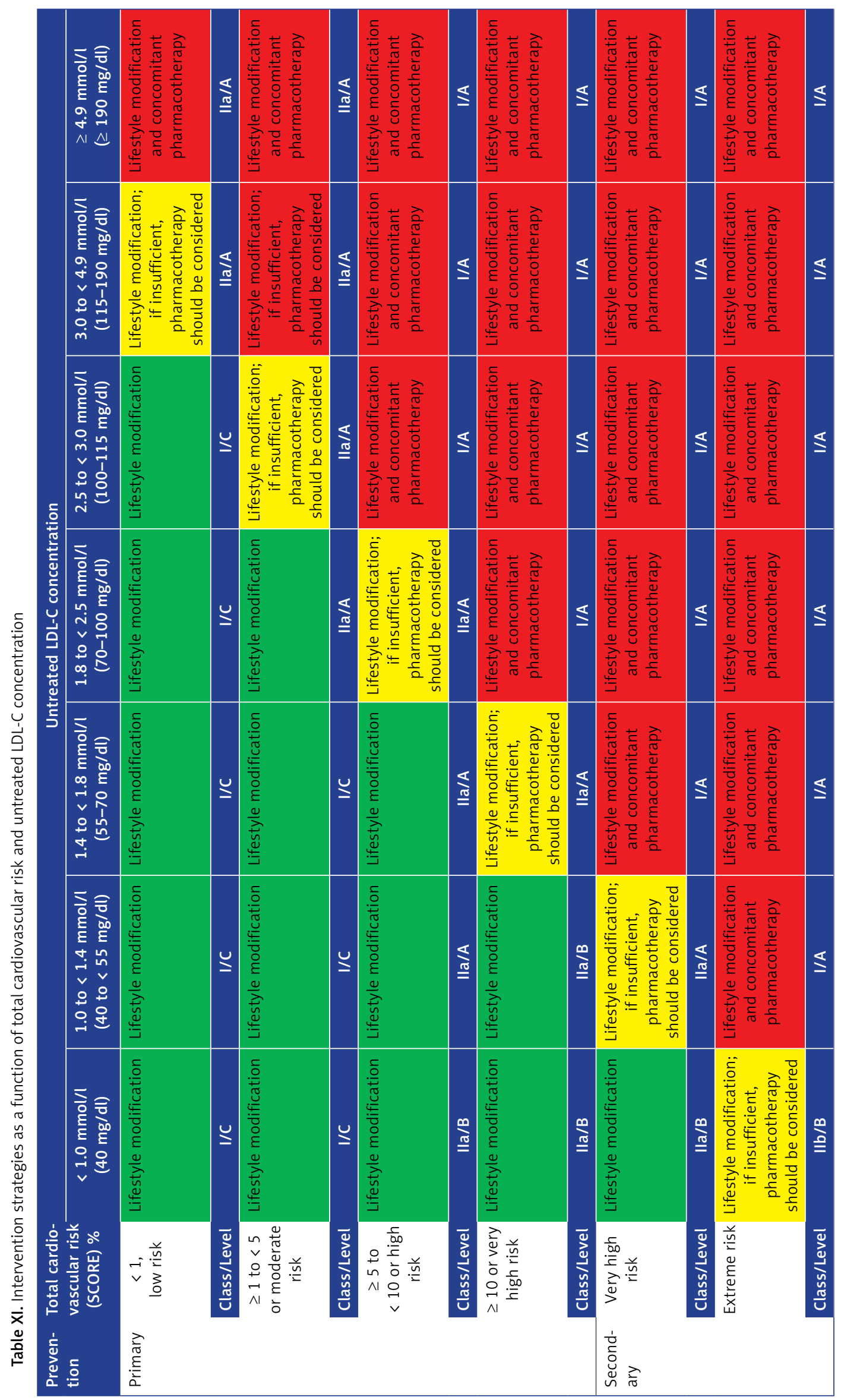


M. Banach, P. Burchardt, K. Chlebus, P. Dobrowolski, D. Dudek, K. Dyrbuś, M. Gąsior, P. Jankowski, J. Jóźwiak, L. Kłosiewicz-Latoszek, I. Kowalska, M. Małecki, A. Prejbisz, M. Rakowski, J. Rysz, B. Solnica, D. Sitkiewicz, G. Sygitowicz, G. Sypniewska, T. Tomasik, A. Windak, D. Zozulińska-Ziółkiewicz, B. Cybulska

with a moderate, high, or very high cardiovascular risk, after the target LDL-C concentration has been achieved. Without calculation of non-HDL-C, having achieved the therapeutic goal for LDL cholesterol, we may omit a significant residual risk in our patient. In general, the target non-HDL cholesterol concentration should be approximately $0.8 \mathrm{mmol} / \mathrm{l}(30 \mathrm{mg} / \mathrm{dl})$ higher than its equivalent LDL-C target.

The results of observational studies indicate that low HDL cholesterol concentration is a risk factor for ischaemic heart disease. However, it has not been decided whether it is a causal factor $[71,77]$. According to the study results published so far, no reduction of the risk of cardiovascular events associated with the use of agents increasing HDL-C concentration has been observed [77, 78]. Therefore, HDL cholesterol concentration is not a treatment target; however, based on data from epidemiological studies, $\mathrm{HDL}-\mathrm{C}<1.0 \mathrm{mmol} / \mathrm{l}$ $(<40 \mathrm{mg} / \mathrm{dl})$ in men and $<1.2 \mathrm{mmol} / \mathrm{l}(<45 \mathrm{mg} / \mathrm{dl})$ in women may be considered markers of increased risk, particularly in terms of SCORE risk estimation.

Available results of prospective and genetic studies as well as meta-analyses of numerous studies indicate that a high triglyceride concentration is an independent risk factor for cardiovascular events, especially in patients with diabetes mellitus or metabolic syndrome [115]. Scientific evidence indicating benefits of reduction of triglyceride concentration, especially with pharmacological treatment, is significantly poorer than the body of evidence for the benefits of LDL-C lowering. Although the relationship between triglyceride concentration and cardiovascular risk is continuous and triglyceride concentration is not a therapeutic target, a concentration $<1.7 \mathrm{mmol} / \mathrm{l}$ $(<150 \mathrm{mg} / \mathrm{dl})$ is considered an indicator of low cardiovascular risk (Table XI).

\section{NON-PHARMACOLOGICAL PREVENTION AND TREATMENT OF LIPID DISORDERS}

One of the primary targets in cardiovascular risk reduction is effective therapy of dyslipidaemia. LDL-C concentration is the most important parameter in diagnosing, prediction, monitoring, and treatment of lipid disorders [35]. According to current guidelines, once the patient's cardiovascular risk has been estimated and the complete lipid profile has been determined, the management strategy recommended for the appropriate patient group should be selected. Lifestyle modification is recommended for all patients, and lipid-lowering agents are recommended only in selected clinical situations. In patients already treated, it is always a combination therapy, and its indispensable component is non-pharmacological treatment associated with lifestyle modification. The opinions expressed in the ESC/EAS 2019 guidelines on treatment of dyslipidaemia concur on this problem [9]. A summary of the effect of non-pharmacological modifications on individual lipoprotein fractions is presented in Table XII.

\subsection{Effect on TC and LDL-C/non-HDL-C}

The greatest effect on reduction of total cholesterol and low-density cholesterol has decreased consumption of saturated fatty acids (SFA) and trans-fatty acids $[9,116]$. The use of phytosterol-containing functional food has comparable effects on TC and LDL-C. Conversion of $1 \%$ of the energy from SFA to energy from monounsaturated fatty acids (MUFA) may reduce plasma LDL concentration by $1.6 \mathrm{mg} / \mathrm{dl}$, and conversion to energy from polyunsaturated fatty acids (PUFA) - by $2 \mathrm{mg} / \mathrm{dl}$ [117-119]. Conversion from SFA to carbohydrates corresponds to the lowest reduction in LDL-C concentration - by $1.2 \mathrm{mg} / \mathrm{dl}$. When switching from SFA-rich foods to carbohydrate-rich foods, products containing high amounts of fibre should be chosen. Fibre actively reduces intestinal fat absorption, and the energy density of most fibre-rich plant products is low, which makes it easier to maintain caloric balance. Weight reduction, as well as physical activity, does not significantly reduce LDL-C concentration ( $L D L-C$ is reduced by an average of $8 \mathrm{mg} / \mathrm{dl}$ for each $10 \mathrm{~kg}$ lost, and with intensive exercise it is possible to reduce LDL-C by approximately 5-7\%), while both overweight and low physical activity are independent risk factors for cardiovascular disease; furthermore, modification of these factors significantly affects the reduction of TG and increase of HDL-C concentration [117-119].

\subsection{Effect on TG}

Among interventions aimed at reduction of triglycerides, weight reduction, regular physical activity, minimum alcohol intake, and decreased consumption of monosaccharides play the most important role [120]. Reduction of body weight and increased physical activity improve tissue insulin sensitivity, which directly affects plasma TG concentration. Intake of calories contained in alcohol can make it difficult to achieve normal body weight. Alcohol consumed in excess (more than 10-30 g/day) significantly increases TG concentration [118, 119, 121]. Conversion from SFA to unsaturated fatty acids (especially PUFA) significantly improves insulin sensitivity. Unfortunately, their intake is rarely sufficient with diet based on natural products; in such cases, supplementation of n-3 PUFA should be considered, which in the last few years has started to play a key role in treatment of hypertriglyceridaemia $[122,123]$. 
TG concentration is also closely associated with impaired carbohydrate metabolism. Excessive intake of monosaccharides, including fructose ( $>10 \%$ of food energy), significantly translates into increased TG concentration [120]. Fructose intake equivalent to $15-20 \%$ of food energy increases plasma TG concentration by up to $30-40 \%$ [124]. The best results in terms of reduction of plasma TG concentration are achieved with food products with a low glycaemic index (e.g., raw fruit, vegetables, thick groats, oat bran, cottage cheese, fish). Glycaemic index makes it possible to identify foods with a rapid glucose absorption profile and differentiate them from products from which carbohydrates are slowly absorbed to plasma. Fibre contained in plant products decreases the glycaemic index of food products by means of glucose absorption followed by its gradual release during intestinal transit [125].

\subsection{Effect on HDL-C}

High density lipoproteins with normal functionality have anti-atherosclerotic properties. Anti-atherosclerotic activity of $\mathrm{HDL}$ is mainly related to their participation in reverse cholesterol transport, but also with their anti-inflammatory, anti-oxidative, anti-apoptotic, anticoagulation, cytoprotective, vasodilatory, or even antitumour activity $[126,127]$. HDL-C concentration provides no information on HDL functionality. Unfortunately, pharmacological attempts to increase concentration of these lipoproteins have not produced satisfactory effects in terms of cardiovascular risk reduction; therefore, only methods of behavioural medicine remain at present at our disposal. Lifestyle modification leading to weight reduction contributes to an increase in HDL-C plasma concentration by $0.01 \mathrm{mmol} / \mathrm{l}(0.4 \mathrm{mg} / \mathrm{dl})$ for every $\mathrm{kg}$ lost. Systematic exercise of moderate intensity ca. $300 \mathrm{~min}$ per week may increase HDL-C concentration by $0.15 \mathrm{mmol} / \mathrm{l}(6 \mathrm{mg} / \mathrm{dl})$ [128]. Each $1000 \mathrm{kcal}$ used translates into an increase of HDL-C concentration by ca. $3 \mathrm{mg} / \mathrm{dl}$. Smoking cessation is also beneficial, provided that it does not result in body weight increase [129].

The most significant HDL-C increase may be observed as a result of trans-fats intake reduction; moreover, unsaturated trans fats increase LDL-C concentration. An increase in HDL-C is observed when SFA intake is increased. Unfortunately, this increase is associated with an increase in LDL-C, which in turn does not produce a beneficial effect in terms of cardiovascular risk reduction and cannot be recommended. It should be emphasised that conversion from fat to monosaccharides as a food energy source results in reduction of HDL-C concentration. However, this effect was not observed with conversion to complex carbohydrates and fibre-rich foods (with a low glycaemic index) [116].

Alcohol consumption is a dietary habit inducing an increase of HDL-C concentration. However, it should be remembered that this applies only to

Table XII. Summary of the effect of non-pharmacological interventions on specific lipid profile parameters

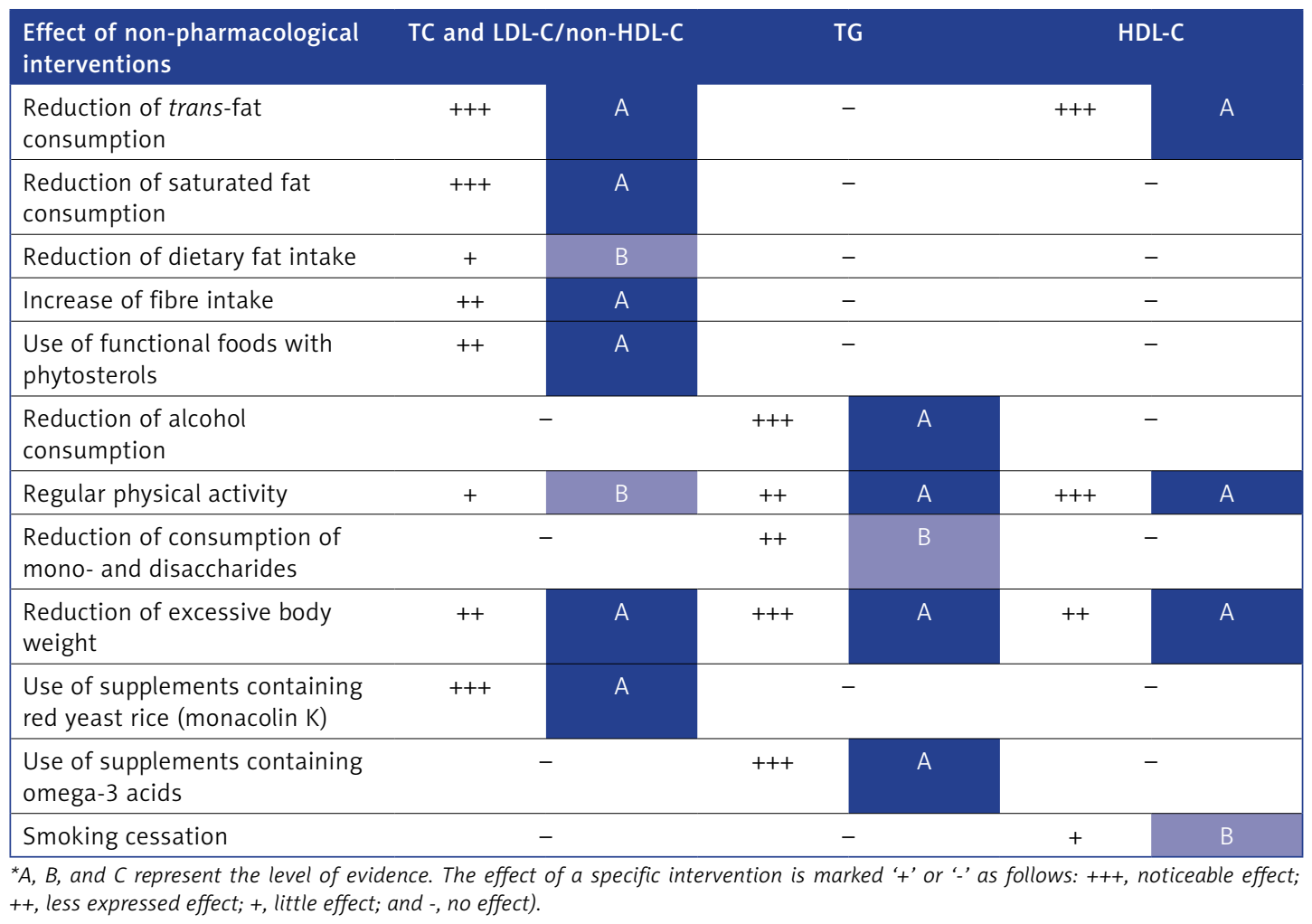


M. Banach, P. Burchardt, K. Chlebus, P. Dobrowolski, D. Dudek, K. Dyrbuś, M. Gąsior, P. Jankowski, J. Jóźwiak, L. Kłosiewicz-Latoszek, I. Kowalska, M. Małecki, A. Prejbisz, M. Rakowski, J. Rysz, B. Solnica, D. Sitkiewicz, G. Sygitowicz, G. Sypniewska, T. Tomasik, A. Windak,

D. Zozulińska-Ziółkiewicz, B. Cybulska

moderate alcohol consumption (up to $30 \mathrm{~g}$ /day in men and up to $20 \mathrm{~g} /$ day in women), and its abuse is a risk factor of numerous diseases. Due to the risk of dependence and alcohol-related harm, its consumption should not be recommended to patients; moreover, recent analyses of the Global Burden of Disease (GBD) expert group clearly indicate that any amount of alcohol is harmful, and such a recommendation should be given to patients [130].

\subsection{Significance of nutraceuticals and modified foods}

Functional foods/nutraceuticals have potentially significant functional effect that helps to achieve therapeutic goals in terms of concentration of TC and individual fractions. Interestingly, most natural products have pleiotropic effects (although it is an incorrect name), affecting not only the lipid profile but also glucose concentration, insulin resistance, vascular stiffness, blood pressure, inflammation, or oxidative stress [131]. Moreover as natural products, they are very safe, provided that production quality is maintained, and no impurities or additional substances are present (e.g., citrinin in red rice). Therefore, for several years, apart from their focus on the properties of nutraceuticals, manufacturers and experts have also very seriously treated safety, its monitoring and reporting the occurrence of all adverse reactions (nutrivigilance) $[132,133]$.

Below we present only a few examples of nutraceuticals with documented lipid-lowering properties; see Table XIII for a complete list. The experts of these guidelines have adapted with minor modifications the recommendations of the International Lipid Expert Panel (ILEP) on the use of nutraceuticals in treatment of lipid disorders [134-136].

Table XIII. Recommendations for the use of nutraceuticals in treatment of lipid disorders (adapted International Lipid Expert Panel 2017 guidelines with modifications [134, 135])

\begin{tabular}{|c|c|c|c|c|}
\hline Name & Recommended dosage & $\begin{array}{l}\text { Expected } L D L-C \\
\text { reduction }\end{array}$ & $\begin{array}{l}\text { Class of recom- } \\
\text { mendation }\end{array}$ & $\begin{array}{l}\text { Level of recom- } \\
\text { mendation }\end{array}$ \\
\hline \multicolumn{5}{|c|}{ Inhibitors of cholesterol absorption from the intestine } \\
\hline Plant sterols and stanols & $400-3000 \mathrm{mg}$ & $-8 \%$ to $-12 \%$ & Ila & A \\
\hline $\begin{array}{l}\text { Soluble fibre (beta-glucan, } \\
\text { psyllium, glucomannan) }\end{array}$ & $5-15 \mathrm{~g}$ & $-5 \%$ to $-15 \%$ & Ila & A \\
\hline Chitosan & $1-6 \mathrm{~g}$ & $-5 \%$ & IIb & A \\
\hline Probiotics & Depending on bacterial strain & $-5 \%$ & IIb & B \\
\hline \multicolumn{5}{|c|}{ Inhibitors of hepatic cholesterol synthesis } \\
\hline Red yeast rice extract & $<3 \mathrm{mg}^{*}$ & $-15 \%$ to $-25 \%$ & 1 & A \\
\hline Garlic & $5-6 \mathrm{~g}$ (extract) & $-5 \%$ to $-10 \%$ & Ila & A \\
\hline $\begin{array}{l}\text { Pantethine (vitamin } B_{5} \\
\text { derivative) }\end{array}$ & $600-900 \mathrm{mg}$ & $-5 \%$ & Ila & A \\
\hline Bergamot & $\begin{array}{l}\text { 500-1000 mg (polyphenol } \\
\text { fractions, BPF) }\end{array}$ & $-15 \%$ to $-40 \%$ & Ila & B \\
\hline Polycosanol & $10-80 \mathrm{mg}$ & $-18 \%$ to $-25 \%$ & $\mathrm{IIb}$ & B \\
\hline \multicolumn{5}{|l|}{ Inducers of LDL-C excretion } \\
\hline Berberine & $500-1500 \mathrm{mg}$ & $-15 \%$ to $-20 \%$ & 1 & A \\
\hline Green tea extract & $25-100 \mathrm{~g}$ & $-5 \%$ & Ila & A \\
\hline Soy and lupin proteins & $25-100 \mathrm{~g}$ & $-3 \%$ to $-10 \%$ & $\mathrm{IIb}$ & A \\
\hline \multicolumn{5}{|c|}{ Other nutraceuticals of mixed properties } \\
\hline $\begin{array}{l}\text { Polyunsaturated } \\
\text { omega-3 fatty acids }\end{array}$ & $2-4 \mathrm{~g}$ & - & 1 & A \\
\hline Gamma-oryzanol & $300 \mathrm{mg}$ & $-5 \%$ to $-10 \%$ & $\mathrm{IIb}$ & B \\
\hline Spirulina & 400-800 UI & $-5 \%$ to $-10 \%$ & Ila & B \\
\hline Curcumin & $0.5-3 \mathrm{~g}$ & $-5 \%$ to $-10 \%$ & Ila & A \\
\hline L-carnitine & $1-2 \mathrm{~g}$ & - & $\mathrm{IIb}$ & B \\
\hline Artichoke & 1-3 g (leaf extract) & $-5 \%$ to $-15 \%$ & Ila & B \\
\hline Vitamin E & 400-800 UI & Up to $-5 \%$ & $\mathrm{Ilb}$ & B \\
\hline Anthocyanins & $100-450 \mathrm{mg}$ & $-5 \%$ to $-10 \%$ & $\mathrm{IIb}$ & B \\
\hline
\end{tabular}

${ }^{*}$ Based on a draft EFSA decision of May 2021. ${ }^{* *}$ Attention should be paid to increased risk of atrial fibrillation. 


\subsubsection{Phytosterols and stanols}

The main phytosterols are sitosterol, campesterol, and stigmasterol. They are present naturally in vegetable fats, vegetables, fresh fruit, whole grain products, and leguminous plants. At present, they are added to certain margarines and yoghurts. Daily intake of $2 \mathrm{~g}$ of phytosterols or stanols (synthesised from plant sterols; naturally present in fruit, nuts, grain, and vegetable oils) translates into a reduction of LDL-C and TC concentration by ca. $7-10 \%[137,138]$.

\subsubsection{MUFA and PUFA}

In this group, $\mathrm{n}-3$ acids deserve particular attention. Their consumption in the amount of about 2-4 g/day translates into a TG reduction by ca. $25-30 \%$, as well as a significant reduction of inflammatory markers. However, such supplementation may translate into only a small reduction of LDL-C concentration (ca. 5\%). The latest data indicate that the effect of MUFA treatment (as well as the use of omega-6 acids) is usually neutral and does not translate into significant clinical benefits; therefore, dietary fat content should not as much be reduced as modified, with focus on their quality and replacement of SFA with omega-3 PUFA [123, 139]. The use of $\mathrm{n}-3$ PUFA is recommended in treatment of hypertriglyceridaemia in patients with very high TG concentration as an adjuvant treatment, and the latest data, especially those concerning highly purified eicosapentaenoic acid (EPA - icosapent ethyl), also indicate that this effect, associated with a significant reduction of TG concentration, translates into a significant reduction in cardiovascular events by $25 \%$. Therefore, the most recent recommendations point to the role of omega-3 acids, particularly in patients diagnosed with ASCVD [140] (Section 9.9).

\subsubsection{Red yeast rice}

The mechanism of action of pigments contained in fermented rice is identical to that of statins. This results from the fact that monacolin $\mathrm{K}$ contained in it is a molecule identical to lovastatin [141]. However, it should be remembered that marketed products containing monacolin $\mathrm{K}$ may differ with respect to dose, which translates into potency. Following a difficult to understand (taking into account ample data available) decision of the European Food Safety Authority (EFSA) of August 2018, the discussion on safety of the applied doses of monacolin $\mathrm{K}$ present in red rice continues [141]. The analyses performed since then indicate very high safety of the use of red rice, even in patients with statin intolerance, and the incidence of adverse events in consumer analysis is estimat- ed at even less than $0.04 \%[132,133]$. The most recent draft ESFA recommendation indicates that formulations containing up to $3 \mathrm{mg}$ of monacolin $\mathrm{K}$ will be commercially available.

However, these products (as well as others with demonstrated lipid-lowering properties) may provide a good solution for: (1) statin-ineligible patients receiving early pharmacotherapy of dyslipidaemia, (2) patients declining statin therapy, (3) statin-intolerant patients, and (4) all those who (both in primary and secondary prevention), despite available treatment, still fail to achieve the treatment goal.

\subsection{Importance of healthy lifestyle}

Overweight and obesity comprise one of the most common risk factors for dyslipidaemia in Polish population; in 2021, after more than a year of the pandemic, it may be present in up to $50 \%$ of Poles [144]. It is therefore postulated that achievement of normal body mass index (BMI), i.e., 18.5-24.9 $\mathrm{kg} / \mathrm{m}^{2}$, should be pursued as one of the elements of struggle for normal lipoprotein concentrations. In addition to BMI, the patient's waist circumference is important in defining obesity. Waist circumference (men $\geq 94 \mathrm{~cm}$; women $\geq 80 \mathrm{~cm}$ ), independent of normal BMI values, determines a higher risk of cardiovascular disease $[8,9]$.

Development of dietary habits should be based not only on correct balance of caloric supply and expenditure, but also on ensuring appropriate proportions of essential nutrients. Fatty acids should not exceed $30 \%$ of energy supply, and SFA should not exceed $10 \%$ of the total energy supply in individuals without dyslipidaemia; in patients with dyslipidaemia, dietary intake of SFA should be limited to a maximum of $7 \%$ (Table XIV) [142, 143, 147]. In regular diet, SFA should optimally be replaced with MUFA, and, above all, PUFA. This may be done with plant-based diets. Such development of dietary habits is consistent with the latest nutrition pyramid proposed by the World Health Organization (WHO). Development of dietary habits based on plant products also allows for a large dietary supply of fibre and reduced consumption of monosaccharides. Complex carbohydrates should account for up to $55 \%$ of total energy supply. Within carbohydrates, complex carbohydrates should predominate, while monosaccharides and disaccharides should not exceed $10 \%$ of energy supply [145-147] (Table XIV).

Lifestyle medicine is one of the most important elements of prevention and treatment of lipid disorders. Modification of dietary habits, physical activity, avoiding of stimulants, and functional food supplementation play the most important role in this aspect. In view of current guidelines, lifestyle modification should be promoted in each patient 
M. Banach, P. Burchardt, K. Chlebus, P. Dobrowolski, D. Dudek, K. Dyrbuś, M. Gąsior, P. Jankowski, J. Jóźwiak, L. Kłosiewicz-Latoszek, I. Kowalska, M. Małecki, A. Prejbisz, M. Rakowski, J. Rysz, B. Solnica, D. Sitkiewicz, G. Sygitowicz, G. Sypniewska, T. Tomasik, A. Windak, D. Zozulińska-Ziółkiewicz, B. Cybulska

Table XIV. Summary of recommendations as to the optimal lipid-lowering diet for a patient with hypercholesterolaemia vs. high TG concentration

\begin{tabular}{|c|c|c|}
\hline Variable & Patient with hypercholesterolaemia & Patient with a high TG concentration \\
\hline Fat intake & $\begin{array}{l}\text { - Saturated fatty acids should account for }<7 \% \text { of } \\
\text { total food energy (the less the better!) } \\
\text { - Cholesterol intake limited to }<300 \mathrm{mg} / \text { day }\end{array}$ & $\begin{array}{l}\text { - Saturated fatty acids should account for } \\
<10 \% \text { of total food energy }\end{array}$ \\
\hline $\begin{array}{l}\text { Carbohydrate } \\
\text { intake }\end{array}$ & $\begin{array}{l}\text { - Carbohydrates generally have a "neutral" effect } \\
\text { on LDL-C concentration }\end{array}$ & $\begin{array}{l}\text { - Excessive carbohydrate intake adverse- } \\
\text { ly affects plasma concentrations of TG } \\
\text { and HDL-C. Carbohydrate intake should } \\
\text { account for } 45-55 \% \text { of total food energy } \\
\text { - Sugar intake should not exceed } 10 \% \text { of } \\
\text { total food energy (this does not apply to } \\
\text { saccharides contained in natural prod- } \\
\text { ucts, such as fruit and milk products) } \\
\text { - More restrictive recommendations con- } \\
\text { cerning sugar intake may be beneficial } \\
\text { in individuals who require weight loss } \\
\text { or those with high plasma TG concen- } \\
\text { tration, metabolic syndrome, or diabe- } \\
\text { tes. Consumption of sweet alcohol-free } \\
\text { as well as alcoholic beverages in gen- } \\
\text { eral population should be eliminated, } \\
\text { primarily in individuals with elevated } \\
\text { plasma TG concentration or abdominal } \\
\text { obesity }\end{array}$ \\
\hline Alcohol & $\begin{array}{l}\text { - Recent data indicate the need to eliminate alco- } \\
\text { hol completely }\end{array}$ & $\begin{array}{l}\text { - Recent data indicate the need to elimi- } \\
\text { nate alcohol completely }\end{array}$ \\
\hline $\begin{array}{l}\text { Dietary } \\
\text { supplements and } \\
\text { functional food }\end{array}$ & $\begin{array}{l}\text { - In statin-ineligible or statin-intolerant individu- } \\
\text { als, as well as in those who are not willing using } \\
\text { statin therapy or do not achieve the therapeutic } \\
\text { target, administration of nutraceuticals (phytos- } \\
\text { terols, red yeast rice, berberine, bergamot, poly- } \\
\text { cosanol, etc.) may be considered }\end{array}$ & $\begin{array}{l}\text { - Nutraceuticals, especially omega-3 ac- } \\
\text { ids, artichoke products, as well as poly- } \\
\text { cosanol and red yeast rice, may be highly } \\
\text { useful in as a supplementary treatment } \\
\text { of hypertriglyceridaemia [142] }\end{array}$ \\
\hline Dietary fibre & $\begin{array}{l}\text { - Dietary fibre (especially soluble), present in le- } \\
\text { guminous plants, vegetables, fruit, and whole } \\
\text { grain (e.g., oats and barley) products, reduces } \\
\text { cholesterol concentration } \\
\text { - Dietary fibre is a good substitute for saturat- } \\
\text { ed fatty acids and has an effect on maximising } \\
\text { benefits in terms of reduction of LDL-C concen- } \\
\text { tration, as well as minimising adverse effects of } \\
\text { high-carbohydrate diet on concentration of oth- } \\
\text { er lipoproteins } \\
\text { - It is recommended to consume } 25-40 \text { g of fibre, } \\
\text { of which } \geq 7-13 \text { g should be soluble fibre }\end{array}$ & $\begin{array}{l}\text { - Increased consumption of fibre reduces } \\
\text { harmful effects of high-carbohydrate } \\
\text { diet on TG }\end{array}$ \\
\hline $\begin{array}{l}\text { Omega-3 } \\
\text { unsaturated fatty } \\
\text { acids }\end{array}$ & $\begin{array}{l}\text { - Consumption of fish (at least } 2 \times / \text { week) and } \\
\text { plant products rich in omega- } 3 \text { fatty acids (EPA/ } \\
\text { DHA) is recommended } \\
\text { - } \alpha \text {-Linolenic acid is present in walnuts, certain } \\
\text { vegetables, and some seed oils; it is associated } \\
\text { with a lower risk of CV death and stroke [143] }\end{array}$ & $\begin{array}{l}\text { - Pharmacological doses of long-chain } \\
\text { omega-3 fatty acids ( } 2-4 \text { g/day) reduce } \\
\text { TG concentration (by ca. } 30 \% \text { ) and post- } \\
\text { prandial increase in lipaemia } \\
\text { - In individuals with elevated TG concen- } \\
\text { tration despite statin therapy, consump- } \\
\text { tion of } 4 \text { g of icosapent ethyl daily in two } \\
\text { doses was associated with reduced risk } \\
\text { of CV events, including CV death [147] }\end{array}$ \\
\hline $\begin{array}{l}\text { Preferred } \\
\text { products in diet }\end{array}$ & \multicolumn{2}{|c|}{$\begin{array}{l}\text { - Whole grain products; raw and boiled vegetables; leguminous plants (lentils, beans, broad } \\
\text { beans, peas, chickpeas, soya beans); fresh or frozen fruit; lean and oily fish, skinned poultry; } \\
\text { skimmed milk and yoghurt; vinegar, mustard, fat-free sauces } \\
\text { - Methods of preparing food: grilling, boiling in water, steaming }\end{array}$} \\
\hline
\end{tabular}


Table XV. Recommendations on healthy lifestyle as an essential component of treatment of lipid disorders Recommendation Class Level

Non-pharmacological modifications (so called lifestyle changes) are recommended in all patients with dyslipidaemia as an essential component of prevention and treatment.

Consumption of saturated fatty acids should be reduced to $<10 \%$ of energy supply, and in patients with hypercholesterolaemia to $<7 \%$ (the lower the better!).

Unsaturated trans fatty acids of natural origin should account for $<1 \%$ of caloric intake. Unsaturated trans fatty acids of industrial origin should be excluded.

At least $200 \mathrm{~g}$ of fruit should be consumed daily.

At least $200 \mathrm{~g}$ of vegetables should be consumed daily.

Fish should be consumed at least once or twice per week.

Regular exercise (preferably no less than 30 min every day) of moderate intensity, from 3.5 to $7 \mathrm{~h}$

per week, is recommended. Every increase in exercise intensity (regardless of baseline parameters) reduces the risk of all-cause mortality and death due to ischaemic heart disease [148].

group as a constant and inherent element of treatment of lipid disorders (Table XV) [148].

\section{PRINCIPLES OF PHARMACOLOGICAL TREATMENT OF LIPID DISORDERS}

\subsection{Statins}

Statins have been present in clinical practice for 30 years [149]. Currently, the two most potent agents in this group are preferred, i.e., atorvastatin and rosuvastatin. Pitavastatin, which in this year (2021) will appear on the Polish market, may also be used, especially as it is the $3^{\text {rd }}$ most potent statin (in a dose of $4 \mathrm{mg}$ it may reduce LDL-C concentration by up to $47 \%$ ), with unique properties associated with reduction of triglyceride concentration, and with the best safety profile (although relatively poorly studied) [150]. Statins inhibit hydroxymethylglutaryl-coenzyme A (HMG-CoA) reductase, a key enzyme in cholesterol synthesis in hepatocytes, resulting in increased LDL receptor activity on these cells and increased clearance of lipoproteins containing apolipoprotein B-100, i.e., LDL and VLDL remnants (including intermediate density lipoprotein - IDL) $[35,50]$. In comparative studies, atorvastatin and rosuvastatin in a dose of $10 \mathrm{mg} / \mathrm{d}$ after 6 weeks of treatment reduced LDL-C concentration by $36.8 \%$ and $45.8 \%$, in a dose of $20 \mathrm{mg} /$ day by $42 \%$ and $52.4 \%$, and in a dose of $40 \mathrm{mg} /$ day by $47.8 \%$ and $55 \%$, respectively [151]. Statins moderately reduce triglyceride concentration. Atorvastatin in a dose of $10 \mathrm{mg} /$ day, $20 \mathrm{mg} /$ day, and $40 \mathrm{mg} /$ day by $20 \%$, $22.6 \%$, and $26.8 \%$, respectively, and rosuvastatin at the same doses by $19.8 \%, 23.7 \%$, and $26.1 \%$, respectively. These two statins are most applicable in terms of achievement of the treatment goal for LDL-C, provided they are used regularly in appropriate doses [152]. Unfortunately, recent data have demonstrated that the highest dose of rosuvastatin $(40 \mathrm{mg}$ ) is used in little more than $5 \%$ of patients, and that of atorvastatin (80 mg) in only $1.3 \%$ ! (Figure 3 ).

The importance of statins is different in specific patient groups, e.g., the safe statin in patients with chronic kidney disease is atorvastatin, while moderate doses of rosuvastatin are preferred in the elderly, due to the best safety profile of this agent in this group [153]. It should also be emphasised that currently we do not recommend the use of simvastatin (particularly in a dose of $80 \mathrm{mg}$ due to adverse reactions), but if the treatment goal has been achieved and the patient tolerates it well, there is no need to change it.

Achievement of treatment goals for LDL-C depends on its baseline concentration, statin strength, and dose. Therefore, knowledge of the $L D L-C$ reduction levels for specific doses and formulations is so important. This makes it possible to adequately plan the treatment (in the context of the possibility of achievement of the therapeutic goal) and initiate lipid-lowering treatment with adequate reduction potential, according not only to the rule of "the lower the better", but also "the earlier the better". For example, in an ACS patient with baseline LDL-C concentration of $127 \mathrm{mg} / \mathrm{dl}$, it is known that statins may reduce LDL-C by an average of $50 \%$ and the treatment goal for this patient is < $55 \mathrm{mg} / \mathrm{dl}(1.4 \mathrm{mmol} / \mathrm{l})$; therefore, statin monotherapy would be insufficient, so we should initiate treatment with a combination of statin with ezetimibe, which has the potential to lower LDL-C by an average of 65\% (and for rosuvastatin $40 \mathrm{mg}$ with ezetimibe $10 \mathrm{mg}$, even more than $70 \%)$. The guidelines concerning treatment of lipid disorders have been changed based on these assumptions in order to provide physicians with tools to achieve new therapeutic goals for patients with very high and extreme cardiovascular risk [109, 140].

By doubling the statin dose, an additional reduction of LDL-C concentration of only $6 \%$ is 
M. Banach, P. Burchardt, K. Chlebus, P. Dobrowolski, D. Dudek, K. Dyrbuś, M. Gąsior, P. Jankowski, J. Jóźwiak, L. Kłosiewicz-Latoszek, I. Kowalska, M. Małecki, A. Prejbisz, M. Rakowski, J. Rysz, B. Solnica, D. Sitkiewicz, G. Sygitowicz, G. Sypniewska, T. Tomasik, A. Windak, D. Zozulińska-Ziółkiewicz, B. Cybulska

$\%$ of atorvastatin doses

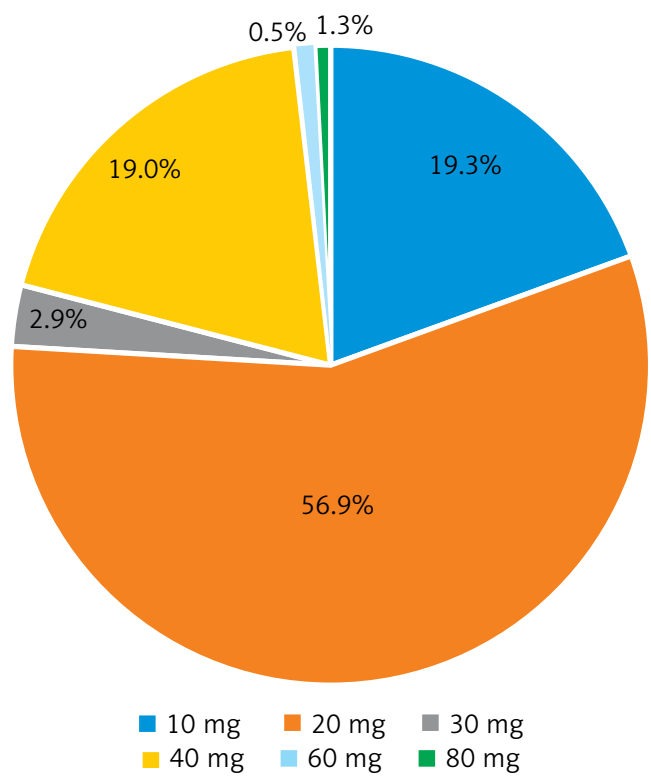

$\%$ of rosuvastatin doses

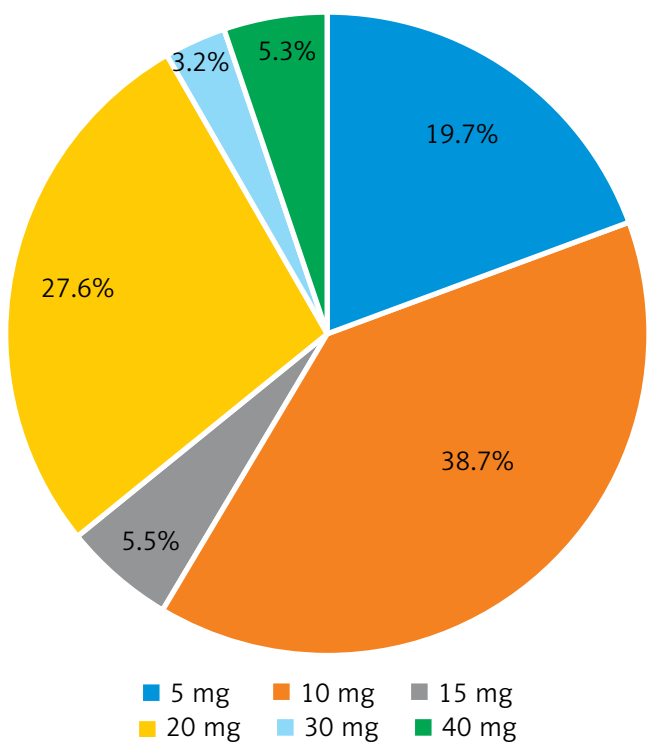

Figure 3. Frequency of prescription of specific doses of atorvastatin and rosuvastatin in Poland (2017April 2021; data based on the IMS)

achieved. This relatively small additional lipid-lowering effect is supposed to be due to an increase in the activity of subtilisin/kexin type 9 proprotein convertase (PCSK 9) during statin therapy (a rebound mechanism associated with reduced LDL-C concentration and an increased number of LDL receptors on hepatocyte surface). This enzyme breaks down LDL receptors in hepatocyte lysosomes and, therefore, once LDL-C particles enter the liver cells, the receptors do not return to the cell membrane to bind to subsequent lipoproteins [154]. Furthermore, particularly in high-risk patients, combination therapy may be more effective than doubling the statin dose both in terms of $\mathrm{LDL}-\mathrm{C}$ reduction (by more than $15 \mathrm{mg} / \mathrm{dl}$ ) and the number of patients achieving treatment goals (almost 2.5 times more) [155].

The main adverse effects of statins are myotoxicity, temporary elevation of alanine aminotransferase activity, and new cases of diabetes mellitus (Section 10.13 and Section 11) [153, 156]. Muscle symptoms are the most common reason for treatment discontinuation. These include mild to severe pain, muscle stiffness, tenderness, cramps, and weakness. They may be accompanied (or not) by elevated creatine kinase (CK) activity. Factors predisposing to myopathy include, but are not limited to, age over 75 years, female sex, renal or hepatic impairment, hypothyroidism, alcohol abuse, excessive physical exercise, genetic susceptibility, perioperative period, and concomitant use of agents that inhibit statin metabolism, e.g. clarithromycin, erythromycin, azole antifungals, dilitiazem, verapamil, amiodarone, fibrates, cyclosporine, clopidogrel, or sulphonamides [8, 9, 153]; concomitant use of antiviral or anti-rheumatic agents should also be considered with care, especially in the current era of a pandemic, as they may also lead to intolerance [157]. Statins may have diabetogenic properties (especially in subjects receiving intensive statin therapy), but despite development of carbohydrate disorders or diabetes mellitus, statin therapy should not be discontinued due to its net benefit (up to 5 times) in terms of cardiovascular risk reduction [158]. The management should include glucose-lowering diet, weight reduction, if this is excessive, and possible use of antidiabetic agents $[8,9,153]$.

In multiple randomised clinical trials, strong evidence for high efficacy of statins in primary and secondary prevention of cardiovascular disease has been provided. The lower LDL-C concentration was achieved, the lower was the risk of cardiovascular events. This relationship was clearly confirmed by a meta-analysis of 26 randomised clinical trials concerning statins [159]. In 21 studies (a statin vs. another intervention, mainly placebo) involving 126,526 patients, a reduction of LDL-C concentration by $1 \mathrm{mmol} / \mathrm{l}(\sim 40 \mathrm{mg} / \mathrm{dl})$ was found to significantly reduce cardiovascular events by $21 \%$. In the same study it was shown that intensive statin treatment, as compared to moderate (5 studies involving 39,612 patients), provided a significant $28 \%$ reduction in cardiovascular events per $1 \mathrm{mmol} / \mathrm{l}$ of LDL-C reduction $(\sim 40 \mathrm{mg} / \mathrm{dl})$. Statin therapy reduces the incidence of stroke, coronary mortality, and overall mortality [159]. 


\section{KEY POINTS TO REMEMBER}

- Statins are the gold standard - first-line agents in treatment of hypercholesterolaemia, and among lipid-lowering agents have the best documented efficacy in primary and secondary prevention of cardiovascular diseases.

- Due to the need to achieve the LDL-C treatment goal, atorvastatin and rosuvastatin are currently the most applicable agents. Unfortunately, due to the therapeutic inertia and lack of adherence, the doses in which they are most frequently used by patients are too low, what results in the lack of achievement of the therapeutic goal in $2 / 3$ of patients [30].

- During treatment, one should pay attention to adverse effects reported by the patient, mainly muscle symptoms, and if these occur, follow the recommendations, and try not to discontinue statin therapy.

\subsection{Ezetimibe}

Ezetimibe selectively inhibits the absorption of cholesterol from the small intestinal lumen to enterocytes by selective blocking of the NPC1L1 (Niemann-Pick C1 like 1) sterol transport protein [160]. As a result of reduced absorption, less cholesterol reaches the liver and consequently the expression of $L D L$ receptors ( $L D L R)$ on the surface of hepatocytes is increased, thus increasing liver uptake of endogenous cholesterol contained in LDL lipoproteins [160]. Ezetimibe monotherapy in a dose of $10 \mathrm{mg}$ reduces $\mathrm{LDL}-\mathrm{C}$ concentration by $15-25 \%$; however, quite a high inter-individual variability is observed [161]. This is determined by dietary variability (the lipid-lowering effect of the agent is increased with a high-cholesterol diet) and probably the variability of genes encoding NPC1L1; therefore, the response to ezetimibe alone may be significantly better in a certain group of patients [162]. This agent reduces TG concentration by $1.7-9.4 \%$ and increases HDL-C concentration to a small extent by $1.3-6.2 \%$ [163]. However, data on the effect of ezetimibe on lipoprotein (a) are inconsistent, although all indicate a numerical Lp(a) reduction (from 2.6 to $7.1 \%$ ) $[164,165]$. Nevertheless, following a meta-analysis by Tsimikas et al. [166] indicating a moderate but statistically significant (although probably clinically insignificant) increase of $L p(a)$ concentration following statin treatment by $6-7 \%$, particularly in high-risk patients with elevated concentration of this lipoprotein, combination therapy with a statin and ezetimibe is recommended [167].

Combination treatment with ezetimibe and a statin, as a result of a synergistic effect, results in greater LDL-C concentration decrease than monotherapy with either agent [168]. Ezetimibe added to a statin reduces LDL-C concentration by another 15-20\%; therefore, a combination of high-intensity statin treatment (i.e., atorvastatin or rosuvastatin at their highest doses) with ezetimibe can reduce LDL-C concentration by up to $65-70 \%[8,9]$. This combination is more effective (by more than $15 \mathrm{mg} / \mathrm{dl}$ ) in terms of $\mathrm{LDL}-\mathrm{C}$ reduction and 2.45 times more effective in achieving the treatment goal as compared to doubling the statin dose $[155,168]$. Unfortunately, the combination of a statin with ezetimibe is still very rarely used not only in Poland and in Europe, but also worldwide, even though for 4 years ezetimibe has been a generic and very cheap product. In the Da Vinci study, the combination therapy was used only in $9.2 \%$ of patients [30], whereas in Central and Eastern European countries, in 7\% [31]. This is only a small increase from the $2016 / 2017$ data in which, based on the TERCET registry, combination therapy with a statin and ezetimibe was used only in less than 3\% of ACS patients [169] (Figure 4).

In published randomised trials with ezetimibe, high lipid-lowering efficacy and favorable safety profile of combination therapy in patients with familial hypercholesterolaemia, renal failure, type 2 diabetes mellitus, metabolic syndrome, high cardiovascular risk, and ACS was demonstrated [8, $9,170,171]$. In all these studies, in the group receiving combination therapy, the target LDL-C concentration was achieved significantly more often, and greater reduction of TC, non-HDL-C, TG and ApoB concentration was observed than with statin monotherapy $[8,9]$. In addition, the results of IMPROVE-IT (Improved Reduction of Outcomes: Vytorin Efficacy International Trial) study demonstrated that $L D L-C$ reduction with ezetimibe significantly reduces the incidence of cardiovascular events, and the higher the patient's baseline cardiovascular risk, the higher the reduction [170, 171].

Ezetimibe is rapidly absorbed from the gastrointestinal tract, mainly as the pharmacologically active ezetimibe glucuronate. Simultaneous food intake does not significantly affect its bioavailability. It is metabolised in the intestine and the liver. It is neither an inducer nor an inhibitor of cytochrome P450 $[8,9]$. Therefore, it does not interact with drugs metabolised by this cytochrome. Ezetimibe concentration profile has several daily peaks; therefore, time of administration does not affect its activity [172]. The agent is mainly (78\%) eliminated with faeces, to a lesser extent (11\%) with urine. Pharmacokinetic parameters of ezetimibe in the elderly and in patients with renal or mild hepatic insufficiency are not significantly altered [172]. It is contraindicated in patients with severe hepatic impairment. In contrast to agents 
M. Banach, P. Burchardt, K. Chlebus, P. Dobrowolski, D. Dudek, K. Dyrbuś, M. Gąsior, P. Jankowski, J. Jóźwiak, L. Kłosiewicz-Latoszek, I. Kowalska, M. Małecki, A. Prejbisz, M. Rakowski, J. Rysz, B. Solnica, D. Sitkiewicz, G. Sygitowicz, G. Sypniewska, T. Tomasik, A. Windak, D. Zozulińska-Ziółkiewicz, B. Cybulska

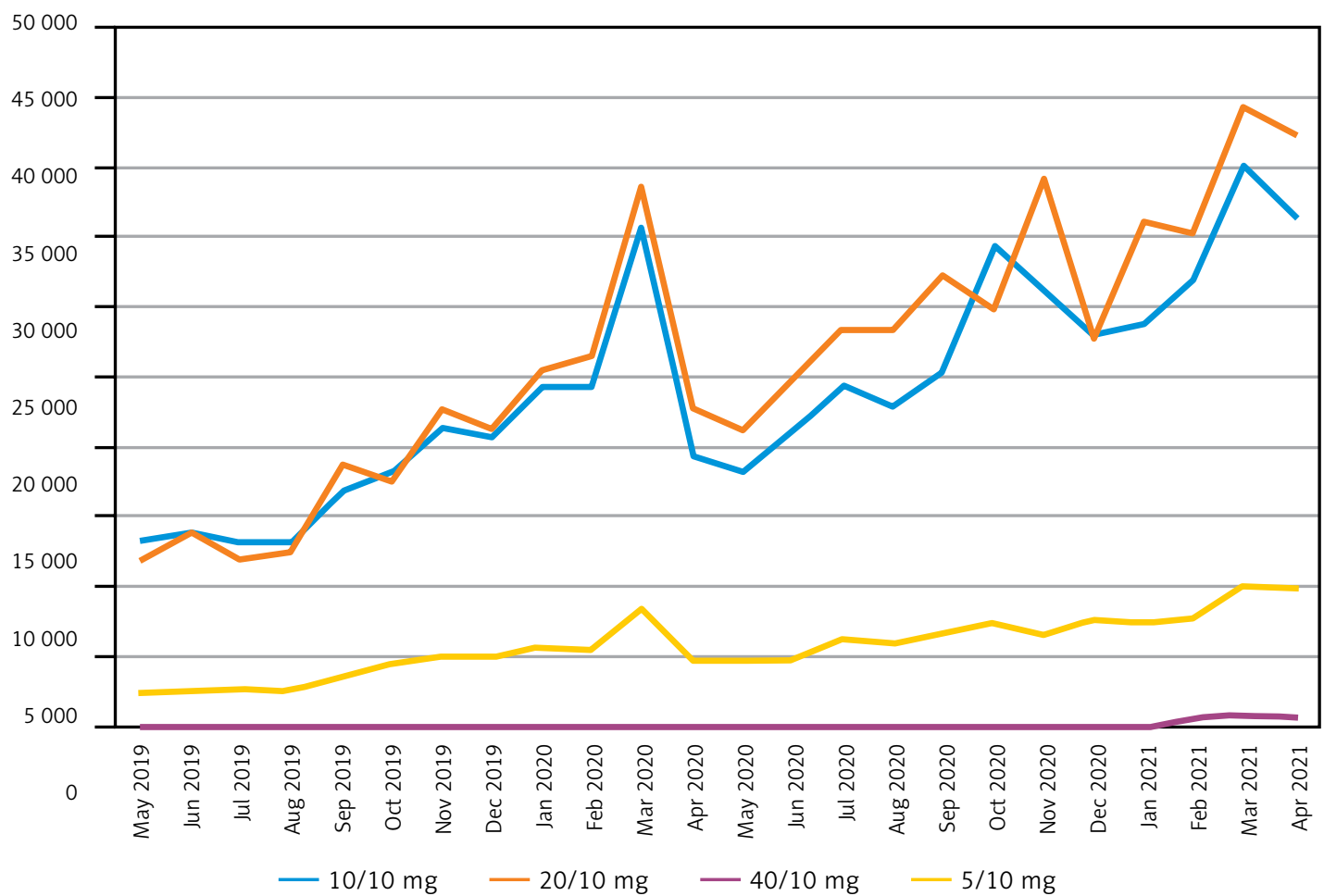

Figure 4. Prescription of rosuvastatin in combination with ezetimibe (fixed combination) in Poland between May 2019 and April 2021 (based on the IMS)

interrupting bile acid reabsorption, ezetimibe does not impair the absorption of fat-soluble vitamins, thyroid hormone, warfarin, or $\beta 1$-adrenolytic drugs. Ezetimibe inhibits the absorption of plant stanols and sterols, so these agents should not be used concomitantly [8, 172]. Data discussed above indicate that ezetimibe is an agent with a high lipid-lowering efficacy and a very good safety profile (it may also be used in pregnant women if benefits outweigh the risk); therefore, it should be used commonly, especially in the context of a very low percentage of patients achieving the therapeutic goal for LDL cholesterol in Poland ( $17 \%$ of very high risk patients achieve concentrations below $55 \mathrm{mg} / \mathrm{dl}(1.4 \mathrm{mmol} / \mathrm{l})$ and in every $4^{\text {th }}$ patient regardless of the risk) $[30,31]$.

\section{KEY POINTS TO REMEMBER}

- Combination therapy with a statin and ezetimibe (intensive lipid-lowering therapy) should be the gold standard of care for patients at very high and extreme risk (Section 9.8) as it significantly increases the chances of achieving new therapeutic LDL-C targets.

- High intensive statin plus ezetimibe provides very significant reduction of LDL-C concentration (by a mean of $65 \%$ ) with a preserved or even better safety profile than high-intensity statin monotherapy.
- Ezetimibe monotherapy should be considered immediately in patients with complete statin intolerance (without waiting for statin rechallenge) (Section 11), and in case of partial intolerance, in combination with the highest statin dose tolerated by the patient.

\subsection{PCSK9 inhibitors}

PCSK9 is a protein responsible for the metabolism of LDL-C bound to LDL-C receptors present in the blood and on the surface of liver cells [173]. This protein binds to LDLR on the hepatocyte surface and, along with LDL-C, undergoes endocytosis and then degradation of these complexes in liver cell lysosomes. This leads to reduced expression of LDL receptors on hepatocyte surface and in the blood, and therefore increases LDL-C concentration [173]. The discovery of this mechanism was accidental and concerned patients with very high LDL-C concentration and diagnosed with autosomal dominant hypercholesterolaemia (a gain of function mutation of PCSK9) as well as those with very low LDL-C $(<20 \mathrm{mg} / \mathrm{dl})$ with a loss of function mutation as a result of which non-functional PCSK9 did not bind to LDLRs, resulting in the receptors' return to the hepatocyte surface and effective LDL-C reduction [174]. This was the starting point for studies on various ways 
of PCSK9 inhibition (using monoclonal antibodies or RNA interference) that could support statins in effective $L D L-C$ reduction.

Studies with PCSK9 inhibitors (evolocumab and alirocumab) were conducted in 3 patient groups, i.e., those at high cardiovascular risk, patients with familial hypercholesterolaemia, and those with statin intolerance [173]. In these studies, high effectiveness of the analysed agents in reducing LDL-C concentration (from $45 \%$ to $65 \%$ depending on the patient group versus placebo and by ca. $35 \%$ to $45 \%$ compared with ezetimibe), allowing up to $80-90 \%$ of patients in these groups to achieve their treatment goals, has been confirmed. Furthermore, PCSK9 inhibitors are also effective with respect to other lipid profile parameters, effectively reducing non-HDL-C concentration (on average by ca. $50 \%$ vs. placebo), apoB (ca. 50\%), TG (15-20\%), and Lp(a) (ca. 25\%), as well as increasing HDL-C (5-10\%) and apoA1 (3-5\%) [173, 175]. Available studies indicate that PCSK9 inhibitors used in monotherapy may reduce LDL-C by $60 \%$ an average and used in combination with statins and ezetimibe by up to $85 \%[8,9]$.

These agents (alirocumab and evolocumab) have been approved by both the US FDA and the European Medicine Agency (EMA) in the following indications: for use in adults with primary hypercholesterolaemia (familial heterozygous and non-familial) or mixed dyslipidaemia in addition to diet: (1) in combination with a statin or a statin and other lipid-lowering agents in patients, in whom the target LDL-C concentration cannot be achieved with the highest tolerated dose of a statin, or (2) alone or in combination with other lipid-lowering agents in statin-intolerant patients or those in whom statins are contraindicated. As evolocumab has been studied in patients with homozygous familial hypercholesterolaemia (the TAUSSIG and TESLA studies), it should also be considered in combination with other lipid-lowering agents in adults and adolescents aged at least 12 years with homozygous $\mathrm{FH}[175]$.

Both the FOURIER study [176] with evolocum$\mathrm{ab}$ and the ODYSSEY OUTCOMES study [177] with alirocumab confirmed high efficacy of both PCSK9 inhibitors in terms of reduction of the primary endpoint (by 15\%), and for alirocumab they demonstrated that PCSK9 inhibitors can also significantly reduce all-cause mortality (also by $15 \%)$. Subsequent sub-analyses, in subgroups of patients with a history of myocardial infarction and stroke, or several cardiovascular events, or an epidemiologically recent $\mathrm{MI}$, or $\mathrm{MI}$ and concomitant peripheral vascular disease or multibed disease, post-MI patients with other risk factors, such as diabetes mellitus or elevated concentration of hsCRP or Lp(a), those with different base- line LDL-C concentration, or, finally, in patients with a long follow-up period (> 3 years), not only confirmed their high efficacy [178], but also provided the basis for identification of patients with extreme cardiovascular risk and creation of a reimbursement programme which since November $1^{\text {st }}, 2018$, has been available for patients with familial hypercholesterolaemia, and since November $1^{\text {st }}, 2020$, for patients post myocardial infarction. Unfortunately, the adopted reimbursement criteria make it possible to include only about $5-7 \%$ of patients with $\mathrm{FH}$ (due to the required high LDL-C concentration despite treatment) and a relatively small group of post-MI patients (mainly due to the need to include them within 12 months of $\mathrm{MI}$ onset). Due to all the above, at the time of preparation of these guidelines approximately 200 patients in total, mostly those with $\mathrm{FH}$ (a little more than 150) in nearly 30 centres in Poland (the list is available on PoLA website: https://ptlipid.pl/2020/09/28/osrodki-w-osrodki-w-polsce-w-polsce-w-ktorych-jest-realizowany-program-lekowy-ktorych-jest-realizowany-program-lekowy-leczenie-hipercholesterolemii-rodzinnej-icd-10-e78-01/) have been included into the therapeutic programme. As a result of intensive activity of the Societies (PoLA, PSC), experts, and patient organisations, the criteria have been changed since September $1^{\text {st }} 2021$, currently enabling treatment of patients with $\mathrm{FH}$ as early as at LDL-C > $100 \mathrm{mg} / \mathrm{dl}(2.5 \mathrm{mmol} / \mathrm{l})$ and after not 6 but 3 months of prior statin and ezetimibe therapy (Table XVI).

The results of studies confirming a high efficacy of PCSK9 inhibitors administered immediately after an ACS (the EVOPACS and EVACS studies with evolocumab $[179,180]$ and the VCU-alirocRT study with alirocumab [181]) are also worth noting, as they were the starting point for recommendation concerning initiation of treatment with PCSK9 inhibitors during hospitalisation (recommendation level Ila C) in the most recent ESC/EAS 2019 guidelines [9]. The EVACS study demonstrated that the use of evolocumab immediately after an ACS was associated with significant LDL-C reduction as early as after 3 days (mean concentration $1.3 \mathrm{mmol} / \mathrm{l}$ ) and below $1 \mathrm{mmol} / \mathrm{l}(40 \mathrm{mg} / \mathrm{dl})$ after 4-7 days, as compared with the control group. Such early treatment resulted in $65.4 \%$ of patients at discharge and more than $85 \%$ after 30 days achieving their LDL-C target concentration below $55 \mathrm{mg} / \mathrm{dl}$ [180].

Studies performed to date do not indicate any significant adverse effects of PCSK9 inhibitors compared to statins and/or ezetimibe. Injection site reactions (redness and soreness) may be observed occasionally. In addition, effects typical for monoclonal antibodies may be observed, 


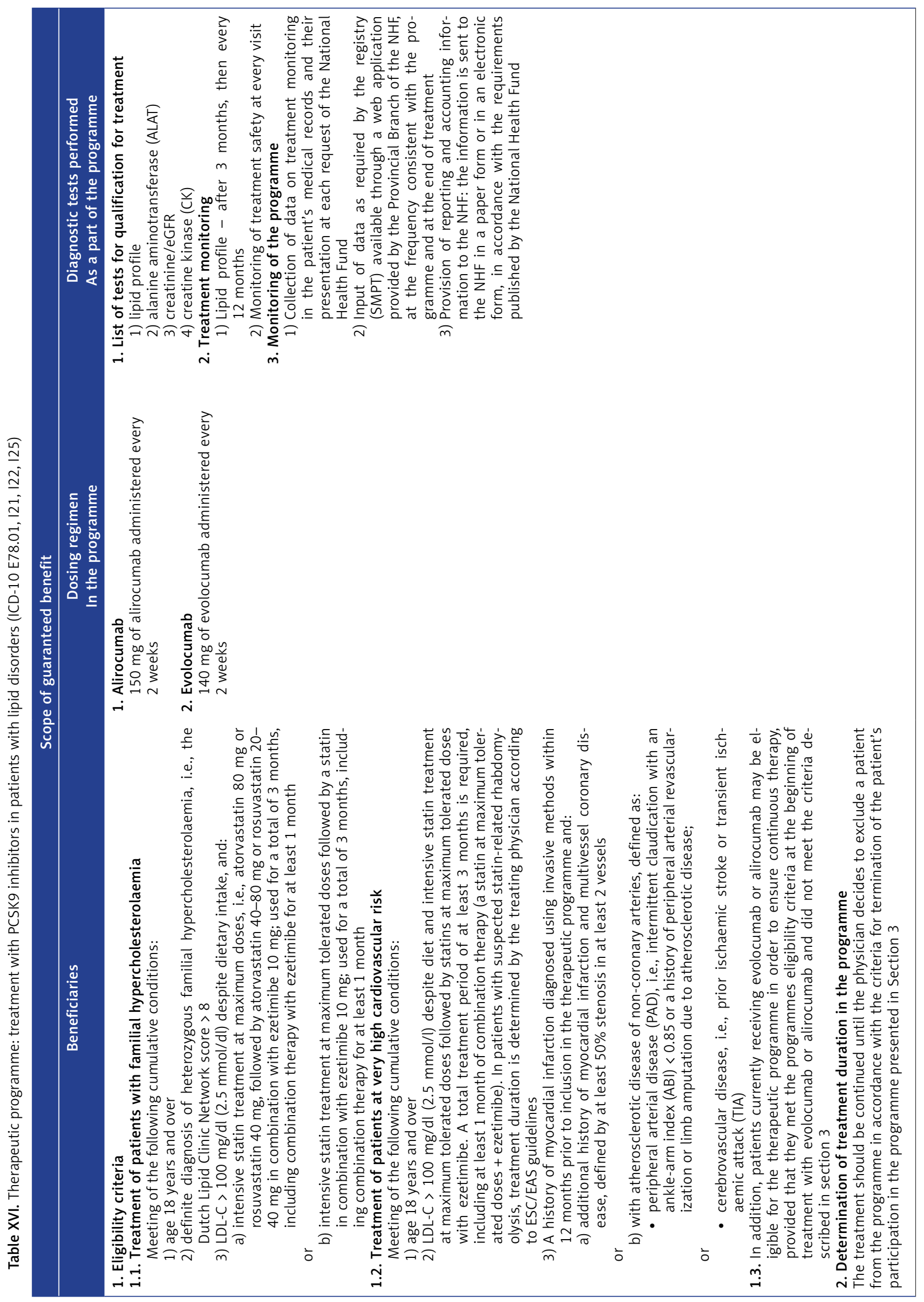




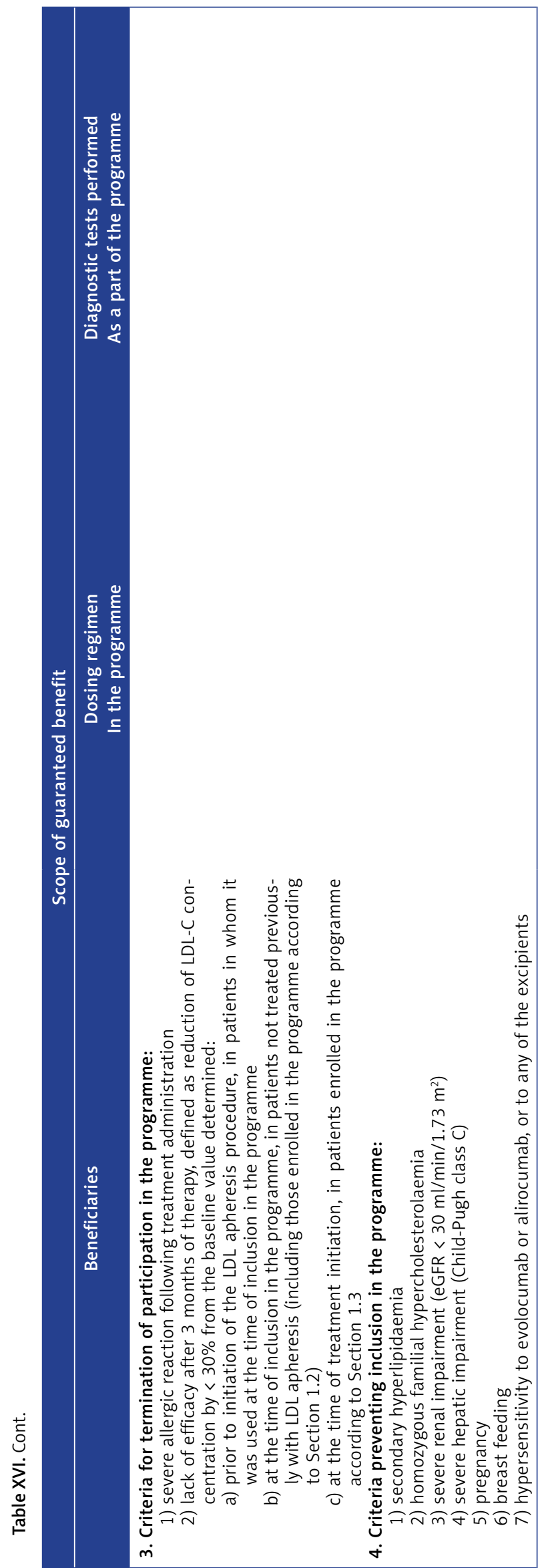

including: nasopharyngitis (<5\%), upper respiratory tract infections (ca. 3\%), back pain (ca. 3\%), arthralgia (ca. 2\%), flu-like symptoms (ca. $2 \%$ ), and nausea (ca. 2\%). Despite numerous studies and much discussion, no increased risk of muscle symptoms (myalgia and myopathy), elevated liver enzymes or creatine kinase, or the risk of new cases of diabetes mellitus or cognitive dysfunction has been confirmed $[9,49,182]$. With reference to the assessment of cognitive risk, the EBBINGHAUS study with evolocumab enrolled 1204 patients followed up for a mean of 19 months [182-184]. No differences between the groups (evolocumab vs. placebo) were observed, either with respect to the primary endpoint (Spatial Working Memory Index) or to the secondary endpoints, i.e., the results for working memory, episodic memory, and psychomotor speed. Exploratory analysis revealed no association between LDL-C concentration and cognitive changes [182-184].

\section{KEY POINTS TO REMEMBER}

- Based on the results of the FOURIER and ODYSSEY OUTCOMES studies and their sub-analyses, PCSK9 inhibitors are recommended in secondary prevention in very highrisk patients who do not achieve their target with the maximum tolerated statin dose and ezetimibe.

- PCSK9 inhibitors are also recommended in very high-risk patients with $\mathrm{FH}$ (i.e., those with ASCVD or another major risk factor) who do not achieve their target with the maximum tolerated statin dose and ezetimibe.

- Available data also demonstrate the importance of PCSK9 inhibitors in primary prevention that may be considered in very high-risk patients (but without FH) if the LDL-C target has not been achieved with the maximum tolerated statin dose and ezetimibe.

- PCSK9 inhibitors should be introduced as soon as possible (after 4-6 weeks if the treatment goal has not been achieved) in patients with extreme cardiovascular risk in whom treatment should be started with a combination of a statin and ezetimibe (Section 9.8).

- Studies performed so far have not indicated any significant adverse effects of this class of agents.

\subsection{Fibrates}

The mechanism of action of fibrates depends on the activation of transcription factors called peroxisome proliferator-activated receptors- $\alpha$ (PPAR- $\alpha$ ) [185]. Fibrates are ligands of PPAR- $\alpha$ and peroxisome proliferators. By activating PPAR- $\alpha$, 
M. Banach, P. Burchardt, K. Chlebus, P. Dobrowolski, D. Dudek, K. Dyrbuś, M. Gąsior, P. Jankowski, J. Jóźwiak, L. Kłosiewicz-Latoszek, I. Kowalska, M. Małecki, A. Prejbisz, M. Rakowski, J. Rysz, B. Solnica, D. Sitkiewicz, G. Sygitowicz, G. Sypniewska, T. Tomasik, A. Windak, D. Zozulińska-Ziółkiewicz, B. Cybulska

these agents affect the expression of key genes encoding proteins involved in lipid metabolism. Reduction of triglycerides concentration is associated with activation of oxidative enzymes which increase oxidation of fatty acids in the liver, resulting in decreased lipid synthesis, and with increased activity of lipoprotein lipase (LPL), an enzyme on the vascular endothelium responsible for hydrolysis of triglycerides, and thus their catabolism. Fibrates increase synthesis of apolipoproteins $\mathrm{A}-\mathrm{I}$ and $\mathrm{A}-\mathrm{II}$, two proteins present in $\mathrm{HDL}$ cholesterol $[8,185]$.

Fibrates reduce TG concentration by $25-50 \%$ and increase HDL-C by $10-25 \%$. In cases of severe hypertriglyceridaemia, treatment should be initiated with a fibrate in order to quickly reduce serum lipid concentration as it is a risk factor for acute pancreatitis, which increases the risk of serious complications, including death [8, 185]. In large clinical trials with fenofibrate, in patients with diabetes (FIELD, the Fenofibrate Intervention and Event Lowering in Diabetes, and ACCORD, Action to Control Cardiovascular Risk in Diabetes) randomised to receive the active agent no effect on cardiovascular risk was observed as compared to placebo [186, 187]. However, such benefits (i.e., reduction of cardiovascular events) were observed in subgroups of patients with atherogenic dyslipidaemia (increased TG and decreased HDL-C concentration) and those with micro- and macroangiopathic complications (retinopathy or diabetic nephropathy) [186, 187]. Furthermore, both studies were subject to significant methodological errors; the largest study concerning statins (i.e., the Heart Protection Study, HPS) which demonstrated significant benefits of statin therapy in patients with diabetes was published during the FIELD trial, resulting in twice as many patients receiving statins in the placebo arm than in the fenofibrate arm. After adjustment of the results, i.e., exclusion of patients treated with statins in both groups, fenofibrate significantly reduced the primary endpoint of the FIELD study $[115,186]$. Similarly, the ACCORD study, in which patients virtually optimally treated with statins with slightly elevated TG concentration were enrolled, also eventually failed to demonstrate reduction of the primary endpoint (excluding patients with atherogenic dyslipidaemia) $[115,187]$. In the ACCORDION study, being continuation of the ACCORD study, 4644 subjects were enrolled, including $35 \%$ of patients with prior cardiovascular events. Only $4.3 \%$ of the study participants continued treatment with fenofibrate after completion of the ACCORD study [188]. In a follow-up period of 9.7 years, the hazard ratio (HR) for the primary endpoint in patients originally randomised to fenofibrate as compared to placebo was 0.93 (95\% Cl: 0.83-1.05; $p=0.25$ ), i.e., comparable to the value originally observed in the ACCORD study $[187,188]$. Again, it was observed that in patients with atherogenic dyslipidaemia (TG > $204 \mathrm{mg} / \mathrm{dl}$ and HDL-C < $34 \mathrm{mg} / \mathrm{dl}$ ), fenofibrate treatment significantly reduced the risk of cardiovascular complications by $27 \%(\mathrm{HR}=$ 0.73; 95\% Cl: 0.56-0.95) [188]. Unfortunately, no large clinical trials with fibrates used exclusively in patients with atherogenic dyslipidaemia have been performed.

The only fibrate available in Poland is fenofibrate, which has the highest number of studies; in other countries bezafibrate is also used, which, similarly to fenofibrate, is highly efficacious in reduction of TG concentration, and its effect on reduction of cardiovascular incidents has been confirmed [189]. Considering a growing percentage of individuals with metabolic disorders in Poland, this agent should also be available on the market for treatment of hypertriglyceridaemia. It is also worth mentioning that research on a new fibrate, i.e., pemafibrate, is ongoing; this agent may prove the strongest in the entire group in terms of TG reduction. In the PROVIDE trial, the efficacy and safety of pemafibrate in subjects with type 2 diabetes and hypertriglyceridaemia was evaluated in a period of 52 weeks [190]. The patients were randomised to placebo or pemafibrate 0.2 or $0.4 \mathrm{mg} /$ day for 24 weeks; the treatment was then continued in all patients through week 52 . The percentage changes in fasting serum TG concentration at the end of the study were $-48.2 \%$, $-42.3 \%$, and $-46.4 \%$ for placebo/pemafibrate $0.2 \mathrm{mg} /$ day, and pemafibrate $0.4 \mathrm{mg} /$ day, respectively. Pemafibrate was well tolerated throughout the study [190]. The ongoing PROMINENT study (Pemafibrate to Reduce Cardiovascular OutcoMes by Reducing Triglycerides IN patiENts With diabeTes), in which 10,000 patients with diabetes mellitus, mild to moderate hypertriglyceridaemia (TG: 200-499 mg/dl), and low HDL-C ( $\leq 40 \mathrm{mg} / \mathrm{dl})$ will be enrolled and treated with pemafibrate $(0.2 \mathrm{mg}$ BID) for a maximum of 5 years (mean: 3.75 years), may answer the question of how this effective TG reduction will translate into reduction of cardiovascular events [191].

The most recent ESC/EAS 2019 guidelines [9] on the management of dyslipidaemia allow consideration of combination therapy with a statin and fenofibrate if TG concentration during statin therapy is still above $200 \mathrm{mg} / \mathrm{dl}$ (> $2.3 \mathrm{mmol} / \mathrm{l}$ ).

Adverse effects of fibrates are generally moderate and rarely observed. Myalgia and myopathy (in combination with high-dose statins) as well as increased aminotransferase activity have been reported. These agents increase creatinine concentration. It should be known that fibrates are in 60-90\% excreted renally, which limits their use 
in chronic kidney disease. Increased homocysteine concentration, cases of acute pancreatitis, and thromboembolism were also observed [8, 115].

\section{KEY POINTS TO REMEMBER}

- The main indication for the fibrate therapy is severe hypertriglyceridaemia. In this case, fibrates are the first-line agents.

- In patients with hypertriglyceridaemia statins are the first-line agents. Addition of a fibrate to a statin should be considered in patients with persistent hypertriglyceridaemia (TG > $200 \mathrm{mg} / \mathrm{dl}$ or $2.3 \mathrm{mmol} / \mathrm{l}$ ) despite statin therapy.

\subsection{Omega-3 acids}

The importance of omega-3 has been discussed in detail in Section 8.4. It should be emphasised that their role in treatment of hypertriglyceridaemia has changed significantly over the last few years, especially after the REDUCE-IT (the Reduction of Cardiovascular Events with Icosapent Ethyl-Intervention Trial) study was published; it concerned highly purified eicosapentaenoic acid (EPA) (icosapent ethyl) which in a dose of $4 \mathrm{~g} /$ day demonstrated high efficacy in both primary prevention (in patients with diabetes and other risk factors) and secondary prevention in patients with ASCVD, reducing the primary endpoint of the study by $25 \%(\mathrm{HR}=0.75 ; 95 \% \mathrm{Cl}: 0.68-0.83$; $p<0.001)$ [147]. It was also observed that cardiovascular mortality was significantly lower in the icosapent ethyl group than in the placebo group (4.3\% vs. $5.2 \% ; \mathrm{HR}=0.80 ; 95 \% \mathrm{Cl}: 0.66-0.98$; $p=0.03$. As to safety, a higher proportion of patients in the icosapent ethyl group were hospitalised due to atrial fibrillation or flutter (3.1\% vs. $2.1 \%, p=0.004$ ) [147]. Further studies demonstrated the effect of icosapent ethyl on reduction of atherosclerotic plaque volume. The EVAPORATE study (Effect of Vascepa on Improving Coronary Atherosclerosis in People With High Triglycerides Taking Statin Therapy) enrolled patients with coronary atherosclerosis ( $\geq 1$ angiographic stenosis $\geq 20 \%$ ) treated with statins with LDL-C concentration 40-115 mg/dl and persistent high triglyceride concentration (135-499 mg/dl). In a 9-month analysis, a significant effect of omega-3 acids on atherosclerotic plaque morphology (i.e. increased plaque calcification, as well as reduction of the fibrous part and total volume of the plaque) was demonstrated [192].

Interestingly, these results have not been confirmed in subsequent studies with the mixture of omega-3 acids (EPA and docosahexaenoic acid -
DHA). The VITAL study included nearly 26,000 individuals (in primary prevention, aged $>50$ years for men and > 55 years for women) who were treated with vitamin $D_{3}$ (2000 IU daily) and $n-3$ fatty acids of marine origin ( $1 \mathrm{~g} /$ day). The use of omega- 3 acids did not significantly affect the study endpoints; only significant reduction in the risk of myocardial infarction was observed $(\mathrm{HR}=$ $0.72 ; 95 \% \mathrm{Cl}: 0.59-0.90)$ [193]. As noted in the comments, negative results of the study could be associated with a low-risk patient population (primary prevention), the form of omega- 3 acids used (mixture), or a low dose used in the study.

Therefore, in a subsequent STRENGTH ( $A$ LongTerm Outcomes Study to Assess STatin Residual Risk Reduction with EpaNova in HiGh Cardiovascular Risk PatienTs with Hypertriglyceridemia) study the effect of a preparation containing EPA and DHA carboxylic acids in a dose of $4 \mathrm{~g}$ /day was investigated in over 13,000 patients with high cardiovascular risk and atherogenic dyslipidaemia treated with statins. Interestingly, in the study corn oil was used as placebo, which might have had an impact on the results of the study. The primary composite endpoint comprised cardiovascular mortality, nonfatal myocardial infarction, nonfatal stroke, coronary revascularization, or unstable angina requiring hospitalization. When 1384 patients experienced the primary endpoint (of the planned 1600 events), the study was prematurely terminated based on an interim analysis that demonstrated low probability of clinical benefit from the use of omega-3 CA vs. the comparator applied. The primary endpoint occurred in 785 (12.0\%) omega-3-treated patients compared with $795(12.2 \%)$ corn oil-treated patients $(H R=0.99$; 95\% Cl: 0.90-1.09; $p=0.84$ ) [194]. In the omega-3 group, a significant reduction in TG concentration by $19 \%$ and hsCRP by $20 \%$ in comparison with the control group was observed [194].

A meta-analysis summarising studies concerning omega- 3 acids published in recent years, which finally included 13 studies covering 127,447 individuals, demonstrated significant reduction of the risk of death due to ischaemic heart disease (risk ratio $(\mathrm{RR})=0.91,95 \% \mathrm{Cl}$ : 0.85-0.97, $p=0.010)$, major vascular events $(\mathrm{RR}=0.95,95 \% \mathrm{Cl}$ : 0.93$0.98, p=0.001)$, nonfatal myocardial infarction $(R R=0.89,95 \% \mathrm{Cl}: 0.83-0.95, p=0.001)$ and all-cause mortality $(\mathrm{RR}=0.95,95 \% \mathrm{Cl}: 0.92-0.99$, $p=0.025$ ) [195].

The REDUCE-IT study significantly changed the view on omega-3 fatty acids and their use in treatment of hypertriglyceridaemia. In December 2019, the FDA approved an icosapent ethyl formulation (Vazkepa) for treatment of hypertriglyceridaemia in order to reduce cardiovascular risk in high-risk patients [196]. In January 2021, the Committee for 
M. Banach, P. Burchardt, K. Chlebus, P. Dobrowolski, D. Dudek, K. Dyrbuś, M. Gąsior, P. Jankowski, J. Jóźwiak, L. Kłosiewicz-Latoszek, I. Kowalska, M. Małecki, A. Prejbisz, M. Rakowski, J. Rysz, B. Solnica, D. Sitkiewicz, G. Sygitowicz, G. Sypniewska, T. Tomasik, A. Windak, D. Zozulińska-Ziółkiewicz, B. Cybulska

Medicinal Products for Human Use (CHMP) of the European Medicines Agency (EMA) adopted a positive opinion recommending marketing authorisation of Vazkepa to reduce the risk of cardiovascular events in patients at high cardiovascular risk [196].

Therefore, currently we recommend the use of omega-3 acids (in Poland Vazkepa is still unavailable, and combined formulations of omega-3 acids in a dose of less than $1 \mathrm{~g}$ are dominant) in treatment of hypertriglyceridaemia in a dose of at least $2 \mathrm{~g}$ daily, as adjunct treatment to statins and fibrates, except in patients already using omega-3 acids in combination with statins, in whom fibrates can be used as a $3^{\text {rd }}$ line treatment.

\section{KEY POINTS TO REMEMBER}

- Omega-3 polyunsaturated acids significantly reduce triglyceride concentration (by 20$30 \%$ ) and hsCRP (by 12-20\%).

- In patients with hypertriglyceridaemia statins are the first-line agents. Addition of omega- 3 acids in a dose of at least $2 \mathrm{~g}$ to a statin and a fibrate may be considered in patients with persistent hypertriglyceridaemia (TG $>200 \mathrm{mg} / \mathrm{dl}$ or $2.3 \mathrm{mmol} / \mathrm{l}$ ) despite combination therapy.

- If available, icosapent ethyl should be considered in a dose of $2 \times 2 \mathrm{~g}$ in addition to a statin in very high-risk patients with ASCVD with persistent TG concentration > $150 \mathrm{mg} / \mathrm{dl}$.

\subsection{Bile acids sequestrants (resins)}

Resins bind bile acids in the intestine, reducing their enterohepatic circulation. In this way, by feedback, conversion of cholesterol into bile acids in the liver is activated. Reduced cholesterol content in hepatocytes increases expression of the LDL receptor, which in turn reduces serum LDL-C concentration [197]. In some patients resins may increase hepatic VLDL formation, resulting in increased serum TG concentration. In addition, they reduce glucose concentration in patients with diabetes mellitus. Addition of colesevelam to antidiabetic agents significantly improves glycaemic control, although no data on the effect of such treatment on cardiovascular risk reduction are available [197].

Bile acids sequestrants in maximum doses, i.e., cholestyramine 24 g/day, colestipol 20 g/day, or colesevelam $4.5 \mathrm{~g} /$ day reduce LDL-C concentration by $18-25 \%$. No significant effect on HDL-C levels has been observed. Treatment with cholestyramine in primary prevention in patients with hypercholesterolaemia resulted in significant reduction in cardiovascular episodes by $19 \%$ [198, 199]. A colesevelam preparation (Cholestagel) is available on the Polish market, and the use of ion exchange resins is currently limited to treatment of severe hypercholesterolaemia during pregnancy.

Resins are not absorbed from the gastrointestinal tract and demonstrate no systemic toxicity. However, they often cause gastrointestinal adverse effects (constipation, flatulence, nausea). They reduce absorption of fat-soluble vitamins. To avoid reduced absorption of other medicines, ion exchange resins should be taken $4 \mathrm{~h}$ before or $1 \mathrm{~h}$ after other medicines. Colesevelam is the best tolerated resin [200].

\section{KEY POINTS TO REMEMBER}

- Bile acids sequestrants in monotherapy should be considered in statin-intolerant patients and may be considered in combination therapy if the treatment goal has not been achieved with the maximum tolerated statin doses.

- Bile acids sequestrants are safe in pregnant and breast-feeding women.

\subsection{Nicotinic acid}

Nicotinic acid (niacin) inhibits lipolysis in adipose tissue, thus reducing synthesis of free fatty acids (FFA) and their inflow into the liver [8, 201]. This leads to reduction of the amount of FFA supplied to the liver and therefore VLDL production. Reduced VLDL synthesis in turn leads to reduced production of intermediate-density lipoprotein (IDL) and LDL $[8,201]$. In addition, niacin directly inhibits hepatic diacylglycerol O-acyltransferase 2 (DGAT2) - the key enzyme in triglyceride synthesis [8], and increases synthesis of apoA1 in the liver, leading to increase in HDL-C concentration [8, 201]. Nicotinic acid in a dose of $2 \mathrm{~g} /$ day reduces LDL-C concentration by ca. 15-18\%, TG by ca. $20-$ $40 \%$, and $\mathrm{Lp}(\mathrm{a})$ by $30 \%$, as well as increases HDL-C concentration by $25 \%[8,201,202]$.

Niacin is rarely used (in most countries it is unavailable or available in targeted import only) due to negative study results as well as adverse effects [8]. Results of the AIM-HIGH (Atherothrombosis Intervention in Metabolic Syndrome with Low HDL/High Triglycerides: Impact on Global Health Outcomes) [203] and HPS2-THRIVE (The Heart Protection Study 2-Treatment of HDL to Reduce the Incidence of Vascular Events) [204] studies contributed to a virtual lack of use of niacin in lipid-lowering therapy. In the AIM-HIGH trial, in highrisk patients with cardiovascular disease, addition of prolonged-release niacin (1500-2000 mg/dl) to standard statin therapy did not result in additional reduction of cardiovascular events $(H R=1.02$; $95 \mathrm{Cl}$ : 0.87-1.21; $p=0.79$ ), despite an increase of 
HDL-C concentration from $35 \mathrm{mg} / \mathrm{dl}(0.91 \mathrm{mmol} / \mathrm{l})$ to $42 \mathrm{mg} / \mathrm{dl}(1.08 \mathrm{mmol} / \mathrm{l})$, and a TG reduction from $164 \mathrm{mg} / \mathrm{dl}(1.85 \mathrm{mmol} / \mathrm{l})$ to $122 \mathrm{mg} / \mathrm{dl}$ (1.38 mmol/l), Lp(a) from 36 to $27 \mathrm{nmol} / \mathrm{l}$, and LDL-C from $74 \mathrm{mg} / \mathrm{dl}(1.91 \mathrm{mmol} / \mathrm{l})$ to $62 \mathrm{mg} / \mathrm{dl}$ $(1.60 \mathrm{mmol} / \mathrm{l})$ [203]. Explanation of these results includes optimum treatment of ASCVD patients (during the study); what is interesting, despite the fact that in the niacin group almost twice as many patients had to reduce the dose because of adverse reactions (6.3\%) and more patients discontinued treatment, the adherence was still above $75 \%$ in $90 \%$ of patients [203]. In the HPS2THRIVE study, also no additional clinical benefit was observed from treatment with prolonged-release niacin and laropiprant (a compound that inhibits prostaglandin D2 synthesis responsible for skin flushing and hot flashes) in combination with a statin [204]. However, in the analysis of all components of the endpoints, significant reduction in coronary revascularisation and all revascularisation ( $10 \%$ reduction, $p=0.03$ ) was observed in the niacin/laropiprant group. In this study, in comparison with statin monotherapy, significantly more cases of infection, hyperglycaemia, new cases of diabetes mellitus, gastrointestinal or musculoskeletal symptoms, gastrointestinal bleeding, and skin symptoms were noted. Those findings were surprising, given the earlier safety data for niacin; therefore, in comments following publication of the study, there was a suggestion that these adverse reactions could be largely due to the use of laropiprant [8, 9].

\section{KEY POINTS TO REMEMBER}

- Currently, there are no indications for the use of nicotinic acid and no formulation of this agent is available in Poland.

- In 2013, the EMA restricted the use of a slow-release formulation of nicotinic acid to the lipid disorders therapy with elevated triglyceride concentration, and only as an alternative therapy. At the same time, niacin in combination with laropiprant was withdrawn from the market.

- In justified circumstances (in which the benefits outweigh the risks), nicotinic acid may be considered in order to reduce residual risk in patients with high $\mathrm{Lp}(\mathrm{a})$ concentration if other agents (i.e., PCSK9 inhibitors or inclisiran) are not available.

\subsection{Combination therapy and guidelines concerning treatment of lipid disorders}

In the context of potential combination therapy, we usually refer to high-risk and very high-risk patients. Unfortunately, more and more often we have problems with adequately effective treatment of low-risk patients, relatively young (40+, $50+$ ), with one isolated risk factor, for example, elevated LDL-C concentration [2, 9]. In the European guidelines $[8,9]$, the management of this group has never been properly described from a practical point of view, i.e. what the non-pharmacological management should be, when to initiate pharmacological treatment, how to achieve the treatment goal effectively. Therefore, in reference to the ILEP recommendations [2], the authors of these guidelines point to the need of possibly optimum non-pharmacological management (lifestyle modification), and in case of failure (unfortunately, this may apply to up to $80 \%$ of individuals) [152], after not more than 6 months, to consider initiation of pharmacological treatment, i.e. nutraceuticals (preferably, in the form of polypills containing several natural substances with proven effect on LDL-C [135]), low-dose statin (with LDL-C reduction up to $30 \%$ ), or ezetimibe (in case of statin intolerance), and if this is not effective, a combination of these therapies; the efficacy of this approach has been demonstrated in available studies (low-dose statin + nutraceutical, nutraceutical + ezetimibe) [135] (Figure 5).

Although many patients achieve their LDL cholesterol target concentration with monotherapy using appropriate doses, a large proportion of high-risk and very high-risk patients, or those with markedly elevated LDL-C concentration, require additional treatment. In the EUROASPIRE- $V$ study, as much as $71 \%$ of high-risk patients did not achieve the treatment goal, and in the Da Vinci study, it was true for $2 / 3$ of all patients, regardless of risk, and as much as $82 \%$ of very high-risk patients; it is also estimated that only ca. $8 \%$ of extreme risk patients achieve the treatment goal [30, 31, 205].

In such cases, combination therapy is justified and should be initiated as soon as possible, and in justified cases immediately after a diagnosis of lipid disorders was established. According to the ESC/EAS 2019 guidelines, addition of ezetimibe (as early as after 4-6 weeks) is recommended in very high-risk individuals and those at high risk despite statin therapy with maximum tolerable doses; if this is not sufficient to achieve treatment goals, addition of a PCSK9 inhibitor is recommended (after another 4-6 weeks). Therefore, the guidelines have definitely shortened the time in which our patient should receive combination therapy - to as little as 8 weeks. At the same time, for the first time (in line with the results of the EVOPACS, EVACS and VCU-alirocRT trials [179181], the possibility of combination therapy with PCSK9 inhibitors during hospitalization was recommended. In most very high-risk patients this is 
M. Banach, P. Burchardt, K. Chlebus, P. Dobrowolski, D. Dudek, K. Dyrbuś, M. Gąsior, P. Jankowski, J. Jóźwiak, L. Kłosiewicz-Latoszek, I. Kowalska, M. Małecki, A. Prejbisz, M. Rakowski, J. Rysz, B. Solnica, D. Sitkiewicz, G. Sygitowicz, G. Sypniewska, T. Tomasik, A. Windak, D. Zozulińska-Ziółkiewicz, B. Cybulska

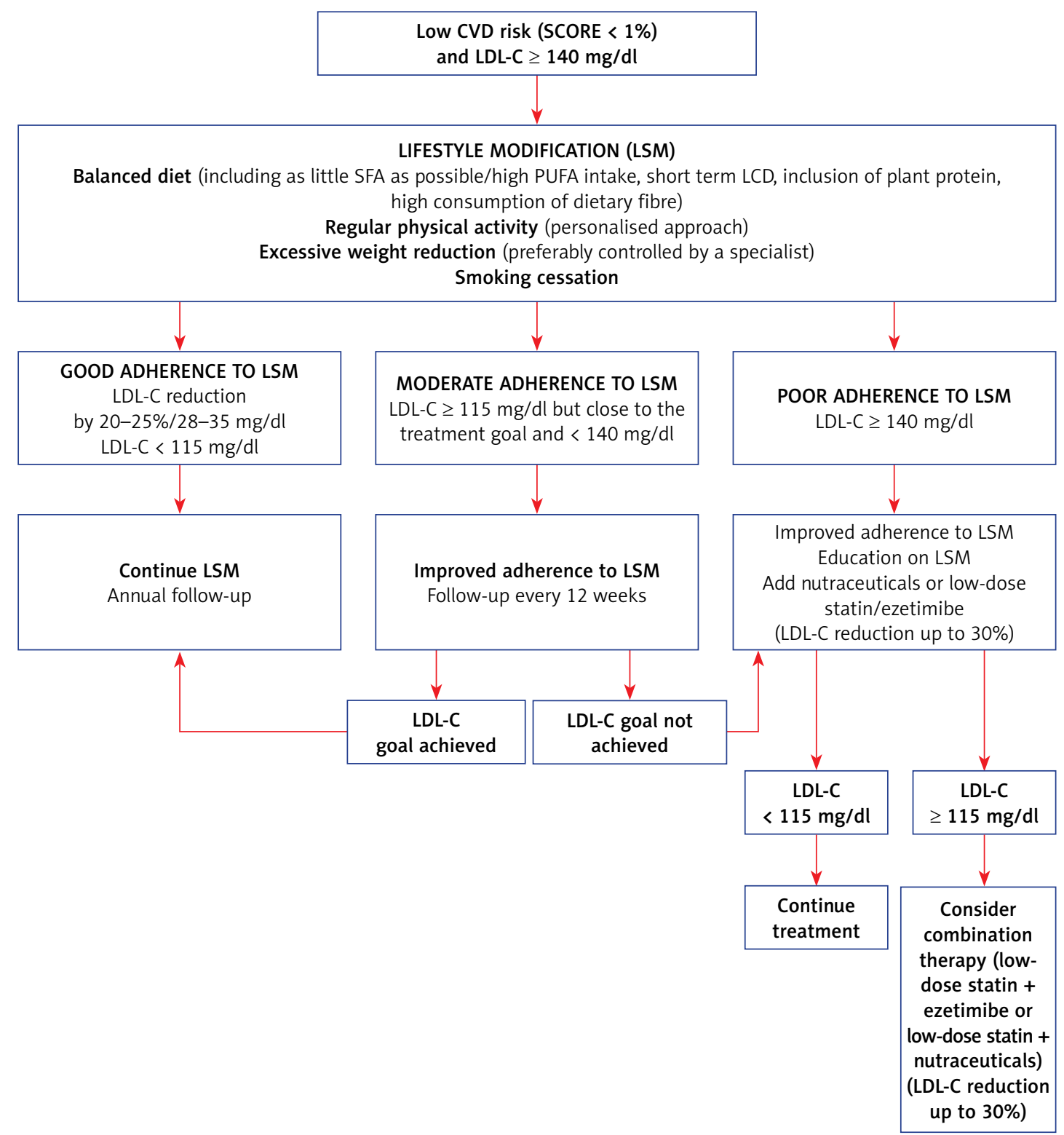

Figure 5. Recommendations for low-risk patients with persistently elevated LDL cholesterol concentration (modified according to the ILEP 2020 recommendations [2])

the only chance to achieve the therapeutic goal, in accordance with the rules: "the lower the better", but also "the earlier the better". Therefore, the authors of these guidelines also recommend that in very high-risk patients (1) with baseline LDL-C concentration that prevents achievement of the therapeutic goal with statin monotherapy (e.g. in patients with LDL-C > $120 \mathrm{mg} / \mathrm{dl}$ (3.1 $\mathrm{mmol} / \mathrm{l})$, assuming that intensive treatment reduces $L D L-C$ concentration by ca. $50 \%$ ), (2) in those with extreme cardiovascular risk, (3) those with statin intolerance (complete or partial), and (4) in patients already receiving intensive statin treatment prior to hospitalisation, combination therapy with ezetimibe should be initiated immediately. Each patient group listed above should achieve the treatment goal as soon as possible, and LDL-C concentration should be as low as possible, even $<40 \mathrm{mg} / \mathrm{dl}(1 \mathrm{mmol} / \mathrm{l})$ in patients with extreme cardiovascular risk. Patients with familial hypercholesterolaemia should also be mentioned here, in whom baseline LDL-C concentration may be above $300 \mathrm{mg} / \mathrm{dl}(7.8 \mathrm{mmol} / \mathrm{l})$; in these patients only immediate initiation of triple therapy provides an opportunity to achieve the therapeutic goal (assuming 85\% reduction on triple therapy). Detailed recommendations concerning the efficacy and use of combination therapy are presented in Tables XVII and XVIII, and in Figures 6-9. In this aspect, the authors of these guidelines agree with and adapt the recommendation of the International Lipid Expert Panel (ILEP) [109]. Of course, these recommendations still do not reflect actual circumstances, especially with respect 
Table XVII. Summary of recommendations on the principles of lipid-lowering therapy Recommendation

High-intensity statin therapy with the highest tolerated dose is recommended in order to achieve the targets defined for a specific level of risk.

If goals have not been achieved with the maximum tolerated statin dose, combination with ezetimibe is recommended.

In post-ACS patients with (1) extreme cardiovascular risk, (2) familial hypercholesterolaemia, or (3) baseline LDL-C concentration (with or without treatment) that prevents achievement of the treatment goal with statin therapy, initiation of combination therapy with ezetimibe may be considered. In very high-risk patients in primary prevention but without $\mathrm{FH}$, combination with a PCSK9 inhibitor may be considered if the LDL-C goal has not been achieved with the maximum tolerated dose of a statin and ezetimibe.

In secondary prevention, combination with a PCSK9 inhibitor is recommended in very high-risk patients in whom the target has not been achieved with the maximum tolerated dose of a statin and ezetimibe.

Combination with a PCSK9 inhibitor is recommended in very high-risk patients with FH (i.e., with ASCVD or another major risk factor) in whom the target has not been achieved with the maximum tolerated dose of a statin and ezetimibe.

If a statin-based regimen is not tolerated at any dose (even after rechallenge), the use of ezetimibe should be considered.

In statin-intolerant patients who require discontinuation of lipid-lowering therapy, immediate initiation of ezetimibe may be considered.

In high-risk patients with partial statin intolerance requiring statin dose reduction, immediate addition of ezetimibe to a tolerated dose of a statin may be considered.

If a statin-based regimen is not tolerated at any dose (even after rechallenge), addition of a PCSK9 inhibitor to ezetimibe should be considered.

In patients requiring statin/ezetimibe combination therapy, a fixed dose formulation (polypill) should be considered.

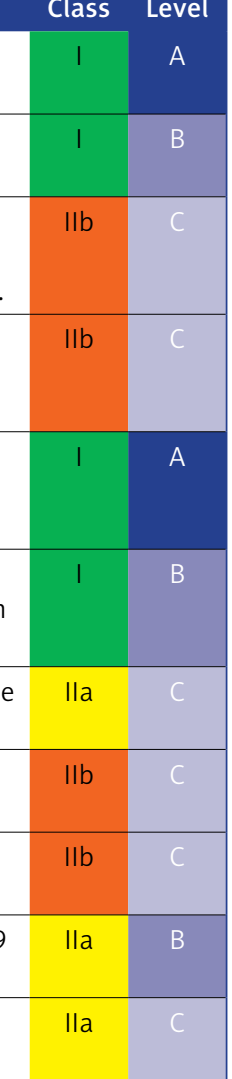

Table XVIII. Recommendations on the intensity of lipid-lowering therapy including combination therapy depending on the cardiovascular risk categories

\begin{tabular}{|c|c|c|c|}
\hline Risk group & LDL-C & Non-HDL-C & Treatment \\
\hline Extreme risk & $\begin{array}{c}<40 \mathrm{mg} / \mathrm{dl} \\
(1.0 \mathrm{mmol} / \mathrm{l})\end{array}$ & $\begin{array}{c}<70 \mathrm{mg} / \mathrm{dl} \\
(1.8 \mathrm{mmol} / \mathrm{l})\end{array}$ & $\begin{array}{l}\qquad \begin{array}{c}\text { Extremely intensive lipid-lowering therapy } \\
\text { (\%LDL-C reduction by } 80-85 \%)\end{array} \\
\text { Atorvastatin 40-80 mg/day + Alirocumab/Evolocumab } \\
\text { Rosuvastatin 20-40 mg/day + Alirocumab/Evolocumab } \\
\text { Atorvastatin 40-80 mg/day + Ezetimibe } 10 \mathrm{mg} / \text { day + } \\
\text { Alirocumab/Evolocumab } \\
\text { Rosuvastatin } 20-40 \mathrm{mg} / \text { day + Ezetimibe } 10 \mathrm{mg} / \text { day + } \\
\text { Alirocumab/Evolocumab } \\
\text { Atorvastatin } 40-80 \mathrm{mg} / \text { day + Inclisiran } 300 \mathrm{mg} \text { every } \\
\text { 3/6 months } \\
\text { Rosuvastatin } 20-40 \mathrm{mg} / \text { day + Inclisiran } 300 \mathrm{mg} \text { every } \\
\text { 3/6 months }\end{array}$ \\
\hline Very high risk & $\begin{array}{c}<55 \mathrm{mg} / \mathrm{dl} \\
(1.4 \mathrm{mmol} / \mathrm{l}) \\
\text { and reduction } \\
\text { of baseline } \\
\mathrm{LDL}-\mathrm{C} \geq 50 \%\end{array}$ & $\begin{array}{c}<85 \mathrm{mg} / \mathrm{dl} \\
(<2.2 \mathrm{mmol} / \mathrm{l})\end{array}$ & $\begin{array}{l}\qquad \begin{array}{l}\text { Very intensive lipid-lowering therapy } \\
\text { (\%LDL-C reduction by } 60-80 \%)\end{array} \\
\text { Atorvastatin 40-80 mg/day + Ezetimibe } 10 \mathrm{mg} / \text { day } \\
\text { Rosuvastatin } 20-40 \mathrm{mg} / \text { day + Ezetimibe } 10 \mathrm{mg} / \text { day } \\
\text { Atorvastatin } 40-80 \mathrm{mg} / \text { day + Ezetimibe } 10 \mathrm{mg} / \text { day + } \\
\text { Bempedoic acid } 180 \mathrm{mg} / \text { day }{ }^{2} \\
\text { Rosuvastatin } 20-40 \mathrm{mg} / \text { day + Ezetimibe } 10 \mathrm{mg} / \text { day + } \\
\text { Bempedoic acid } 180 \mathrm{mg} / \text { day } \\
\text { Rosuvastatin } 10 \mathrm{mg}+\text { Ezetimibe } 10 \mathrm{mg} / \text { day + Bempedoic } \\
\text { acid } 180 \mathrm{mg} / \text { day } \\
\text { Atorvastatin } 20 \mathrm{mg}+\text { Ezetimibe } 10 \mathrm{mg} / \text { day + Bempedoic } \\
\text { acid } 180 \mathrm{mg} / \text { day } \\
\text { Alirocumab } 150 \mathrm{mg} \text { every } 2 \text { weeks } \\
\text { Evolocumab } 140 \mathrm{mg} \text { every } 2 \text { weeks } \\
\text { Rosuvastatin 5-10 mg/day (+ Ezetimibe } 10 \mathrm{mg} / \text { day) + } \\
\text { Alirocumab/Evolocumab/Inclisiran } \\
\text { Atorvastatin } 10-20 \mathrm{mg} / \text { day (+ Ezetimibe } 10 \mathrm{mg} / \text { day) + } \\
\text { Alirocumab/Evolocumab/Inclisiran } \\
\text { Simvastatin } 20-40 \mathrm{mg} / \text { day (+ Ezetimibe } 10 \mathrm{mg} / \text { day) + } \\
\text { Alirocumab/Evolocumab/Inclisiran }\end{array}$ \\
\hline
\end{tabular}


M. Banach, P. Burchardt, K. Chlebus, P. Dobrowolski, D. Dudek, K. Dyrbuś, M. Gąsior, P. Jankowski, J. Jóźwiak, L. Kłosiewicz-Latoszek, I. Kowalska, M. Małecki, A. Prejbisz, M. Rakowski, J. Rysz, B. Solnica, D. Sitkiewicz, G. Sygitowicz, G. Sypniewska, T. Tomasik, A. Windak, D. Zozulińska-Ziółkiewicz, B. Cybulska

Table XVIII. Cont.

\begin{tabular}{|c|c|c|c|}
\hline Risk group & LDL-C & Non-HDL-C & Treatment \\
\hline High risk & $\begin{array}{c}<70 \mathrm{mg} / \mathrm{dl} \\
(<1.8 \mathrm{mmol} / \mathrm{l}) \\
\text { and reduction } \\
\text { of baseline } \\
\mathrm{LDL}-\mathrm{C} \geq 50 \%\end{array}$ & $\begin{array}{l}<100 \mathrm{mg} / \mathrm{dl} \\
(<2.5 \mathrm{mmol} / \mathrm{l})\end{array}$ & $\begin{array}{l}\qquad \begin{array}{l}\text { Intensive lipid-lowering therapy } \\
\text { (\%LDL-C reduction by 50-60\%) }\end{array} \\
\text { Atorvastatin 40-80 mg/day } \\
\text { Rosuvastatin } 20-40 \mathrm{mg} / \text { day } \\
\text { Rosuvastatin } 5-10 \mathrm{mg} / \text { day + Ezetimibe } 10 \mathrm{mg} / \text { day } \\
\text { Atorvastatin } 10-20 \mathrm{mg} / \text { day + Ezetimibe } 10 \mathrm{mg} / \text { day } \\
\text { Pitavastatin } 4 \mathrm{mg}+\text { Ezetimibe } 10 \mathrm{mg} / \text { day } \\
\text { Simvastatin } 20-40 \mathrm{mg} / \text { day + Ezetimibe } 10 \mathrm{mg} / \text { day } \\
\text { Pravastatin } 40 \mathrm{mg} / \text { day + Ezetimibe } 10 \mathrm{mg} / \text { day } \\
\text { Lovastatin } 40 \mathrm{mg} / \text { day + Ezetimibe } 10 \mathrm{mg} / \text { day } \\
\text { Fluvastatin } 80 \mathrm{mg} / \text { day + Ezetimibe } 10 \mathrm{mg} / \text { day } \\
\text { Inclisiran } 300 \mathrm{mg} \text { every } 3 / 6 \text { months }\end{array}$ \\
\hline Moderate risk & $\begin{array}{c}<100 \mathrm{mg} / \mathrm{dl} \\
(<2.5 \mathrm{mmol} / \mathrm{l})\end{array}$ & $\begin{array}{l}<130 \mathrm{mg} / \mathrm{dl} \\
(3.4 \mathrm{mmol} / \mathrm{l})\end{array}$ & $\begin{array}{l}\qquad \begin{array}{c}\text { Moderately intensive lipid-lowering therapy } \\
\text { (\%LDL-C reduction by } 30-50 \%)\end{array} \\
\text { Rosuvastatin 5-10 mg/day } \\
\text { Atorvastatin } 10-20 \mathrm{mg} / \text { day } \\
\text { Pitavastatin } 4 \mathrm{mg} / \text { day } \\
\text { Simvastatin } 20-40 \mathrm{mg} / \text { day } \\
\text { Pravastatin } 40 \mathrm{mg} / \text { day } \\
\text { Lovastatin } 40 \mathrm{mg} / \text { day } \\
\text { Fluvastatin } 80 \mathrm{mg} / \text { day } \\
\text { Pitavastatin } 1-2 \mathrm{mg}+\text { Ezetimibe } 10 \mathrm{mg} / \text { day } \\
\text { Simvastatin } 10-20 \mathrm{mg} / \text { day + Ezetimibe } 10 \mathrm{mg} / \text { day } \\
\text { Pravastatin } 20 \mathrm{mg} / \text { day + Ezetimibe } 10 \mathrm{mg} / \mathrm{day} \\
\text { Lovastatin } 20 \mathrm{mg}+\text { Ezetimibe } 10 \mathrm{mg} / \text { day } \\
\text { Fluvastatin } 40 \mathrm{mg}+\text { Ezetimibe } 10 \mathrm{mg} / \mathrm{day} \\
\text { Bempedoic acid } 180 \mathrm{mg} / \text { day + Ezetimibe } 10 \mathrm{mg} / \text { day }\end{array}$ \\
\hline Low risk & $\begin{array}{l}<115 \mathrm{mg} / \mathrm{dl} \\
(<3 \mathrm{mmol} / \mathrm{l})\end{array}$ & - & $\begin{array}{l}\qquad \begin{array}{l}\text { Low-intensity lipid-lowering therapy } \\
\text { (\%LDL-C reduction by < 30\%) }\end{array} \\
\text { Pitavastatin } 1 \mathrm{mg} / \text { day } \\
\text { Simvastatin } 10 \mathrm{mg} / \text { day } \\
\text { Pravastatin } 10-20 \mathrm{mg} / \text { day } \\
\text { Lovastatin } 10-20 \mathrm{mg} / \mathrm{day} \\
\text { Fluvastatin } 40 \mathrm{mg} / \mathrm{day} \\
\text { Ezetimibe } 10 \mathrm{mg} / \text { day } \\
\text { Bempedoic acid } 180 \mathrm{mg} / \text { day }\end{array}$ \\
\hline
\end{tabular}

${ }^{1}$ The recommended dose is $300 \mathrm{mg}$ of inclisiran as a single subcutaneous injection administered: for the first time, again after 3 months, and then every 6 months thereafter. ${ }^{2}$ as monotherapy or as a fixed dose combination.

to limitations concerning PCSK9 inhibitors, but provide a clear recommendation for immediate use of statin/ezetimibe combination therapy in selected groups of patients (similarly to lipid-lowering therapy) and indicate the need to extend the therapeutic programme with PCSK9 inhibitors as soon as possible, with the possibility of immediate inclusion for selected patient groups (i.e. without the need to wait 3-6 months, in accordance with current regulations).

In addition, in some patients with mixed hyperlipidaemia (dyslipidaemia or atherogenic dyslipidaemia), in order to optimise cardiovascular risk, a fibrate (fenofibrate) or a formulation of unsaturated omega- 3 acids should be used in addition to a statin or a statin and ezetimibe. The use of several agents with different mechanisms of action may significantly increase treatment efficacy, and in some cases makes it possible to use lower doses, which in turn leads to a lower risk of adverse reactions to these agents.

At the same time, it should be emphasised that lipid disorders are often accompanied by other conditions which often require pharmacotherapy. Therefore, patients treated for hyperlipidaemia often use several or even a dozen medicines at the same time, which results in errors, irregular medication use, and frequent discontinuation of treatment (i.e., the lack of adherence and/or compliance). For those reasons, in treatment of lipid disorders, as in treatment of arterial hypertension, combination preparations containing two or more active agents in one tablet are increasingly used. It was demonstrated that reduction of the number of tablets used and simplification of the dosing regimen, with the same daily doses of medicines used, is associated with more regular use of prescribed medication and less frequent treatment discontinuation, which directly translates into better treatment effects and, consequently, reduction of the risk of cardiovascular events [206, 207]. In treatment of hyperlipidaemia, combinations of different statins (atorvastatin and rosuvastatin in all doses) with ezetimibe in one tablet are currently available. Similarly, a combination of ezetimibe with bempedoic acid should appear on Polish 


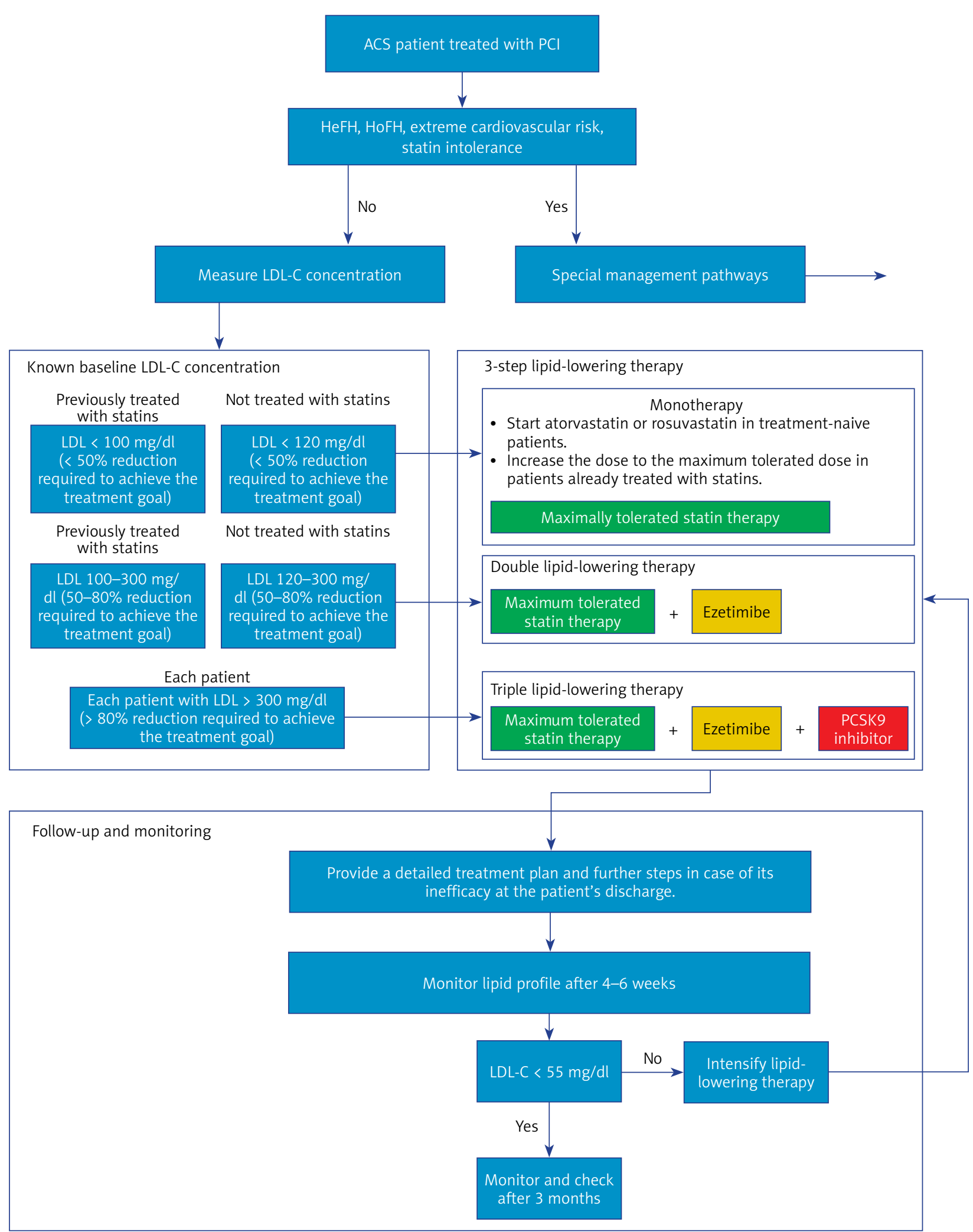

Figure 6. Algorithm for intensive lipid-lowering combination therapy in patients with ACS at very high or extreme risk 
M. Banach, P. Burchardt, K. Chlebus, P. Dobrowolski, D. Dudek, K. Dyrbuś, M. Gąsior, P. Jankowski, J. Jóźwiak, L. Kłosiewicz-Latoszek,

I. Kowalska, M. Małecki, A. Prejbisz, M. Rakowski, J. Rysz, B. Solnica, D. Sitkiewicz, G. Sygitowicz, G. Sypniewska, T. Tomasik, A. Windak,

D. Zozulińska-Ziółkiewicz, B. Cybulska
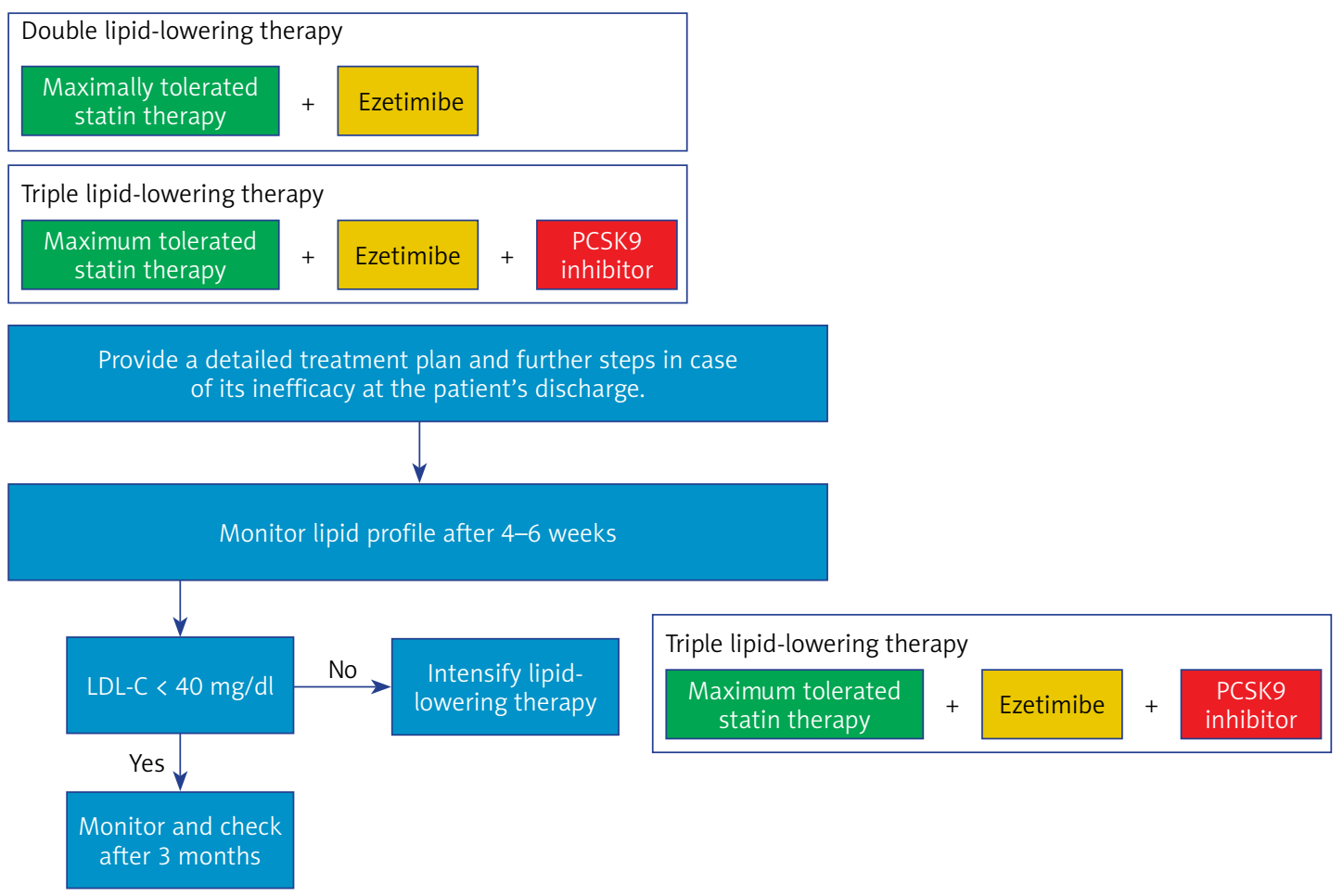

Figure 7. Algorithm for intensive lipid-lowering combination therapy in patients at extreme cardiovascular risk

Lipid-lowering therapy in a patient with confirmed complete statin intolerance

\section{Monotherapy \\ Ezetimibe}

Double lipid-lowering therapy

Ezetimibe + PCSK9

inhibitor

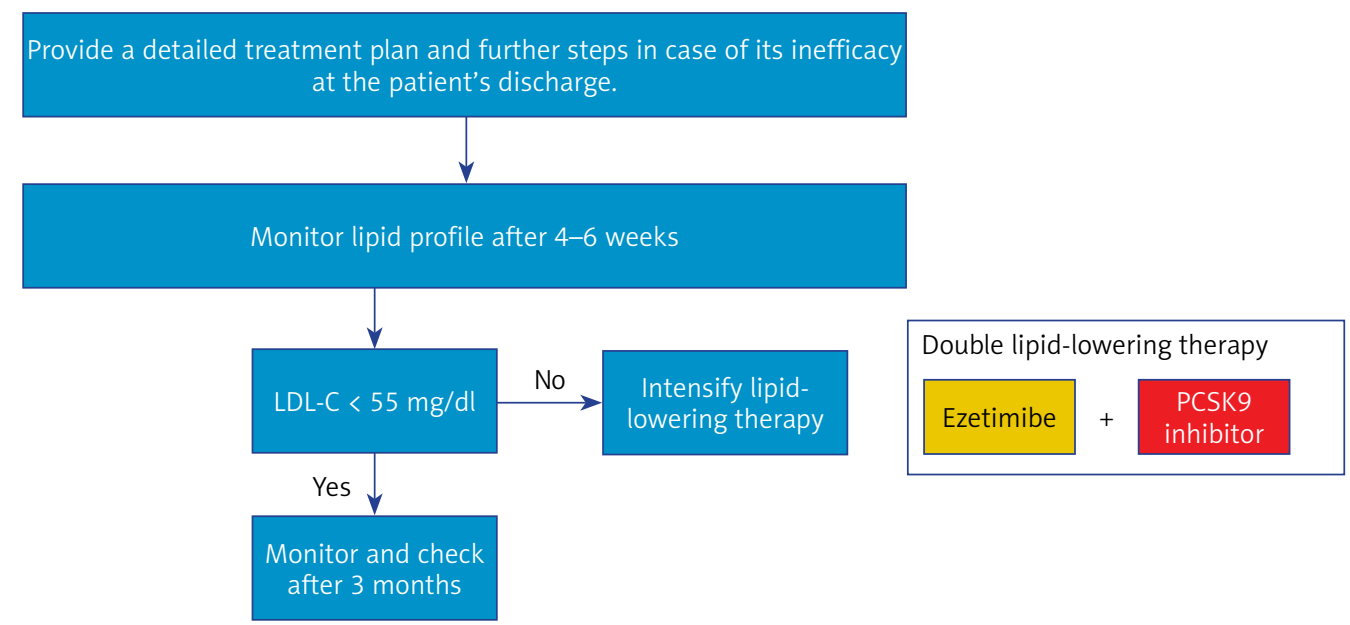

Figure 8. Algorithm for lipid-lowering therapy in statin-intolerant patients with ACS 
Patient on admission has received high-intensity statin and ezetimibe therapy for at least 8-12 weeks and the LDL-C concentration is $>120 \mathrm{mg} / \mathrm{dl}$

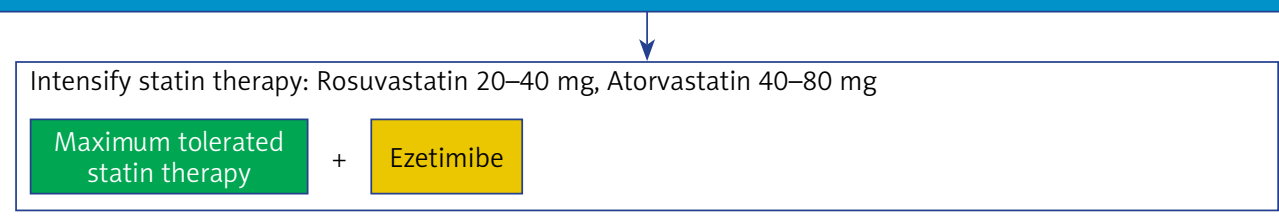

Consider immediate PCSK9 inhibitor therapy (during-hospitalization)
Maximum tolerated
statin therapy
$+\quad$ Ezetimibe
PCSK9
inhibitor

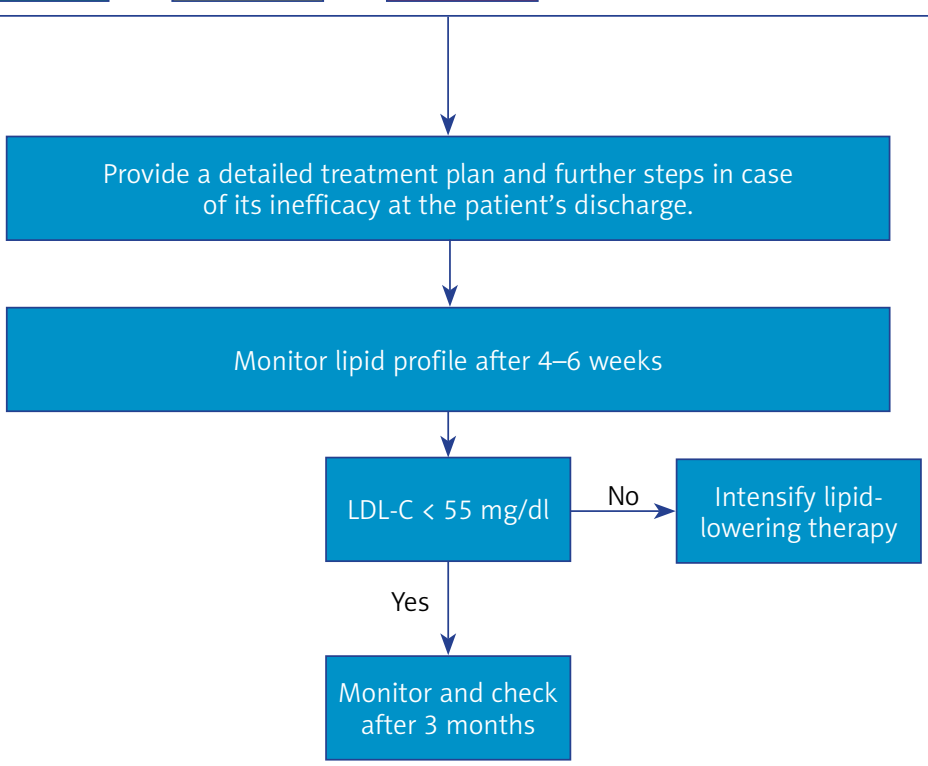

Figure 9. Algorithm for intensive lipid-lowering combination therapy in patients with ACS optimally treated before hospitalization

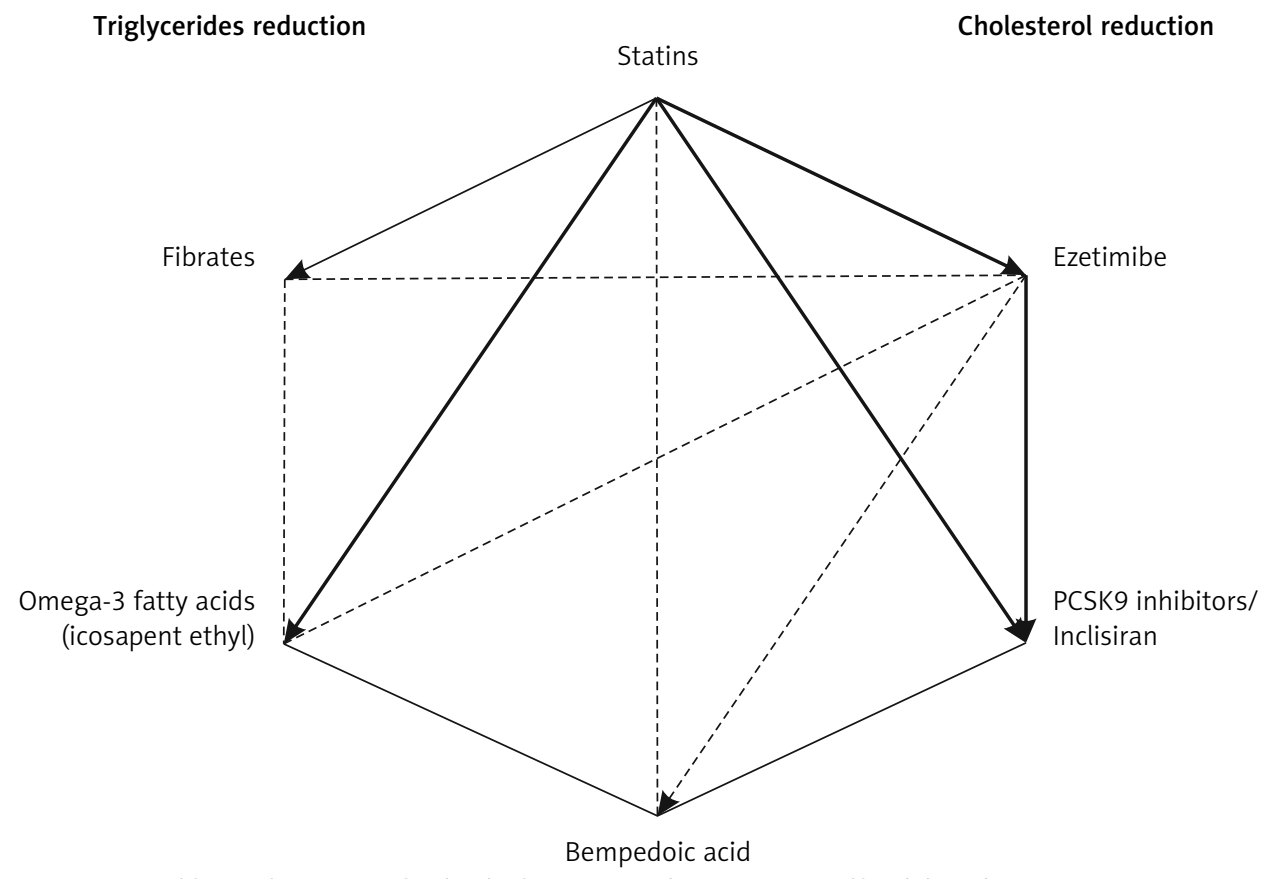

Figure 10. Possible combinations of individual agents used in treatment of lipid disorders 
M. Banach, P. Burchardt, K. Chlebus, P. Dobrowolski, D. Dudek, K. Dyrbuś, M. Gąsior, P. Jankowski, J. Jóźwiak, L. Kłosiewicz-Latoszek, I. Kowalska, M. Małecki, A. Prejbisz, M. Rakowski, J. Rysz, B. Solnica, D. Sitkiewicz, G. Sygitowicz, G. Sypniewska, T. Tomasik, A. Windak, D. Zozulińska-Ziółkiewicz, B. Cybulska

market this year. It has been demonstrated that use of one preparation containing a statin and ezetimibe leads to greater reduction of cholesterol concentration and more frequent achievement of recommended cholesterol concentration than use of the same agents in the same doses, but as separate tablets [208, 209]. Results of studies demonstrating the efficacy and safety of combination formulations of bempedoic acid with ezetimibe as well as atorvastatin with fenofibrate are also available [209, 210]. Possible combinations of individual agents used in treatment of lipid disorders are summarised in Figure 10.

\subsection{Recommendations on management of hypertriglyceridaemia}

Hypertriglyceridaemia (HTG) is defined as fasting triglyceride (TG) concentration $\geq 1.7 \mathrm{mmol} / \mathrm{l}$ $(150 \mathrm{mg} / \mathrm{dl})$ and non-fasting $\geq 2 \mathrm{mmol} / \mathrm{l}(175 \mathrm{mg} / \mathrm{dl})$. It may be mild to moderate with TG concentration of $1.7-9.9 \mathrm{mmol} / \mathrm{l}(150-885 \mathrm{mg} / \mathrm{dl})$ or severe with TG concentration > $10 \mathrm{mmol} / \mathrm{l}(885 \mathrm{mg} / \mathrm{dl})$; the latter is associated with a high risk of pancreatitis [211]. Mild to moderate HTG is related to elevated concentration of VLDL triglycerides (VLDL-TG) or triglyceride-rich lipoprotein (TRL) remnants, while in severe HTG, occurring much less often, chylomicrons in fasting plasma are present. HTG is classified as primary (Table XIX) or secondary (Table $X X)$. Before treatment initiation, it should be diagnosed whether HTG is a primary disorder (occurring in only a few percent of patients) or is associated with another disease or medication. Primary hypertriglyceridaemia is a monogenic (rare) or polygenic (common) disorder [211]. Large population-based studies, clinical trials in secondary prevention, and genetic studies (variants of genes affecting TG concentration) have demonstrated an association between TG concentration and the risk of cardiovascular diseases [212]. Apparently, atherogenic properties are associated not as much with triglycerides themselves as with TG-containing lipoproteins, primarily smaller VLDL and so-called remnants, i.e., partially catabolised VLDL (largely free of triglycerides) and chylomicrons. Therefore, complex hyperlipidaemia (small VLDL + elevated LDL-C concentration) and dysbetalipoproteinaemia (remnants) are associated with a high risk of cardiovascular disease. The mechanism of atherogenic action of smaller VLDL and remnants is similar to that of LDL molecules. Newly formed chylomicrons themselves are not atherogenic because they are too large to enter the vascular wall. Thus, the main threat associated with severe HTG with fasting chylomicronaemia is acute pancreatitis (AP) $[99,213]$. Up to $10 \%$ of AP cases develop as a consequence of severe HTG.
In patients diagnosed with hypertriglyceridaemia, secondary causes should be first ruled out, as appropriate management of a concomitant condition or modification of medications used may improve lipid profile. It should be noted that in secondary HTG indeterminated multigene genetic basis may also be present. In case of severe HTG, fasting serum is equally lipaemic (milky), and when stored in a refrigerator (temperature $+4^{\circ} \mathrm{C}$ ) for over $12 \mathrm{~h}$, a layer of fat (chylomicrons) separates on the serum surface $[99,214]$; this is a positive result of the cold flotation test (fridge test). Severe HTG with the presence of chylomicrons in fasting serum may be monogenic (very rarely) or polygenic (much more often) (Table XIX). Monogenic chylomicronaemia (formerly called familial chylomicronaemia syndrome, FCS or historically, according to the Fredrickson classification, type 1 hyperlipoproteinaemia) occurs with a prevalence of 1 case/100,000 population. Clinical signs, es pecially in homozygous individuals, include nodular xanthomatosis, yellow papules on the trunk, arms and lower extremities, and retinal lipaemia. In multifactorial or polygenic chylomicronaemia syndrome (MCS, or Fredrickson type 5 hyperlipoproteinaemia), in addition to chylomicrons, VLDLTG concentration is also elevated. This lipid disorder is usually associated with factors increasing hypertriglyceridaemia, such as alcohol, carbohydrate-rich diet (fructose), uncontrolled diabetes mellitus, obesity, hypothyroidism, pregnancy, or certain medications [99].

In Table XIX, in addition to primary severe hypertriglyceridaemia, classification of mild to moderate hypertriglyceridaemia is presented. It includes multifactorial or polygenic HTG (formerly familial HTG or type 4 hyperlipoproteinaemia with increased VLDL-TG concentration), dysbetalipoproteinaemia (formerly type 3 hyperlipoproteinaemia or dysbetalipoproteinaemia or remnant disease) with elevated concentration of VLDL remnants and chylomicron remnants as a result of their impaired catabolism, and combined hyperlipoproteinaemia (formerly type $2 \mathrm{~b}$ hyperlipoproteinaemia or familial combined hyperlipoproteinaemia) with elevated VLDL-TG and LDL-C concentration [212].

Although the target triglyceride concentrations have not been established, lower concentrations indicate lower cardiovascular risk and values $>2.3 \mathrm{mmol} / \mathrm{l}(200 \mathrm{mg} / \mathrm{dl})$ have been considered an indication for pharmacological reduction [8, 9]. Failure to set the TG target results from the lack of evidence from randomised clinical trials that would make its determination possible. The most important treatment goal in prevention of cardiovascular diseases remains low LDL-C concentration, and in patients with TG concentration 
Table XIX. Classification of primary hypertriglyceridaemia

\begin{tabular}{|c|c|c|c|}
\hline \multirow[t]{2}{*}{ Types of HTG } & \multirow[t]{2}{*}{ Risk } & \multicolumn{2}{|c|}{ Diagnostic evaluation } \\
\hline & & Clinical & Laboratory \\
\hline $\begin{array}{l}\text { Monogenic } \\
\text { chylomicronaemia } \\
\text { (familial chylomicronaemia } \\
\text { syndrome, FCS) } \\
\text { - mutation of one of the } \\
5 \text { genes: } \\
\text { most frequently } \\
\text { lipoprotein lipase, } \\
\text { apolipoprotein CII, } \\
\text { apolipoprotein CV, LIMF1, } \\
\text { or GPIHBP1 }\end{array}$ & $\begin{array}{l}\text { - Risk of recurrent acute } \\
\text { pancreatitis }\end{array}$ & $\begin{array}{l}\text { - Xanthomata or yellow } \\
\text { papules (xanthomas) on } \\
\text { the skin, retinal lipaemia } \\
\text { in homozygotes } \\
\text { - Paroxysmal abdominal } \\
\text { pains may occur }\end{array}$ & $\begin{array}{l}\text { - High TG and total } \\
\text { cholesterol (TC) } \\
\text { concentration - it is } \\
\text { chylomicron cholesterol } \\
\text { - LDL-C and } \\
\text { apolipoprotein B not } \\
\text { elevated } \\
\text { - Milky fasting serum } \\
\text { - Positive cold flotation } \\
\text { test (chylomicron layer } \\
\text { at the serum surface) }\end{array}$ \\
\hline $\begin{array}{l}\text { Multifactorial or polygenic } \\
\text { chylomicronaemia } \\
\text { (multifactorial } \\
\text { chylomicronaemia } \\
\text { syndrome, MCS) } \\
\text { - accumulation of } \\
\text { genes associated } \\
\text { with increased TG } \\
\text { concentration }\end{array}$ & $\begin{array}{l}\text { - } \text { Risk of acute } \\
\text { pancreatitis } \\
\text { - Risk of CVD may be } \\
\text { increased }\end{array}$ & $\begin{array}{l}\text { - Paroxysmal abdominal } \\
\text { pains may occur }\end{array}$ & $\begin{array}{l}\text { - High TG and TC } \\
\text { concentrations - this is } \\
\text { chylomicron cholesterol } \\
\text { and VLDL cholesterol } \\
\text { - LDL-C, usually not } \\
\text { elevated } \\
\text { - Milky fasting serum } \\
\text { - Positive cold flotation } \\
\text { test (chylomicron } \\
\text { layer at the surface, } \\
\text { cloudy serum under } \\
\text { chylomicron layer due } \\
\text { to increased VLDL-TG }\end{array}$ \\
\hline $\begin{array}{l}\text { Dysbetalipoproteinaemia } \\
\text { (formerly type III HLP or } \\
\text { dysbetalipoproteinaemia } \\
\text { or remnant disease) - } \\
\text { apo E2/apo E2 } \\
\text { homozygosity }\end{array}$ & - Very high risk of CVD & $\begin{array}{l}\text { - Characteristic palmar } \\
\text { tendon xanthomas }\end{array}$ & $\begin{array}{l}\text { - } \uparrow \mathrm{TG} \text { and } \uparrow \mathrm{TC} \text { (from } \\
\text { remnants) } \\
\text { - } \downarrow \text { HDL-C } \\
\text { - } \text { Apo B not elevated } \\
\text { - } \text { DNA testing (genotype } \\
\text { apo E2/apo E2) }\end{array}$ \\
\hline $\begin{array}{l}\text { Multifactorial or polygenic } \\
\text { hypertriglyceridaemia } \\
\text { (formerly type IV HLP or } \\
\text { familial HTG) }\end{array}$ & $\begin{array}{l}\text { - Increased risk of CVD. } \\
\text { May be a risk factor of } \\
\text { AP with high VLDL-TG } \\
\text { concentration }\end{array}$ & - & $\begin{array}{l}\text { - Significantly elevated TG } \\
\text { concentration (VLDL-TG) } \\
\text { - LDL-C normal or slightly } \\
\text { increased } \\
\text { - Cold flotation test } \\
\text { negative - cloudy to } \\
\text { milky serum without } \\
\text { a chylomicron layer on } \\
\text { the surface after } 10-12 \mathrm{~h} \\
\text { of refrigerated storage }\end{array}$ \\
\hline $\begin{array}{l}\text { Combined } \\
\text { hyperlipoproteinaemia } \\
\text { (formerly type Ilb HLP } \\
\text { or familial combined } \\
\text { hyperlipoproteinaemia). } \\
\text { This is a polygenic disorder }\end{array}$ & - High risk of CVD & $\begin{array}{l}\text { - } \text { Premature CVD } \\
\text { and/or combined } \\
\text { hyperlipidaemia in first- } \\
\text { degree relatives } \\
\text { - Intraindividual and } \\
\text { interindividual (relatives, } \\
\text { phenotypic variation), i.e. } \\
\text { periodically elevated TG } \\
\text { and LDL-C, or elevated } \\
\text { TG alone or LDL-C alone }\end{array}$ & $\begin{array}{l}\text { Typically elevated } \\
\text { concentration of TG, } \\
\text { LDL-C and apo B }\end{array}$ \\
\hline
\end{tabular}


M. Banach, P. Burchardt, K. Chlebus, P. Dobrowolski, D. Dudek, K. Dyrbuś, M. Gąsior, P. Jankowski, J. Jóźwiak, L. Kłosiewicz-Latoszek, I. Kowalska, M. Małecki, A. Prejbisz, M. Rakowski, J. Rysz, B. Solnica, D. Sitkiewicz, G. Sygitowicz, G. Sypniewska, T. Tomasik, A. Windak, D. Zozulińska-Ziółkiewicz, B. Cybulska

Table XX. Secondary causes of hypertriglyceridaemia

- Obesity

- Diabetes mellitus

- Excessive alcohol consumption

- Hypothyroidism

- Renal diseases (proteinuria, uraemia, glomerulonephritis)

- Paraproteinaemia, systemic lupus erythematosus

- Pregnancy (especially third trimester)

- Diet rich in monosaccharides

- Medicines: glucocorticosteroids, oral oestrogens, non-cardioselective $\beta$-adrenolytic drugs, thiazides, retinols, agents disrupting bile acid circulation, protease inhibitors used in HIV treatment, tamoxifen, cyclophosphamide, cyclosporine, $\mathrm{L}$-asparaginase, second-generation antipsychotics (clozapine, olanzapine)

$>4.5 \mathrm{mmol} / \mathrm{l}(400 \mathrm{mg} / \mathrm{dl})$, non-HDL-C concentration.

\subsubsection{Dietary management}

Dietary management is of significant importance in treatment of hypertriglyceridaemia [8, 9]. It may vary depending on whether the condition is a result of elevated concentration of VLDL triglycerides or chylomicron triglycerides and VLDLTG. In patients with elevated VLDL-TG concentration, reduction and preferably avoidance of alcohol consumption is considered important. Obese patients should reduce body weight (improved sensitivity to insulin). Hyperinsulinaemia associated with abdominal obesity stimulates TG synthesis in the liver; lipolysis in adipose tissue is increased, and released fatty acids transported to the liver are a substrate for TG synthesis. Hypertriglyceridaemia may be a symptom of metabolic syndrome, in which abdominal obesity is usually the main feature. It may be said that obesity removes the mask of a patient with HTG. This also applies to alcohol and carbohydrate consumption [8, 9].

Important nutritional recommendations with high efficacy in reducing VLDL-TG include reduction of total carbohydrate intake, in particular mono- and disaccharides (fructose and sucrose). Carbohydrates are substrates for hepatic TG production. The effect of carbohydrate-rich products on triglycerides is much weaker if diet is based on high-fibre foods with low glycaemic index. In reduction of TG concentration, physical activity is also very important as working muscles use fatty acids contained in them as a source of energy [8, 9]. It must not be forgotten to replace saturated fats with mono-, and above all polyunsaturated fats $[139,143]$, or generally speaking animal fats with vegetable fats, with the exception of two tropical oils, i.e., coconut and palm oil.

In patients with elevated concentration of chylomicron triglycerides and VLDL triglycerides (polygenic chylomicronaemia), diet is very important, although more difficult to implement, as it should be targeted at reduction of chylomicron synthesis in the intestinal epithelium, so fat intake must be very limited ( $<15-20 \%$ of energy) $[99,211,213]$, and at the same time at reduction of VLDL triglyceride synthesis (recommendations discussed above). Chylomicrons are formed from both saturated and unsaturated fat, hence drastic reduction of total fat intake. The effect of such diet is very rapid. A large decrease in TG occurs after a few days. In some patients, medium-chain TG (MCT) may be considered as a source of energy; these are transported directly to the liver through the portal vein and metabolised there, so chylomicrons do not form. Alcohol abstinence is recommended. In monogenic chylomicronaemia (FCS), the primary treatment is low-fat diet, although recently a new agent has been introduced, which offers hope for effective treatment of patients with FCS.

\subsubsection{Pharmacological management}

In high-risk patients with TG concentration $>2.3 \mathrm{mmol} / \mathrm{l}(200 \mathrm{mg} / \mathrm{dl})$, treatment is always initiated with a statin (atorvastatin or rosuvastatin). This is a class I recommendation. Following publication of the REDUCE IT study results, in which the use of EPA (icosapent ethyl $2 \times 2 \mathrm{~g} /$ day) for 4.9 years in patients optimally treated with statins with fasting TG concentration 1.5 to $5.6 \mathrm{mmol} / \mathrm{l}(135-499 \mathrm{mg} / \mathrm{dl})$ and high cardiovascular risk resulted in a reduction of incidence of cardiovascular events by $25 \%$ [147], European experts recommended adding EPA to a statin in such cases (IlaB) [9]. A fibrate may also be added to a statin in primary prevention (IIbB) as well as in high-risk patients in whom LDL-C concentration corresponds to the target and TG concentration exceeds $2.3 \mathrm{mmol} / \mathrm{l}(\mathrm{IlbC})$ [9]. The authors of these guidelines generally accept European recommendations, however, pointing out a much greater role of fibrates in high-risk patients, which may be very effective in reduction of the risk of micro- and macrovascular complications (recommendation level IlaB), and the fact that icosapent ethyl is still unavailable on Polish market; therefore, the recommendations include for the first time omega-3 acids in high doses (at least $2 \mathrm{~g} /$ day - recommendation level IIbC) (see sections on omega-3 acids and fibrates; Table XXI and Figure 11).

If TG concentration is $\geq 5.6 \mathrm{mmol} / \mathrm{l}(500 \mathrm{mg} /$ $\mathrm{dl}$ ), treatment is initiated with fibrate to quickly decrease its concentration and reduce the risk of AP. If chylomicrons are present in the fasting state and VLDL-TG concentration is increased (multifactorial or polygenic chylomicronaemia), combination pharmacotherapy with a fibrate and n-3 PUFA 
Table XXI. Recommendations on treatment of hypertriglyceridaemia

Statins are recommended as first-line therapy to reduce the risk of CVD in high-risk individuals with hypertriglyceridaemia ( $\mathrm{TG}>2.3 \mathrm{mmol} / \mathrm{l} />200 \mathrm{mg} / \mathrm{dl}$ ).

In at least high-risk patients with TG $\geq 1.7 \mathrm{mmol} / \mathrm{l}(\geq 150 \mathrm{mg} / \mathrm{dl})$ despite statin treatment, icosapent ethyl $(2 \times 2 \mathrm{~g} /$ day $)$ in combination with a statin should be considered.*

In at least high-risk patients with TG $\geq 2.3 \mathrm{mmol} / \mathrm{l}(\geq 200 \mathrm{mg} / \mathrm{dl}$ ) despite statin therapy, omega-3 acids (PUFA in a dose of 2 to $4 \mathrm{~g} /$ day) in combination with a statin may be considered.

In patients in primary prevention who achieved their LDL-C goals with persistent TG concentration $>2.3 \mathrm{mmol} / \mathrm{l}$ (> $200 \mathrm{mg} / \mathrm{dl}$ ), fenofibrate in combination with a statin may be considered.

In high-risk patients who achieved their LDL-C goals with persistent TG concentration $>2.3 \mathrm{mmol} / \mathrm{I}$ ( $>200 \mathrm{mg} / \mathrm{dl}$ ), fenofibrate in combination with a statin should be considered.

*Increased risk of atrial fibrillation should be kept in mind.

High and very high-risk patients with elevated TG

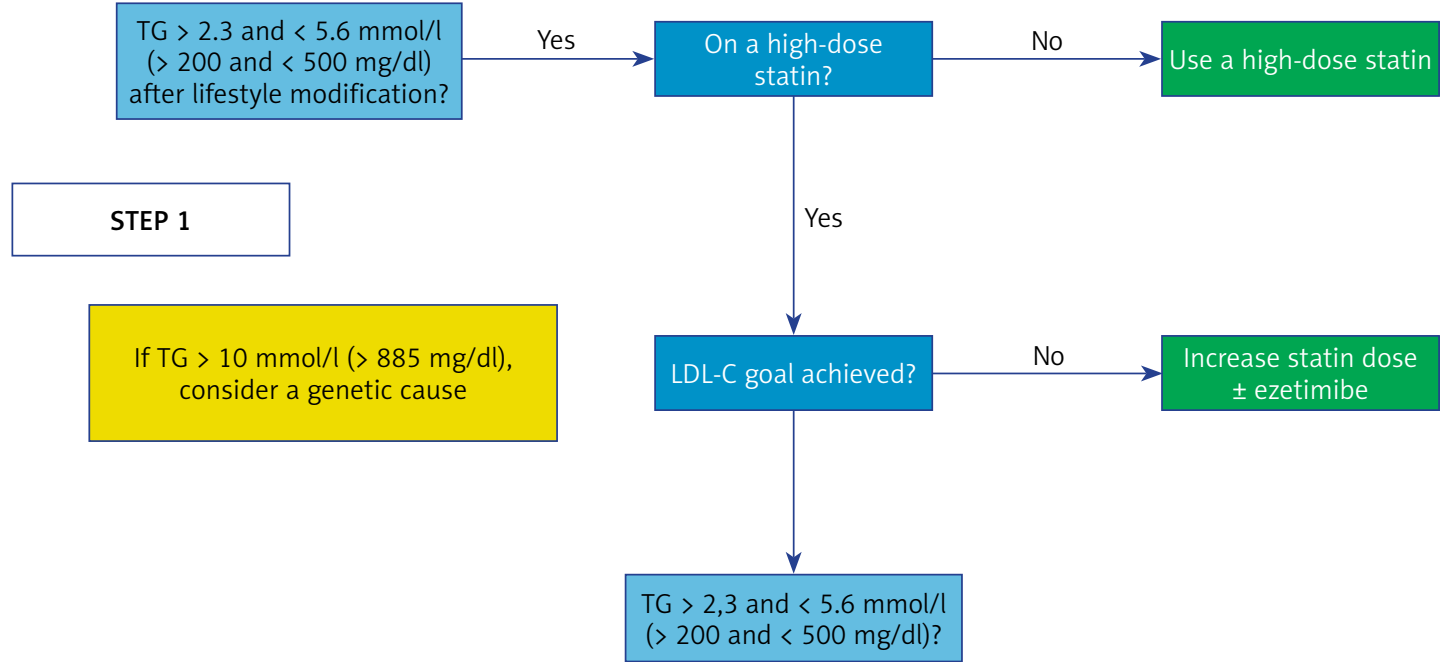

Monitor LDL-C and TG for 4-6 weeks

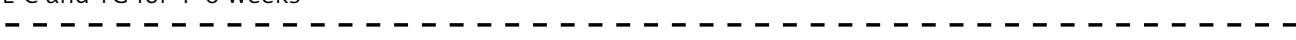

STEP 2

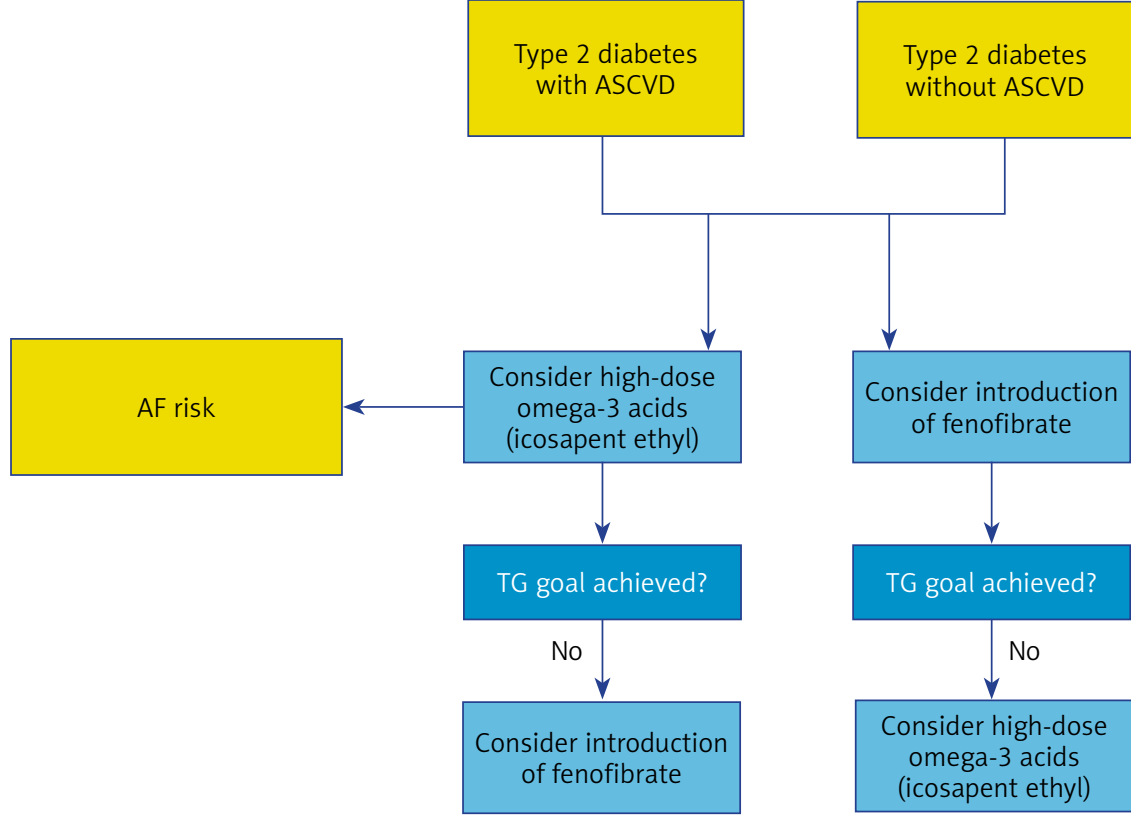

Figure 11. Recommendations on treatment of hypertriglyceridaemia (adapted and modified, based on the EAS Expert Opinion 2021 [140]) 
M. Banach, P. Burchardt, K. Chlebus, P. Dobrowolski, D. Dudek, K. Dyrbuś, M. Gąsior, P. Jankowski, J. Jóźwiak, L. Kłosiewicz-Latoszek, I. Kowalska, M. Małecki, A. Prejbisz, M. Rakowski, J. Rysz, B. Solnica, D. Sitkiewicz, G. Sygitowicz, G. Sypniewska, T. Tomasik, A. Windak, D. Zozulińska-Ziółkiewicz, B. Cybulska

Table XXII. Summary of hypertriglyceridaemia management recommendations

\begin{tabular}{|c|c|c|}
\hline Variable & $\begin{array}{l}\text { Mild to moderate - } \\
\text { Elevated VLDL-TG }\end{array}$ & $\begin{array}{c}\text { Severe - } \\
\text { Chylomicrons and } \uparrow \text { VLDL-TG present }\end{array}$ \\
\hline TG concentration & $150-885 \mathrm{mg} / \mathrm{dl}(1.7-10 \mathrm{mmol} / \mathrm{l})$ & $>885 \mathrm{mg} / \mathrm{dl}(>10 \mathrm{mmol} / \mathrm{l})$ \\
\hline $\begin{array}{l}\text { Primary treatment } \\
\text { goal }\end{array}$ & Target LDL-C concentration & TG reduction \\
\hline $\begin{array}{l}\text { Secondary } \\
\text { treatment goal }\end{array}$ & Target non-HDL-C concentration & $\begin{array}{l}\text { Target } L D L-C \text { and non-HDL-C, if the risk of AP } \\
\text { is reduced }\end{array}$ \\
\hline $\begin{array}{l}\text { Non- } \\
\text { pharmacological } \\
\text { treatment }\end{array}$ & $\begin{array}{l}\text { - Limited consumption of alcohol or } \\
\text { - Wbstinence } \\
\text { - Reight reduction in case of obesity } \\
\text { in particular fructose and sucrose } \\
\text { - Increased physical activity } \\
\text { - Substitution of saturated fats with } \\
\text { unsaturated fats (especially } \\
\text { polyunsaturated) }\end{array}$ & $\begin{array}{l}\text { - Alcohol abstinence } \\
\text { - Restrictive low-fat diet (10-15\% of total } \\
\text { energy) } \\
\text { - Weight reduction in case of obesity } \\
\text { - Reduction of total carbohydrate intake, } \\
\text { particularly fructose and sucrose } \\
\text { - Increased physical activity }\end{array}$ \\
\hline $\begin{array}{l}\text { Pharmacological } \\
\text { treatment }\end{array}$ & $\begin{array}{l}\text { - Statin (atorvastatin, rosuvastatin, } \\
\text { pitavastatin) } \\
\text { - Start with fibrate alone if TG > } 500 \mathrm{mg} / \mathrm{dl} \\
\text { ( } 5.6 \mathrm{mmol} / \mathrm{l}) \text { to reduce the risk of ACS } \\
\text { - Consider adding PUFA } \mathrm{n}-3 \\
\text { - in case of high cardiovascular risk and TG } \\
>150 \mathrm{mg} / \mathrm{dl}(1.7 \mathrm{mmol} / \mathrm{l}) \\
\text { - Consider adding a fibrate if the target } \\
\text { LDL-C has been achieved } \\
\text { and TG > } 200 \mathrm{mg} / \mathrm{dl}(>2.3 \mathrm{mmol} / \mathrm{l}) \text { in } \\
\text { primary prevention and in high-risk } \\
\text { patients }\end{array}$ & $\begin{array}{l}\text { - Fibrate (fenofibrate) + PUFA n-3 } \\
\text { - Volanesorsen in monogenic } \\
\text { chylomicronaemia (family } \\
\text { chylomicronaemia syndrome, FCS) (still } \\
\text { unavailable in Poland) }\end{array}$ \\
\hline Genetic testing & $\begin{array}{l}\text { - HTG mainly polygenic. No indications for } \\
\text { genetic testing }\end{array}$ & $\begin{array}{l}\text { - HTG very likely to be monogenic. Genetic } \\
\text { tests indicated in children and adolescents. } \\
\text { Recommended cold flotation test }\end{array}$ \\
\hline
\end{tabular}

$(2 \times 2 \mathrm{~g} /$ day $)$ is used together with diet. In monogenic chylomicronaemia, the efficacy of treatment with a fibrate and PUFA $n-3$ is low, and as mentioned above, effective pharmacotherapy has become possible only recently [215]. It is also worth noting that recently (May 2019) the EMA has granted conditional approval for the use of a novel agent effectively lowering TG concentration in monogenic chylomicronaemia [215]. Volanesorsen is an antisense oligonucleotide that inhibits translation of apolipoprotein CIII (Apo CIII) mRNA. Apo CIII, present in lipoproteins transporting TG, inhibits lipoprotein lipase (LPL) activity. Volanesorsen is administered subcutaneously once a week for 3 months, then once every 2 weeks. It still has not been approved by the FDA. Thrombocytopenia is a common adverse reaction associated with volanesorsen (see section on new agents in treatment of lipid disorders) [215].

A practical summary of management of hypertriglyceridaemia is presented in Table XXII.

\subsection{New agents in lipid disorders therapy}

\subsubsection{Bempedoic acid}

Bempedoic acid is an ATP-citrate lyase $(\mathrm{ACL})$ inhibitor that decreases LDL-C concentration by means of inhibition of cholesterol synthesis in the liver. $A C L$ is an enzyme preceding 3-hydroxy-3-methylglutarylcoenzyme A (HMG-CoA) reductase in the cholesterol biosynthesis pathway [216]. Importantly, bempedoic acid is an inactive prodrug and requires activation by coenzyme $A(C O A)$ with long-chain acyl-CoA 1 synthetase (ACSVL1), and the entire process takes place in the liver rather than in skeletal muscles, which from the very beginning indicated that it may be a very effective agent for statin-intolerant patients [216]. Inhibition of ACL by bempedoic acid decreases hepatic cholesterol synthesis and reduces blood LDL-C concentration by increasing the activity of LDL receptors; it also affects simultaneous inhibition of hepatic biosynthesis of fatty acids [216].

The efficacy of bempedoic acid has been investigated in numerous phase II studies and 4 pivotal phase III studies in the CLEAR programme (Cholesterol Lowering via Bempedoic acid, an ACL-Inhibiting Regimen). In the CLEAR Tranquility study [217], patients with a history of statin intolerance and LDL-C concentration $\geq 100 \mathrm{mg} / \mathrm{dl}$ were enrolled. After a 4-week lead-in period of treatment with ezetimibe, 269 patients were randomised $2: 1$ to bempedoic acid $180 \mathrm{mg}$ or placebo once daily 
added to ezetimibe for 12 weeks. Bempedoic acid reduced LDL-C cholesterol by $28.5 \%$ in comparison with placebo $(p<0.001)$, as well as non-HDL $(-23.6 \%)$, TC (-18.0\%), ApoB (-19.3\%), and what is particularly interesting in terms of residual risk associated with inflammation, hsCRP (-31.0\%). The treatment was well tolerated; the incidence of treatment-related adverse events, muscle-related adverse events, and treatment discontinuation was similar between the bempedoic acid and placebo groups [217].

In the CLEAR Harmony study [218], patients with ASCVD and/or heterozygous $\mathrm{FH}$ and LDL-C concentration $\geq 70 \mathrm{mg} / \mathrm{dl}(1.8 \mathrm{mmol} / \mathrm{l})$ despite maximum tolerated statin therapy with or without additional lipid-lowering therapy were enrolled. The primary endpoint was safety, and the key secondary endpoint was percent change in LDL cholesterol concentration after 12 weeks of treatment. The study included 2230 patients, of whom 1488 received bempedoic acid and 742 placebo; the follow-up period was 52 weeks. The incidence of adverse events and serious adverse events during the intervention period did not differ significantly between the two groups, but the incidence of adverse events leading to treatment discontinuation was higher in the bempedoic acid group than in the placebo group (162 (10.9\%) patients vs. $53(7.1 \%)$ patients), as was the incidence of gout (18 (1.2\%) patients vs. 2 (0.3\%) patients). Bempedoic acid reduced mean LDL-C concentration by $18.1 \%$ in comparison with placebo [218].

In the CLEAR Serenity study [219], 345 patients with hypercholesterolaemia and a history of intolerance to at least 2 statins, including one at the lowest available dose, were randomised. Mean age of the enrolled patients was 65.2 years, mean baseline LDL-C concentration was $157.6 \mathrm{mg} / \mathrm{dl}$, and $93 \%$ of patients reported a history of muscle symptoms associated with statin therapy. Treatment with bempedoic acid, in comparison with placebo, significantly reduced LDL-C concentration by $21.4 \%(95 \% \mathrm{Cl}:-25.1$ to $-17.7 \% ; p<0.001)$, non-HDL-C by $17.9 \%$, total cholesterol by $14.8 \%$, as well as ApoB (-15.0\%) and hsCRP (-24.3\%). Bempedoic acid was safe and well tolerated; muscle-related adverse effects (muscle pain) occurred in $4.7 \%$ and $7.2 \%$ of patients who received bempedoic acid and placebo, respectively [219].

In another study, CLEAR Wisdom [220], a total of 779 patients with ASCVD and/or heterozygous familial hypercholesterolaemia and LDL-C concentration $\geq 70 \mathrm{mg} / \mathrm{dl}(1.8 \mathrm{mmol} / \mathrm{l})$ while receiving maximum tolerated lipid-lowering therapy were enrolled. The follow-up period was 52 weeks. Bempedoic acid reduced LDL-C concentration significantly more than placebo $(-17.4 \% ; 95 \% \mathrm{Cl}$ : $-21.0 \%$ to $-13.9 \%$; $p<0.001)$; a significant reduc- tion of non-HDL cholesterol (-13.0\%), total cholesterol $(-11.2 \%)$, and ApoB concentration $(-13.0 \%)$, as well as hsCRP (median: $-18.7 \%$ vs. $-9.4 \%$ ), was also observed. Common adverse events included nasopharyngitis (5.2\% vs. $5.1 \%$ for bempedoic acid and placebo, respectively), urinary tract infection (5.0\% vs. $1.9 \%)$, and hyperuricaemia (4.2\% vs. $1.9 \%)$ [220].

In another study, being a pooled analysis of 4 phase III studies, the efficacy and safety of bempedoic acid in patients with ASCVD and/or FH as well as in patients with partial and complete statin intolerance was assessed [221]. The final analysis included 2425 patients in the group receiving bempedoic acid and 1198 in the placebo group. Mean age of patients was $66 \pm 9$ years and the mean baseline LDL-C value at randomisation was $108 \pm 33 \mathrm{mg} / \mathrm{dl}$ and $144 \pm 39 \mathrm{mg} / \mathrm{dl}$ in the statin-intolerant group. After 12 weeks of treatment, in comparison with placebo, LDL-C was reduced by $17.8 \%$ in the bempedoic acid group, whereas in the statin-intolerant subgroup, the LDL-C reduction was $24.5 \%$; this effect was maintained after 52 weeks of the study. Significant decrease of concentration of non-HDL cholesterol, TC, ApoB, and hsCRP was also observed in the bempedoic acid group. Treatment with bempedoic acid was well tolerated but was associated with a higher incidence of mild (resolving upon treatment discontinuation) adverse events, such as increased uric acid concentration ( $2.1 \%$ vs. $0.5 \%)$, decreased eGFR $(0.7 \%$ vs. < $0.1 \%)$, increased aminotransferase activity ( $2.8 \%$ vs. $1.3 \%)$, and an increased incidence of gout (1.4\% vs. $0.4 \%$ ) [221]. We have obtained very similar results in a meta-analysis of 10 phase II and III trials, which enrolled nearly 4000 patients, where, interestingly, as also observed in phase III trials, treatment with bempedoic acid was associated with a $41 \%$ reduction in the risk of development of new cases of diabetes $(\mathrm{OR}=0.59 ; 95 \% \mathrm{Cl}: 0.39-0.90 ; p=0.01)$ [222].

Only the CLEAR Outcomes study, in which 14,014 high-risk patients with statin intolerance were enrolled, will answer the question on how the addition of bempedoic acid may translate into a reduction in cardiovascular events. The study is planned to complete in December 2022; it will continue until 1620 patients experience the primary endpoint. The minimum duration of treatment will be 36 months, and the predicted median exposure to treatment -42 months [223]. However, the currently available study results provided the basis for positive assessment of bempedoic acid and its combination with ezetimibe by the FDA (February 2020) and by the EMA (April 2020).

According to the EMA regulations, bempedoic acid is indicated in adults with primary hypercholesterolaemia (heterozygous familial and non-fa- 
M. Banach, P. Burchardt, K. Chlebus, P. Dobrowolski, D. Dudek, K. Dyrbuś, M. Gąsior, P. Jankowski, J. Jóźwiak, L. Kłosiewicz-Latoszek, I. Kowalska, M. Małecki, A. Prejbisz, M. Rakowski, J. Rysz, B. Solnica, D. Sitkiewicz, G. Sygitowicz, G. Sypniewska, T. Tomasik, A. Windak, D. Zozulińska-Ziółkiewicz, B. Cybulska

Table XXIII. Recommendations on the use of bempedoic acid Recommendation Class Level

In patients with ASCVD who have not achieved the LDL-C target at their maximum tolerated dose of a statin and ezetimibe, combination therapy with bempedoic acid may be considered.

In $\mathrm{FH}$ patients at very high risk not achieving the LDL-C target with the maximum tolerated dose of a statin and ezetimibe, combination with bempedoic acid may be considered.

If a statin-based regimen is not tolerated at any dose (even after rechallenge), bempedoic acid or the combination of ezetimibe and bempedoic acid may be considered.

milial) or mixed dyslipidaemia in addition to diet: (1) in combination with a statin or a statin and other lipid-lowering therapies in patients, in whom the target $L D L-C$ reduction has not been achieved with the maximum tolerated statin dose, OR (2) alone or in combination with other lipid-lowering therapies in patients who are intolerant to or have contraindications for statin therapy. Based on available studies, the authors of these guidelines also decided to recommend bempedoic acid (and its combination with ezetimibe) in selected groups of patients with lipid disorders (Table XXIII).

\subsubsection{Inclisiran}

The primary mechanism of action of inclisiran is inhibition of PCSK9 synthesis (by catalytic degradation of PCSK9 mRNA), which binds to and promotes degradation of LDL-C receptors, resulting in increased LDL-C concentration. Inclisiran is a so-called short interfering RNA, i.e. a double-stranded RNA molecule with a length of about 20-25 base pairs that silences the expression of genes with homologous sequence (RNAi) - in this case the mRNA which carries information for PCSK9 synthesis [224]. It is worth remembering that for discovery of the phenomenon of RNA interference, American scientists Andrew Z. Fire and Craig C. Mello received a Nobel Prize in Medicine and Physiology in 2006.

Inclisiran binds to asialoglycoprotein receptors on the hepatocyte surface (present only on these cells) and then binds to the RNA-induced silencing complex (RISC) which has the activity of ribonuclease and makes it possible to degrade the information RNA (mRNA) coding for PCSK9. As a result, inclisiran decreases PCSK9 synthesis in ribosomes (by means of inhibition of translation, often referred to as "gene silencing"), increases the number of LDL receptors on the surface of hepatocytes, and decreases the LDL cholesterol concentration $[225,226]$. Inclisiran is administered parenterally (subcutaneously) and its characteristic feature is a long duration of activity, which allows for application every 6 months.

The safety and efficacy of inclisiran is being evaluated in the ORION programme (and currently in the follow-up VICTORION programme), in which its efficacy in high cardiovascular risk patients with ASCVD or FH (both hetero- and homozygous) is evaluated, as well as in primary prevention in patients with so-called cardiovascular risk equivalent, and in populations with a socalled unmet need, i.e. patients with low treatment adherence (including statin intolerance), or those with chronic kidney disease (including those with severe renal impairment and GFR between $<30 \mathrm{ml} / \mathrm{min} / 1.73 \mathrm{~m}^{2}$ ) and chronic liver disease [224-226].

In recently published studies, it has been demonstrated that inclisiran reduces LDL-C cholesterol by ca. $50 \%$ (up to $55 \%$ ), among others in individuals with familial hypercholesterolaemia (the ORION-9 study, which enrolled 482 patients with $\mathrm{FH}$ and a mean LDL-C concentration of $4.0 \mathrm{mmol} / \mathrm{l}(155 \mathrm{mg} / \mathrm{dl}), 90 \%$ of subjects were treated with a statin and $53 \%$ with ezetimibe), those with a history of atherogenic cardiovascular disease (CHD, CVD, or PAD) (the ORION-10 study, which enrolled 1561 patients; mean LDL-C concentration $2.7 \mathrm{mmol} / \mathrm{l}, 89 \%$ treated with a statin, $10 \%$ with ezetimibe), and those with or without ASCVD, but with high cardiovascular risk, i.e. socalled ASCVD risk equivalent (the ORION 11 study, 1617 patients enrolled, mean LDL cholesterol concentration: $2.7 \mathrm{mmol} / \mathrm{l}, 95 \%$ treated with a statin, $7 \%$ with ezetimibe) $[227,228]$. In addition, in these studies a decrease of triglyceride concentration by $7 \%$ to $13 \%$, and $L p(a)$ by $17 \%$ to $26 \%$ was observed, as well as an increase in HDL-C by $3 \%$ to $6 \%$ in the inclisiran-treated groups in comparison with patients receiving placebo. All studies demonstrated very good tolerance of the agent, except for local injection site reactions, which occurred several times more often in the inclisiran groups [227, 228].

The objective of the studies discussed above was not assessment the effect of inclisiran on the risk of cardiovascular events; therefore, the number of patients enrolled, and the number of such endpoints did not allow to draw reliable conclusions in this regard. However, a meta-analysis of these studies (total number of patients analysed: 3660) demonstrated that inclisiran not only reduced the LDL cholesterol concentration (by a mean of $50.5 \%$ ) but also reduced the risk of major cardiovascular events (a composite endpoint of cardiac death, sudden cardiac arrest, myocardi- 
al infarction, and stroke) by $24 \%(p=0.01)$ [229]. The meta-analysis once again confirmed very good tolerability of the product [229]. Furthermore, the association between decreased LDL-C concentration and reduced risk of cardiovascular events as a result of inclisiran treatment has been shown to be similar to the relationship between cardiovascular risk reduction and change in LDL-C concentration for alirocumab and evolocumab [230]. Of course, only the results of the ORION-4 study, which are awaited by the end of 2024, will answer the question on how this significant LDL-C reduction plus a unique mode of administration (two doses per year), which will definitely translate into improved adherence, will reduce cardiovascular events and mortality.

It is worth noting that completed phase II and III studies as well as pooled analyses of these studies and meta-analyses were the basis for the approval of inclisiran by the EMA in December 2020. According to this decision, the product should be administered in a dose of 300 mg subcutaneously (inclisiran sodium equivalent to $284 \mathrm{mg}$ of inclisiran in $1.5 \mathrm{ml}$ of solution); after the first injection, the next dose should be given after 3 months, and then every 6 months in the following indications:

- in adults with primary hypercholesterolaemia (heterozygous familial hypercholesterolaemia and multigenic hypercholesterolaemia), or mixed dyslipidaemia, as an adjunct to diet,

- in combination with a statin, or a statin with other lipid-lowering agents, in patients who cannot achieve their target LDL-C concentration with the maximum tolerated statin dose OR

- alone or in combination with other lipid-lowering agents in patients who are statin-intolerant or in whom statin treatment is contraindicated. In Poland, inclisiran is available (few patients have been already administrated) but still not reimbursed, and work on the preparation of a therapeutic drug programme is ongoing. However, in view of the above, primarily the results of the available studies, the authors of these guidelines have decided to propose the first recommendations on the use of inclisiran and the groups of patients who might most benefit (Table XXIV).

\subsubsection{Apabetalone}

Apabetalone is an oral BET (bromodomain and extra-terminal domain) inhibitor with particular affinity for bromodomain-containing protein 4 (BRD4) [231]. Apabetalone binds to the second bromodomain, thus inhibiting epigenetic modulators of gene transcription. The effects of apabetalone include stimulation of gene expression and production of ApoA-I, the main component of high-density lipoproteins (HDL). Beneficial effects of the agent on severity of inflammation and the composition and volume of atherosclerotic plaques have also been demonstrated [231]. A meta-analysis of three small studies comprising the BETonMACE programme $(n=798)$ demonstrated a beneficial effect of the agent on the concentration of apolipoprotein A-I, HDL-C, the number of large HDL particles, and CRP [232]. In addition, a significant reduction of the risk of cardiovascular events in comparison with placebo was observed, especially in patients with diabetes, low HDL cholesterol concentration, and in those with elevated CRP concentration [232]. However, the published results of the BETonMACE study, which included 2425 post-ACS patients with type 2 diabetes and low HDL-C concentration, did not confirm a statistically significant difference in the risk of a composite endpoint of cardiovascular death, myocardial infarction, or stroke $(10.3 \%$ vs. $12.4 \%, p=0.11)$ between the groups receiving apabetalone (100 $\mathrm{mg}$ bid) and placebo [233]. As a result of good tolerability of the new agent and a low number of adverse reactions during treatment, results of subsequent studies on "the first agent modifying processes on the epigenetical level in patients with cardiovascular diseases" may be awaited; the agent may be a valuable addition to treatment of lipid disorders in selected groups of patients (currently, it seems that patients with atherogenic dyslipidaemia may comprise such a group) [231-233]. The results of a subanalysis of the BETonMACE study in patients with ACS, diabetes and chronic kidney disease may be a confirmation [234]. The median follow-up period was 27 months; in patients with CKD apabetalone in comparison with placebo was associated with fewer major adverse cardiovascu-

Table XXIV. Recommendations on the use of inclisiran

\begin{tabular}{|c|c|c|}
\hline Recommendation & Class & Level \\
\hline $\begin{array}{l}\text { In patients with ASCVD and/or FH who do not achieve the target at the maximum tolerated dose } \\
\text { of a statin and ezetimibe, initiation of inclisiran may be considered. }\end{array}$ & IIb & B \\
\hline $\begin{array}{l}\text { If a statin-based regimen is not tolerated at any dose (even after rechallenge), treatment with } \\
\text { inclisiran may be considered. }\end{array}$ & IIb & C \\
\hline $\begin{array}{l}\text { In primary or secondary prevention in very high-risk patients who are non-adherent to lipid- } \\
\text { lowering therapy or who are not willing to use statin therapy, treatment with inclisiran may be } \\
\text { considered. }\end{array}$ & IIb & C \\
\hline
\end{tabular}


M. Banach, P. Burchardt, K. Chlebus, P. Dobrowolski, D. Dudek, K. Dyrbuś, M. Gąsior, P. Jankowski, J. Jóźwiak, L. Kłosiewicz-Latoszek, I. Kowalska, M. Małecki, A. Prejbisz, M. Rakowski, J. Rysz, B. Solnica, D. Sitkiewicz, G. Sygitowicz, G. Sypniewska, T. Tomasik, A. Windak, D. Zozulińska-Ziółkiewicz, B. Cybulska

lar events (MACE) $(\mathrm{HR}=0.50 ; 95 \% \mathrm{Cl}$ : 0.26-0.96) and hospitalisations related to heart failure (HR $=0.48 ; 95 \% \mathrm{Cl}: 0.26-0.86)$. In patients with CKD, a similar number of adverse events was observed, regardless of randomisation to apabetalone or placebo, and fewer serious adverse events (29\% vs. $43 \% ; p=0.02$ ) in the apabetalone group [234].

\subsubsection{Volanesorsen}

Volanesorsen is an antisense oligonucleotide that inhibits the synthesis of ApoC-III, a protein known as an inhibitor of lipoprotein lipase $(\mathrm{LPL})$, a regulator of triglyceride metabolism and hepatic clearance of chylomicrons and other lipoproteins with a high content of triglycerides [235]. It has recently been shown that apoC-III increases triglyceride concentration on a pathway independent of lipoprotein lipase as well [236]. Volanesorsen selectively binds to information ribonucleic acid (mRNA) coding for apoC-III and prevents translation. The agent reduces the concentration of apoC-III by ca. $80-90 \%$ and that of triglycerides by ca. 70\% [235]. The safety and efficacy of volanesorsen in patients with elevated triglyceride concentration were assessed in two phase III trials [236, 237]. The primary indication for volanesorsen is chylomicronaemia (FCS, type I hyperlipoproteinaemia).

In a recently published COMPASS study (phase III), adult patients $(n=114)$ with multifactorial severe hypertriglyceridaemia or FCS, BMI of $45 \mathrm{~kg} / \mathrm{m} 2$ or less, and fasting plasma triglycerides at least $500 \mathrm{mg} / \mathrm{dl}$ were enrolled $[238,239]$. Patients were randomised $(2: 1)$ to receive subcutaneous volanesorsen $(300 \mathrm{mg}$ ) or placebo $(1.5 \mathrm{ml})$ once a week for 26 weeks. After 13 weeks of treatment, the dose was changed to $300 \mathrm{mg}$ of volanesorsen or placebo every 2 weeks. Volanesorsen reduced the mean plasma triglyceride concentration by $71.2 \%$ (95\% Cl: -79.3 to -63.2$)$ from baseline, compared with $0.9 \%(-13.9$ to 12.2$)$ in the placebo group ( $p<0.0001)$, which represents an absolute mean decrease of fasting plasma triglyceride concentration by $869 \mathrm{mg} / \mathrm{dl}(95 \% \mathrm{Cl}:-1,018$ to $-720 ; 9.82 \mathrm{mmol} / \mathrm{l}(-11.51$ to -8.14$))$ in the volanesorsen group compared with a $74 \mathrm{mg} / \mathrm{dl}$ increase $(-138$ to $285 ; 0.83 \mathrm{mmol} / \mathrm{l}(-1.56$ to $3.22) ; p<0.0001)$ in the placebo group. In the safety analysis, 5 cases of acute pancreatitis were reported, all in the placebo group [239].

In August 2018, the FDA made a negative decision on the use of volanesorsen in FCS. In May 2019, volanesorsen (Waylivra) was approved by the EMA for the treatment of familial chylomicronaemia syndrome (FSC). It is available as a solution for subcutaneous injections, at the beginning of treatment administered once a week; after
3 months, patients in whom a sufficient decrease in triglyceride concentration has occurred may receive volanesorsen every 2 weeks. The frequency of injections is re-adjusted after 6 and 9 months of treatment.

\subsubsection{Evinacumab}

Evinacumab is a monoclonal antibody binding to angiopoietin-like protein 3 (ANGPTL3). The contribution of ANGPTL3 to lipid metabolism consists primarily in the inhibition of lipoprotein lipase (LPL) and endothelial lipase activity [240, 241]. In the phase III ELIPSE HoFH (Evinacumab Lipid Studies in Patients with Homozygous Familial Hypercholesterolemia) study, the use of evinacumab for 24 weeks was associated with a reduction in LDL cholesterol (baseline mean concentration of $255.1 \mathrm{mg} / \mathrm{dl}$ ) by $49 \%$ (absolute reduction: $132.1 \mathrm{mg}$ ), and triglyceride concentration by $50 \%$ in patients with homozygous familial hypercholesterolaemia [240]. The agent is also effective in individuals with refractory hypercholesterolaemia. In a study involving 272 subjects (83\% treated with a statin, $38 \%$ with ezetimibe, $96 \%$ with a PCSK-9 inhibitor) evinacumab reduced LDL-C concentration by $24 \%$ to $56 \%$, depending on the dose and route of administration (300-450 mg/ week, or $300 \mathrm{mg}$ s.c. twice a week, or $15 \mathrm{mg} / \mathrm{kg}$ bw/4 weeks, or $5 \mathrm{mg} / \mathrm{kg}$ bw/4 weeks) [241]. The most recent analysis (a phase I study) demonstrated that the use of evinacumab in patients with mixed dyslipidaemia and elevated triglyceride concentration (even up to $1500 \mathrm{mg} / \mathrm{dl}$ ) was associated with a very significant reduction of triglycerides, with a peak median reduction of $81.8 \%$ (compared with $20.6 \%$ in the placebo group); the median achieved concentration was $83 \mathrm{mg} / \mathrm{dl}$ vs. $444.0 \mathrm{mg} / \mathrm{dl}$ in the evolocumab and placebo group, respectively [242].

In February 2021, the FDA approved evinacumab (Evkeeza) as an add-on therapy for patients over 12 years of age with homozygous $\mathrm{FH}$. The same recommendation was adopted by the EMA in June 2021. Evinacumab is administered as intravenous infusion over 60 min every 4 weeks in the recommended dose of $15 \mathrm{mg} / \mathrm{kg}$ body weight.

\subsubsection{Antisense therapies}

Translation is the second process (following transcription) in protein biosynthesis. Polypeptide chain formation is controlled by the mRNA sequence. Translation occurs in the cytoplasm or on the membrane of the endoplasmic reticulum. This process is catalysed by a ribosome as its subunits move along the mRNA strand [243]. In antisense therapy strategies, gene expression inhibition takes place at the stage of translation. 
In this method oligonucleotides with sequences complementary to mRNA areas critical for translation are used. These oligonucleotides bind to mRNA fragments and thus prevent protein synthesis [243]. An example of such an oligonucleotide is volanesorsen (discussed above). Another example is vupanorsen that inhibits ANGPTL-3 synthesis. Study results have demonstrated that the agent effectively reduces triglyceride concentration (by $36-53 \%$ depending on the dosage), while its effect on LDL-C concentration is relatively small [243]. Another agent, mipomersen, inhibits the synthesis of apolipoprotein B-100, one of the main molecules contained in low and very low-density lipoproteins ( $L D L$ and VLDL), and was registered in certain countries for the treatment of homozygous familial hypercholesterolaemia [244].

\subsection{Management of elevated Lp(a) concentration}

The molecule of lipoprotein (a) (Lp(a)), structurally similar to LDL, contains apolipoprotein (a) (apo(a)) which is covalently bound by a disulfide bridge to ApoB 100 [245, 246]. The apo(a) molecule is highly similar to plasminogen, which results in pro-atherogenic activity associated with the procoagulant effect. Due to its small diameter (<70 nm), Lp(a) may flow freely across the endothelial barrier and, like LDL, be retained in the artery wall, which in turn may increase the risk of atherosclerotic cardiovascular diseases [246]. Pro-inflammatory and antifibrinolytic effects are also attributed to $L P(a)$, which is important for progression of the atherosclerotic process $[45,246]$. Large observational studies and meta-analyses have demonstrated a relationship between the $L p(a)$ concentration and the risk of ischaemic heart disease, ischemic stroke, and aortic valve stenosis [45, 247-250]. Although $\mathrm{Lp}(\mathrm{a})$ is a weaker risk factor than LDL-C, it is an independent factor, as evidenced by the fact that up to $30 \%$ of patients with familial hypercholesterolaemia and/or acute coronary syndrome may have an elevated concentration of this lipoprotein with a desired LDL-C concentration [45]. High Lp(a) concentration is associated with an increased risk of major cardiovascular events by $40 \%$ compared with low concentration [45]. A similar risk (41\%) of ischaemic stroke was demonstrated in patients with $\mathrm{Lp}(\mathrm{a})>50 \mathrm{mg} / \mathrm{dl}$ $[9,45]$.

The assumed desired $L p(a)$ concentration is $<30 \mathrm{mg} / \mathrm{dl}$ (< $75 \mathrm{nmol} / \mathrm{l})$ (Table VIII). Conversely, a concentration $\geq 30 \mathrm{mg} / \mathrm{dl}$ indicates increased risk; it was assumed that concentrations $>180 \mathrm{mg}$ (> $450 \mathrm{nmol} / \mathrm{l})$ indicated a very high risk of myocardial infarction and aortic valve stenosis
[9, 50, 249]. Detailed recommendations on when and in whom $L p(a)$ concentration should be measured have been discussed above in Sections 6.8 and 6.9, and Tables VIII and IX. Experts agree that at least once in every adult individual's life Lp(a) concentration should be measured to detect patients at the highest risk, i.e., those with $L p(a)$ $>180 \mathrm{mg} / \mathrm{dl}$. Furthermore, Lp(a) measurement should be considered in all patients with premature onset of cardiovascular disease, lack of effect of statin treatment, and in those at moderate to high risk. The authors of these guidelines also recommend consideration of $\mathrm{Lp}(\mathrm{a})$ measurement in individuals with ASCVD or $\mathrm{FH}$, and in pregnant women. LP(a) has also been added to the definition of extreme risk patients as an additional risk-modifying factor in patients with ACS and diabetes (Table X).

Clinical trial results have demonstrated that lipid-lowering agents reduce $L p(a)$ concentration, although their effects are very variable (Table XXV). The most controversial results were obtained in patients treated with statins as both reduced and increased Lp(a) concentrations (particularly with pitavastatin) were observed [92]. Of currently available agents, the most promising clinical significance in $L p(a)$ reduction and incident reduction is attributed to PCSK9 inhibitors [251-253]. In the FOURIER study, in a group of patients with stable coronary artery disease treated with evolocumab, a $26.9 \%$ (6.2-46.7\%) reduction of $L p(a)$ concentration was achieved, and a $23 \%$ incident reduction $(\mathrm{HR}=0.77$; 95\% Cl: 0.67-0.88) in those with baseline $L p(a)$ above the median ( $37 \mathrm{nmol} / \mathrm{l} \sim 15 \mathrm{mg} / \mathrm{dl}$ ), while in the group with $\mathrm{Lp}(\mathrm{a})$ below the median by only $7 \%(\mathrm{HR}=0.93 ; 95 \% \mathrm{Cl}: 0.80-1.08)$ [252]. The number needed-to-treat (NNT) was 41 and 105, respectively. A significant relationship between a $15 \%$ reduction in the risk of major coronary events (95\% Cl: 2-25\%; $p=0.0199)$ and a reduction of $L p(a)$ by $25 \mathrm{nmol} / \mathrm{l}$ was demonstrated after adjustment for LDL [252].

Table XXV. Effects of lipid-lowering drugs on Lp(a)

\begin{tabular}{|lc|}
\hline Treated & $\begin{array}{c}\text { Estimated } \% \text { Lp(a) } \\
\text { change }\end{array}$ \\
\hline $\begin{array}{l}\text { Antisense oligonucleotides } \\
\text { against apo(a) }\end{array}$ & $\downarrow$ by $70-90 \%$ \\
\hline Lipoprotein apheresis & $\downarrow$ by $20-30 \%$ \\
\hline Niacin & $\downarrow$ by $30 \%$ \\
\hline PCSK9 inhibitors & $\downarrow$ by $20-30 \%$ \\
\hline CETP inhibitors & $\downarrow$ by $25 \%$ \\
\hline Mipomersen & $\downarrow$ by $25 \%$ \\
\hline Inclisiran & $\downarrow 15-26 \%$ \\
\hline Ezetimibe & $\downarrow$ up to $7 \%$ \\
\hline Statins & Possible $\uparrow$ by $6-10 \%$ \\
\hline
\end{tabular}


M. Banach, P. Burchardt, K. Chlebus, P. Dobrowolski, D. Dudek, K. Dyrbuś, M. Gąsior, P. Jankowski, J. Jóźwiak, L. Kłosiewicz-Latoszek, I. Kowalska, M. Małecki, A. Prejbisz, M. Rakowski, J. Rysz, B. Solnica, D. Sitkiewicz, G. Sygitowicz, G. Sypniewska, T. Tomasik, A. Windak, D. Zozulińska-Ziółkiewicz, B. Cybulska

Similar results have been obtained in a subanalysis of the ODYSSEY OUTCOMES study in post-ACS patients treated with alirocumab. Risk reduction after 4 months of treatment analysed in patient groups with baseline $\operatorname{Lp}(\mathrm{a})$ concentration $<6,7 \mathrm{mg} / \mathrm{dl}, 6.7$ to $21.2 \mathrm{mg} / \mathrm{dl}, 21.2$ to $59.6 \mathrm{mg} / \mathrm{dl}$, and $\geq 59.6 \mathrm{mg} / \mathrm{dl}$ was, respectively, $5 \%(\mathrm{HR}=0.95 ; 95 \% \mathrm{Cl}: 0.97-1.15), 15 \%$ (0.85; $0.71-1.03), 21 \%(0.79,0.66-0.94)$, and $17 \%$ $(0.83 ; 0.70-0.98)$. A reduction in $\mathrm{Lp}(\mathrm{a})$ by $5 \mathrm{mg} /$ $\mathrm{dl}$ was associated with a significant reduction of cardiovascular events by $2.5 \%[253,254]$. Reduction of the risk of ischaemic heart disease was also demonstrated in an analysis of 62,240 patients with this disease compared with a control group of 127,000 patients. It was demonstrated that each reduction of $\mathrm{Lp}(\mathrm{a})$ by $10 \mathrm{mg} / \mathrm{dl}$ was associated with a reduction of the risk of ischaemic heart disease by $5.8 \%(\mathrm{OR}=0.94 ; 95 \% \mathrm{Cl}$ : 0.93-0.95). In contrast, a reduction of LDL-C concentration by $10 \mathrm{mg} / \mathrm{dl}$ resulted in a significant reduction of the risk of this disease by $14.5 \%$ (OR $=0.86 ; 95 \% \mathrm{Cl}: 0.82-0.89)$. It was demonstrated that with a decrease of $L p(a)$ concentration by $101.5 \mathrm{mg} / \mathrm{dl}$ a similar reduction in ischaemic disease was achieved as with a decrease of LDL-C by $38.7 \mathrm{mg} / \mathrm{dl}$ [255].

Significant reduction of $\mathrm{Lp}(\mathrm{a})$ concentration can also be achieved using lipoprotein apheresis or new agents (apo(a) antisense oligonucleotides, e.g., pelacarsen) which are still not widely available and require further clinical studies [45].

\section{KEY POINTS TO REMEMBER}

- Lp(a) measurement is indicated at least once in every adult individual's life to detect elevated lipoprotein (a) concentration that can significantly modify residual risk, as well as patients with the highest risk of ASCVD, i.e., those with $L p(a)>180 \mathrm{mg} / \mathrm{dl}$ (> $450 \mathrm{nmol} / \mathrm{l}$ ).

- Measurement of Lp(a) should be considered in patients with premature onset of cardio vascular disease, lack of statin effect, and in those with a borderline risk level between moderate and high to improve risk assessment.

- Measurement of Lp(a) may be considered in patients with very high cardiovascular risk and atherosclerotic cardiovascular disease, in patients with familial hypercholesterolaemia, and in pregnant women in prevention of pre-eclampsia or miscarriage, in recurrent pregnancy loss, or intrauterine growth restriction.

- High Lp(a) concentration may cause an artifactual increase in LDL-C concentration.

\subsection{The importance of antihyperglycaemic agents in treatment of lipid disorders and cardiovascular risk reduction}

Pharmacological reduction of hyperglycaemia in multifactorial treatment of type 2 diabetes mellitus (in addition to treatment of hypertension and dyslipidaemia, lifestyle modification, antiplatelet therapy, etc.) is essential in prevention and inhibition of the progress of chronic diabetes-related complications (macro- and microvascular) and thus affects life expectancy $[125,256,257]$. In selection of therapy and combination of antihyperglycaemic medications, their effects on non-glycaemic parameters (mortality, cardiovascular or renal risk, body weight, risk of hypoglycaemia, lipid profile, etc.) should be taken into consideration while following the principle of personalisation of treatment. In patients with atherosclerotic cardiovascular disease, systolic heart failure, chronic kidney disease, or multiple cardiovascular risk factors, agents with proven beneficial effects on the risk of progression of these conditions as well as on overall and cardiovascular mortality should be used first (Table XXVI). This effect has been demonstrated for certain inhibitors of sodium-glucose cotransporter-2 (SGLT2) (flozins) and certain glucagon-like peptide-1 (GLP-1) receptor agonists [125, 256, 257]. In patients with chronic kidney disease and systolic heart failure, the choice of a flozin should be preferred, and if they are contraindicated, a GLP-1 analogue [125, $256,257]$. In patients diagnosed with ASCVD, both classes should be considered, and in the case of multiple risk factors, GLP-1 receptor agonists should be considered first. Early combination therapy with metformin and certain flozins and/ or GLP-1 receptor agonists should be considered in the cases listed above in each patient, regardless of the achievement of the treatment goal $[125,256,257]$. Also in concomitant obesity, it is recommended to prefer GLP-1 receptor agonists or SGLT2 inhibitors. If the risk of hypoglycaemia is high, the same classes of agents and a dipeptidyl peptidase 4 (DPP-4) inhibitor or a peroxisome proliferator-activated receptors (PPAR- $\gamma$ ) agonist should be considered. In Poland, with limited reimbursement of new antihyperglycaemic agents, the most readily available and affordable classes of agents are sulfonylurea derivatives, PPAR- $\gamma$ agonists, and acarbose [125, 256, 257].

\subsection{Apheresis in lipid disorders}

\subsubsection{LDL apheresis}

LDL apheresis is a mechanical method of removal of LDL particles from serum. Blood collected from the patient is first divided in a separator into morphotic elements and plasma, which 
Table XXVI. The effects of antihyperglycaemic agents on the lipid profile and cardiovascular risk

\begin{tabular}{|c|c|c|c|c|c|c|}
\hline $\begin{array}{l}\text { Antihyperglycaemic } \\
\text { agent }\end{array}$ & LDL-C & TG & HDL-C & $\begin{array}{l}\text { Body } \\
\text { weight }\end{array}$ & $\begin{array}{l}\text { Effect on atherosclerotic } \\
\text { cardiovascular events }\end{array}$ & Heart failure \\
\hline Metformin & $\downarrow$ & $\downarrow$ & $\uparrow$ & $\downarrow \leftrightarrow$ & Favourable & Neutral \\
\hline $\begin{array}{l}\text { Sulfonylurea } \\
\text { derivatives }\end{array}$ & $\leftrightarrow$ & $\leftrightarrow$ & $\leftrightarrow$ & $\begin{array}{l}\uparrow \text { with the } \\
\text { exception of } \\
\text { gliclazide }\end{array}$ & Neutral & Neutral \\
\hline $\begin{array}{l}\text { SGLT-2 inhibitors } \\
\text { (flozins) }\end{array}$ & $\stackrel{\leftrightarrow}{\uparrow}$ or & $\leftrightarrow$ & $\uparrow$ & $\downarrow$ & $\begin{array}{l}\text { Favourable } \\
\text { (empagliflozin, } \\
\text { canagliflozin, } \\
\text { dapagliflozin) }\end{array}$ & $\begin{array}{l}\text { Favourable } \\
\text { (empagliflozin, } \\
\text { canagliflozin, } \\
\text { dapagliflozin) }\end{array}$ \\
\hline $\begin{array}{l}\text { GLP-1 receptor } \\
\text { agonists (incretins) }\end{array}$ & $\downarrow$ & $\downarrow$ & $\uparrow$ & $\downarrow \downarrow$ & $\begin{array}{c}\text { Favourable (liraglutide, } \\
\text { semaglutide, } \\
\text { dulaglutide) }\end{array}$ & Neutral \\
\hline $\begin{array}{l}\text { DPP-4 inhibitors } \\
\text { (gliptins) }\end{array}$ & $\downarrow \leftrightarrow$ & $\leftrightarrow$ & $\leftrightarrow$ & $\leftrightarrow$ & Neutral & $\begin{array}{c}\text { Neutral } \\
\text { (unfavourable } \\
\text { saxagliptin) }\end{array}$ \\
\hline Pioglitazone & $\leftrightarrow$ & $\downarrow$ & $\uparrow$ & $\uparrow$ & Potentially favourable & Unfavourable \\
\hline Acarbose & $\leftrightarrow$ & $\leftrightarrow$ & $\leftrightarrow$ & $\leftrightarrow$ & Neutral & Neutral \\
\hline Insulin & $\leftrightarrow$ & $\downarrow$ & $\uparrow$ & $\uparrow$ & Neutral & Neutral \\
\hline
\end{tabular}

goes further into a set of LDL-C-separating filters. Once the plasma is filtered, it is transfused back to the patient together with cellular elements. The entire procedure lasts from 2 to $4 \mathrm{~h}$. During this period, about 1.5-3 I of blood is filtered, and a reduction of LDL-C by $55-70 \%$ is achieved [258]. During apheresis, not only LDL-C, but also VLDL, fibrinogen, $L p(a), \alpha 2$-macroglobulin, and coagulation factors are removed from the plasma [259]. Clinical observations suggest that long-term use of LDL-apheresis in patients with severe $\mathrm{HoFH}$ contributes to regression and stabilisation of atherosclerotic plaques, improves cardiovascular prognosis, and reduces xanthomata of the skin and tendons [260].

Despite high costs (the mean procedure cost amounts to PLN 5616) and the burden for the patient, LDL apheresis is still a very important complementary therapy for homozygous FH [259, 261-263]. The most recent ESC/EAS recommendations [9] and the position of the EAS experts [264] on $\mathrm{HoFH}$ did not significantly change the position on this issue, while recommending maintenance of pharmacological treatment at maximum tolerated doses [9, 264]. Importantly, LDL apheresis is a safe method for pregnant women [259, 261].

The results of key clinical trials which may significantly affect the position of LDL-apheresis in the next edition of recommendations are worth noting; even today, they are a real clinical alternative for the few patients undergoing these procedures in our country. The results of the TESLA [265] and TAUSSIG [266] studies concerning treatment of $\mathrm{HoFH}$ with evolocumab have demonstrated the efficacy of PCSK9 inhibitors in LDL-C reduction, comparable to LDL apheresis, with good treatment tolerance. Also in HeFH well-documented clinical trials have been performed and their results allow for replacement of apheresis with biological treatment. The ODYSSEY ESCAPE study met its primary endpoint showing that in patients in whom alirocumab was added to their previous regimen a significant $75 \%$ reduction in the frequency of apheresis in comparison with placebo was achieved. In $63 \%$ of patients receiving alirocumab apheresis was no longer required, compared with no such patients among those receiving placebo [267]. In view of lower costs and definitely better tolerability in comparison with LDL-apheresis, this creates a highly promising perspective for patients with $\mathrm{HeFH}$. For patients with confirmed $\mathrm{FH}$, such an alternative is already available in a therapeutic programme financed by the NHF (Table XVI).

In the position of the Working Group for Apheresis of the Polish Society of Nephrology [268] which was widely discussed and criticised at many sites, other (in addition to $\mathrm{HoFH}$ and $\mathrm{HeFH}$ ) indications for treatment with LDL-apheresis have also been listed:

1. Primary prevention of cardiovascular disease: in patients with documented risk factors for coronary artery disease or its equivalent (e.g. peripheral atherosclerotic disease) who cannot be diagnosed with $\mathrm{FH}$ according to the Dutch criteria, although they have lipid disorders and do not achieve their LDL-C targets, according to the adopted guidelines (...), and in whom all other standard therapies have failed (for at least 3 months) or are poorly tolerated, and/or there are contraindications to pharmacological treatment (adverse effects, complications, e.g. rhabdomyolysis).

2. Secondary prevention of cardiovascular disease in high-risk patients diagnosed with car- 
M. Banach, P. Burchardt, K. Chlebus, P. Dobrowolski, D. Dudek, K. Dyrbuś, M. Gąsior, P. Jankowski, J. Jóźwiak, L. Kłosiewicz-Latoszek, I. Kowalska, M. Małecki, A. Prejbisz, M. Rakowski, J. Rysz, B. Solnica, D. Sitkiewicz, G. Sygitowicz, G. Sypniewska, T. Tomasik, A. Windak,

D. Zozulińska-Ziółkiewicz, B. Cybulska

diovascular disease (status post myocardial infarction or stroke, peripheral arterial disease), type 2 diabetes, or moderate to severe chronic kidney disease (CKD 4-5): in patients who cannot be diagnosed with $\mathrm{FH}$ according to Dutch criteria, although they have lipid disorders and do not achieve their LDL-C targets, according to the adopted guidelines (...), and in whom all other standard therapies have failed (for at least 3 months) or are poorly tolerated, and/or there are contraindications to pharmacological treatment (adverse effects, complications, e.g. rhabdomyolysis).

3. Isolated Lp(a) hyperlipoproteinaemia $>60 \mathrm{mg} / \mathrm{dl}$ with normal and/or high LDL-C concentration despite diet and maximum tolerated treatment for 3 months, with documented coronary artery disease.

4. Severe mixed hyperlipidaemia (refractory nephrotic syndrome in the course of focal segmental glomerulosclerosis).

5. Sudden sensory loss of hearing.

6. Severe hypertriglyceridaemia (TG $\geq 11.3 \mathrm{mmol} / \mathrm{l}$ $(1000 \mathrm{mg} / \mathrm{dl}))$ with acute pancreatitis with the use of double filtration LDL apheresis with citrate anticoagulation.

The most important adverse effects of LDL-apheresis include: hypotension, abdominal pain, nausea, vomiting, vertigo and headache, hypocalcaemia, iron deficiency anaemia, allergic reactions, haemolysis, and thrombocytopenia. Due to the risk of hypotension in patients treated for arterial hypertension, it is recommended to omit hypotensive medication on the day of the procedure. Complete blood count and iron concentration should be monitored and supplemented, if necessary [9]. Antiplatelet therapy should not be discontinued.

\subsubsection{Apheresis in severe HTG}

The procedure may be used in prevention of acute pancreatitis [269]. It is estimated that ca. $7 \%$ of cases of acute pancreatitis are associated with hypertriglyceridaemia [269]. The apheresis procedure may be considered on an individual basis, in addition to other elements of standard therapy [270], i.e., reduction of food energy and fat content, alcohol abstinence, and pharmacotherapy: fibrates (fenofibrate) and omega-3 fatty acids (2-4 g/day) (Sections 9.4 and 9.9). Effective insulin therapy is required in patients with diabetes. The efficacy of apheresis in acute pancreatitis has not been confirmed yet. The results of the only study comparing the efficacy of intensive insulin therapy with that of plasmapheresis are still unknown at the time of publication of these recommendations [271].

\subsubsection{Lp(a) apheresis}

The effects of reduction of $L p(a)$ concentration by means of apheresis have been documented not only in terms of anti-atherosclerotic, but also anti-inflammatory and anticoagulant activity; therefore, it is considered the intervention of choice in patients with high $L p(a)$ levels and signs of rapid progression of atherosclerosis [272]. German findings based on the German Lipoprotein Apheresis Registry (GLAR) demonstrated a 71\% decrease in $\mathrm{Lp}(\mathrm{a})$ concentration with an associated decrease in MACE by $78 \%$ as early as after 2 years of follow-up [273]. As high efficacy of LDL-apheresis in reduction of $L p(a)$ concentration ( $>60 \%$ ) has been demonstrated, even in comparison with new treatment options (mipomersen $25 \%$, CETP inhibitors 25\%, PCSK9 inhibitors 30\%; Table XXV) it seems an interesting option for patients with high $\mathrm{Lp}(\mathrm{a})$ concentration and rapidly progressive atherosclerosis [274].

\section{KEY POINTS TO REMEMBER}

- LDL-apheresis may be considered as adjunctive therapy in patients with $\mathrm{HoFH}$.

- LDL-apheresis should be considered in patients not meeting the criteria for treatment with PCSK9 inhibitors in therapeutic programmes (currently in HeFH and secondary prevention), when further progression of clinically evident atherosclerosis is observed despite maximum tolerated lipid-lowering therapy.

- LDL apheresis should be considered in patients with high Lp(a) concentration and signs of rapid progression of atherosclerosis.

\section{TREATMENT OF LIPID DISORDERS IN SPECIFIC POPULATIONS}

\subsection{Familial hypercholesterolaemia}

Familial hypercholesterolaemia is a single-gene, autosomal dominant dyslipidaemia that results in life-long elevated serum LDL-C concentration, leading to premature complications of atherosclerosis. Untreated, it usually leads to premature CAD (in women before 60 years of age, and in men before 55 years) which means an up to 10-fold increase in the risk of CAD [275]. Heterozygous $\mathrm{FH}(\mathrm{HeFH})$ is relatively common; according to the latest meta-analysis including over 11 million patients, the rate for the world population is $1: 313$, but in patients with ischaemic heart disease the incidence is 10 times higher $(1: 31)$, with premature ischaemic heart disease 20 times (1: 15), and in those with severe hypercholesterolaemia, 
Table XXVII. Diagnostic criteria for heterozygous familial hypercholesterolaemia (HeFH) according to the Dutch Lipid Clinic Network $[8,9]$

\begin{tabular}{|c|c|c|}
\hline Parameter & Criteria & Score \\
\hline \multirow[t]{2}{*}{ Family history } & $\begin{array}{l}\text { A first-degree relative with premature cardiovascular disease and/or LDL-C } \\
\qquad>95 \text { centile }(190 \mathrm{mg} / \text { dl, i.e. } 5.0 \mathrm{mmol} / \mathrm{l})\end{array}$ & 1 \\
\hline & $\begin{array}{l}\text { A first-degree relative with tendinous xanthomata and/or }<18 \text { years of age } \\
\text { with } L D L-C>95 \text { centile }(155 \mathrm{mg} / \mathrm{dl} \text {, i.e. } 4.0 \mathrm{mmol} / \mathrm{l})\end{array}$ & 2 \\
\hline \multirow[t]{2}{*}{ Clinical history } & $\begin{array}{l}\text { Premature cardiovascular disease (before } 55 \text { years of age in men and before } \\
\qquad 60 \text { years in women) }\end{array}$ & 2 \\
\hline & Premature cerebrovascular or peripheral arterial disease & 1 \\
\hline \multirow[t]{2}{*}{ Physical examination } & Tendinous xanthomata & 6 \\
\hline & Arcus cornealis before 45 years of age & 4 \\
\hline \multirow[t]{4}{*}{ LDL-C } & $\geq 330 \mathrm{mg} / \mathrm{dl}(\geq 8.5 \mathrm{mmol} / \mathrm{l})$ & 8 \\
\hline & $250-329 \mathrm{mg} / \mathrm{dl}(6.5-8.4 \mathrm{mmol} / \mathrm{l})$ & 5 \\
\hline & $190-249 \mathrm{mg} / \mathrm{dl}(5.0-6.4 \mathrm{mmol} / \mathrm{l})$ & 3 \\
\hline & $155-189 \mathrm{mg} / \mathrm{dl}(4.0-4.9 \mathrm{mmol} / \mathrm{l})$ & 1 \\
\hline DNA testing & LDLR, ApoB or PCSK9 gene mutation & 8 \\
\hline
\end{tabular}

*Interpretation: > 8 points, certain HeFH; 6-8 points, probable HeFH; 3-5 points, possible HeFH.

23 times higher $(1: 14)$ [276]. The global number of people affected by $\mathrm{FH}$ is estimated at 14-34 million [277], with only a small proportion of them diagnosed and treated [278].

In Poland, according to a meta-analysis of six large observational studies, based on the Dutch Lipid Clinic Network (DLCN) criteria (Table XXVII), $\mathrm{FH}$ was diagnosed in approximately one in 250 individuals aged $20-79$ years [279], which translates into approximately 122.5 thousand people with $\mathrm{FH}$ in our country (based on the 2014 GUS data on the population of Poland). Similar estimates were obtained in other studies, although according to the LIPIDOGRAM study, which enrolled nearly 34,000 patients, the estimated prevalence may be even higher [278, 280].

Genetic causes of $\mathrm{FH}$ are single-gene loss of function mutations in the LDLR or $A$ poB genes or gain of function mutations in the PCSK9 gene. LDLR mutations are definitely most common ( $>1700$ different mutations have been identified [281]), while gain of function mutations in the PSCK9 gene comprise only a few percent of all FH cases.

In most cases, the diagnosis of $\mathrm{FH}$ is based on the clinical presentation, although significance of molecular testing is increasingly emphasised in the literature [282]. The superiority and importance of genetic testing consists primarily in the possibility of diagnosis at an early age by performing cascade diagnostics among first-degree relatives [9, 283, 284]. DLCN criteria, presented in the table above, are usually used in clinical diagnosis; alternatively, the Simone Broome registry or WHO criteria are used $[8,9]$. It should be stressed that for proper assessment, one (the highest) criterion in each category (family history, clinical history, physical examination, LDL-C concentration, genetic testing) should be summed up. It is worth noting that LDL-C concentration should be measured without treatment; with statins, the values obtained may be multiplied by 1.43 [285] to estimate LDL-C concentration without a specific lipid-lowering therapy.

In the management of $\mathrm{FH}$ patients, effective treatment reducing $\mathrm{LDL}-\mathrm{C}$ concentration (to the target values compliant with the ESC recommendations) [9] which may significantly reduce the risk of CAD is the most important issue. According to the criteria adopted in these guidelines, subjects with $\mathrm{FH}$ and without other major risk factors are considered high-risk patients, while those with $\mathrm{FH}$ and ASCVD or other major risk factors are considered very high-risk patients, which implies a recommendation to achieve specific treatment goals $(<55 \mathrm{mg} / \mathrm{dl}(1.4 \mathrm{mmol} / \mathrm{l}))$. Furthermore, the authors of these guidelines believe that patients with FH and ACS should be considered extreme cardiovascular risk patients in whom, depending on baseline LDL-C values, immediate dual (intensive statin therapy + ezetimibe) or triple therapy (plus a PCSK9 inhibitor) should be considered (Tables $V$ and $X X$, Section 9.8).

It is recommended to start treatment immediately once the diagnosis has been established. Modification of the patient's lifestyle with respect to modifiable risk factors is a necessary but definitely insufficient therapeutic intervention. The treatment should include a potent high-dose statin, i.e., atorvastatin (40-80 mg/day) or rosuvastatin (20-40 mg/day), with a focus on the highest available doses of both statins. For very high-risk $\mathrm{FH}$ patients with ASCVD, the recommended treatment goal is reduction of LDL-C concentration by 
M. Banach, P. Burchardt, K. Chlebus, P. Dobrowolski, D. Dudek, K. Dyrbuś, M. Gąsior, P. Jankowski, J. Jóźwiak, L. Kłosiewicz-Latoszek, I. Kowalska, M. Małecki, A. Prejbisz, M. Rakowski, J. Rysz, B. Solnica, D. Sitkiewicz, G. Sygitowicz, G. Sypniewska, T. Tomasik, A. Windak, D. Zozulińska-Ziółkiewicz, B. Cybulska

$\geq 50 \%$ from baseline and a target LDL-C concentration of $<1.4 \mathrm{mmol} / \mathrm{l}(<55 \mathrm{mg} / \mathrm{dl})$. Unless it is possible to achieve treatment goals with statin monotherapy, combination therapy with ezetimibe is recommended; this should be initiated immediately post diagnosis in selected patients (see above), with a focus on the role of combination tablets (polypills), further improving adherence to treatment.

In primary prevention in very high-risk patients with $\mathrm{FH}$, reduction of $\mathrm{LDL}-\mathrm{C}$ concentration by $\geq 50 \%$ from baseline and a target LDL-C concentration of $<1.4 \mathrm{mmol} / \mathrm{l}(<55 \mathrm{mg} / \mathrm{dl})$ should be considered the treatment goal. If this has not been achieved in very high-risk FH patients despite the use of the highest tolerated dose of a statin in combination with ezetimibe, a PCSK9 inhibitor is recommended (Tables XVII and XVIII).

Earlier than before, i.e., at the age of 5 years, it is recommended to start diagnostics for $\mathrm{FH}$ in children, and if $\mathrm{HoFH}$ is suspected, even earlier. That is why it seems so important to introduce the need for LDL-C measurement in the child's health evaluation - at the age of 6 years at the latest. Unfortunately, the efforts to do so in Poland have not been successful so far. In children diagnosed with $\mathrm{FH}$, it is recommended to start statin therapy at the age of 8 , or at the latest 10 years, with education on appropriate diet. At the age $>10$ years, the target LDL-C concentration should be $<3.4 \mathrm{mmol} / \mathrm{l}(<130 \mathrm{mg} / \mathrm{dl})[8,9,286]$. The main problem is treatment of children with $\mathrm{FH}$, since it is introduced gradually, usually too low doses are used, and it is often poorly monitored, which ultimately leads to very rare achievement of therapeutic goals in children [287].

Homozygous $\mathrm{FH}$ is a rare disease (ca. 1 : $160,000)$ resulting from the inheritance of a genetic mutation from both parents, resulting in pathologically elevated plasma LDL-C concentration (>500 mg/dl) and an increased rate of atherosclerosis development (tendon and skin xanthomata below 10 years of age) and significantly increased cardiovascular risk $[9,265]$. The prognosis in untreated $\mathrm{HoFH}$ is poor, and the majority of patients die before the age of 30 years. Since effective $L D L-C$ reduction is the most important method to improve the prognosis in $\mathrm{HoFH}$, intensive treatment should be carried out, involving all available interventions, i.e., high doses of potent statins, ezetimibe, PCSK9 inhibitors, and LDL apheresis [265, 284]. The ESC recommendations, as well as these guidelines, emphasise the importance of LDL apheresis [9], with the frequency adjusted to the patient's individual needs. In this patient group, the efficacy of LDL-C reduction using PCSK9 inhibitors, i.e., evolocumab [265] and alirocumab [288], is well documented. Early genetic testing (including cascade screening of the patient's relatives) and early intensive lipid-lowering therapy remain essential for the survival of patients with $\mathrm{HoFH}$. Highly promising results have been achieved using new agents dedicated to this group of patients, including lomitapide (Lojuxta) [289] available in doses from 5 to $60 \mathrm{mg}$, mipomersen (Kynamro, which was not authorised for use by the EMA in 2013), as well as new therapies, including, above all, evinacumab (Evkeeza) (Section 9.10), which since June 2021, following a positive decision of the EMA, have been authorised for use in patients with $\mathrm{HoFH}$ in the European Union.

\section{KEY POINTS TO REMEMBER}

- Heterozygous familial hypercholesterolaemia is a relatively common condition in Polish population with a prevalence of 1 case per 250 adults or higher (even up to 120140,000 adult Poles).

- In Poland, only ca. $5 \%$ of patients with FH have been diagnosed; most of them still remain undiagnosed and are not treated.

- Genetic testing is highly useful in confirming the diagnosis of $\mathrm{FH}$, especially in young patients and in screening of the family members (cascade screening), but is not required to initiate therapy;

- Potent statins in the highest doses should be used in combination with ezetimibe; if therapeutic goals are not achieved, PCSK9 inhibitors should be added.

- In extreme-risk patients (FH and ACS) and in those with high baseline LDL-C concentration (> 120 and > $300 \mathrm{mg} / \mathrm{dl}$, respectively), immediate combination therapy with a statin and ezetimibe (polypill combination therapy is preferred) or triple therapy should be considered;

- In primary prevention in very high-risk patients with $\mathrm{FH}$ and in patients with $\mathrm{FH}$ and ASCVD, the recommended treatment goal is reduction of $\mathrm{LDL}-\mathrm{C}$ concentration by $\geq 50 \%$ from baseline and a target LDL-C concentration $<1.4 \mathrm{mmol} / \mathrm{l}(<55 \mathrm{mg} / \mathrm{dl})$.

\subsection{Prediabetes and diabetes mellitus}

Despite advances in early diagnosis and treatment strategies that reduce atherosclerotic CVD risk factors, diabetes mellitus remains one of the major causes of cardiovascular morbidity and mortality. It is an independent risk factor for CVD and nullifies the protective role of gender in women [290, 291]. Current data suggest that in patients with diabetes the risk of CVD is, on average, twice as high, but this risk varies widely de- 
Table XXVIII. Cardiovascular risk categories in patients with diabetes mellitus

\begin{tabular}{|c|c|}
\hline Extreme & $\begin{array}{l}\text { Status post-acute coronary syndrome in a patient with diabetes and at least one additional risk } \\
\text { factor (increased } \mathrm{Lp}(\mathrm{a})>50 \mathrm{mg} / \mathrm{dl} \text { or } \mathrm{hsCRP}>3 \mathrm{mg} / \mathrm{l} \text { or chronic kidney disease } \\
\left.\qquad\left(\mathrm{eGFR}<60 \mathrm{ml} / \mathrm{min} / 1.73 \mathrm{~m}^{2}\right)\right)\end{array}$ \\
\hline Very high & $\begin{array}{c}\text { Type } 2 \text { diabetes with organ damage }{ }^{1} \text { or other major risk factors }{ }^{2,3} \text {, type } 1 \text { diabetes with early onset } \\
\text { and duration }>20 \text { years }\end{array}$ \\
\hline High & Diabetes mellitus without organ damage (regardless of duration) ${ }^{4}$ \\
\hline
\end{tabular}

pending on the population studied and the treatment applied. In patients with diabetes, increased cardiovascular risk is strongly determined by the presence of organ damage, mainly diabetic kidney disease. The diagnosis of type 2 diabetes typically coexists with other cardiovascular risk factors, such as abdominal obesity, dyslipidaemia, and arterial hypertension, defining so-called metabolic syndrome [290, 291].

A vast majority of patients with diabetes are at very high or high cardiovascular risk. The last guidelines [9], however, have definitely made risk stratification in patients with diabetes more difficult, which may translate into inappropriate treatment (underestimated risk resulting in not adequately intensive treatment) [292]. Therefore, the authors of these guidelines have decided to simplify risk assessment in patients with diabetes mellitus, considering that in each case at least high cardiovascular risk should be assumed (Table XXVIII).

\subsubsection{Lipid disorders in patients with type 2 diabetes}

For type 2 diabetes, atherogenic dyslipidaemia is characteristic, with elevated TG concentration, decreased HDL-C concentration, and usually increased LDL-C concentration in the lipid profile. It is a consequence of insulin resistance and relative insulin deficiency. Increasing concentration of large VLDL particles in type 2 diabetes initiates a sequence of events that generates atherogenic remnants, small dense LDL, and small dense dysfunctional HDL particles with high TG content [41]. In the natural course of type 2 diabetes mellitus, quantitative and qualitative changes of lipoproteins are observed already in prediabetes. Increased plasma concentration of Apo C-III slows down the removal of TG-rich particles. Thus, increased synthesis and defective catabolism of TGrich particles lead to increased plasma concentration of TG and Apo B [293].

\subsubsection{Lipid disorders in patients with type 1 diabetes}

In individuals with type 1 diabetes and continuously well controlled glycaemia, a "super-normal" lipid profile is observed, characterised by high plasma HDL-C concentration as well as low TG and LDL-C concentration. In individuals with newly diagnosed type 1 diabetes, an increase of HDL-C concentration is observed as early as 3 months after initiation of insulin therapy [294]. This may be explained by subcutaneous administration of insulin, which increases LPL activity in adipose tissue and skeletal muscles, and consequently accelerates VLDL particle turnover [295]. A positive quantitative composition does not mean equally good quality and function. HDL-C dysfunctionality confers pro-atherogenic properties to these particles [296]. In a considerable proportion of patients with type 1 diabetes, concomitant obesity and insulin resistance-related metabolic disorders are observed. Too high doses of exogenous insulin and its route of administration generate secondary insulin resistance with its metabolic consequences.

\subsubsection{Pharmacotherapy of lipid disorders in patients with diabetes}

In patients with diabetes, the goal of lipid-lowering therapy is to reduce LDL-C concentration to values dependent on cardiovascular risk. The secondary target of therapy in this group is to reduce non-HDL-C concentration [9, 125]. In contrast, the authors of these guidelines are the first to point out that both LDL-C and non-HDL-C goals should be considered the primary objectives, which is particularly important for patients with atherogenic dyslipidaemia.

It is worth noting that adequate metabolic control of diabetes plays an important role in treatment of lipid disorders, especially in the case of hypertriglyceridaemia. Starting with the Heart Protection Study (HPS), research data suggest that all patients with type 2 diabetes benefit significantly from statin therapy (with a possible addition of ezetimibe), regardless of baseline LDL-C concentration $[8,9]$. In the IMPROVE-IT study, in the subgroup of patients with diabetes, ezetimibe in addition to simvastatin was particularly effective, reducing the relative risk by $15 \%(95 \% \mathrm{Cl}$ : $6-22 \%)$, and the absolute risk by $5.5 \%$ [297]. The FOURIER study demonstrated that therapy with a PCSK9 inhibitor provides similar benefits in pa- 
M. Banach, P. Burchardt, K. Chlebus, P. Dobrowolski, D. Dudek, K. Dyrbuś, M. Gąsior, P. Jankowski, J. Jóźwiak, L. Kłosiewicz-Latoszek, I. Kowalska, M. Małecki, A. Prejbisz, M. Rakowski, J. Rysz, B. Solnica, D. Sitkiewicz, G. Sygitowicz, G. Sypniewska, T. Tomasik, A. Windak, D. Zozulińska-Ziółkiewicz, B. Cybulska

tients with and without diabetes; however, due to a higher baseline risk in patients with diabetes, a trend towards greater absolute risk reduction was observed $(2.7 \%$ absolute reduction in major vascular events over 3 years) [298]. Of note, an LDL-C concentration of $0.8 \mathrm{mmol} / \mathrm{l}(31 \mathrm{mg} / \mathrm{dl})$ was achieved in the evolocumab arm. The same benefits were demonstrated in the ODYSSEY Outcomes study in patients with diabetes mellitus post ACS [299]. Additional analyses concerning new agents, i.e., inclisiran and bempedoic acid, are also awaited. The latter may indeed be an interesting treatment option because it not only reduces $L D L$ and non-HDL concentration, but also hsCRP, and the largest meta-analysis of Phase II and III studies has shown its significant efficacy in reducing the risk of new cases of diabetes [222] (Section 9.10).

There is evidence of an increased risk of diabetes mellitus with statin therapy, especially in patients with prediabetes or risk factors for diabetes, particularly those receiving intensive lipid-lowering therapy. Potential risk of diabetes should not affect the recommendation of statin therapy, as cardiovascular benefits should guide treatment strategies, and these are up to 5-fold higher than the risk of diabetes, particularly for atorvastatin and rosuvastatin [158]. A total lack of effect and even improved metabolic indices (glucose concentration, $\mathrm{HbA}_{1 \mathrm{c}}, \mathrm{HOMA}-\mathrm{IR}$ ) with pitavastatin treatment are also worth noting [150] (Section 9.1). Similarly, no increased risk of diabetes mellitus associated with the use of ezetimibe or PCSK9 inhibitors was observed in RCTs.

In type 2 diabetes, the lipid profile is often typical for atherogenic dyslipidaemia and, therefore, addition of fibrates to statin therapy may be associated with an additional benefit of reducing the incidence of cardiovascular events, but the evidence supporting recommendation of such management is not sufficient to date [9]. However, it should be emphasised that the evidence comes from studies with significant methodolog ical limitations, and additional subgroup analyses confirmed the importance of treatment with fenofibrate in patients with diabetes. Moreover, the current ESC/EAS 2019 recommendations, approved also in these guidelines with the recommendation level increased to Ila (from $\mathrm{llb}$ ), unequivocally state that fibrate therapy should be considered in all statin-treated patients with hypertriglyceridaemia and TG concentration $>200 \mathrm{mg} / \mathrm{dl}(2.3 \mathrm{mmol} / \mathrm{l})$. Subjects with type 1 diabetes with coexisting microalbuminuria and chronic kidney disease should be treated with statins regardless of baseline LDL-C values. Their goal should be reduction of LDL-C concentration by at least 50\% from baseline [9] (Table XXIX).

\subsection{Arterial hypertension and lipid disorders}

Elevated arterial blood pressure and hypercholesterolaemia are, beside smoking, two main modifiable cardiovascular risk factors determining cardiovascular risk. An approach targeting both risk factors if they coexist is the basis for primary and secondary prevention of cardiovascular events.

In the WOBASZ II study, performed in the years 2013-2014 in a randomly selected cross-sectional sample of over 6000 individuals aged 19-99 years, the coexistence of arterial hypertension and hypercholesterolaemia in Polish population was assessed. In $34.5 \%$ of men and $31 \%$ of women (32.2\% of the overall population), coexistence of these two main cardiovascular risk factors was

Table XXIX. Recommendations on treatment of lipid disorders in patients with diabetes

\begin{tabular}{|c|c|c|}
\hline Recommendation & Class & Level \\
\hline $\begin{array}{l}\text { In patients with obesity and pre-diabetes or type } 2 \text { diabetes, weight reduction is recommended by } \\
\text { changing dietary habits and increased exercise. }\end{array}$ & 1 & A \\
\hline $\begin{array}{l}\text { Patients with type } 2 \text { diabetes at very high cardiovascular risk should be treated in order to } \\
\text { reduce } \mathrm{LDL}-\mathrm{C} \text { concentration by } \geq 50 \% \text { from baseline; the recommended target is }<55 \mathrm{mg} / \mathrm{dl} \\
(<1.4 \mathrm{mmol} / \mathrm{l}) \text {, and the secondary objective is to reduce non-HDL-C concentration to below } \\
85 \mathrm{mg} / \mathrm{dl}(<2.2 \mathrm{mmol} / \mathrm{l}) \text {. }\end{array}$ & I & $A$ \\
\hline $\begin{array}{l}\text { Patients with type } 2 \text { diabetes at high cardiovascular risk should be treated in order to reduce LDL-C } \\
\text { concentration by } \geq 50 \% \text { from baseline; the recommended target is }<70 \mathrm{mg} / \mathrm{dl}(<1.8 \mathrm{mmol} / \mathrm{l}) \text {, and } \\
\text { the secondary objective is to reduce non-HDL-C concentration to below } 100 \mathrm{mg} / \mathrm{dl}(<2.6 \mathrm{mmol} / \mathrm{l}) \text {. }\end{array}$ & I & A \\
\hline $\begin{array}{l}\text { Patients post-acute coronary syndrome with diabetes and at least one additional risk factor } \\
\text { (increased } \mathrm{Lp}(\mathrm{a})>50 \mathrm{mg} / \mathrm{dl} \text { or hsCRP }>3 \mathrm{mg} / \mathrm{lor} \text { chronic kidney disease }(\mathrm{eGFR}<60 \mathrm{ml} / \mathrm{min} / \\
\left.1.73 \mathrm{~m}^{2}\right) \text { ) should be treated in order to reduce } \mathrm{LDL}-\mathrm{C} \text { concentration }<40 \mathrm{mg} / \mathrm{dl}(<1.0 \mathrm{mmol} / \mathrm{l}) \text {, } \\
\text { and the secondary objective is to reduce non-HDL-C concentration below } 70 \mathrm{mg} / \mathrm{dl}(<2.6 \mathrm{mmol} / \mathrm{l}) \text {. }\end{array}$ & IIb & B \\
\hline $\begin{array}{l}\text { In patients with diabetes, if statin therapy has not produced the desired effect, addition of } \\
\text { ezetimibe is recommended. }\end{array}$ & 1 & B \\
\hline $\begin{array}{l}\text { In individuals with type } 2 \text { diabetes, addition of a fibrate to statin therapy should be considered if } \\
\text { TG concentration remains }>200 \mathrm{mg} / \mathrm{dl}(2.3 \mathrm{mmol} / \mathrm{l}) \text {. }\end{array}$ & Ila & B \\
\hline Statins are recommended for patients with type 1 diabetes at high or very high risk. & 1 & A \\
\hline
\end{tabular}


found [300]. The prevalence of coexistence of lipid disorders and arterial hypertension depends on age. In the population of individuals aged 50-59 years, arterial hypertension and hypercholesterolaemia coexist in nearly half of the patients (46.2\%). After 60 years of age, in more than $50 \%$ of the population lipid disorders coexist with arterial hypertension [300].

The WOBASZ study also made it possible to assess the frequency of control of arterial hypertension and lipid disorders [300]. The control rate of both arterial hypertension and lipid disorders in the overall population was $5.4 \%$ and in no age group, except for those aged 80 years and older, exceeded $10 \%$. It should be noted that the low control rate could result from an unsatisfactory percentage of patients receiving pharmacological treatment - of patients with concomitant arterial hypertension and lipid disorders, only $59 \%$ received hypotensive treatment and only 31\% lipid-lowering therapy. Factors associated with control of arterial hypertension and lipid disorders have also been identified. Multivariate analysis demonstrated that higher education and diagnosed cardiovascular disease were associated with achievement of therapeutic goals, whereas smoking was associated with worse control of arterial blood pressure and LDL-C concentration [300] (Section 13).

Treatment of arterial hypertension should be carried out in accordance with the Polish Society of Hypertension (PSH) 2019 guidelines, in which the 2018 ESC/ESH guidelines have been adapted. The need to use combination therapy, based on fixeddose combinations (a two-component product in the $1^{\text {st }}$ step of the therapy and a three-component product in the $2^{\text {nd }}$ step), and to achieve lower arterial blood pressure values than previously accepted (i.e., 120-129/70-79 mm Hg) in patients below 65 years of age, should be emphasised [301, 302]. It has been demonstrated that simplified therapy with the use of fixed-dose combination products is associated with improved compliance [303]. Therefore, combination products containing antihypertensive agent(s) and a statin are a valuable supplement to the therapy. Combination products available in Poland containing two antihypertensive agents and a statin are based on optimum and consistent with the guidelines combinations of long-acting antihypertensive agents and a potent, long-acting statin; therefore, they can be used once daily in the morning [301].

Special populations should also be taken into consideration, which should be more often and more closely than individuals in the general population controlled for risk factors, including arterial blood pressure and lipid profile parameters:

- patients with arterial hypertension and target organ damage (left ventricular hypertrophy, moderate albuminuria) [301, 302, 304],
- women with a history of pre-eclampsia or gestational hypertension [305],

- young people with isolated systolic hypertension [306],

- patients with obstructive sleep apnoea [306],

- patients with primary hyperaldosteronism [306],

- patients with atherosclerotic renal artery stenosis [306].

The patient groups listed above are at increased cardiovascular risk; therefore, therapeutic interventions should be earlier and more intensive in these groups.

\section{KEY POINTS TO REMEMBER}

- Coexistence of arterial hypertension and hypercholesterolaemia is very common. The level of control of arterial hypertension and hypercholesterolaemia is definitely too low.

- Treatment of arterial hypertension is based on combination therapy with fixed-dose combination products. Combination products containing an anti-hypertensive agent (or agents) and a statin are available; their use may lead to improved control of arterial hypertension and hypercholesterolaemia by simplifying therapy and increasing compliance (adherence).

- Several groups of patients have been identified which, due to their cardiovascular risk being higher than that assessed using classic risk scores, require careful control of arterial blood pressure and cholesterol concentration, as well as earlier and more intensive therapeutic decisions, e.g. patients with arterial hypertension and target organ damage, women with a history of gestation-related hypertensive states, young individuals with isolated systolic hypertension, and patients with secondary forms of arterial hypertension.

\subsection{Ischaemic heart disease}

\subsubsection{Stable coronary syndromes}

All patients with documented coronary atherosclerosis are at very high cardiovascular risk or extreme cardiovascular risk as defined previously. The rules for management of lipid disorders in this group of patients remain the same as in other patients at very high and/or extreme risk. In patients at very high cardiovascular risk, the treatment goal is to reduce LDL-C concentration by $\geq 50 \%$ from baseline and achieve a target LDL-C concentration of $<1.4 \mathrm{mmol} / /(<55 \mathrm{mg} / \mathrm{dl})$. In patients at extreme cardiovascular risk, reduction 
M. Banach, P. Burchardt, K. Chlebus, P. Dobrowolski, D. Dudek, K. Dyrbuś, M. Gąsior, P. Jankowski, J. Jóźwiak, L. Kłosiewicz-Latoszek, I. Kowalska, M. Małecki, A. Prejbisz, M. Rakowski, J. Rysz, B. Solnica, D. Sitkiewicz, G. Sygitowicz, G. Sypniewska, T. Tomasik, A. Windak, D. Zozulińska-Ziółkiewicz, B. Cybulska

of LDL-C concentration by $\geq 50 \%$ from baseline should also be aimed at (although not considered the treatment goal), with a target concentration of $<40 \mathrm{mg} / \mathrm{dl}$ (1 mmol/l) (Tables X and XI).

The mainstay of treatment are potent statins (atorvastatin and rosuvastatin), administered in high doses, allowing for the above-mentioned reduction by $\geq 50 \%$ and achievement of the treatment goals (Table XVIII). In patients undergoing coronary angioplasty $(\mathrm{PCI})$ or coronary artery bypass grafting (CABG), administration of a loading statin dose before the planned procedure should be considered, and the treatment goals remain the same as discussed above.

Despite their high efficacy, even with the most potent statins used in monotherapy the patients are less and less likely to achieve their target lipid concentrations (at present, the proportion does not exceed 40\%) [179]. If high-intensity statin therapy remains ineffective, combination therapy with agents of a different mechanism of action should always be considered. The primary agent used in combination treatment is ezetimibe which has already been available for 4 years in the form of generic products and combination products with statins (polypills). If combination treatment with a statin and ezetimibe remains ineffective, PCSK9 inhibitors should be added. In case of intolerance of high-dose statins, a low dose of a statin should be used in combination with other agents. Atorvastatin and rosuvastatin may also be used every $2-3$ days with significant reduction of LDL-C concentration [307]. In case of complete statin intolerance, treatment with ezetimibe, bempedoic acid, or PCSK9 inhibitors//inclisiran, or even nutraceuticals as monotherapy or in combination therapy, should be considered.

In the current guidelines [9], much lower LDL-C target concentrations in comparison with the pre- vious guidelines should be noticed. This position was based on the results of trials in which combinations of statins with ezetimibe, or statins with PCSK9 inhibitors and/or ezetimibe were used. Historically, the first large study in patients with recent ACS who received more intensive lipid-lowering therapy with simvastatin and ezetimibe (IMPROVE-IT) demonstrated significantly higher efficacy of combination therapy and improved long-term outcomes in comparison with statin treatment alone [297]. In the 7-year follow-up period, long-term maintenance of low LDL-C concentration $(<55 \mathrm{mg} / \mathrm{dl}(<1.4 \mathrm{mmol} / \mathrm{l}))$ was not associated with any obvious adverse effects [297]. New recommendations were affected by even better outcomes of LDL-C lowering therapies that have been achieved with addition of PCSK9 inhibitors to conventional treatment. In combination with high or maximum tolerated statin doses and/or ezetimibe, alirocumab and evolocumab reduced LDL-C concentration by $46-73 \%$ in comparison with placebo and by $30 \%$ in comparison with ezetimibe [308]. In patients who cannot use statins, PCSK9 inhibitors administered in combination with ezetimibe reduce $\mathrm{LDL}-\mathrm{C}$ concentration by more than $60 \%$ and significantly reduce atherosclerotic plaque volume [309]. Both alirocumab and evolocumab have been shown to effectively reduce $\mathrm{LDL}-\mathrm{C}$ concentration in patients at high and very high (as well as extreme) cardiovascular risk, including those with diabetes, inflammation, hyper-Lp(a), peripheral vascular disease/multiple level atherosclerosis, after several vascular events, post-stroke, and the elderly [49]. In addition, it was found that maintenance of low LDL-C concentration (even $<20 \mathrm{mg} / \mathrm{dl}(<0.5 \mathrm{mmol} / \mathrm{l}))$ for several years did not cause any worsening of cognitive function or a higher risk of dementia in

Table XXX. Recommendations for target LDL cholesterol values in patients with stable coronary syndrome at very high or extreme risk

\begin{tabular}{|c|c|c|}
\hline Recommendations & Class & Level \\
\hline $\begin{array}{l}\text { In secondary prevention patients at very high risk it is recommended to reduce LDL-C } \\
\text { concentration by } \geq 50 \% \text { from baseline }{ }^{1} \text { with LDL-C concentration of }<1.4 \mathrm{mmol} / /(<55 \mathrm{mg} / \mathrm{dl}) \\
\text { recommended as the target value. }\end{array}$ & 1 & A \\
\hline $\begin{array}{l}\text { In patients (1) with ASCVD who had a second vascular event within } 2 \text { years (not necessarily of } \\
\text { the same type as the first), (2) after ACS and with peripheral vascular disease or polyvascular } \\
\text { disease }^{2} \text { (multilevel atherosclerosis), (3) post ACS with multivessel coronary disease, (4) post ACS } \\
\text { with familial hypercholesterolaemia, and (5) post ACS in a patient with diabetes and at least } \\
\text { one additional risk factor (elevated Lp(a) }>50 \mathrm{mg} / \mathrm{dl} \text { or hsCRP }>3 \mathrm{mg} / \text { or chronic kidney disease } \\
\left(\text { (eGFR }<60 \mathrm{ml} / \mathrm{min} / 1.73 \mathrm{~m}^{2}\right) \text { ) despite maximum tolerated statin therapy, LDL-C concentration } \\
<1.0 \mathrm{mmol} / \mathrm{l}(<40 \mathrm{mg} / \mathrm{dl}) \text { may be considered the target value. }\end{array}$ & IIb & B \\
\hline $\begin{array}{l}\text { Routine pre-treatment or loading (in patients receiving chronic statins) with a high dose of statin } \\
\text { should be considered in patients undergoing } \mathrm{PCI} \text { for ACS or elective } \mathrm{PCI} \text {. }\end{array}$ & Ila & B \\
\hline
\end{tabular}


treated individuals, and even led to a reduction in all-cause mortality and a significant reduction in further cardiovascular events [310].

The algorithms for management of patients with chronic stable coronary syndromes are presented in Table XXX.

\section{KEY POINTS TO REMEMBER}

- Statins are the first-line treatment in patients with stable coronary syndrome.

- In every patient, and primarily after $\mathrm{PCl}$ or CABG, one should aim to achieve LDL-C concentration $<1.4 \mathrm{mmol} / \mathrm{l}(<55 \mathrm{mg} / \mathrm{dl})$.

- In treatment of a patient after percutaneous coronary intervention, with regard to LDL-C concentration, the rules of "the lower the better", "the earlier the better", and "the longer the better" should be applied.

- In each patient planned for PCI or CABG, a loading dose of a potent statin should be considered.

- In each patient meeting the definition of extreme cardiovascular risk, one should aim to achieve LDL-C concentration $<1.0 \mathrm{mmol} / \mathrm{l}$ (<40 mg/dl).

- After percutaneous coronary intervention, each patient should undergo lifelong lipid-lowering therapy.

- A large percentage of patients after percutaneous coronary intervention require combination treatment; in some of them it should be initiated already during hospitalisation (Section 9.8) in order to achieve the treatment goal.

- Fixed combination products (polypills) available on the market are very helpful in treatment, mainly as a tool to improve the patient's therapy adherence.

\subsubsection{Acute coronary syndromes}

Following an acute coronary syndrome (ACS), patients are at increased risk of recurrent cardiovascular events, which in Poland may affect up to $20 \%$ of patients within 1 year after the incident. In all ACS patients without contraindications or intolerance to statins, treatment with a potent statin in a high dose (atorvastatin 80 or rosuvastatin $40 \mathrm{mg}$ daily) is recommended, i.e. should be continued or initiated as soon as possible, regardless of baseline LDL-C concentration. If the target LDL-C concentration has not been achieved after 4-6 weeks of statin therapy at the highest tolerated dose, it is recommended to start combination therapy with a statin and ezetimibe. If the target LDL-C value has not been achieved after another 4-6 weeks, addition of a PCSK9 inhibitor is recommended. It means that treatment with PCSK9 inhibitors can be initiated as early as after 8 weeks. In patients who develop ACS and have not achieved their target LDL-C concentration despite the use of a statin in the highest tolerated dose in combination with ezetimibe, addition of a PCSK9 inhibitor immediately after the event (if possible, even during hospitalisation) should be considered. Treatment with ezetimibe in combination with a statin during hospitalisation is currently the subject of a vigorous debate. Although no trials are available to support the clinical efficacy of this therapy, based on the rules of the lower the better and the earlier the LDL-C goal is achieved the better, the authors of these guidelines recommend that combination therapy with a statin and ezetimibe may be considered during hospitalisation, in particular in patients (1) already receiving intensive/optimal therapy, (2) in statin-treated patients with still high LDL-C concentration (> $100 \mathrm{mg} / \mathrm{dl}$ ), (3) in untreated patients with baseline LDL-C concentration too high to achieve their target LDL-C concentration after 4-6 weeks of statin treatment (>120 mg/dl), (4) in extreme-risk patients, and (5) in patients with partial or complete statin intolerance (Table XXXI, Section 9.8, Figures 6-9).

As in patients with stable coronary syndrome, in those undergoing percutaneous coronary intervention for ACS, routine initial treatment or loading (in patients receiving chronic statins) with a high dose of statin should be considered. Such treatment in ACS reduces infarction size [311]. Initial treatment with a statin also reduces the risk of contrast-induced acute kidney injury after coronary angiography or $\mathrm{PCl}$.

If a statin-based regimen is not tolerated at any dose (even after rechallenge), the use of ezetimibe in monotherapy or in combination with PCSK9 inhibitors should be considered [312]. The algorithms for management of patients with myocardial infarction, including those with extreme cardiovascular risk, are presented in Figures 6-9. 
M. Banach, P. Burchardt, K. Chlebus, P. Dobrowolski, D. Dudek, K. Dyrbuś, M. Gąsior, P. Jankowski, J. Jóźwiak, L. Kłosiewicz-Latoszek, I. Kowalska, M. Małecki, A. Prejbisz, M. Rakowski, J. Rysz, B. Solnica, D. Sitkiewicz, G. Sygitowicz, G. Sypniewska, T. Tomasik, A. Windak, D. Zozulińska-Ziółkiewicz, B. Cybulska

Table XXXI. Recommendations for lipid-lowering therapy in patients with acute coronary syndromes (ACS) Recommendation Class Level

In all ACS patients without contraindications or a history of confirmed intolerance, it is recommended to initiate or continue high-dose statin therapy as early as possible, regardless of baseline LDL-C concentration.

Lipid concentration should be re-evaluated 4-6 weeks after ACS to determine if reduction of LDL-C concentration $\geq 50 \%$ from baseline and the target LDL-C concentration of $<1.4 \mathrm{mmol} / \mathrm{l}(<55 \mathrm{mg} / \mathrm{dl})$ have been achieved. In such cases, the safety of treatment should be evaluated, and statin doses adjusted accordingly.

If the target LDL-C values have not been achieved after 4-6 weeks of treatment with the maximum tolerated statin dose, it is recommended to combine a statin with ezetimibe.

In post-ACS patients, especially those (1) already receiving intensive/optimal treatment, (2) statintreated with still high LDL-C concentration (> $100 \mathrm{mg} / \mathrm{dl}$ ), (3) in untreated patients with baseline LDL-C concentration too high to achieve their target LDL-C concentration after 4-6 weeks of statin treatment (>120 mg/dl), including patients with familial hypercholesterolaemia, (4) in patients at extreme cardiovascular risk, and (5) with partial or complete statin intolerance, initiation of combination therapy with a statin and ezetimibe may be considered during hospitalisation.

If the target LDL-C values have not been achieved after 4-6 weeks of treatment with the maximum tolerated statin dose in combination with ezetimibe, it is recommended to add a PCSK9 inhibitor.

In patients with confirmed statin intolerance or in whom statins are contraindicated, the use of ezetimibe should be considered.

In patients who develop ACS and have not achieved their target LDL-C concentration despite the use of a statin in the highest tolerated dose in combination with ezetimibe, addition of a PCSK9 inhibitor immediately after the event (during hospitalisation due to ACS, if possible) should be considered.

LDL-C - low density lipoprotein cholesterol, ACS - acute coronary syndrome, PCSK9 - subtilisin/kexin type 9 proprotein convertase.

\section{KEY POINTS TO REMEMBER}

- In each patient with acute coronary syndrome, the maximum tolerated statin dose should be initiated as soon as possible, regardless of the lipid profile.

- In each patient with acute coronary syndrome, administration of a loading dose of a potent statin before $\mathrm{PCl}$ should be considered.

- In each patient post-acute coronary syndrome, one should aim to achieve LDL-C concentration $<1.4 \mathrm{mmol} / \mathrm{l}(<55 \mathrm{mg} / \mathrm{dl})$ as early as possible to effectively prevent further events.

- In each patient meeting the definition of extreme cardiovascular risk, the treatment goal should be LDL-C concentration $<1.0 \mathrm{mmol} / \mathrm{l}(<40 \mathrm{mg} / \mathrm{dl})$.

- Lipid-lowering therapy in each post-ACS patient should be lifelong.

- A large proportion of post-ACS patients require combination therapy to achieve their treatment goal.

- Fixed combination products (polypills) available on the market are helpful in treatment, mainly as a tool to improve the patient's therapy adherence.

\subsection{Cerebral stroke}

The use of statins in primary prevention makes it possible to reduce the risk of ischaemic stroke by $22 \%$ [313]. Patients with a history of stroke or a transient ischaemic attack (TIA) are at a higher risk of another cerebral event (by as much as $40 \%$ ), but also of other major cardiovascular events [9]. Patients with atherosclerotic stroke require intensive lipid-lowering therapy, all the more so that the results of a meta-analysis of randomised trials involving more than 170,000 patients indicate that reduction of $\mathrm{LDL}-\mathrm{C}$ concentration by $1.0 \mathrm{mmol} / \mathrm{l}(38 \mathrm{mg} / \mathrm{dl})$ with statins decreases the risk of serious vascular events (myocardial infarction, coronary death, all-cause stroke, or coronary revascularization) by about $22 \%$, and all strokes by $17 \%$ [159]. Post-stroke patients should be treated as those with very high or extreme cardiovascular risk (as patients with multibed disease), and the treatment goal should be reduction of LDL-C concentration by $\geq 50 \%$ from baseline and achievement of the target LDL-C concentration of $<55 \mathrm{mg} / \mathrm{dl}(<1.4 \mathrm{mmol} / \mathrm{l})$ or $<40 \mathrm{mg} / \mathrm{dl}$ $(1 \mathrm{mmol} / \mathrm{l})$, respectively (Tables $X$ and $\mathrm{XI}$ ).

Individuals with haemorrhagic stroke often do not benefit from lipid-lowering therapy, and it may even be harmful if this form of stroke occurs in non-atherosclerotic patients [314]. However, it should be noted in this context that the lack of benefit in patients post haemorrhagic stroke is a different issue from the risk of stroke with inten- 
sive lipid-lowering therapy (statins or combination therapy, including PCSK9 inhibitors) and even extremely low LDL-C values achieved $(<20 \mathrm{mg} / \mathrm{dl})$. Available data from recent meta-analyses of randomised trials and observational studies do not confirm such an association [315-317].

\section{KEY POINTS TO REMEMBER}

- In primary prevention of stroke, statin therapy should be recommended in patients with other atherosclerotic diseases.

- In patients with a history of atherosclerotic stroke or TIA, intensive statin therapy or intensive lipid-lowering combination therapy are the mainstay of treatment; the aim is to achieve the treatment LDL-C goal as soon as possible.

- No causal relationship between intensive lipid lowering therapy (statins, combination therapy including PCSK9 inhibitors) and in consequence very low LDL-C concentration, and the risk of haemorrhagic stroke has been confirmed.

\subsection{Peripheral vascular disease}

Atherosclerotic lesions are the predominant cause (>95\%) of chronic lower limb ischaemia and amputation. Symptoms of lower limb ischaemia in the form of intermittent claudication may sometimes be the first clinical manifestation of systemic atherosclerosis [9]. Peripheral arterial atherosclerotic lesions are an independent risk factor for cardiovascular events, including ACS and stroke. To improve prognosis, in a patient with peripheral arterial atherosclerosis active pharmacological and non-pharmacological management should be urgently initiated [10]. In this group of patients, lipid-lowering therapy not only contributes to inhibition of atherosclerosis progression in the peripheral arterial bed, but reduces the risk of serious events in other vascular beds (i.e., coronary, cerebral) [9]. That is why not only peripheral vascular disease, but multibed disease, defined as the involvement of at least two out of three vascular beds, has been recently discussed. Especially now, in the era of innovative therapies, analyses are available indicating that intensive lipid-lowering therapy, especially combination therapy with the use of PCSK9 inhibitors, may translate into a highly significant reduction in the risk of patients with multibed disease, and the more advanced the disease (more beds involved), the greater the benefits. Data concerning alirocumab indicate that such treatment may translate into an absolute risk reduction by up to $13 \%$, with the benefit seen in every $7-8$ patient $(N N T=8)$ [113].
A meta-analysis of 18 clinical trials involving more than 10,000 patients with lower limb atherosclerosis has demonstrated that lipid-lowering therapy decreases the risk of cardiovascular events by nearly $20 \%$ and reduces all-cause mortality by $14 \%$ [314]. Patients with peripheral atherosclerotic disease (multibed disease) should be treated as patients with very high or extreme cardiovascular risk, and the treatment goal should be reduction of LDL-C concentration by $\geq 50 \%$ from baseline and achievement of the target LDL-C concentration of $<55 \mathrm{mg} / \mathrm{dl}(<1.4 \mathrm{mmol} / \mathrm{l})$ or $<40 \mathrm{mg} / \mathrm{dl}$ $(1 \mathrm{mmol} / \mathrm{l})$, respectively (Tables $X$ and $\mathrm{XI}$ ).

\section{KEY POINTS TO REMEMBER}

- In patients with peripheral atherosclerosis, treatment goals and management are the same as in other patients with very high/ extreme cardiovascular risk.

- In patients with peripheral vascular disease, non-pharmacological lifestyle modification is essential, including non-smoking and increased regular physical activity (Table XV, Section 8.5), including march training (which not only has a positive effect on lipoprotein concentration, but stimulates development of collateral circulation and improves metabolism of ischaemic muscles).

- In a patient with risk factors and cardiovascular disease, one should always bear in mind the assessment and monitoring of peripheral vascular bed for atherosclerotic lesions (ankle-brachial index (ABI), Doppler ultrasonography).

\subsection{Heart failure}

Numerous available studies have demonstrated that treatment with statins in patients with ischaemic heart disease as well as in primary prevention reduces the risk of heart failure $[8,9$, 318]. It has also been demonstrated that highdose statins used in these groups reduce the risk of hospitalisation due to heart failure in comparison with low doses [318]. Patients with advanced chronic heart failure usually have lower cholesterol concentrations [9, 318]. In contrast to those without heart failure, low cholesterol concentration in patients with heart failure is associated with poorer prognosis. Although the results of observational studies suggest a beneficial effect of statins on the risk of death in patients with heart failure, this effect has not been confirmed in interventional studies (despite numerous methodological errors of these studies). However, the safety of statins in patients with heart failure has been demonstrated [318-321]. 
M. Banach, P. Burchardt, K. Chlebus, P. Dobrowolski, D. Dudek, K. Dyrbuś, M. Gąsior, P. Jankowski, J. Jóźwiak, L. Kłosiewicz-Latoszek, I. Kowalska, M. Małecki, A. Prejbisz, M. Rakowski, J. Rysz, B. Solnica, D. Sitkiewicz, G. Sygitowicz, G. Sypniewska, T. Tomasik, A. Windak, D. Zozulińska-Ziółkiewicz, B. Cybulska

It has been suggested that the role of lipid-lowering therapy may vary slightly depending on the left ventricular systolic function, which may be due to different aetiology and different mechanisms leading to development of heart failure [320-322]. Opinions based on analysis of pathogenetic mechanisms of heart failure and the mechanism of action of statins, but not the results of large clinical trials, indicate potentially greater benefits in patients with heart failure with preserved ejection fraction. Statin therapy has not been demonstrated to reduce the risk of death in patients with heart failure with reduced ejection fraction; however, a meta-analysis of 12 placebo-controlled randomised trials indicates that statin therapy may be associated with a $12 \%$ reduction in the risk of hospitalisation due to heart failure (confidence interval: 8-16\%) [323]. No results from randomised trials are available to evaluate the efficacy of statins in patients with heart failure with preserved ejection fraction. However, analyses of observational studies suggest that expectation of such benefits is reasonable [320].

In summary, according to current evidence, statins are not recommended when heart failure is the only indication. However, it seems reasonable to continue statin therapy in patients who develop ischaemic heart failure. An indirect comparison of the efficacy of lipophilic and hydrophilic statins in patients with heart failure indicates lower risk of cardiovascular events in the group receiving lipophilic statins (atorvastatin, pitavastatin, simvastatin) than in the hydrophilic rosuvastatin group [324]. At present, still no data on the efficacy of PCSK-9 inhibitors in patients with heart failure are available. Treatment with unsaturated omega-3 acids may bring little benefit, as has been demonstrated in the GISSI-HF study (a reduction in the risk of death by $9 \%$ ) [325], although the study included a relatively small number of patients with heart failure of any aetiology, and only $1 \mathrm{~g}$ of a mixture of omega- 3 acids daily was applied, which, in view of our current knowledge, is an ineffective dose in terms of achieving a significant reduction of cardiovascular events (currently at least $2 \mathrm{~g}$ daily is recommended, with the target of $4 \mathrm{~g}$ ) [325] (Tables XIII and XIV, Sections 8.4 and 9.9).

\section{KEY POINTS TO REMEMBER}

- Lipid-lowering therapy with statins should not be applied if heart failure is the only indication.

- Statin therapy should be continued in patients with ischaemic heart disease who develop heart failure. Dyslipidemic therapy discontinuation is one of the most common errors observed in the therapy of patients with heart failure.

\subsection{Chronic kidney disease}

In patients with chronic kidney disease, early evaluation of the complete lipid profile is recommended. In these patients, atherogenic dyslipidaemia is usually observed, often with normal or slightly elevated LDL-C and elevated Lp(a) concentration [326]. Cardiovascular risk categorisation is based on the stage of chronic kidney disease, cholesterol concentration, and other clinical and demographic characteristics. Individuals with advanced chronic kidney disease are at very high $\left(\right.$ eGFR $\left.<30 \mathrm{ml} / \mathrm{min} / 1.73 \mathrm{~m}^{2}\right)$ or high (eGFR 30$60 \mathrm{ml} / \mathrm{min} / 1.73 \mathrm{~m}^{2}$ ) cardiovascular risk (Table V).

In patients with chronic kidney disease, direct relationship between cholesterol concentration and cardiovascular risk is less pronounced than in general population [327]. The results of a meta-analysis of 28 randomised trials indicate that relative benefits of lipid-lowering therapy decrease with progression of chronic kidney disease. The relative risk of a vascular event associated with a reduction of LDL-C concentration by $1 \mathrm{mmol} / \mathrm{l}$ with a statin is 0.78 (95\% Cl: $0.75-0.82$ ) in patients with eGFR $\geq 60 \mathrm{ml} /$ $\mathrm{min} / 1.73 \mathrm{~m}^{2}$ and 0.76 (0.70-0.81), 0.85 (0.75-0.96), 0.85 (0.71-1.02), and $0.94(0.79-1.11)$ in those with eGFR in the range of $45-60 \mathrm{ml} / \mathrm{min} / 1.73 \mathrm{~m}^{2}$, 30-45 ml/min/1.73 $\mathrm{m}^{2}$, $30 \mathrm{ml} / \mathrm{min} / 1.73 \mathrm{~m}^{2}$ not receiving dialysis therapy, and those receiving dialysis therapy, respectively ( $p$ for trend 0.008) [328]. Similar results have been obtained by other authors, indicating no benefit in patients with endstage renal disease and in those receiving dialysis [329], no or minor effect on specific parameters of renal function (depending on treatment duration), and decreased effect of reduction of specific lipid fractions in this group of patients [330, 331]. This can be explained in a number of ways, one of which is the lack of real possibility of statin effect due to increased inflammation and vascular calcification; it is also worth mentioning that (severe) chronic kidney disease so strongly modifies cardiovascular risk that it is no longer possible to significantly reduce this risk with statin treatment.

Similar relationships are observed when considering the association of statin use with the risk of other endpoints, including all-cause mortality. This may be due to relatively higher non-vascular mortality in patients with more advanced renal disease, as well as difficulties in correct diagnosis of vascular events due to their atypical symptoms in patients with kidney failure [332]. As mentioned above, no effect of lipid-lowering therapy on prognosis in patients receiving dialysis therapy has been demonstrated, whereas available evidence justifies the recommendation of statins in kidney transplant patients [333].

Ezetimibe in combination with a statin reduced the risk of cardiovascular events in patients with 
Table XXXII. Recommendations on treatment of lipid disorders in patients with chronic kidney disease Recommendation Class Level

Patients with chronic kidney disease are at very high (those with eGFR $<30 \mathrm{ml} / \mathrm{min} / 1.73 \mathrm{~m}^{2}$ ) or high (eGFR 30-60 ml/min/1.73 $\mathrm{m}^{2}$ ) cardiovascular risk.

In patients not requiring dialysis therapy, intensive lipid-lowering therapy is recommended, with a statin in the first line, followed by a combination of a statin with ezetimibe.

In patients not requiring dialysis therapy, combination with a PCSK9 inhibitor should be considered

if the LDL-C goal has not been achieved with the maximum tolerated dose of a statin and ezetimibe.

If a patient requires initiation of dialysis therapy, it is recommended to continue their previous therapy with a statin or a statin and ezetimibe.

Initiation of lipid-lowering agents in patients requiring dialysis is not recommended in the absence of atherosclerotic cardiovascular disease.

chronic kidney disease [334], although the SHARP study did not provide clear answers, despite a demonstrated $17 \%$ reduction in the primary endpoint. In the study, methodological errors were made, consisting in modification of the endpoint during the study (so-called major atherosclerotic events were assessed), or the lack of a control group, i.e. individuals receiving statin monotherapy; therefore, it is difficult to draw conclusions from the results of this study alone [335].

It has been demonstrated that in selected groups of patients with chronic kidney disease, fibrate therapy may reduce the risk of cardiovascular events, but not all-cause mortality [336]. However, while statins have beneficial effects on glomerular filtration and proteinuria, the use of fibrates may be associated with increased creatinine concentration [336]. High efficacy of PCSK9 inhibitors in terms of lowering LDL-C concentration and in reducing the risk of cardiovascular events in patients with chronic kidney disease (with eGFR $\geq 30 \mathrm{ml} / \mathrm{min} / 1.73 \mathrm{~m}^{2}$ ) has been demonstrated, similar to their efficacy in other patient groups [337, 338]. Interestingly, studies with inclisiran suggest that this may be the first lipid-lowering therapy that can be used in patients with end-stage renal disease with eGFR $15-30 \mathrm{ml} /$ $\mathrm{min} / 1.73 \mathrm{~m}^{2}$ [339].

The safety of lipid-lowering therapy is particularly important in advanced stages of chronic kidney disease. The risk of adverse events depends on blood concentration of the agent or its metabolites, affected by both the dose and renal function. In patients with chronic kidney disease, increased risk of drug interactions is observed. It is reasonable to prefer agents that are predominantly metabolised and eliminated by the liver (atorvastatin, fluvastatin, pitavastatin, ezetimibe) [340]. In certain studies, comparing the efficacy and safety of atorvastatin and rosuvastatin in patients with chronic kidney disease, more favourable effects of atorvastatin have been demonstrated [341].

In general, the target LDL cholesterol concentration in patients with chronic kidney disease does not differ from that in other patient groups and depends primarily on the cardiovascular risk category. Due to safety concerns, gradual escalation of lipid-lowering therapy should be considered, especially in patients with advanced chronic kidney disease [340]. First-choice lipid lowering agents in patients with chronic kidney disease should be statins. Certain analyses suggest that in this class of agents, only atorvastatin and rosuvastatin have proven effect on the risk of cardiovascular events in people with advanced chronic kidney disease [342]. In addition, atorvastatin less often requires dose adjustment due to renal function. Concerns about safety of the applied treatment may justify the preference of low-dose statin therapy combined with ezetimibe over high-dose statin monotherapy [9]. Concomitant use of statins and fibrates in patients with chronic kidney disease is not recommended [340]. It should be emphasised that available data are still insufficient, and recommendations are based on just a few large, randomised trials, meta-analyses, and post-hoc analyses of subgroups of patients in large clinical trials.

In conclusion, patients with advanced chronic kidney disease are at very high (those with eGFR $<30 \mathrm{ml} / \mathrm{min} / 1.73 \mathrm{~m}^{2}$ ) or high (eGFR 30-60 ml/ $\min / 1.73 \mathrm{~m}^{2}$ ) cardiovascular risk. Intensive lipid-lowering therapy is recommended in patients not requiring dialysis. Statins are first-choice agents; combination therapy with ezetimibe and PCSK9 inhibitors should be considered in patients who do not achieve their treatment goal. In patients without atherosclerotic cardiovascular diseases who receive dialysis therapy, lipid-lowering agents should be initiated with great caution or not initiated at all (Table XXXII).

\subsection{Children and adolescents}

With respect to children and adolescents, no credible data on the efficacy and safety of longterm treatment of lipid disorders are available. There is a common belief that treatment should be 
M. Banach, P. Burchardt, K. Chlebus, P. Dobrowolski, D. Dudek, K. Dyrbuś, M. Gąsior, P. Jankowski, J. Jóźwiak, L. Kłosiewicz-Latoszek, I. Kowalska, M. Małecki, A. Prejbisz, M. Rakowski, J. Rysz, B. Solnica, D. Sitkiewicz, G. Sygitowicz, G. Sypniewska, T. Tomasik, A. Windak, D. Zozulińska-Ziółkiewicz, B. Cybulska

started in childhood, but the time point of treatment initiation is usually arbitrary [343]. Delaying appropriate treatment until adult age, especially in children at risk, can lead to development of cardiovascular disease at an early age or in young adults. Recommendations with this regard are largely extrapolated from studies on familial hypercholesterolaemia and from studies in adults [343].

The aim of treatment of dyslipidaemia in children and adolescents is to achieve LDL-C concentration $<130 \mathrm{mg} / \mathrm{dl}(<3.4 \mathrm{mmol} / \mathrm{l}$, below the $95 \mathrm{th}$ percentile) or its reduction by $30-50 \%$. In children with diabetes mellitus or $\mathrm{FH}$ and a family history of coronary artery disease before 40 years of age, it is recommended to achieve LDL-C concentration $<100 \mathrm{mg} / \mathrm{dl}(<2.6 \mathrm{mmol} / \mathrm{l})$ or its reduction by at least 50\% [344-346]. So far, no similar cut-off points have been established for non-HDL-C or TG.

Treatment of dyslipidaemia in children and adolescents involves broad health education, lifestyle modification, and pharmacotherapy. Education should apply to all members of the child's family. The scope and method of provided information should take into account the child's age and the effectiveness of communication with caregivers. It is necessary to plan enough time to provide information and, if necessary, to complete this task even during numerous visits. Information should concern the causes and consequences of lipid disorders, cardiovascular risk factors, and principles and importance of therapy. Personalised counselling should be applied, and views, concerns and doubts of the young patient and their family should be openly discussed. Decisions concerning management should also be made collectively. It is reasonable to minimise the risk of providing contradictory advice, especially by doctors and nurses of the same practice, but also by specialist medical staff. The educational tasks are facilitated by previously developed, appropriate therapeutic relationships and awareness of psychosocial circumstances, both those facilitating (e.g., positive emotions, high social status) and hindering lifestyle modification (stress, tension in the family, social isolation) [8, 344, 345]. Lifestyle modifications include the introduction and consolidation of healthy dietary habits, focus on increasing physical activity, normalisation of body weight, prevention of passive smoking, and smoking and alcohol abstinence in adolescents. Lifestyle modifications should be introduced as early as at 2 years of age in every child with LDL-C concentration > $100 \mathrm{mg} / \mathrm{dl}(2.6 \mathrm{mmol} / \mathrm{l})$ and/or elevated TG concentration (children $<10$ years with TG $\geq 100 \mathrm{mg} / \mathrm{dl}(\geq 1.1 \mathrm{mmol} / \mathrm{l})$; children 10 19 years with $\mathrm{TG} \geq 130 \mathrm{mg} / \mathrm{dl}[1.5 \mathrm{mmol} / \mathrm{l}])$ [344, 345] (Table XXXIII).

Dietary management should be initiated in every child with dyslipidaemia above 2 years of age. Dietary interventions at an earlier age should be introduced by an experienced physician at a specialist clinic, with the assistance of a dietician. If possible, a dietician should be involved in the entire treatment process, especially as all dietary changes require careful monitoring of the child's development [347]. If the effect of dietary treatment supervised by the family physician is insufficient, the patient and the family should be referred for dietary consultation (which extends beyond the care guaranteed by the NHF) or to a specialist clinic (cardiology, metabolic diseases) that provides such services. Elevated LDL-C concentration is an indication for: reduction of the energy supply from fats to $30 \%$, including $<7 \%$ from saturated fats (the less the better), replacement of saturated fats with unsaturated fats (primarily polyunsaturated), and reduction of cholesterol intake < 200 mg/day [9, 348] (Section 8). Clinical studies have confirmed normal development of children undergoing dietary fat restriction provided that their needs for energy and micronutrients are met [9, 111, 348, 349]. Increased dietary fibre intake is recommended (in the amount of about $10 \mathrm{~g}$ at 5 years of age, $15 \mathrm{~g}$ at 10 , and $20 \mathrm{~g}$ at the age of 15), as well as consumption of sea fish, vegetables, fruits, nuts and seeds, skimmed milk, and introduction of plant sterols and stanols (up to $2 \mathrm{~g} /$ day) [345, 350]. Increased TG concentration is an indication to reduce the consumption of monosaccharides, to increase the intake of fibre and polysaccharides, and to reduce body weight [351].

Parents should be motivated to significantly limit or prohibit watching TV by children under 2 years of age. Older children should be advised to limit the time spent before a TV or computer screen to $2 \mathrm{~h} /$ day, if possible, and to increase their physical activity to 90 min of exercise per day [347, 352].

Pharmacotherapy should be initiated after 6 months of lifestyle modification if treatment goals have not been achieved. Its long-term efficacy and safety have not been established. Statins are well tolerated; especially as very high doses are seldom used in the paediatric population [353]. The values at which pharmacotherapy is recommended in children and adolescents $\geq 10$ years of age are presented in Table XXXIV.

Statin therapy may be initiated by a family physician in children $\geq 10$ years of age (except for children with $\mathrm{FH}$, in whom the Forum of Lipid Experts in Poland recommends the use of statins $>8$ years of age (accumulating data support lowering of this age even to 6 years), and in children with homozygous $\mathrm{FH}<8$ years of age with LDL-C concentration > $500 \mathrm{mg} / \mathrm{dl}(12.9 \mathrm{mmol} / \mathrm{l}))$ [344]. Results of two measurements (performed 2 weeks to 3 months apart) in the fasting state and assessment of cardiovascular risk factors 
Table XXXIII. Recommendations concerning lifestyle changes in children with lipid disorders Recommendations Class Level

In all children aged $>2$ years and adolescents with lipid disorders, early lifestyle modification is recommended as first-line treatment.

An appropriate diet, increased physical activity, normalisation of body weight, and cessation of alcohol consumption and smoking are recommended.

Adequate (well-balanced) intake of nutrients and calories to ensure normal development and regular monitoring of the efficacy and safety of dietary interventions are recommended.

In primary cardiovascular prevention, initiation of pharmacotherapy is recommended after 6 months if lifestyle modification is not sufficient.

Statin therapy should be considered in children $\geq 10$ years of age without risk factors with persistent LDL-C > $190 \mathrm{mg} / \mathrm{dl}$, and in those with risk factors at LDL-C >160 mg/dl, beginning with a low statin dose and gradually increasing it.

In children with $\mathrm{FH}$, the initiation of pharmacotherapy may be considered at an earlier age, i.e., over the age of 8 years.

Table XXXIV. Initiation of pharmacotherapy in children and adolescents, risk factors and lipid concentration

With one high ${ }^{1}$ risk factor and two intermediate ${ }^{2}$ risk factors, with a family history of early cardiovascular disease (before 55 years of age) LDL-C $\geq 160 \mathrm{mg} / \mathrm{dl}(4.2 \mathrm{mmol} / \mathrm{l})$

With diabetes or with $\mathrm{FH}$ $\mathrm{LDL}-\mathrm{C} \geq 130 \mathrm{mg} / \mathrm{dl}(3.4 \mathrm{mmol} / \mathrm{l})$

Without or with risk factors

TG $\geq 200 \mathrm{mg} / \mathrm{dl}(2.2 \mathrm{mmol} / \mathrm{l})$

${ }^{1}$ High risk factors: hypertension requiring pharmacotherapy, renal failure, BMI > 97 percentile. ${ }^{2}$ Intermediate risk factors: arterial hypertension without pharmacotherapy, HDL $<1.0 \mathrm{mmol} / \mathrm{l}$ (40 mg/dl), BMI 95-97 percentile, chronic inflammatory disease (rheumatoid arthritis, systemic lupus erythematosus), nephrotic syndrome.

should be taken into account. Treatment starts with the lowest available dose, administered once daily in the evening [344]. The dose should be increased slowly, depending on the therapeutic effect, and the occurrence of possible adverse reactions should be monitored. The activity of aminotransferases and creatine kinase should be assessed prior to treatment [8, 344, 354]. Treatment with ezetimibe should be initiated under the supervision of a physician at a specialist clinic. The safety and efficacy of this agent in patients under the age of 17 have not been established, although there is also no evidence of any risk associated with such treatment. No precise dosing recommendations are available; in this case, based on data for the adult population, a dose of $10 \mathrm{mg} /$ day should be suggested. Principles of the use of new therapeutic options, i.e., mipomersen [355] or PCSK9 inhibitors, have not yet been established in children, although in treatment of familial hypercholesterolaemia, these agents provide some hope for the future, especially when studies with

Table XXXV. Agents used in treatment of lipid disorders in children and adolescents available in Poland

\begin{tabular}{|c|c|c|c|}
\hline Agent name(s) & $\begin{array}{c}\text { Doses } \\
\text { initial maximum }\end{array}$ & Possible adverse effects & Contraindications in children \\
\hline $\begin{array}{l}\text { Statins: } \\
\text { Simvastatin } \\
\text { Atorvastatin } \\
\text { Rosuvastatin } \\
\text { Pravastatin }\end{array}$ & $\begin{array}{c}5-40 \mathrm{mg} \\
5-40 \mathrm{mg} \\
5-20 \mathrm{mg} \\
5-20 \mathrm{mg} \text { before } \\
13 \text { years of age } \\
40 \mathrm{mg} \text { before } 18 \text { years } \\
\text { of age }\end{array}$ & $\begin{array}{c}\text { Elevated hepatic } \\
\text { aminotransferases, myalgia, } \\
\text { myopathy, rhabdomyolysis } \\
\text { (very rare), gastrointestinal } \\
\text { disorders, fatigue, insomnia, } \\
\text { headache, skin lesions, } \\
\text { peripheral neuropathy, lupus- } \\
\text { like syndrome }\end{array}$ & $\begin{array}{l}\text { Drug hypersensitivity, myopathy } \\
\text { due to statin administration, } \\
\text { active liver disease, high activity of } \\
\text { aminotransferases or } 3 \text { times the } \\
\text { upper limit of normal range during } \\
\text { statin administration, renal failure, } \\
\text { severe infections, serious trauma and } \\
\text { surgery, severe metabolic disorders, } \\
\text { hormonal, uncontrolled epileptic } \\
\text { seizures }\end{array}$ \\
\hline $\begin{array}{l}\text { Inhibitor of } \\
\text { cholesterol } \\
\text { absorption: } \\
\text { Ezetimibe }\end{array}$ & $10 \mathrm{mg}$ & $\begin{array}{l}\text { Myalgia, myopathy, fatigue, } \\
\text { headache, abdominal } \\
\text { pain, diarrhoea, flatulence, } \\
\text { dyspepsia, gastroesophageal } \\
\text { reflux disease, nausea, } \\
\text { elevated aminotransferase } \\
\text { activity }\end{array}$ & $\begin{array}{c}\text { Drug hypersensitivity, impaired } \\
\text { hepatic function, high } \\
\text { aminotransferase activity }\end{array}$ \\
\hline
\end{tabular}


M. Banach, P. Burchardt, K. Chlebus, P. Dobrowolski, D. Dudek, K. Dyrbuś, M. Gąsior, P. Jankowski, J. Jóźwiak, L. Kłosiewicz-Latoszek, I. Kowalska, M. Małecki, A. Prejbisz, M. Rakowski, J. Rysz, B. Solnica, D. Sitkiewicz, G. Sygitowicz, G. Sypniewska, T. Tomasik, A. Windak, D. Zozulińska-Ziółkiewicz, B. Cybulska

alirocumab and evolocumab have been completed in children with both homo- and heterozygous $\mathrm{FH}$. Available results from the Odyssey KIDS and HAUSER-RCT studies indicate the safety of PCSK9 inhibitors in the paediatric population and high efficacy (LDL-C reduction from 44.5 to $46 \%$ ) [356, 357]. In addition, studies with inclisiran in children with FH (ORION 13 and 16) were also initiated. Dosage of lipid-lowering agents in children as well as adverse effects and contraindications are presented in Table XXXV. If the target LDL-C concentration has not been achieved with lifestyle modification and maximum statin doses, combination of lipid-lowering agents may be considered [358].

In case of hypertriglyceridaemia, pharmacotherapy is usually reserved for patients with a high TG concentration (> $500 \mathrm{mg} / \mathrm{dl}$ - risk of acute pancreatitis, urgent reduction required) and genetic diseases (Section 9.9). The child should be referred to a specialist clinic for detailed diagnostics of elevated triglyceride concentration, and the possibility of treatment with statins, fibrates and omega-3 fatty acids should be considered $[359,360]$.

\section{KEY POINTS TO REMEMBER}

- Treatment of lipid disorders should be initiated in childhood, since delaying therapy to adulthood may lead to development of cardiovascular diseases as early at a young age.

- The aim of treatment of dyslipidaemia in children and adolescents is to achieve an LDL-C concentration $<130 \mathrm{mg} / \mathrm{dl}(<3.4 \mathrm{mmol} / \mathrm{l})$ and in children with diabetes mellitus or $\mathrm{FH}$ $<100 \mathrm{mg} / \mathrm{dl}(<2.6 \mathrm{mmol} / \mathrm{l})$ or at least a $50 \%$ reduction in LDL-C.

- Health education should be provided to the patient as well as all his/her family members. Lifestyle recommendations include similar elements as in adults; other modifiable risk factors should also be considered when introducing them; dietary treatment should be initiated by the family physician only in a child over 2 years of age.

- Pharmacotherapy should be initiated after 6 months of lifestyle modification if treatment goals have not been achieved; statins can be introduced in children $\geq 10$ years of age ( $>8$ years in children with heterozygous familial hypercholesterolaemia).

\subsection{Elderly individuals}

Cholesterol is a significant risk factor for coronary artery disease, regardless of age, although this relationship is somewhat less pronounced in the elderly. A reduction in TG concentration by $1 \mathrm{mmol} / \mathrm{l}(38.7 \mathrm{mg} / \mathrm{dl})$ is associated with a reduc- tion in cardiovascular mortality in patients aged $40-49$ by about $50 \%$, and in patients aged $80-89$ by only $15 \%(H R=0.85)[361,362]$.

The most important way to prevent cardiovascular diseases in the elderly is to promote a healthy lifestyle. A meta-analysis of 28 randomised clinical trials in patients over 75 years of age demonstrated that statin therapy reduced the relative risk of major cardiovascular events by $21 \%$ $(\mathrm{RR}=0.79,95 \% \mathrm{Cl}: 0.77-0.81)$ for each $1.0 \mathrm{mmol} / \mathrm{l}$ of reduction in LDL-C concentration [363]. These benefits were independent of age for individuals diagnosed with cardiovascular disease (also in the oldest population) but decreased with age in those receiving statins in primary prevention and no significance for individuals older than 70 years of age was shown. In the same study, a $12 \%(R R=0.88$, $95 \% \mathrm{Cl}: 0.85-0.91)$ reduction in the risk of cardiovascular death for every $1 \mathrm{mmol} / \mathrm{l}$ of reduction in LDL-C concentration was also observed [363]. Another meta-analysis confirmed these results not only for statins, but also for non-statin agents, showing a significant reduction in the risk of major vascular events for all assessed endpoints, regardless of age. However, it should be noted that also in this analysis, individuals in secondary prevention comprised a majority [364]. A valuable supplement to the results discussed above is the latest meta-analysis of 10 observational studies which included over 815,000 patients aged over 65 years in primary prevention [365]. This analysis is the more valuable because in randomised trials primarily composite endpoints are assessed rather than the effect of a specific therapy on the components of these endpoints; usually, the number of elderly patients is very limited, not to mention the follow-up duration, usually up to 5 years (in this analysis, the follow-up ranged from 5 to 24 years) [365]. The authors demonstrated that statin therapy in the elderly was associated with a significant $14 \%$ reduction in all-cause mortality, a $20 \%$ reduction in cardiovascular mortality, a $15 \%$ reduction in stroke, and a $26 \%$ numerical reduction (not statistically significant) in the risk of myocardial infarction. Importantly, this significant effect (reduction of all-cause mortality) was maintained regardless of age, also in patients $>75,>80$, and $>85$ years of age (risk reduction of 12,16 , and $12 \%$, respectively), in both women and men, but mainly in individuals with diabetes $(18 \%$ risk reduction) [365].

The most recent ESC/EAS guidelines (2019) on the management of lipid disorders recommend that treatment with statins in primary prevention in individuals $\leq 75$ years of age be used according to the estimated level of cardiovascular risk (IA). After 75 years of age, statin treatment in primary prevention may be considered in high- or very high-risk individuals (IIb B) [9]. In secondary 
Table XXXVI. Recommendations on treatment of lipid disorders in the elderly

$$
\text { Recommendations }
$$

Statin therapy is recommended in elderly patients diagnosed with cardiovascular disease in the same way as in younger patients.

Statin treatment is recommended for primary prevention in elderly patients $\leq 75$ years of age depending on the level of cardiovascular risk.

Statin therapy in primary prevention $>75$ years of age may be considered in high- or very high-risk individuals.

In case of significant renal impairment and/or potential for drug interactions, it is recommended to start with a low-dose statin and then increase the dose to achieve the LDL-C treatment goal.

prevention, statin treatment is recommended in elderly patients diagnosed with cardiovascular disease, according to the same rules as in younger patients (IA) [9].

Old age is a factor causing significant changes in pharmacokinetics, mainly at the stage of distribution (increased content of adipose tissue and $\alpha 1$ acid glycoprotein, reduced water content and albumin concentration) and elimination (impaired renal function, slower hepatic metabolism) [153, 366]. In addition, treatment in this group of patients is complicated by multimorbidity, the need of polypharmacotherapy, and patient non-compliance. Old age is an independent factor of increased risk of statin intolerance, especially muscle complaints [153]. Therefore, the International Lipid Expert Panel recommends treatment of the elderly with hydrophilic statins (rosuvastatin, pravastatin), as it is associated with greater safety [153]. Statin therapy should be initiated with low doses, gradually increasing them to achieve the target LDL-C concentration $[8,9]$. Temporary discontinuation of a statin should be considered in elderly patients in situations in which there is an increased risk of intolerance, e.g., hypothyroidism, acute severe infection, major surgery, or malnutrition, bearing in mind that discontinuation of therapy increases both general and cardiovascular mortality [153] (Table XXXVI).

\subsection{Autoimmune, rheumatic, and inflammatory diseases}

In the course of autoimmune, rheumatic and inflammatory diseases, an increased risk of cardiovascular diseases is observed [8, 367]. Increased cardiovascular risk in diseases such as systemic lupus erythematosus, psoriasis, psoriatic arthritis, antiphospholipid syndrome, rheumatoid arthritis, ankylosing spondylitis, ulcerative colitis, or Crohn's disease is associated with vasculitis and endothelial dysfunction, leading to aggravation of atherosclerosis $[8,368]$. This results in higher rates of cardiovascular morbidity and mortality in individuals suffering from these diseases in comparison with general population $[8,369]$. It should be emphasised that currently there are no indications for the preventive use of lipid-lowering agents solely on the basis of the presence of autoimmune diseases, rheumatic diseases, or diseases of inflammatory aetiology, and prevention and treatment of dyslipidaemia does not differ from general rules of management in this regard. However, it is worth remembering that in the case of autoimmune, rheumatic, or inflammatory diseases, the values of lipid parameters may increase as a result of anti-inflammatory treatment of these diseases [369]. It is also worth noting that in this patient population, lipid-lowering therapy may be difficult due to elevated creatine kinase (CK) activity; therefore, the therapy should be monitored, in close contact with the attending physician (rheumatologist or gastroenterologist). In such cases, a combination therapy (with low-dose statins) or even the use of non-statin lipid-lowering agents may be considered (depending on the risk and target LDL-C values).

\section{KEY POINTS TO REMEMBER}

- Autoimmune, rheumatic, and inflammatory diseases are associated with aggravation of atherosclerosis resulting in increased cardiovascular morbidity and mortality.

- Before initiating treatment of dyslipidaemia in individuals with autoimmune and rheumatic diseases, it should be borne in mind that the classical use of the SCORE to assess cardiovascular risk in these patients may not be sufficient and the actual risk may be higher than estimated.

- Prevention and treatment of dyslipidaemia in patients with autoimmune, rheumatic, and inflammatory diseases does not differ from general rules of management in this regard.

- It should be remembered that lipid-lowering therapy may be difficult due to elevated CK activity and higher risk of statin intolerance; therefore, combination therapy may be considered in these patients, and therapy should be performed in cooperation with the attending physician. 
M. Banach, P. Burchardt, K. Chlebus, P. Dobrowolski, D. Dudek, K. Dyrbuś, M. Gąsior, P. Jankowski, J. Jóźwiak, L. Kłosiewicz-Latoszek, I. Kowalska, M. Małecki, A. Prejbisz, M. Rakowski, J. Rysz, B. Solnica, D. Sitkiewicz, G. Sygitowicz, G. Sypniewska, T. Tomasik, A. Windak, D. Zozulińska-Ziółkiewicz, B. Cybulska

\subsection{Pregnancy and lactation}

During pregnancy, the greatest challenge associated with potential lipid disorders is significant up to $2.5 \times$ physiological increase in triglycerides in the second, and in particular the third trimester of pregnancy, which may be associated with a higher risk of pancreatitis. Total cholesterol and LDL-C concentration usually increase by not more than $50 \%$, but a significant (30-40\%) increase in lipoprotein(a) concentration may also be observed which may increase the risk of pre-eclampsia, premature delivery, or low birth weight [370].

Statins should be discontinued for at least 3 months before planned pregnancy, as well as during pregnancy and lactation [8]. Statins may have teratogenic properties and are classified as category $X$ (the risk of using these agents considerably outweighs any benefits) according to the most recent ESC 2018 guidelines [371]. However, it should be strongly emphasised that teratogenicity or the occurrence of congenital defects following statin exposure were mainly observed in experimental studies. Recent data do not confirm these findings. A recent systematic review and a meta-analysis of nearly 2.5 million cases [372] demonstrated no significant increase in congenital malformations after statin therapy. The authors emphasised that there was no evidence of teratogenic effects of statins during pregnancy, and this issue required further investigation, especially as more and more pregnant women were at high cardiovascular risk (women with established cardiovascular disease, women with $\mathrm{HoFH}$ ) and might benefit from statin therapy [372]. In this context, the available data from South Africa, where statins were used in pregnant women with homozygous $\mathrm{FH}$, also did not reveal any risks for either the mother or the child [373]. Recent studies and data also indicated the possibility of using pravastatin in pregnant women during the last trimester of pregnancy to prevent pre-eclampsia [370]. Unfortunately, the latest results of a randomised study involving 1120 patients did not confirm this relationship; however, once again, the safety of statins in this group of women has been confirmed [374].

It should be emphasised that in women receiving chronic statin therapy, the risk of harm to the foetus is not high, and in the case of accidental pregnancy, the woman should be reassured, and the gynaecologist-obstetrician should be immediately informed of the fact $[8,9]$. The only safe lipid-lowering agents in pregnancy are ion exchange resins (currently unavailable in Poland) [8]. The best tolerated resin is colesevelam. In women with $\mathrm{HoFH}$, continuation of LDL-apheresis during pregnancy is safe and indicated $[8,9]$. According to the latest guidelines, it is also possible to consider ezetimibe and fenofibrate (when potential benefits outweigh the risk) [371].

Recommended methods of contraception in women of childbearing potential with $\mathrm{FH}$ include low oestrogen oral contraceptives, intrauterine devices, and condoms. Oral contraceptives with high oestrogen content may increase triglyceride and LDL-C concentration and therefore it is important to monitor lipid profile in women with $\mathrm{FH}$ using these agents. Medical consultations are also necessary for all women of childbearing potential whose parents have been diagnosed with $\mathrm{FH}$, as the risk of homozygous $\mathrm{FH}$ in their offspring is as high as $25 \%[8,9]$.

\section{KEY POINTS TO REMEMBER}

- Lipid-lowering therapy should be discontinued in women at least 3 months before planned pregnancy, as well as during pregnancy and lactation.

- Statins are not recommended due to the risk of teratogenicity, despite the lack of clear evidence confirming such a relationship.

- More and more reports confirm the lack of risk of statins and the benefits of their use, especially in pregnant women with an underlying disease that threatens the life of the mother and the foetus (diagnosed cardiovascular disease or homozygous familial hypercholesterolaemia).

\subsection{Cognitive disorders}

Cognitive disorders comprise a heterogeneous group of conditions with respect not only to aetiology but also the extent of impairment, including mild memory disorders, mild cognitive impairment (MCID), and, in the most advanced form, dementia. Many systems are used for classification of dementia, including those based on the location of the causative brain damage, the type of symptoms, or the aetiopathogenesis. The most common cause of dementia are neurodegenerative diseases of the central nervous system (CNS), including Alzheimer's disease (resulting from deposition of $\beta$-amyloid in the extracellular space of the central nervous system), accounting for ca. $50-70 \%$ of cases [375]. Dementia due to vascular disease is the second most represented group of diseases and accounts for approximately $15 \%$ of cases.

From the perspective of years and the available study results, it seems that lowering LDL-C concentration, and regardless of that the use of statins, reduces the amount of insoluble precur- 
sor protein for amyloid and has anti-inflammatory effects, which has a beneficial effect in terms of reduction of Alzheimer type neurodegenerative lesions. Reduction in LDL concentration is an established vascular protection factor. This has been confirmed in meta-analyses of tens of clinical trials concerning statins published in the last few years which demonstrated a significant reduction in Alzheimer's dementia, vascular dementia, and generally mild cognitive impairment with statin use [376, 377], of which pleiotropic properties of this class of agents are supposed to be the cause.

Data concerning the effect of the method and rate of achieving the LDL treatment goal on neurocognitive functions depending on the age of patients receiving a specific therapy are still scarce. Data are available that suggest that lipid-lowering treatment reducing LDL concentration prevents development of cognitive deficits in middle-aged and elderly individuals, but not after the age of 80 . In these patients, high concentration of low-density lipoproteins is not considered a risk factor for dementia (this may also be associated with the lipid paradox observed in this group of patients) [378, 379].

Another important issue is neurological safety related to $L D L$ reduction. With this respect, evidence is available from studies with PCSK9 inhibitors, including a subanalysis dedicated to neuropsychological evaluation (the EBBINGHAUS study) [176, 184, 380]. In those trials, patients achieving LDL concentration below $30 \mathrm{mg} / \mathrm{dl}$ did not show any deterioration of their cognitive processes in comparison with those with higher LDL concentration. These results confirm the few previous observations in individuals with loss of function PCSK9 gene mutations who, despite extremely low LDL concentration, often below $30 \mathrm{mg} / \mathrm{dl}$, showed no neurocognitive disorders [381]. This also proves slightly different mechanisms of lipoprotein circulation in the CNS and the impermeability of both the blood-brain barrier and the blood-cerebrospinal fluid barrier to cholesterol and plasma lipoproteins (except for the precursor of small spherical HDL particles). There are also single reports that a disorder of local (rather than plasma) lipoprotein metabolism in the central nervous system and cerebrospinal fluid is most likely the cause of decreased supply of cholesterol necessary for the recovery of myelin sheaths, which is probably associated with neurodegenerative diseases [382].

For certain, the results of many studies with statins have proven no deterioration of cognitive function in people receiving this treatment. Therefore, the ESC position on the impact of these products on cognitive functions remains neutral [9].

\section{KEY POINTS TO REMEMBER}

- Treatment of lipid disorders in patients with neurocognitive disorders requires routine management based on the assessment of cardiovascular risk, determining the choice of therapy with adequate lipid-lowering potency.

- There is no convincing evidence of increased risk of cognitive disorders as a result of the use of statins or in individuals with low LDL-C concentration.

- On the contrary, scientific evidence supporting the protective effect of statins on the development of cognitive impairment, especially of vascular aetiology, is increasing.

\subsection{Liver diseases}

For years, increased aminotransferase activity was considered by physicians a contraindication to statins; as a result, patients with high cardiovascular risk often received no lipid-lowering therapy at all. Unfortunately, this is still the most common cause of statin dose reduction or treatment discontinuation [8, 152]. However, further experimental, and clinical trials as well as cohort studies have shown that in fact direct mechanisms that could contribute to hepatocyte damage in the course of statin therapy are still not fully known, and the phenomenon of asymptomatic elevation of aminotransferase activity in the course of treatment is rare $(<1 \%)$ and transient $[8,153]$. In February 2012, the FDA was the first agency to recommend that liver enzyme (alanine aminotransferase - ALT) activity should be measured prior to initiation of therapy, and no routine monitoring is necessary during its continuation unless clinical symptoms develop. Further associations and expert opinions, including the International Lipid Expert Panel (ILEP) or the latest ESC/EAS 2016 guidelines, have maintained this opinion [8, 153], although they point to the possibility of assessing aminotransferase activity 8-12 weeks after treatment initiation or dose increase, which refers to treatment optimisation every 4-6 weeks [9].

Furthermore, available studies indicate that statin therapy should be continued, and patients may benefit even in case of chronic B (hepatitis B virus, $\mathrm{HBV}$ ) and $C$ hepatitis (HCV), although not those with acute or active forms, which is the only contraindication to statins $[8,153]$. Among the benefits, there is a significant risk reduction of hepatocellular carcinoma (HCC) by up to $28 \%$ in patients with $\mathrm{HBV}$ and $\mathrm{HCV}$, and reduction of the presence of hepatitis $C$ virus in the blood by inhibition of its replication $[8,153]$. Studies are also available that indicate the beneficial role of statins in patients with primary biliary cirrhosis (PBC), in 
M. Banach, P. Burchardt, K. Chlebus, P. Dobrowolski, D. Dudek, K. Dyrbuś, M. Gąsior, P. Jankowski, J. Jóźwiak, L. Kłosiewicz-Latoszek, I. Kowalska, M. Małecki, A. Prejbisz, M. Rakowski, J. Rysz, B. Solnica, D. Sitkiewicz, G. Sygitowicz, G. Sypniewska, T. Tomasik, A. Windak, D. Zozulińska-Ziółkiewicz, B. Cybulska

terms of the effect on the course of the disease itself as well as the reduction of cardiovascular risk in this group of patients [153]. Even greater benefits may be observed in patients with non-alcoholic fatty liver disease (NAFLD) and non-alcoholic steatohepatitis (NASH), diseases which at present are much more common causes of cirrhosis than alcoholism [8, 153]. Hypertriglyceridaemia with decreased HDL-C concentration is common in the course of these diseases, as well as increased occurrence of atherogenic lipoprotein subfractions, i.e., VLDL and LDL $[8,153]$. Available studies have demonstrated that statin therapy very effectively reduces the risk of cardiovascular morbidity and mortality in the group of patients with NAFLD in comparison with patients not receiving statins (68 vs. $39 \%, p=0.007$ ) [383]. Available studies also indicate that statin treatment in these patient groups is safe [9]. Therefore, in patients with NAFLD or NASH and baseline ALT > $3 \times$ the upper limit of normal (ULN), low-dose statins may be considered, with the need to monitor ALT monthly for 3 months and subsequently $4 \times$ per year $[8,9]$.

This has been confirmed by the results of the most recent meta-analysis of 9 studies evaluating the potential protective role of statins in patients with chronic viral liver disease [384]. The results demonstrated no significant difference in the risk of death from any cause between patients receiving and not receiving statins in the overall analysis. However, the risk of death was significantly reduced by $39 \%$ in patients receiving statins and followed-up for more than 3 years. In addition, the risk of HCC, fibrosis, and cirrhosis in statin users was reduced by $53 \%, 45 \%$, and $41 \%$, respectively.

\section{KEY POINTS TO REMEMBER}

- Liver enzyme (ALT) activity should be measured prior to initiation of therapy (it may be considered during dose titration) and no routine monitoring is necessary during treatment continuation (unless clinical symptoms develop).

- Due to the benefits related to the course of the disease itself and its complications, as well as reduced cardiovascular risk, statin therapy is recommended in patients with chronic hepatitis B and C.

- In patients with NAFLD/NASH, statin therapy is safe, contributes to improved disease course, and significantly reduces cardiovas cular risk.

- The only contraindication to statin therapy is acute, active liver disease.

- In patients with liver diseases, lipid disorders should be treated in consultation with a hepatologist/gastroenterologist.
Interestingly, ALT and AST activity decreased slightly (and not increased!) after statin therapy; this reduction was not statistically significant [384].

\subsection{HIV/AIDS}

In terminal diseases and palliative conditions, careful assessment of the benefits and potential risk of adverse reactions in treatment of dyslipidaemia should be performed [385]. These groups of patients were typically excluded from large randomised clinical trials; therefore, the evidence is weak and leads to controversies and differences in the approach in guidelines published to date. Some studies also indicate that in palliative patients discontinuation of statin therapy was not associated with deterioration of cardiovascular parameters, including mortality, while significantly improving the quality of life of these patients [386, 387]. These data are still not sufficient to draw any conclusions; certainly, an individual approach to the patient should sometimes be considered, but one should always bear in mind that discontinuation of statin therapy may be associated with increased risk of cardiovascular events [153].

Patients with HIV/AIDS are such a difficult group of patients, with very scarce data from the studies. In this group, not only lipid-lowering therapy is important (in these patients, lipid disorders may occur as often as in general population), but particular attention should be paid to possible drug interactions, especially as these patients often receive multiple concomitant medications. Particular attention should be paid to interactions between statins and protease inhibitors in HIV patients due to metabolism via CYP3A4, leading to an increased risk of myopathy and rhabdomyolysis [9]. While in these patient groups TG and LDL-C concentrations are often decreased, treatment may negatively affect the lipid profile. Highly active antiretroviral therapy (HAART), primarily protease inhibitors, negatively affects the lipid profile, increasing in particular the risk of atherogenic dyslipidaemia [388]. If such lipid disorders are identified, the use of different agents in HAART may be considered; pravastatin may also be considered as it is recommended in patients with HIV due to its minimal metabolism by the cytochrome P450 isoenzyme system [8, 9]. The results of a recent study indicate that pitavastatin (available already in Poland), the metabolism of which practically does not involve cytochrome P450 isoenzymes (a few percent involvement of CYP 2C8 and 2C9), is more likely than pravastatin to contribute to a decrease in immune activation and arterial inflammation in HIV-infected individuals [389]. Furthermore, a subsequent study demonstrated that pitavastatin was more effec- 
tive in reducing $L D L$ cholesterol in this group of patients, with a safety profile comparable to that of pravastatin [390]. In addition to pravastatin and pitavastatin, other statins may be considered in treatment of dyslipidaemia in this group of patients, although dose adjustment may be necessary [391]. Detailed information on drug interactions in patients with HIV can be found at: www. hiv-druginteractions.org.

It is also worth noting that cardiovascular risk in a HIV patient is higher than in a patient without HIV (by up to $60 \%$ and more), and antiretroviral agents, in particular protease inhibitors, increase the risk as much as two-fold [392, 393].

\section{KEY POINTS TO REMEMBER}

- In patients with HIV/AIDS, treatment should be selected depending on cardiovascular risk and the benefits the patient may obtain from long-term therapy.

- In most HIV patients receiving antiretroviral therapy, non-pharmacological management is insufficient, and the addition of a statin should be considered. Pitavastatin and pravastatin are the preferred statins in this group. In case of statin intolerance, ezetimibe (or combination therapy in partial intolerance) is a treatment option.

\subsection{Terminal diseases and palliative conditions}

The aim of treatment of lipid disorders is to reduce cardiovascular events and mortality, as well as overall mortality. However, there is no evidence from clinical trials for the absolute benefit of statins in patients with terminal diseases and palliative conditions. For obvious reasons, such patients were excluded from randomised clinical trials.

A randomised clinical trial was conducted several years ago comparing the 60-day mortality in patients with an estimated life expectancy from 1 month to 1 year who decided not to receive statins with those who continued treatment [394]. The duration of previous statin therapy, in primary or secondary prevention, was at least 3 months. There were 189 patients in the treatment discontinuation group and 192 in the continuation group. The mean age of patients was $74.1 \pm 11.6$ years. Of these, $48.8 \%$ suffered from cancer, and $22 \%$ had cognitive impairment. Mortality did not differ significantly between the treatment continuation group and those who discontinued therapy (23.8\% vs. $20.3 \% ; p=0.36$ ). The quality of life (QoL) was also assessed using the McGill questionnaire, and the occurrence of various complaints using the Edmonton Symptoms Assessment scale. It turned out that the quality of life of patients who discontinued statin therapy was significantly higher that of those receiving a statin (McGill score: 7.11 vs. 6.85; $p=0.04$ ). Based on those results, the authors concluded that discontinuation of therapy in this group of patients is safe and beneficial due to improved quality of life [394].

What is the real-life approach to statin therapy in patients with limited life expectancy? A study conducted in New Zealand may serve as an example [395]. The rate of statin discontinuation in the last 12 months of life was evaluated in 20,482 individuals over the age of 75, including 4832 people with cancer. The treatment was discontinued in $70.4 \%$ of patients with cancer diagnosis and in $55 \%$ without this disease $(p<0.05)$, even in secondary prevention [395]. In recent joint guidelines of twelve American scientific societies on cholesterol management, the experts have stated that it is reasonable for people over 75 years of age to stop treatment if there is functional decline (physical or cognitive), multimorbidity, frailty, or reduced life expectancy [251]. In contrast, in the 2019 ESC/EAS guidelines the experts did not refer to statin therapy in patients with terminal diseases and palliative conditions [9].

Recently, a group of investigators reviewed 18 current guidelines on cardiovascular disease prevention with regard to recommendations on discontinuation of statin therapy in older adults [396]. In conclusion, they stated that "Current international CVD prevention guidelines provide little specific guidance for physicians who are considering statin discontinuation in older adults in the context of declining health status and short life expectancy", indicating that this topic is often overlooked in the guidelines on prevention and treatment of cardiovascular diseases [396].

Therefore, the decision is difficult and should apparently be made on an individual basis. Continuation of statin therapy in terminal patients and in palliative conditions does not prolong life, and apparently impairs its quality! On the other hand, in patients at high cardiovascular risk receiving statin treatment for a long time without adverse reactions, continuation of therapy may be considered in order to avoid a possible cardiovascular event.

Finally, the opinion from an article by Prof. Banach and Dr. Serban may be cited: “(...) it needs to be emphasised that the available data are not sufficient to draw any direct conclusions or recommendations, and any reduction in the statin dose or discontinuation should be balanced with the increased risk of cardiovascular events" [385]. 
M. Banach, P. Burchardt, K. Chlebus, P. Dobrowolski, D. Dudek, K. Dyrbuś, M. Gąsior, P. Jankowski, J. Jóźwiak, L. Kłosiewicz-Latoszek, I. Kowalska, M. Małecki, A. Prejbisz, M. Rakowski, J. Rysz, B. Solnica, D. Sitkiewicz, G. Sygitowicz, G. Sypniewska, T. Tomasik, A. Windak,

\section{KEY POINTS TO REMEMBER}

- In terminally ill patients and those receiving palliative treatment, data indicate that discontinuation of statin therapy does not increase the risk of cardiovascular events and may improve their quality of life.

- Therefore, in these patients decisions should be made on an individual basis, taking into consideration the patient's life expectancy and the potential to reduce cardiovascular risk with statin therapy, the occurrence of adverse effects and drug interactions with statins and, which should be particularly emphasised, the patient's quality of life.

\subsection{Viral diseases including COVID-19}

The coronavirus pandemic laid bare the shortcomings of the Polish healthcare system, showed very weak patient education on health and, consequently, contributed to significant deterioration of population health in every aspect, particularly in the context of cardiovascular diseases.

Observations to date point to a number of factors associated with worse course of SARS-CoV-2 infection [397]. The most commonly reported factors include diabetes and obesity [398, 399]. The possibility of cardiovascular events in the course of COVID-19, including myocarditis, acute coronary syndrome, or thrombotic complications, is also emphasised. Despite concerns expressed at the beginning of the pandemic, no adverse relationship between the use of the renin-angiotensin system inhibitors and the risk of development and the course of COVID-19 has been proven $[400,401]$. It should be emphasised that certain previous observations indicate that the renin-angiotensin system inhibitors and statins may reduce the risk of death due to pneumonia [400]. Study results also indicate at least neutral effect of statins on the risk of development and the course of COVID-19. In contrast, the number of studies indicating their very important role, improving the prognosis not only in the course of COVID-19, but also after recovery, in the socalled Long-Covid period (> 12 weeks after recovery), is increasing [402]. This is associated with the mechanisms of action of statins, not only their anti-inflammatory and anti-oxidative properties, stabilising atherosclerotic plaque (especially during the so-called cytokine storm), but also inhibition of the main coronavirus protease, reduction of the availability of lipid structural components of the virus envelope, degradation of so-called viral lipid rafts, or inhibition of its replication [403-405]. Some observations indicate potential benefits of statins (used prior to hospitalisation) on the course of COVID-19, manifested by reduced risk of severe course and death $[406,407]$. One of the recent meta-analyses of 24 studies including over 32,000 patients has demonstrated that statin use significantly reduced the risk of admission to the intensive care unit in the course of COVID-19 (by 22\%) and mortality (by $30 \%$ ), with no significant effect on the risk of intubation. An additional analysis showed also that the risk of death was even lower if statins were used in hospital settings in patients with COVID-19 (60\% risk reduction, $95 \% \mathrm{Cl}: 0.22-0.73)$ in comparison with prehospital use alone (23\% reduction) [408].

In patients with COVID-19, due to possible use of antiviral, antiretroviral, or antirheumatic agents, consideration should be given to the possibility of drug interactions with statins and statin intolerance. In this case, the ILEP 2020 recommendations should be followed, in which possible interactions have been discussed in detail in the guidelines for patients with $\mathrm{FH}$ [157].

Regarding management of lipid disorders during the COVID-19 pandemic, the following recommendations should be proposed, presented in detail in Table XXXVII.

Table XXXVII. Recommendations on treatment of lipid disorders in patients with COVID-19

\begin{tabular}{|l|c|}
\hline Recommendations & Class \\
\hline In individuals with COVID-19, treatment of elevated LDL cholesterol concentration should be \\
optimised as soon as possible, especially in those at high or very high cardiovascular risk, in whom \\
the highest recommended statin doses should be used.
\end{tabular}




\section{ADVERSE EFFECTS ASSOCIATED WITH TREATMENT OF DYSLIPIDAEMIA/STATIN INTOLERANCE}

Statin intolerance is a phenomenon that has been observed for years, but the interest in it in recent years is associated with the introduction of new agents in combination therapy (PCSK9 inhibitors, inclisiran, and bempedoic acid) (Section 9.10). Non-adherence is associated with intolerance, as adverse reactions associated with statin use are the most common cause of non-adherence or treatment discontinuation. To this, reluctance to use statins and the effect of drucebo (the term introduced by Prof. Banach in the ILEP $[409,410])$, i.e., adverse reactions observed in patients receiving a specific agent, but not being a result of its use, which may account for $>70 \%$ of all post-statin symptoms, should be added [152, 153, 410].

According to the results of the most recent meta-analysis, including data from more than 4 million patients, the global incidence of statin intolerance is $9.1 \%$, and if intolerance is diagnosed using existing definitions, including the ILEP definition [153], the incidence ranges from 5.9\% to 7\% [411]. Statin intolerance should be defined as inability to receive statin therapy adequate (with respect to the product or the dose) to the existing cardiovascular risk [8]. In other words, statin intolerance is
Table XXXVIII. Definition of statin intolerance proposed in the ILEP recommendations (2015)

Inability to tolerate at least 2 statins - one at the lowest initial daily dose and the other at any dose available.

Intolerance associated with confirmed adverse effects associated with statin use and/or a significant increase in markers (creatine kinase).

Reduction (improvement) of clinical symptoms and/ or biochemical parameters after statin dose reduction or treatment discontinuation (the dechallenge phenomenon).

Occurrence of clinical symptoms and/or change in biochemical parameters not associated with other factors or conditions that increase the risk of statin intolerance, including drug interactions.

not only the lack of statin treatment due to clinical or biochemical symptoms (so-called complete intolerance, which affects only $3-5 \%$ of patients), but also the phenomenon of underdosage or the use of a statin too weak in relation to the cardiovascular risk [8]. In March 2015, the International Lipid Expert Panel (ILEP) proposed a new definition of statin intolerance [153] (Table XXXVIII).

Therefore, one of the most difficult challenges is not only the right management, but above all the right, objective diagnosis of true statin intolerance. In this context, the authors of these guidelines rec-

Table XXXIX. Modified Statin-Associated Muscle Symptom Clinical Index (SAMS-CI) [412]

1. Location and pattern of muscle symptoms

(if more than one category applies, record the highest number)

Symmetric, hip flexors or thighs 3

\begin{tabular}{ll}
\hline Symmetric, calves & 2 \\
\hline Symmetrical. poximal upper extremity*
\end{tabular}

Symmetrical, proximal upper extremity* 2

Asymmetric, intermittent, or not specific to any area. 1

2. Timing of muscle symptom onset in relation to starting statin regimen

$<4$ weeks 3

$4-12$ weeks 2

$>12$ weeks 1

3. Dechallenge - timing of muscle symptom improvement after withdrawal of statin

$<2$ weeks 2

$\begin{array}{ll}2-4 \text { weeks } & 1\end{array}$

No improvement after 4 weeks 0

4. Rechallenge - timing of recurrence of similar muscle symptoms in relation to starting second regimen $<4$ weeks 3

$\begin{array}{ll}4-12 \text { weeks } & 1\end{array}$

$>12$ weeks or similar symptoms did not reoccur.

INTERPRETATION:

(likelihood that the patient's muscle symptoms are due to statin use):

*The coracobrachialis muscle, the biceps brachii muscle, the brachialis muscle. 
M. Banach, P. Burchardt, K. Chlebus, P. Dobrowolski, D. Dudek, K. Dyrbuś, M. Gąsior, P. Jankowski, J. Jóźwiak, L. Kłosiewicz-Latoszek, I. Kowalska, M. Małecki, A. Prejbisz, M. Rakowski, J. Rysz, B. Solnica, D. Sitkiewicz, G. Sygitowicz, G. Sypniewska, T. Tomasik, A. Windak,

D. Zozulińska-Ziółkiewicz, B. Cybulska

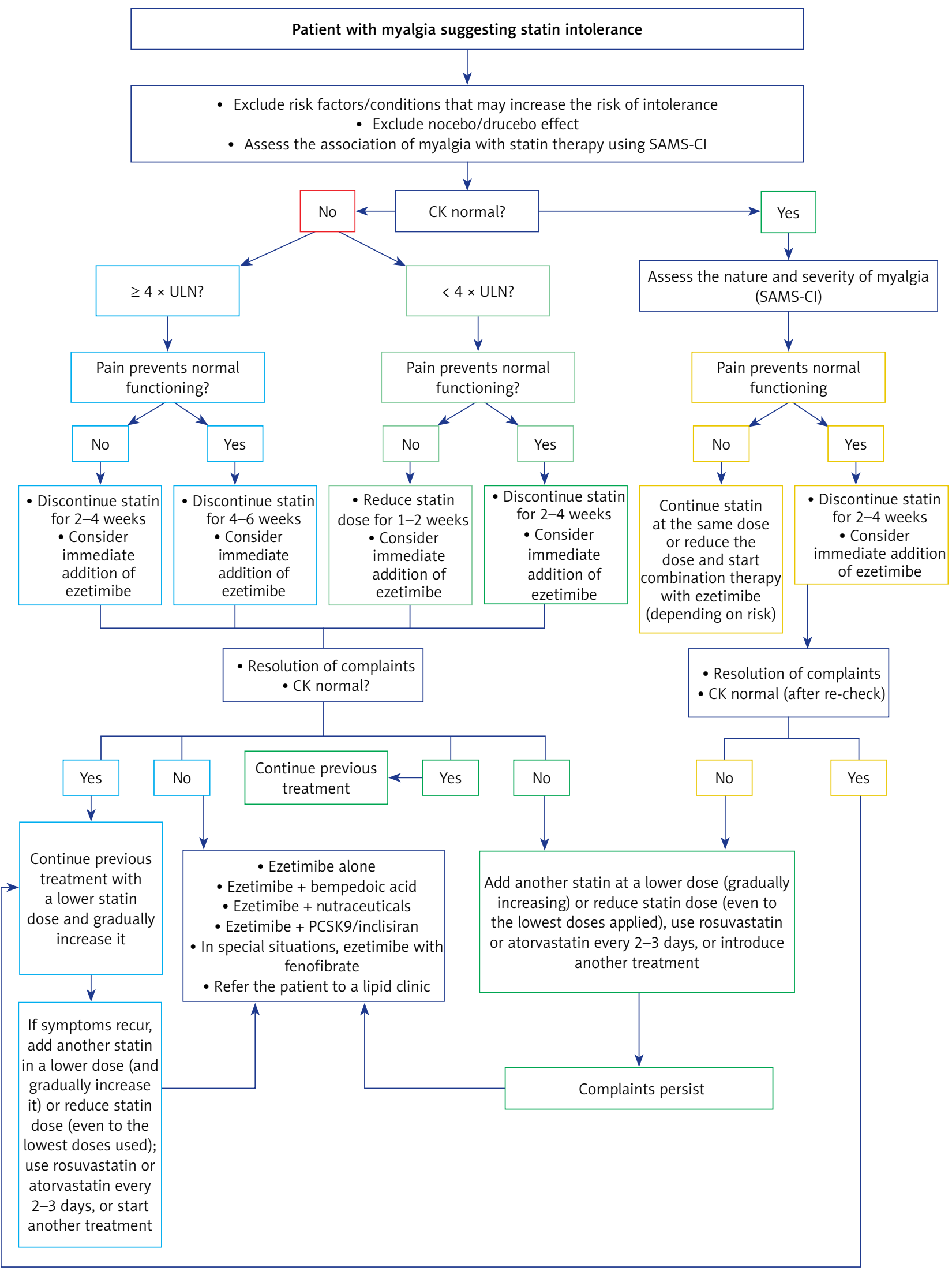

Figure 12. Detailed recommendations for management of patients with statin intolerance 
ommend the use of the Statin-Associated Muscle Symptom Clinical Index (SAMS-CI) for objective assessment whether reported muscle pains are associated with statin treatment [412] (Table XXXIX).

It should be noted that there are many risk factors which may increase the chance for statin intolerance, including but not limited to: physical activity, especially after initiation or increase in intensity; liver and/or kidney disease, hypothyroidism, vitamin D deficiency [413], alcohol consumption, rheumatic diseases, major surgical procedures, low body weight, female gender, or elderly age $[8,153]$. These risk factors were most cited as expert opinions and have never been confirmed with respect to potential causality or simply association with development of statin intolerance. In the meta-analysis mentioned above [411], the first attempt at such validation has been made. The most important risk factors for intolerance were: elderly age $(O R=1.33$; as a continuous variable), female gender (1.48), Asian (1.25) or African origin (1.29), diabetes (1.27), obesity (1.31), hypothyroidism (1.38), chronic liver (1.24) or kidney disease (1.25), alcohol consumption (1.22), exercise (1.23), the use of antiarrhythmic agents (1.31), calcium channel blockers (1.36) or statins, primarily at high doses (1.38) [411].

Discussing the phenomenon of intolerance, attention should be paid to several key elements. Symptoms of intolerance in $90 \%$ occur within the first 6 months after initiation of statin therapy or dose increase, and in 75\% within the first 12 weeks of this therapy [414]. Intolerance symptoms are unlikely to occur 1 year after treatment initiation or dose increase, unless a factor increasing this risk appears (disease exacerbation, a new medication interacting with statins) [414]. The most common reasons of statin intolerance are muscle symptoms manifested as pain (myalgia), muscle cramps or weakness, with or without elevated creatine kinase (CK) activity (myopathy), with or without inflammation (myositis) [415]. Myonecrosis and rhabdomyolysis are extremely rare ( $<2 / 100,000$ patient-years) and may often be associated with genetic predisposition, exacerbation of a concomitant disease, or treatment error $[156,414]$. Other symptoms, with a confirmed causal relationship to statin administration, include new cases of diabetes and temporary elevation of alanine aminotransferase activity [415]. Other symptoms of statin intolerance mentioned in the literature, including hair loss, sleep disturbances, flu-like symptoms, lupus-like symptoms, rashes, gastrointestinal symptoms, decreased libido, and gynaecomastia, are very rare and their causal relationship to statin use has not been confirmed [153, 156, 415].

In statin-intolerant patients, the appropriate management (so-called step-by-step approach, i.e., thorough history taking and gradual exclusion of reasons for intolerance, prompt initiation of appropriate management) may contribute to the fact that more than $95 \%$ of those patients may still receive statins [416]. Currently, in the management of patients with statin intolerance, the dominant rule is to try to retain even the lowest statin dose that is tolerated and/or use it even every 2-3 days (data suggest this possibility for atorvastatin and rosuvastatin [307]), and in the case of complete statin intolerance, after discontinuation, especially in high-risk patients, ezetimibe [109] and other non-statin therapies should be introduced immediately (bempedoic acid, which in this year will be available in Poland, PCSK9 inhibitors, inclisiran, and nutraceuticals or their combinations with proven lipid-lowering effect [136]). It is also worth noting that pitavastatin is already available on the market, which, due to its metabolism (practically no involvement of CYP450) and properties (bioavailability $50 \%$ ) has potentially the lowest risk of intolerance in the form of myalgia (estimated at ca. $2 \%$ for $4 \mathrm{mg}$ ) or new cases of diabetes (estimated at ca. $4.5 \%$ for the highest dose); in both cases, these values are comparable with those for placebo. Detailed guidelines for management of statin intolerance are presented in Figures 8 and 12, and Table XVII.

\section{RECOMMENDATIONS ON MONITORING LIPIDS AND BIOCHEMICAL PARAMETERS DURING TREATMENT OF LIPID DISORDERS}

In this section, recommendations presented in the ILEP 2015 position [153] and EAS 2015 [417] as well as European guidelines (ESC/EAS) on the management of dyslipidaemia (2019) are summarised and approved [9]. Statins are the most commonly used agents reducing LDL-C concentration; therefore, most attention was paid to their safety. The most common adverse effects associated with statin therapy are muscle symptoms (SAMS), usually pain (myalgia), muscle weakness, and cramps. One of the most serious muscle symptoms is myopathy, particularly rhabdomyolysis, which requires immediate hospitalisation. The manifestations of rhabdomyolysis include marked elevation of creatine kinase (CK) activity, increased myoglobin concentration with myoglobinuria (dark urine), and acute renal failure with increased creatinine and potassium concentration $[8,9]$.

According to the ESC/EAS (2019) experts, prior to initiation of pharmacotherapy lipid parameters should be assessed at least twice (except for patients with ACS) at intervals of 1-12 weeks, and after $6 \pm 4$ weeks following treatment initiation. Lipid concentration should also be assessed after $6 \pm 4$ weeks following the change of lipid-lowering 
M. Banach, P. Burchardt, K. Chlebus, P. Dobrowolski, D. Dudek, K. Dyrbuś, M. Gąsior, P. Jankowski, J. Jóźwiak, L. Kłosiewicz-Latoszek, I. Kowalska, M. Małecki, A. Prejbisz, M. Rakowski, J. Rysz, B. Solnica, D. Sitkiewicz, G. Sygitowicz, G. Sypniewska, T. Tomasik, A. Windak, D. Zozulińska-Ziółkiewicz, B. Cybulska

therapy, until the target LDL-C concentration has been achieved [9]. Then lipids should be tested at 6-12-month intervals. At the same time as the baseline lipid profile, CK and alanine aminotransferase (ALT) activity should be assessed, and $\mathrm{HbA}_{1 \mathrm{c}}$ or glucose concentration measurement should be considered. The last two tests and their monitoring are applicable to patients at high risk of diabetes mellitus, those on high-dose statin therapy, the elderly, obese individuals, and those with metabolic syndrome. This requirement is associated with potential diabetogenic effect of statins.

Statin therapy is not initiated if ALT $\geq 3 \times$ upper limit of normal (ULN) or CK $\geq 4 \times$ ULN [9]. Routine monitoring of these enzymes is unnecessary during statin therapy, although European experts recommend an ALT measurement 8-12 weeks after treatment initiation and after dose increase, and then only in case of alarming symptoms [9]. Experts also remind that mild transient increase in ALT activity may occur during treatment with statins, which disappears with continued treatment (Section 10.14). An indication for ALT activity measurement is development of liver symptoms during treatment (pain, weakness, jaundice), and development of muscle symptoms for CK measurement.

The situation is different during treatment with a fibrate; in this case, ALT activity should be monitored regularly, and prior to introduction of this agent, creatinine should be measured, in addition to ALT and CK.

Continuation or cessation of pharmacotherapy depends on whether ALT $<3 \times$ ULN or $\geq 3 \times$ ULN. If $\mathrm{ALT}<3 \times \mathrm{ULN}$, treatment can be continued and the test repeated after 4-6 weeks (usually, the activity normalises in this period); if ALT $\geq 3 \times U L N$, treatment should be interrupted or the dose reduced (which is preferred by the authors of these guidelines), the test repeated after 4 weeks, and the therapy gradually resumed after normalisation of ALT activity.

The indication for CK assessment is development of muscle symptoms, which may be accompanied by a CK activity increase of varying degrees. Occasionally, increased CK activity is detected in a patient without muscle symptoms. A decision on whether to continue or discontinue treatment is based on the presence or absence of SAMS and the increase in CK, i.e. $<4 \times$ ULN or $\geq 4 \times$ ULN [9] (Figure 12).

\section{Statin therapy may be continued, if:}

- $\mathrm{CK}<4 \times$ ULN in a patient without muscle symptoms (the patient should be informed of the possibility of symptoms and CK activity should be measured).

- $\mathrm{CK}<4 \times$ ULN and muscle symptoms:

- monitor symptoms and CK activity regularly,
- if symptoms persist, discontinue treatment, and re-assess symptoms after 2-4 weeks.

- $\mathrm{CPK} \geq 4 \times$ ULN but $<10 \times$ ULN without muscle symptoms:

- monitor CK every 2 weeks,

- exclude idiopathic hyperCKaemia.

Statin therapy should be discontinued immediately, if:

- $\mathrm{CK}>10 \times$ ULN:

- assess renal function and monitor CK every 2 weeks,

- $C P K \geq 4 \times$ ULN but $<10 \times$ ULN with muscle symptoms:

- monitor CK,

- after normalisation of CK and symptoms, gradually introduce treatment,

- $\mathrm{CK}<4 \times$ ULN and persistent muscle symptoms making it impossible to function:

- assess their occurrence after 2-4 weeks following treatment discontinuation and re-evaluate the indications for statin therapy,

- CK within normal values but muscle symptoms intolerable,

In statin-intolerant patients, the following treatment options should be considered when CK activity returns to normal: dose reduction of the same statin, use of another statin, statin administration every other day or once/twice a week, combination pharmacotherapy (including new agents), and lipid-lowering nutraceuticals [415].

\section{KEY POINTS TO REMEMBER}

- Prior to initiation of pharmacotherapy, lipid concentration should be assessed at least twice.

- The first lipid assessment is performed after $6 \pm 4$ weeks following the initiation of pharmacotherapy. This interval should also be maintained after treatment modification.

- If treatment goals are achieved, it is sufficient to control lipid concentration once or twice per year.

- Muscle symptoms comprise the most common adverse effect of statins. Hepatotoxicity is rare and transient.

- Prior to statin treatment, ALT and CK activity should be measured, and $\mathrm{HbA}_{1 \mathrm{c}}$ or glucose measurement should be considered; ALT and CK activity and creatinine concentration should be assessed prior to fibrate treatment.

- Treatment should not be initiated if $\mathrm{CK} \geq 4 \times$ ULN or ALT $\geq 3 \times$ ULN.

- There is no need for routine assessment of CK and ALT. The test is performed when muscle or hepatic symptoms develop. 


\section{CAUSES OF INEFFECTIVE TREATMENT OF LIPID DISORDERS}

Effective treatment of lipid disorders means, in the first place, achievement of the target LDL cholesterol concentration. However, successful treatment does not translate into the patient's well-being, but into the number of cardiovascular events avoided. The key to successful treatment of dyslipidaemia is to create the right relationship between the physician and the patient, which allows the patient to fully understand the purpose and expected effects of treatment.

\subsection{Efficacy of treatment of dyslipidaemia}

The term "compliance" is very broad and difficult to define precisely; formally, it is defined as "the act or process of doing what one has been asked or ordered to do". In medical context, this refers to medical advice. Putting it simply, compliance can be determined on the basis of the efficacy of treatment of a specific condition, in this case dyslipidaemia. This efficacy has improved over recent years. According to the results of the 3ST-POL study, which was conducted in the years 2007-2008, the recommended total cholesterol concentration was achieved in less than $10 \%$ of patients with and less than $16 \%$ of patients without cardiovascular risk, and the target LDL concentration in $15.6 \%$ and $22.7 \%$, respectively. However, that study involved only outpatients [418]. In the same period, according to the Polish results of the EUROASPIRE study, the target total cholesterol concentration was achieved in up to $70 \%$ of patients after myocardial infarction and the target LDL-C in 39\% of patients [419]. The latest data on the efficacy of treatment of hypercholesterolaemia have been provided by the WOBASZ II study (2013-2014). With regard to the general population of Poland, only $6 \%$ of patients with hypercholesterolaemia are treated effectively, $15 \%$ are treated ineffectively, and others either are not aware of the disease or receive no pharmacological treatment. In comparison with the WOBASZ study in the years 2003-2005, a significant increase in the percentage of patients receiving pharmacotherapy as well as the percentage of patients treated effectively was observed [21].

\subsection{Therapeutic persistence in treatment of dyslipidaemia}

Studies demonstrate that a large proportion of patients quickly discontinue treatment of hypercholesterolaemia. According to the 3ST-POL study [418], $25 \%$ of patients discontinued statins as early as 3 months after treatment initiation. After 3 years, only $15 \%$ of patients were using statins. An analysis of data from the National Health Fund demonstrated that therapeutic persistence with statins in Poland is definitely too low [420]. Only $12 \%$ of patients met the current criteria for adherence and therapeutic persistence. In addition, the results of a pilot analysis of almost 200,000 e-prescriptions issued in 2018 in Poland indicated that as much as $20.8 \%$ of them were not filled. For statins, this percentage was $17.5 \%$ (simvastatin 14.3\%; atorvastatin 18.9\%; rosuvastatin 17.4\%) [421]. It should be emphasised that this applies only to single prescriptions, which may translate into a significant proportion of patients who discontinue or periodically interrupt long-term treatment.

An analysis of adherence in patients post myocardial infarction or stroke suggests high variability of therapeutic persistence over time, both in terms of improvement and worsening of adherence [422]. This indicates that adherence must be closely monitored, especially in patients with a history of a cardiac or cerebrovascular event.

Treatment discontinuation is a very serious problem and may be a result of the decision of either the patient or the physician. This is extremely dangerous because, particularly in high-risk and very high-risk individuals, it may be associated with plaque instability and the risk of a (recurrent) cardiovascular event [8, 9]. It has been demonstrated that strict adherence $(\geq 90 \%)$ to statin therapy in comparison with $<50 \%$ adherence (evaluated by means of the medicine possession ratio) is associated with a $30 \%$ increase in the risk of death in a nearly 3-year follow-up [423].

\subsection{Therapeutic inertia}

The role of a physician in the therapeutic process is clearly essential. In treatment of dyslipidaemia, the physician is the person who assesses the overall cardiovascular risk, confirms indications for the initiation of pharmacotherapy, decides on the choice of a specific agent or agents, as well as monitors the safety and efficacy of the selected treatment regimen. In Poland, especially in outpatient care, a problem of so-called therapeutic inertia has been observed for years. In the context of treatment of dyslipidaemia, the following issues are primarily observed:

- Underestimation of the importance of nonpharmacological interventions;

- Unnecessary deferral of the introduction of pharmacotherapy of dyslipidaemia;

- The use of too low statin doses in relation to the intended treatment goals;

- Treatment failure not resulting in modification of statin dose;

- Unjustified discontinuation of statin therapy;

- Fear of using high-dose statins or combination therapy;

- Failure to perform tests to monitor treatment efficacy. 
Analysis of the WOBASZ and WOBASZ II studies made it possible to analyse trends in high-dose statin treatment over a decade. At all levels of cardiovascular risk, an increase in the proportion of patients receiving high-intensity or moderate-intensity statin treatment, as well as a reduction in the proportion of those receiving low-dose statins and the proportion of individuals treated with diet alone was observed. Moreover, the most noticeable change occurred in patients with a very high cardiovascular risk, of whom $18 \%$ were receiving high-dose therapy, another $49 \%$ of patients were receiving moderate-intensity statin treatment, and only $10 \%$ were treated with diet alone [419]. The use of statins in higher and moderate doses was associated with higher proportions of patients achieving their treatment goals (30\% and 33\%, respectively) as compared to $25 \%$ of patients using low-dose statins. It should be emphasised that despite the observed improvement, still too few patients receive high-dose statins, i.e. only $17.9 \%$ and $7.7 \%$ of patients with very high and high cardiovascular risk [419].

\subsection{Causes of ineffective treatment of lipid disorders}

When considering the causes of ineffective treatment, a number of demographic and socio- economic factors should be taken into consideration. In most studies, it was demonstrated that women were less compliant with statins than men [424]. Age is another factor associated with statin adherence. It is worth emphasising that the relationship between adherence to statins and age has the shape of reverse $U$ curve, i.e., the worst adherence is observed in young patients ( $<50$ years) and the elderly ( $\geq 70$ years) [425]. Race has also been shown to affect the adherence to statins. African Americans are significantly less compliant. The income and education level also affect the compliance rate, i.e., lower-income patients are less likely to adhere to statin treatment than those with higher income. Similarly, individuals with a low level of education are less compliant than those with higher education [426]. Concomitant diseases may affect adherence in different ways. Depression, dementia, malignancies, renal and pulmonary diseases, including obstructive sleep apnoea, are associated with poorer adherence to statin therapy [426]. On the other hand, diabetes mellitus, obesity, or a history of stroke or myocardial infarction are associated with better compliance [426]. In addition, Lemstra et al. demonstrated that patients prescribed with statins for the first time followed the recommendations worse than those previously receiving

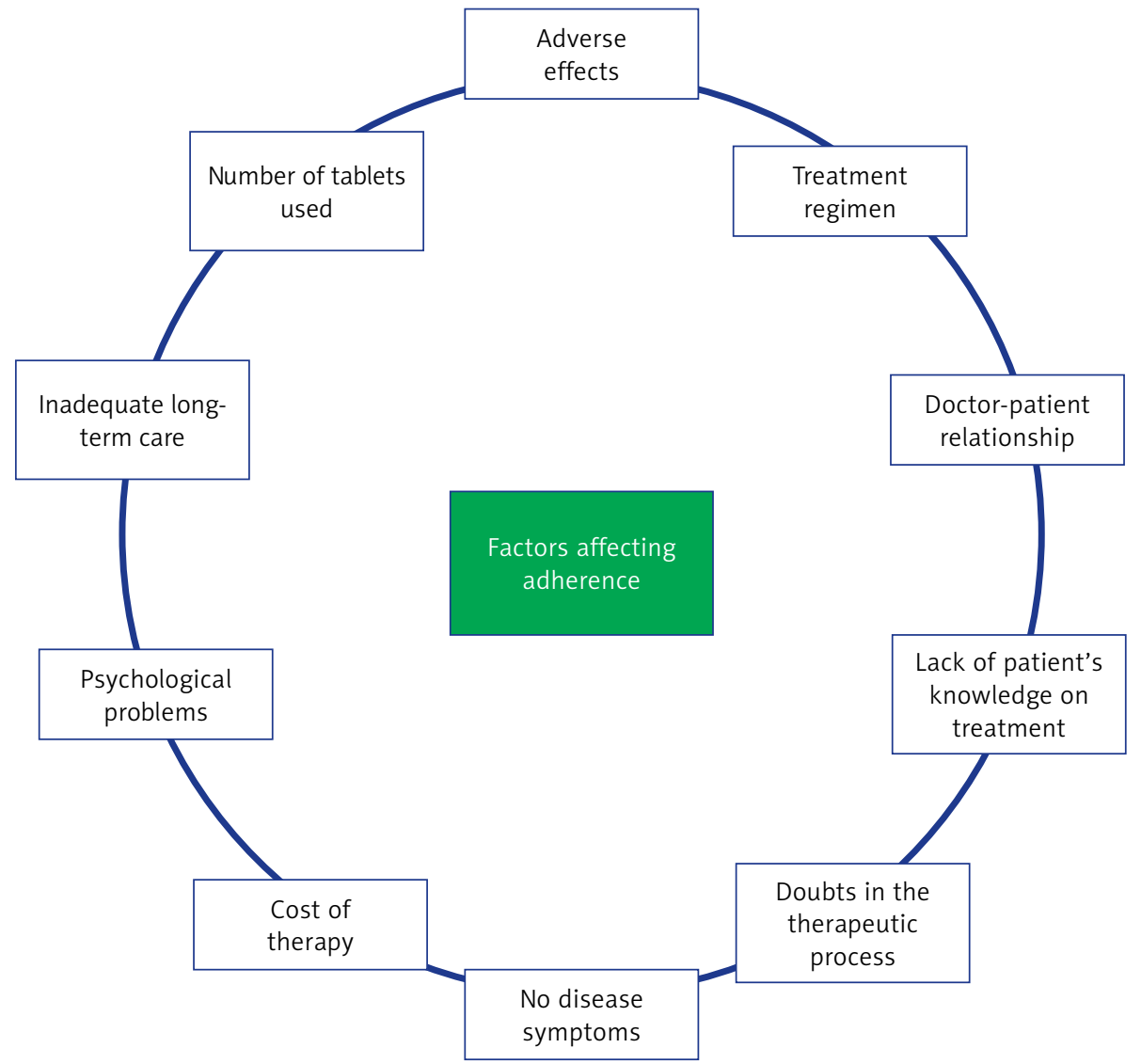

Figure 13. Key reasons for non-adherence (modified based on [428]) 
a statin [427]. All the factors discussed above can be classified as non-modifiable factors affecting adherence to lipid-lowering therapy.

Niklas et al. conducted an analysis of factors associated with achievement of the treatment goal in hypercholesterolaemia in relation to the population of Poland as a part of the WOBASZ II study [300]. Younger age, diabetes mellitus, non-smoking status, concomitant cardiovascular disease, and the number of physician visits $\geq 4$ / year have been shown to be independently associated with keeping cholesterol concentration within the target range.

Non-compliance with statin therapy is also affected by a number of modifiable factors (Figure 13) [428]. It is worth emphasising that they are often easy to establish and, most importantly, their discussion with patients and modification is possible. One of the most important issues is to present the disease to the patient and the effect of elevated cholesterol values on their health in a comprehensible way [428]. This knowledge may contribute to the elimination of one of the most significant reasons for non-compliance, i.e., questioning of the health risk associated with elevated cholesterol concentration, and therefore the justification of the therapeutic process. Therefore, a proper doctor-patient relationship should be a tool to improve treatment efficacy $[425,428]$. Another very important aspect of improvement of treatment of lipid disorders is simplification of the therapeutic regimen, for example by reducing the number of tablets. It is postulated that the use of combination products (statin + ezetimibe or statin + antihypertensive agent/agents) may increase treatment efficacy. Furthermore, the available data indicate that this improvement in adherence may result in a better prognosis in comparison with treatment with the same agents at the same doses, but not in combination products [429].

\subsection{Recommendations on how to improve doctor-patient cooperation and thus the efficacy of lipid-lowering therapy, and effectively fight against anti-statin movements}

Statins have been shown to be effective in reducing cardiovascular events and mortality, and even though they are very affordable, they remain significantly unused. Widespread claims of adverse effects that are enhanced and promoted by the media have been consistently associated with adverse effects on the use of statins worldwide. While the academic community must strive to work together with the media to harmonise public health messaging, physicians caring for their patients play a key role in reducing disinformation and actively stopping its effect on the vicious cycle of the falsely attributed adverse effects and the effect of nocebo [430]. An analysis performed in the UK indicated that during a period of increased public discussion on the risk of statin use, a transient increase in the proportion of patients who discontinued statin therapy was observed. This study highlights the potential of widely discussed health-related messages and the impact of media on healthcare behaviour [431].

\section{KEY POINTS TO REMEMBER}

- Effective treatment of lipid disorders is the achievement of the target LDL cholesterol concentration. The measure of treatment success is not the patient's well-being but the number of cardiovascular events avoided. The key to successful treatment of dyslipidaemia is to create the right relationship between the physician and the patient, which allows the patient to understand in a proper way the purpose and expected effects of treatment;

- The latest data from the WOBASZ II study indicate that with regard to the general population of Poland, only $6 \%$ of patients with hypercholesterolaemia are treated effectively, $15 \%$ are treated ineffectively, and others either are not aware of the disease or receive no pharmacological treatment; the results were slightly better in the Da Vinci study, in which only $17 \%$ of patients in Poland at very high cardiovascular risk achieved their treatment goals;

- A number of modifiable and non-modifiable factors associated with statin non-adherence have been identified. It is worth emphasising that the modifiable factors are often easy to establish and, most importantly, their discussion with patients and modification is possible.

- Adherence must be closely monitored, especially in patients with a history of a cardiac or cerebrovascular event;

- The academic and scientific community must strive to work together with the media to harmonise public health messaging; physicians caring for their patients play a key role in reducing disinformation and actively stopping its effect on the vicious cycle of the falsely attributed post-statin adverse effects.

\section{ORGANISATION OF HEALTHCARE IN LIPID DISORDERS IN POLAND}

The main burden of prevention as well as diagnostics and treatment of lipid disorders lies with family physicians (primary healthcare - $\mathrm{PCH}$ /pri- 
M. Banach, P. Burchardt, K. Chlebus, P. Dobrowolski, D. Dudek, K. Dyrbuś, M. Gąsior, P. Jankowski, J. Jóźwiak, L. Kłosiewicz-Latoszek, I. Kowalska, M. Małecki, A. Prejbisz, M. Rakowski, J. Rysz, B. Solnica, D. Sitkiewicz, G. Sygitowicz, G. Sypniewska, T. Tomasik, A. Windak,

D. Zozulińska-Ziółkiewicz, B. Cybulska

Table XL. Recommendations on the assessment of lipid profile

Regular lipid profile assessment should be performed in individuals:

- diagnosed with cardiovascular disease

- diagnosed with familial hypercholesterolaemia

- with a family history of premature cardiovascular disease

- diagnosed with diabetes mellitus

- with chronic kidney disease

- diagnosed with autoimmune, rheumatic, or inflammatory diseases

- chronic smokers

- with HIV infection or during HAART therapy

mary care physicians - PCP) [432]. Their role consists in:

- Early diagnosis of dyslipidaemia,

- Determining the type of lipid disorders and establishing the diagnosis,

- Patient and family education,

- Treatment initiation and monitoring,

- Determination of indications and referral for specialist consultations,

- Cooperation with a specialist,

- Detection of lipid disorders in family members,

- Diagnosing complications and organ damage at an early stage.

In prophylactic and therapeutic management, lifestyle modification, including improper dietary habits, should always be taken into consideration; this may require cooperation with a dietician [13]. Treatment of lipid disorders requires cooperation between primary care physicians and specialist care physicians (internists, paediatricians, cardiologists, specialists in metabolic diseases, diabe- tologists, nephrologists, neurologists, or geriatricians).

Screening for dyslipidaemia should be performed in individuals with at least 1 risk factor for cardiovascular disease (e.g. arterial hypertension, obesity, tobacco dependence, positive family history) and in all men aged $>40$ years, in women aged > 50 years, in postmenopausal women, in women with diabetes, in pregnant women, those with hypertension during pregnancy, in HIV-infected patients or those receiving HAART therapy, in men with erectile dysfunction, and in cases in which symptoms suggestive of cardiovascular diseases are present (Table $\mathrm{XL}$ ).

In Table XLI the level of care at which a patient with dyslipidaemia should be treated is presented $[433,434]$. Only good cooperation and continuous communication (e.g., organised as a part of coordinated care in primary prevention of cardiovascular diseases) between specific levels may guarantee appropriate and effective care for patients with lipid disorders.

While discussing the organisation of care for patients with lipid disorders in Poland, it seems necessary to mention the Prevention 40 PLUS programme, introduced by the Ministry of Health on July $1^{\text {st }}$, 2021, which constitutes a good beginning for coordinated care programmes in primary prevention. The programme has significant limitations in terms of the type and scope of tests, the lack of continuity of care (one-time package), and the lack of wide health-related education, which would be the best motivator to undergo such tests for young people, a majority of whom do not feel any disease; however, this is a step in the right

Table XLI. Patient characteristics and levels of care in the healthcare system at which care is provided to patients with lipid disorders, including FH

\begin{tabular}{|c|c|c|c|}
\hline \multicolumn{4}{|c|}{ Level of care } \\
\hline Primary healthcare (PCH) & $\begin{array}{l}\text { Combined care } \\
\text { (PHC and OSC) }\end{array}$ & $\begin{array}{l}\text { Outpatient specialist care } \\
\text { (OSC) }\end{array}$ & Hospitalisation \\
\hline $\begin{array}{l}\text { Patient: } \\
\text { - Without CVD } \\
\text { - Other risk factors are } \\
\text { not present or are } \\
\text { controlled } \\
\text { - Treatment goals (LDL-C) } \\
\text { have been achieved } \\
\text { - Age over } 18 \text { years }\end{array}$ & $\begin{array}{l}\text { Patient: } \\
\text { - With stable CVD } \\
\text { - Certain risk factors are } \\
\text { difficult to control } \\
\text { - Treatment goals slightly } \\
\text { diverge from the desired } \\
\text { values } \\
\text { - Mild symptoms of statin } \\
\text { intolerance } \\
\text { - Heterozygous FH } \\
\text { - Age over } 10 \text { years }\end{array}$ & $\begin{array}{l}\text { Patient: } \\
\text { - Age less than } 10 \text { years } \\
\text { - Unstable CVD } \\
\text { - Several uncontrolled risk } \\
\text { factors } \\
\text { - Recent myocardial } \\
\text { infarction, stroke, or } \\
\text { revascularisation, } \\
\text { - Treatment goal not } \\
\text { achieved despite } \\
\text { combination therapy } \\
\text { (LDL-C) } \\
\text { - Severe symptoms of } \\
\text { statin intolerance } \\
\text { - Homozygous FH } \\
\text { - Other: pre-conceptive } \\
\text { period, pregnancy, } \\
\text { apheresis, preparation } \\
\text { for surgery }\end{array}$ & $\begin{array}{l}\text { - Acute cardiovascular } \\
\text { event } \\
\text { - Exacerbation of CVD } \\
\text { - Rhabdomyolysis } \\
\text { - End-stage renal disease } \\
\text { - Planned liver } \\
\text { transplantation }\end{array}$ \\
\hline
\end{tabular}

PHC - primary healthcare, OSC - outpatient specialist care, CVD - cardiovascular disease, FH - familial hypercholesterolaemia. 
direction (assuming widespread implementation of this programme) in order to make prevention of cardiovascular diseases and other chronic diseases in Poland real at long last. The scope of possible tests is presented in Table XLII. The authors of these guidelines encourage the dissemination of information on the programme, promotion of the programme among patients, and continuation of work with the Ministry of Health and the payer to extend this programme to a full-fledged programme of coordinated care for primary prevention of cardiovascular and chronic diseases in Poland.

\section{KEY POINTS TO REMEMBER}

The main burden of prevention as well as diagnostics and treatment of lipid disorders lies with family physicians (PHC physicians). Treatment of lipid disorders requires cooperation between primary care physicians and specialist care physicians.

\section{ACKNOWLEDGMENTS}

All experts and scientific societies they represent accepted the final version of these guidelines. In development of these guidelines, the societies were represented by the following persons: Polish Lipid Association (PoLA: Maciej Banach, Jacek Rysz, Michał Rakowski, Barbara Cybulska), College of Family Physicians in Poland (CFPiP: Tomasz Tomasik, Adam Windak, Jacek Jóźwiak), Polish Cardiac Society (PCS: Krzysztof Chlebus, Paweł Burchardt, Piotr Dobrowolski), Polish Society of Laboratory Diagnostics (PSDL: Bogdan Solnica, Dariusz Sitkiewicz, Grażyna Sygitowicz, Grażyna Sypniewska), Polish Diabetological Association (PSD: Dorota Zozulińska-Ziółkiewicz, Irina Kowalska, Maciej Małecki), and Polish Society of Hypertension (PSH: Aleksander Prejbisz, Piotr Dobrowolski, Piotr Jankowski); other members of the writing committee were invited independently as recognised experts in the area of lipid disorders (Longina Kłosiewicz-Latoszek, Dariusz Dudek, Mariusz Gąsior, Krzysztof Dyrbuś).

\section{CONFLICT OF INTEREST}

Maciej Banach has received grant/research support from Amgen, Sanofi, Mylan/Viatris, and has worked as a consultant/received lecture fees from: Amgen, Daichii Sankyo, Esperion, Freia Pharmaceuticals, Herbapol, Kogen, KRKA, Mylan/Viatris, Novo Nordisk, Novartis, Polfarmex, Polpharma, Sanofi, Teva, Zentiva; works as CMO in Nomi Biotech Corporation Ltd.; Dariusz Dudek
Table XLII. Scope of tests that can be performed in the Prevention 40 PLUS programme

The diagnostic test package for women contains:

1. Peripheral blood cell count with differential white blood cells (WBC) count and platelets

2. Total cholesterol concentration or control lipid profile

3. Blood glucose concentration

4. ALT, AST, $\gamma$-glutamyl transpeptidase (GGTP)

5. Blood creatinine level

6. General urine test

7. Blood uric acid level

8. Immunochemical faecal occult blood test (iFOBT)

The diagnostic test package for men contains:

1. Peripheral blood cell count with differential WBC count and platelets

2. Total cholesterol concentration or control lipid profile

3. Blood glucose concentration

4. ALT, AST, GGTP

5. Blood creatinine level

6. General urine test

7. Blood uric acid level

8. Immunochemical faecal occult blood test (iFOBT)

9. Total prostate-specific antigen (PSA)

Common diagnostic test package:

1. Arterial blood pressure measurement

2. Measurement of body weight, height, waist circumference, and calculation of body mass index (BMI)

3. Heart rhythm assessment

has received honoraria and grant/research support from: Amgen, Astra Zeneca, Cardinal Health, Gedeon Richter, Sanofi Piotr Jankowski has received honoraria and research grants from: Amgen, Sanofi, Novartis, Servier, Zentiva; Jacek Jóźwiak has received grant/research support from Valeant and has worked as a consultant/received lectures from: Amgen, Boehringer Ingelheim, Teva, Zentiva, Celgene, Servier, Bioton, ALAB; works as ADMO in Synexus; Irina Kowalska worked as consultant/received lecture fees from: Ascensia Diabetes Care, Boehringer Ingelheim, Eli Lilly, Novo Nordisk, Sanofi; Bogdan Solnica has received lecture fees from Abbott Laboratories Poland, Argenta, Beckman Coulter, Euroimmun, Roche Diagnostics, Siemens Healthcare; Tomasz Tomasik declares cooperation with Boehringer Ingelheim, Novartis, Shire, Biofarm, Eli Lilly, and AstraZeneca; Dorota Zozulińska-Ziółkiewicz has received grant/ research support from Novo Nordisk and worked as a consultant/received lecture fees from: Abbott, Astra Zeneca, Bioton, Boehringer Ingelheim, Dexcom, Eli Lilly, Medtronic, Mundipharma, Novo Nordisk, Roche, Sanofi, Zentiva; other experts report no conflict of interest. 
M. Banach, P. Burchardt, K. Chlebus, P. Dobrowolski, D. Dudek, K. Dyrbuś, M. Gąsior, P. Jankowski, J. Jóźwiak, L. Kłosiewicz-Latoszek, I. Kowalska, M. Małecki, A. Prejbisz, M. Rakowski, J. Rysz, B. Solnica, D. Sitkiewicz, G. Sygitowicz, G. Sypniewska, T. Tomasik, A. Windak, D. Zozulińska-Ziółkiewicz, B. Cybulska

\section{References}

1. Soran H, Adam S, Mohammad JB, et al. Hypercholesterolaemia - practical information for non-specialists Arch Med Sci 2018; 14: 1-21.

2. Penson PE, Pirro M, Banach M. LDL-C: lower is better for longer-even at low risk. BMC Med 2020; 18: 320.

3. Ling JZJ, Montvida O, Khunti K, Zhang AL, Xue CC, Paul SK. Therapeutic inertia in the management of dyslipidaemia and hypertension in incident type 2 diabetes and the resulting risk factor burden: real-world evidence from primary care. Diabetes Obes Metab 2021; 23: 1518-31.

4. Zdrojewski T, Solnica B, Cybulska B, et al. Prevalence of lipid abnormalities in Poland. The NATPOL 2011 survey. Kardiol Pol 2016; 74: 213-23.

5. Banach M, Penson PE. Cellular senescence, telomeres, and cardiovascular risk in familial hypercholesterolaemia. Eur J Prev Cardiol 2020 Dec 30: zwaa145. doi: 10.1093/eurjpc/zwaa145.

6. Cybulska B, Kłosiewicz-Latoszek L, Penson PE, Nabavi SM, Lavie CJ, Banach M; International Lipid Expert Panel (ILEP). How much should LDL cholesterol be lowered in secondary prevention? Clinical efficacy and safety in the era of PCSK9 inhibitors. Prog Cardiovasc Dis 2021; 67: 65-74.

7. Banach M, Penson PE. Statins and LDL-C in secondary prevention-so much progress, so far to go. JAMA Netw Open 2020; 3: e2025675.

8. Banach M, Jankowski P, Jóźwiak J, et al. PoLA/CFPiP/PCS guidelines for the management of dyslipidaemias for family physicians 2016. Arch Med Sci 2017; 13: 1-45.

9. Mach F, Baigent C, Catapano AL, et al.; ESC Scientific Document Group. 2019 ESC/EAS Guidelines for the management of dyslipidaemias: lipid modification to reduce cardiovascular risk. Eur Heart J 2020; 41: 111-88.

10. Jóźwiak JJ, Studziński K, Tomasik T, et al.; LIPIDOGRAM2015 Investigators. The prevalence of cardiovascular risk factors and cardiovascular disease among primary care patients in Poland: results from the LIPIDOGRAM2015 study. Atheroscler Suppl 2020; 42: e15-24.

11. NCD Risk Factor Collaboration (NCD-RisC). National trends in total cholesterol obscure heterogeneous changes in HDL and non-HDL cholesterol and total-toHDL cholesterol ratio: a pooled analysis of 458 population-based studies in Asian and Western countries. Int J Epidemiol 2020; 49: 173-92.

12. NCD Risk Factor Collaboration (NCD-RisC). Repositioning of the global epicentre of non-optimal cholesterol. Nature 2020; 582: 73-7.

13. Jóźwiak J. Dyslipidemie. In: Medycyna rodzinna. Podręcznik dla lekarzy i studentów. Windak A, Mastalerz-Migas A, Chlabicz S (eds.). Termedia, Poznan 2015.

14. Rywik S, Broda G, Piotrowski W, et al. Epidemiologia chorób układu krążenia - Program Pol-MONICA Warszawa. Kardiol Pol 1996; 44 (Suppl. 2): 7-35.

15. Tendera M, Kozakiewicz K, Bartnik M, et al. Występowanie głównych czynników ryzyka choroby niedokrwiennej serca w grupie 41927 osób objętych akcją prewencji pierwotnej w Polsce południowej (Southeren Poland Epidemiological Survey - SPES). Wiad Lek 2001; 54: 293-303.

16. Zdrojewski T, Bandosz P, Szpakowski P, et al. Rozpowszechnienie głównych czynników ryzyka chorób układu sercowo-naczyniowego w Polsce. Wyniki badania NATPOL PLUS. Kardiol Pol 2004; 61 (Suppl. 4): 1-26.
17. Pająk A, Wiercińska E, Polakowska M, et al. Rozpowszechnienie dyslipidemii u mężczyzn i kobiet w wieku 20-74 lat w Polsce. Wyniki programu WOBASZ. Kardiol Pol 2005; 63 (Suppl. 4): 620-6.

18. Jóźwiak J, Mastej M, Lukas W, et al. LIPIDOGRAM2003 - Ocena i porównanie parametrów pełnego lipidogramu i wskaźnika masy ciała BMI w zależności od płci i wieku w populacji pacjentów Polski południowej i zachodniej. Część II: częstość występowania zaburzeń lipidowych w zależności od płci i BMI. Probl Med Rodz 2005; 7: 33-9.

19. Jóźwiak J, Mastej M, Lukas W, et al. Czy problem zaburzeń lipidowych w równym stopniu dotyczy różnych regionów Polski? Kardiol Pol 2006; 64 (Suppl. 2): 137-45.

20. Konduracka E, Jóźwiak J, Mastej M, et al. Prevalence of dislipidemia and general ineffectiveness of its treatment In both primary and secondary prevention of coronary heart disease within family medicine framework - results of LIPIDOGRAM 2005 a nationwide epidemiological study. Dislipidemia in Poland - ineffective treatment. Przegl Lek 2008; 65: 834-7.

21. Pająk A, Szafraniec K, Polak M, et al. Changes in the prevalence, management and treatment of hypercholesterolemia and other dyslipidemias over 10 years in Poland. The WOBASZ study. Pol Arch Med Wewn 2016; 126: $642-52$

22. Kaess B, Jozwiak J, Mastej M, et al. Association between anthropometric obesity measures and coronary artery disease: a cross-sectional survey of 16,657 subjects from 444 Polish cities. Heart 2010; 96: 131-5.

23. Tomasik T, Jozwiak J, Windak A, et al. Prevention of coronary heart disease in primary medical care in Poland: results from the LIPIDOGRAM Study. Eur J Cardiovasc Prev Rehabil 2011; 18: 287-96.

24. Kaess BM, Jóźwiak J, Nelson CP, et al. The relation of rapid changes in obesity measures to lipid profile - insights from a nationwide metabolic health survey in 444 Polish cities. PLoS One 2014; 9: e86837.

25. Jankowski P, Czarnecka D, tukaszewska A, et al. Factors related to the effectiveness of hypercholesterolemia treatment following hospitalization for coronary artery disease. Pol Arch Med Wewn 2016; 126: 388-94.

26. Jankowski, Czarnecka, Badacz L, et al. Practice setting and secondary prevention of coronary artery disease. Arch Med Sci 2018; 14: 979-87.

27. Jóźwiak JJ, Kasperczyk S, Tomasik T, et al. Design and rationale of a nationwide screening analysis from the LIPIDOGRAM2015 and LIPIDOGEN2015 studies. Arch Med Sci 2020; doi.org/10.5114/aoms.2020.96052.

28. Harrison SL, Lane DA, Banach M, et al. Lipid levels, atrial fibrillation and the impact of age: results from the LIPIDOGRAM2015 study. Atherosclerosis 2020; 312: 16-22.

29. Gańczak M, Miazgowski T, Kożybska M, et al. Changes in disease burden in Poland between 1990-2017 in comparison with other Central European countries: a systematic analysis for the Global Burden of Disease Study 2017. PLoS One 2020; 15: e0226766.

30. Ray KK, Molemans B, Schoonen WM, et al. EU-wide cross-sectional observational study of lipid-modifying therapy use in secondary and primary care: the DAVINCI study. Eur J Prev Cardiol 2021; 28; 1279-89.

31. Vrablik M, Seifert B, Parkhomenko A, et al. Are riskbased LDL-C goals achieved in primary and secondary care in Central and Eastern Europe? Comparison with other Europe regions from the DA VINCI observational study. Atherosclerosis 2021; (in press). doi: https://doi. org/10.1016/j.atherosclerosis.2021.06.072. 
32. Podgórski M, Szatko K, Stańczyk M, et al. "Apple does not fall far from the tree" - subclinical atherosclerosis in children with familial hypercholesterolemia. Lipids Health Dis 2020; 19: 169.

33. EAS Familial Hypercholesterolaemia Studies Collaboration (FHSC). Global perspective of familial hypercholesterolaemia: a cross-sectional study from the EAS Familial Hypercholesterolaemia Studies Collaboration (FHSC). Lancet 2021 Sep 7:S0140-6736(21)01122-3. doi: 10.1016/S0140-6736(21)01122-3.

34. Dyrbuś K, Gąsior M, Desperak P, Osadnik T, Nowak J, Banach $M$. The prevalence and management of familial hypercholesterolemia in patients with acute coronary syndrome in the Polish tertiary centre: results from the TERCET registry with 19,781 individuals. Atherosclerosis 2019; 288: 33-41.

35. Langlois MR, Chapman MJ, Cobbaert C, et al. Quantifying atherogenic lipoproteins: current and future challenges in the era of personalized medicine and very low concentrations of LDL cholesterol. A Consensus Statement from EAS and EFLM. Clin Chem 2018; 64: 1006-33.

36. Sathiyakumar V, Pallazola VA, Park J, et al. Modern prevalence of the Fredrickson-Levy-Lees dyslipidemias: findings from the very large database of lipids and national health and nutrition examination survey. Arch Med Sci 2019; 16: 1279-87.

37. Boren J, Chapman MJ, Krauss RM, et al. Low-density lipoproteins cause atherosclerotic cardiovascular disease: pathophysiological, genetic, and therapeutic insights: a consensus statement from the European Atherosclerosis Society Consensus Panel. Eur Heart J 2020; 41: 2313-30.

38. Carr SS, Hooper AJ, Sullivan DR, Burnett JR. NonHDL-cholesterol and apolipoprotein B compared with LDL-cholesterol in atherosclerotic cardiovascular disease risk assessment. Pathology 2019; 51: 148-54.

39. Enger SC, Hjermann I, Foss OP, et al. High density lipoprotein cholesterol and myocardial infarction or sudden coronary death: a prospective case-control study in middle-aged men of the Oslo study. Artery 1979; 5: $170-81$.

40. Gordon DJ, Probstfield JL, Garrison RJ, et al. High-density lipoprotein cholesterol and cardiovascular disease. Four prospective American studies. Circulation 1989; 79: 8-15.

41. Otocka-Kmiecik A, Mikhailidis DP, Nicholls SJ, Davidson M, Rysz J, Banach M. Dysfunctional HDL: a novel important diagnostic and therapeutic target in cardiovascular disease? Prog Lipid Res 2012; 51: 314-24.

42. Barylski M, Toth PP, Nikolic D, Banach M, Rizzo M, Montalto $\mathrm{G}$. Emerging therapies for raising high-density lipoprotein cholesterol (HDL-C) and augmenting HDL particle functionality. Best Pract Res Clin Endocrinol Metab 2014; 28: 453-61.

43. Stahel P, Xiao C, Hegele RA, Lewis GF. The atherogenic dyslipidemia complex and novel approaches to cardiovascular disease prevention in diabetes. Can J Cardiol 2018; 34: 595-604.

44. Iqbal J, Al Qarni A, Hawwari A, Alghanem AF, Ahmed G. Metabolic syndrome, dyslipidemia and regulation of lipoprotein metabolism. Curr Diabetes Rev 2018; 14: 427-33.

45. Cybulska B, Kłosiewicz-Latoszek L, Penson PE, Banach $M$. What do we know about the role of lipoprotein(a) in atherogenesis 57 years after its discovery? Prog Cardiovasc Dis 2020; 63: 219-27.
46. Kamstrup PR. Lipoprotein(a) and ischemic heart disease - a causal association? A review. Atherosclerosis 2010; 211: 15-23.

47. Banach M. Lipoprotein (a) - we know so much yet still have much to learn .... J Am Heart Assoc 2016; 5: e003597.

48. Zdrojewski T, Jankowski P, Bandosz P, et al. A new version of cardiovascular risk assessment system and risk charts calibrated for Polish population. Kardiol Pol 2015; 73: 958-61.

49. Banach M, Penson PE. What have we learned about lipids and cardiovascular risk from PCSK9 inhibitor outcome trials: ODYSSEY and FOURIER? CardiovasC Res 2019; 115: e26-31.

50. Solnica B, Sygitowicz G, Sitkiewicz D, et al. 2020 Guidelines of the Polish Society of Laboratory Diagnostics (PSLD) and the Polish Lipid Association (PoLA) on laboratory diagnostics of lipid metabolism disorders. Arch Med Sci 2020; 16: 237-52.

51. Lambert JE, Parks EJ. Postprandial metabolism of meal trigliceryde in humans. Biochim Biophys Acta 2012; 1821: 721-6.

52. Boren J, Matikainen N, Adiels M, Taskinen MR. Postprandial hipertriglicerydemia as a coronary risk factor. Clin Chim Acta 2014; 431: 131-42.

53. Nordestgaard BG, Langsted A, Mora S, et al. European Atherosclerosis Society (EAS) and the European Federation of Clinical Chemistry and Laboratory Medicine (EFLM) Consensus Panel. Fasting is not routinely required for a lipid profile: clinical and laboratory implications including flagging at desirable concentration cut-points - a joint consensus statement from the European Atherosclerosis Society and European Federation of Clinical Chemistry and Laboratory Medicine. Clin Chem 2016; 62: 930-46.

54. Maierean SM, Mikhailidis DP, Toth PP, et al. The potential role of statins in preeclampsia and dyslipidemia during gestation: a narrative review. Expert Opin Investig Drugs 2018; 27: 427-35.

55. Bucolo G, David H. Quantitative determination of serum triglycerides by the use of enzymes. Clin Chem 1973; 19: 476-82.

56. Myasoedova E, Crowson CS, Maradit Kremers H, et al. Lipid paradox in rheumatoid arthritis: the impact of serum lipid measures and systemic inflammation on the risk of cardiovascular disease. Ann Rheum Dis 2011; 70: 482-7.

57. Colantonio LD, Bittner V, Reynolds K, et al. Association of serum lipids and coronary heart disease in contemporary observational studies. Circulation 2016; 133 : 256-64.

58. Gibbons GF, Islam K, Pease RJ. Mobilisation of triacylglycerol stores. Biochim Biophys Acta 2000; 1483: 37-57.

59. Ramirez M, Amate L, Gil A. Absorption and distribution of dietary fatty acids from different sources. Early Hum Dev 2001; 65 Suppl: S95-101.

60. Nordestgaard BG. Triglyceride-rich lipoproteins and atherosclerotic cardiovascular disease new insights from epidemiology, genetics, and biology. Circ Res 2016; 118: 547-63.

61. Quispe R, Hendrani AD, Baradaran-Noveiry B, et al. Characterization of lipoprotein profiles in patients with hypertriglyceridemic Fredrickson-Levy and Lees dyslipidemia phenotypes: the Very Large Database of Lipids Studies 6 and 7. Arch Med Sci 2019; 15: 1195-202. 
M. Banach, P. Burchardt, K. Chlebus, P. Dobrowolski, D. Dudek, K. Dyrbuś, M. Gąsior, P. Jankowski, J. Jóźwiak, L. Kłosiewicz-Latoszek, I. Kowalska, M. Małecki, A. Prejbisz, M. Rakowski, J. Rysz, B. Solnica, D. Sitkiewicz, G. Sygitowicz, G. Sypniewska, T. Tomasik, A. Windak, D. Zozulińska-Ziółkiewicz, B. Cybulska

62. Quispe R, Manalac RJ, Faridi KF, et al. Relationship of the triglyceride to high-density lipoprotein cholesterol (TG/HDL-C) ratio to the remainder of the lipid profile: the Very Large Database of Lipids-4 (VLDL-4) study. Atherosclerosis 2015; 242: 243-50

63. Catapano AL, Tokgozoglu L, Silva AM, Bruckert E. Atherogenic markers in predicting cardiovascular risk and targeting residual cardiovascular risk. Atherosclerosis 2019; Suppl: 1000001.

64. Siedel J, Schmuck R, Staepels J, et al. Long term stable, liquid ready-to-use mono reagent for the enzymatic assay of serum or plasma triglycerides (GPO-PAPmethod). AACC Meeting Abstract 34. Clin Chem 1993; 39: 1127.

65. Elshourbagy NA, Meyers HV, Abdel-Meguld SS. Cholesterol: the good, the bad, and the ungry - therapeutic target for the treatment of dyslipidemia. Med Princ Pract 2014; 23: 999-1111.

66. Rynkiewicz A, Cybulska B, Banach M, et al. Management of familial heterozygous hypercholesterolemia: position paper of the Polish Lipid Expert Forum. J Clin Lipidol 2013; 7: 217-21.

67. Allain CC, Poon LS, Chan CS, et al. Enzymatic determination of total serum cholesterol. Clin Chem 1974; 20: 470-5.

68. Cmont L, Chapman MJ, Kontush A. Biological activities of HDL subpopulations and their relevance to cardio vascular disease. Trends Mol Med 2011; 17: 594-603.

69. Soran H, Schofeld JD, Durrington PN. Antioxidant properties of HDL. Front Pharmacol 2015; 6: 222.

70. Van Lenten BJ, Navab M, Shih D, Fogelman AM, Lusis AJ. The role of high-density lipoproteins in oxidation and inflammation. Trends Cardiovasc Med 2001; 11: 155-61.

71. Rysz-Górzyńska M, Banach $M$. Subfractions of high-density lipoprotein (HDL) and dysfunctional HDL in chronic kidney disease patients. Arch Med Sci 2016; 12: 844-9.

72. Ganjali S, Watts GF, Banach M, Reiner Ž, Nachtigal P, Sahebkar A. The Yin and Yang of high-density lipoprotein and atherosclerotic cardiovascular disease: focusing on functionality and cholesterol efflux to reframe the HDL hypothesis. Curr Med Chem 2021; 28: 6066-81.

73. Ganjali S, Momtazi AA, Banach M, Kovanen PT, Stein EA, Sahebkar A. HDL abnormalities in familial hypercholesterolemia: focus on biological functions. Prog Lipid Res 2017; 67: 16-26.

74. Movva R, Rader DJ. Laboratory assessment of HDL heterogeneity and function. Clin Chem 2008; 54: 788-800.

75. Hafiane A, Genest J. High density lipoproteins: measurement techniques and potential biomarkers of cardiovascular risk. Biochem Biophys Acta 2015; 3: 175-88

76. Rizzo M, Otvos J, Nikolic D, Montalto G, Toth PP, Banach $M$. Subfractions and subpopulations of HDL: an update. Curr Med Chem 2014; 21: 2881-91.

77. Rysz-Gorzynska M, Gluba-Brzozka A, Banach M. Highdensity lipoprotein and low-density lipoprotein subfractions in patients with chronic kidney disease. Curr Vasc Pharmacol 2017; 15: 144-51.

78. The HPS2-THRIVE Collaborative Group. Effects of extended-release niacin with laropiprant in high-risk patients. N Engl J Med 2014; 371: 203-12.

79. Martin SS, Blaha MJ, Elshazly MB, et al. Comparison of a novel method vs the Friedewald equation fore stimulating low-density lipoprotein cholesterol levels from the standard lipid profile. JAMA 2013; 310: 2061-8.
80. Quispe R, Hendrani A, Elshazly MB, et al. Accuracy of low-density lipoprotein cholesterol estimation at very low levels. BMC Med 2017: 15: 83.

81. Chaen H, Kinchiku S, Miyata M, et al. Validity of a novel method for estimation of low-density lipoprotein cholesterol levels in diabetic patients. J Atheroscler Thromb 2016; 23: 1355-64.

82. Miller WG, Myers GL, Sakurabayashi I, et al. Seven direct methods for measuring $\mathrm{HDL}$ and LDL cholesterol compared with ultracentrifugation reference measurement procedures. Clin Chem 2010; 56: 977-86.

83. Sampson $M$, Ling C, Sun $Q$, et al. A new equation for calculation of low-density lipoprotein cholesterol in patients with normolipidemia and/or hypertriglyceridemia. JAMA Cardiol 2020; 5: 540-8.

84. Li KM, Wilcken DE, Dudman NP. Effect of serum lipoprotein(a) on estimation of low-density lipoprotein cholesterol by the Friedewald formula. Clin Chem 1994; 40: 571-3.

85. Tabas I, Williams KJ, Boren J. Subendothelial lipoprotein retention as the initiating process in atherosclerosis: update and therapeutic implications. Circulation 2007; 116: 1832-44.

86. Boren J, Williams KJ. The central role of arterial retention of cholesterol-rich apolipoprotein-B-containing lipoproteins in the pathogenesis of atherosclerosis: a triumph of simplicity. Curr Opin Lipidol 2016; 27: 473-83.

87. National trends in total cholesterol obscure heterogeneous changes in HDL andnon-HDLcholesterol and total-to-HDL cholesterol ratio: a pooled analysis of 458 population-based studies in Asian and Western countries. NCD Risk Factor Collaboration. Int J Epidemiol 2020; 49: 173-92.

88. Sygitowicz G, Filipiak KJ, Sitkiewicz D. Czy nie-HDL cholesterol lepiej niż cholesterol frakcji LDL odzwierciedla ryzyko sercowo-naczyniowe? Folia Cardiol 2018; 13: 435-41.

89. Dominiczak MH, Caslake MJ. Apolipoproteins: metabolic role and clinical biochemistry applications. Ann Clin Biochem 2011; 48: 498-515.

90. Contois JH, McConnell JP, Sethi AA, et al. Apolipoprotein $B$ and cardiovascular disease risk: position statement from the AACC lipoproteins and vascular diseases division working group on best practices. Clin Chem 2009; 55: 407-19.

91. Marcovina SM, Albers JJ. Lipoprotein (a) measurements for clinical application. J Lipid Res 2016; 57: 526-37.

92. Blanchard V, Chemello K, Hollstein T, et al. The size of apolipoprotein (a) is an independent determinant of the reduction in lipoprotein (a) induced by PCSK9 inhibitors. Cardiovasc Res 2021 Jul 26: cvab247. doi: 10.1093/cvr/cvab247.

93. Ferretti G, Bacchetti T, Johnston TP, Banach M, Pirro M, Sahebkar A. Lipoprotein(a): a missing culprit in the management of athero-thrombosis? J Cell Physiol 2018; 233: 2966-81.

94. Toth PP, Jones SR, Monsalvo ML, Elliott-Davey M, López JAG, Banach M. Effect of evolocumab on nonhigh-density lipoprotein cholesterol, apolipoprotein B, and lipoprotein(a): a pooled analysis of phase 2 and phase 3 studies. J Am Heart Assoc 2020; 9: e014129.

95. Banach M. Lipoprotein (a) - we know so much yet still have much to learn ... . J Am Heart Assoc 2016; 5: e003597.

96. Cao J, Steffen BT, Guan W, et al. Evaluation of lipoprotein(a) electrophoretic and immunoassay methods in 
discriminating risk of calcific aortic valve disease and incident coronary heart disease: the multi-ethnic study of atherosclerosis. Clin Chem 2017; 63: 1705-13.

97. Nordestgaard BG, Chapman MJ, Ray K, et al. Lipoprotein(a) as a cardiovascular risk factor: current status. Eur Heart J 2010; 31: 2844-53.

98. Tsimikas S. A test in context: lipoprotein(a) diagnosis, prognosis, controversies, and emerging therapies. JACC 2017; 69: 692-711.

99. Moulin P, Dufour R, Averna M, et al. Identification and diagnosis of patients with familial chylomicronaemia syndrome (FCS): expert panel recommendations and proposal of an "FCS score". Atherosclerosis 2018; 275: 265-72.

100. Fahed AC, Nemer GM. Familial hypercholesterolemia: the lipids or the genes? Nutr Metab 2011; 8: 23.

101. Masson W, Lobo M, Siniawski D, et al. Role of non-statin lipid-lowering therapy in coronary atherosclerosis regression: a meta-analysis and meta-regression. Lipids Health Dis 2020; 19: 111.

102. Banach M, Serban C, Sahebkar A, et al.; Lipid and Blood Pressure Meta-analysis Collaboration (LBPMC) Group. Impact of statin therapy on coronary plaque composition: a systematic review and meta-analysis of virtual histology intravascular ultrasound studies. BMC Med 2015; 13: 229.

103. Nicholls SJ, Puri R, Anderson T, et al. Effect of evolocumab on coronary plaque composition. J Am Coll Cardiol 2018; 72: 2012-21.

104. Barrios V, Escobar C, Banach M. Primary prevention. The cornerstone to reduce the burden of cardiovascular disease. Rev Esp Cardiol 2021 May 31: S18855857(21)00143-2.

105. Wang N, Jordan Fulcher J, Abeysuriya N, et al. Intensive LDL cholesterol-lowering treatment beyond current recommendations for the prevention of major vascular events: a systematic review and meta-analysis of randomised trials including 327037 participants. Lancet Diabetes Endocrinol 2020; 8: 36-49.

106. Ference BA, Ginsberg HN, Graham I, et al. Low-density lipoproteins cause atherosclerotic cardiovascular disease. 1. Evidence from genetic, epidemiologic, and clinical studies. A consensus statement from the European Atherosclerosis Society Consensus Panel. Eur Heart J 2017; 38: 2459-72.

107. Mannarino MR, Sahebkar A, Bianconi V, Serban MC, Banach M, Pirro M. PCSK9 and neurocognitive function: should it be still an issue after FOURIER and EBBINGHAUS results? J Clin Lipidol 2018; 12: 1123-32.

108. Silva Marques J, Ennis G, Venade G, João Soares R, Monteiro N, Gomes A. Association of statins with functional outcome and 30-day mortality in patients with intracerebral hemorrhage. Cureus 2021; 13: e14421.

109. Banach M, Penson PE, Vrablik M, et al.; ACS EuroPath Central \& South European Countries Project. Optimal use of lipid-lowering therapy after acute coronary syndromes: a position paper endorsed by the International Lipid Expert Panel (ILEP). Pharmacol Res 2021; 166: 105499.

110. Bohula EA, Bonaca MP, Braunwald E, et al. Atherothrombotic risk stratification and the efficacy and safety of vorapaxar in patients with stable ischemic heart disease and previous myocardial infarction. Circulation 2016; 134: 304-13.

111. Jellinger PS, Handelsman Y, Rosenblit PD, et al. American Association of Clinical Endocrinologists and American College of Endocrinology guidelines for manage- ment of dyslipidemia and prevention of cardiovascular disease. Endocr Pract 2017; 23: 479-97.

112. Sabatine MS, De Ferrari GM, Giugliano RP, et al. Clinical benefit of evolocumab by severity and extent of coronary artery disease: analysis from FOURIER. Circulation 2018; 138: 756-66.

113. Jukema JW, Szarek M, Zijlstra LE, et al.; ODYSSEY OUTCOMES Committees and Investigators. Alirocum$a b$ in patients with polyvascular disease and recent acute coronary syndrome: ODYSSEY OUTCOMES trial. J Am Coll Cardiol 2019; 74: 1167-76.

114. Dyrbuś K, Gąsior M, Desperak P, et al. Risk-factors associated with extremely high cardiovascular risk of mid- and long-term mortality following myocardial infarction: analysis of the Hyperlipidaemia Therapy in tERtiary Cardiological cEnTer (TERCET) registry. Atherosclerosis 2021; 333: 16-23.

115. Katsiki N, Nikolic D, Montalto G, Banach M, Mikhailidis DP, Rizzo M. The role of fibrate treatment in dyslipidemia: an overview. Curr Pharm Des 2013; 19: 3124-31.

116. Mensink RP, Zock PL, Kester AD, Katan MB. Effects of dietary fatty acids and carbohydrates on the ratio of serum total to HDL cholesterol and on serum lipids and apolipoproteins: a meta-analysis of 60 controlled trials. Am J Clin Nutr 2003; 77: 1146-55.

117. Riccardi G, Vaccaro O, Costabile G, Rivellese AA. How well can we control dyslipidemias through lifestyle modifications? Curr Cardiol Rep 2016; 18: 66.

118. Nordmann AJ, Nordmann A, Briel M, et al. Effects of low-carbohydrate vs low-fat diets on weight loss and cardiovascular risk factors: a meta-analysis of randomized controlled trials. Arch Intern Med 2006; 166: 285-93.

119. Shaw K, Gennat H, O'Rourke P, Del Mar C. Exercise for overweight or obesity. Cochrane Database Syst Rev 2006; 4: CD003817.

120. Zhubi-Bakija F, Bajraktari G, Bytyçi I, et al.; International Lipid Expert Panel (ILEP). The impact of type of dietary protein, animal versus vegetable, in modifying cardiometabolic risk factors: a position paper from the International Lipid Expert Panel (ILEP). Clin Nutr 2021; 40: 255-76.

121. Brien SE, Ronksley PE, Turner BJ, Mukamal KJ, Ghali WA. Effect of alcohol consumption on biological markers associated with risk of coronary heart disease: systematic review and meta-analysis of interventional studies. BMJ 2011; 342: d636.

122. Sahebkar A, Serban MC, Gluba-Brzózka A, et al. Lipidmodifying effects of nutraceuticals: an evidencebased approach. Nutrition 2016; 32: 1179-92.

123. Mazidi M, Mikhailidis DP, Sattar N, et al.; International Lipid Expert Panel (ILEP) \& Lipid and Blood Pressure Meta-analysis Collaboration (LBPMC) Group. Association of types of dietary fats and all-cause and cause-specific mortality: a prospective cohort study and meta-analysis of prospective studies with 1,164,029 participants. Clin Nutr 2020; 39: 3677-86.

124. Taskinen MR, Soderlund S, Bogl LH, et al. Adverse effects of fructose on cardiometabolic risk factors and hepatic lipid metabolism in subjects with abdominal obesity. J Intern Med 2017; 282: 187-201.

125. Cosentino F, Grant PJ, Aboyans V, et al. The Task Force for diabetes, pre-diabetes, and cardiovascular diseases of the European Society of Cardiology (ESC) and the European Association for the Study of Diabetes (EASD). 2019 ESC Guidelines on diabetes, pre-diabetes, and cardiovascular diseases developed in collaboration with the EASD. Eur Heart J 2020; 41: 255-323. 
M. Banach, P. Burchardt, K. Chlebus, P. Dobrowolski, D. Dudek, K. Dyrbuś, M. Gąsior, P. Jankowski, J. Jóźwiak, L. Kłosiewicz-Latoszek, I. Kowalska, M. Małecki, A. Prejbisz, M. Rakowski, J. Rysz, B. Solnica, D. Sitkiewicz, G. Sygitowicz, G. Sypniewska, T. Tomasik, A. Windak, D. Zozulińska-Ziółkiewicz, B. Cybulska

126. Ganjali S, Banach M, Pirro M, Fras Z, Sahebkar A. HDL and cancer - causality still needs to be confirmed? Update 2020. Semin Cancer Biol 2021; 73: 169-77.

127. Ganjali S, Ricciuti B, Pirro M, et al. High-density lipoprotein components and functionality in cancer: stateof-the-art. Trends Endocrinol Metab 2019; 30: 12-24.

128. Huffman KM, Hawk VH, Henes ST, et al. Exercise effects on lipids in persons with varying dietary patterns-does diet matter if they exercise? Responses in studies of a targeted risk reduction intervention through defined exercise. Am Heart J 2012; 164: 117-24.

129. Maeda K, Noguchi Y, Fukui T. The effects of cessation from cigarette smoking on the lipid and lipoprotein profiles: a meta-analysis. Prev Med 2003; 37: 283-90.

130. GBD 2016 Alcohol Collaborators. Alcohol use and burden for 195 countries and territories, 1990-2016: a systematic analysis for the Global Burden of Disease Study 2016. Lancet 2018; 392: 1015-35.

131. Penson PE, Banach M. Natural compounds as anti-atherogenic agents: clinical evidence for improved cardiovascular outcomes. Atherosclerosis 2021; 316: 58-65.

132. Fogacci F, Banach M, Mikhailidis DP, et al.; Lipid and Blood Pressure Meta-analysis Collaboration (LBPMC) Group; International Lipid Expert Panel (ILEP). Safety of red yeast rice supplementation: a systematic review and meta-analysis of randomized controlled trials. Pharmacol Res 2019; 143: 1-16.

133. Banach $M$, Katsiki N, Latkovskis G, et al. Postmarketing nutrivigilance safety profile: a line of dietary food supplements containing red yeast rice for dyslipidemia. Arch Med Sci 2021; 17: 856-63.

134. Cicero AFG, Colletti A, Bajraktari G, et al. Lipid lowering nutraceuticals in clinical practice: position paper from an International Lipid Expert Panel. Arch Med Sci 2017; 13: 965-1005.

135. Cicero AFG, Colletti A, Bajraktari G, et al. Lipid-lowering nutraceuticals in clinical practice: position paper from an International Lipid Expert Panel. Nutr Rev 2017; 75: 731-67.

136. Banach M, Patti AM, Giglio RV, et al.; International Lipid Expert Panel (ILEP). The role of nutraceuticals in statin intolerant patients. J Am Coll Cardiol 2018; 72 96-118.

137. Gylling H, Plat J, Turley S, et al.; European Atherosclerosis Society Consensus Panel on Phytosterols. Plant sterols and plant stanols in the management of dyslipidaemia and prevention of cardiovascular disease. Atherosclerosis 2014; 232: 346-60.

138. Poli A, Barbagallo CM, Cicero AFG, et al. Nutraceuticals and functional foods for the control of plasma choles terol levels. An intersociety position paper. Pharmacol Res 2018; 134: 51-60.

139. Mazidi M, Katsiki N, Shekoohi N, Banach M. Monounsaturated fatty acid levels may not affect cardiovascular events: results from a mendelian randomization analysis. Front Nutr 2020; 7: 123.

140. Averna M, Banach M, Bruckert E, et al. Practical guid ance for combination lipid-modifying therapy in high- and very-high-risk patients: a statement from a European Atherosclerosis Society Task Force. Athero sclerosis 2021; 325: 99-109.

141. Banach M, Bruckert E, Descamps OS, et al. The role of red yeast rice (RYR) supplementation in plasma cholesterol control: a review and expert opinion. Atheroscler Suppl 2019; 39: e1-8.

142. Morze J, Osadnik T, Osadnik K, et al. A network meta-analysis on the comparative efficacy of nutraceuticals on lipid profile. Circulation 2019; 140: A13360.
143. Momtazi AA, Banach M, Pirro M, Katsiki N, Sahebkar A Regulation of PCSK9 by nutraceuticals. Pharmacol Res 2017; 120: 157-69.

144. Stepniak U, Micek A, Waśkiewicz A, et al. Prevalence of general of abdominal obesity and overweight among adults in Poland. Results of the WOBASZ II study (2013-2014) and comparison with the WOBASZ study (2003-2005). Pol Arch Med Wewn 2016; 126: 662-71.

145. Hartley L, May MD, Loveman E, Colquitt JL, Rees K. Di etary fibre for the primary prevention of cardiovascular disease. Cochrane Database Syst Rev 2016; 2016 : CD011472.

146. Rivellese AA, Maffettone A, Vessby B, et al. Effects of dietary saturated, monounsaturated and $n-3$ fatty acids on fasting lipoproteins, LDL size and post-prandial lipid metabolism in healthy subjects. Atherosclerosis 2003; 167: 149-58.

147. Bhatt DL, Steg PG, Miller M, et al.; REDUCE-IT Inves tigators. Cardiovascular risk reduction with icosapent ethyl for hypertriglyceridemia. N Engl J Med 2019; 380: 11-22.

148. Moholdt T, Lavie CJ, Nauman J. Sustained physical activity, not weight loss, associated with improved survival in coronary heart disease. J Am Coll Cardiol 2018; 71: 1094-101.

149. Toth PP, Banach M. Statins: then and now. Methodist Debakey Cardiovasc J 2019; 15: 23-31.

150. Shehab A, Elnour AA, Bhagavathula AS, et al. A multicenter prospective hospital-based cohort study on the efficacy and safety of pitavastatin. Curr Diabetes Rev 2021; 17: e122820189541.

151. Jones PH, Davidson MH, Stein EA, et al. Comparison of the efficacy and safety of rosuvastatin versus atorvastatin, simvastatin, and pravastatin across doses (STELLAR* Trial). Am J Cardiol 2003; 92: 152-60.

152. Banach M, Stulc T, Dent R, Toth PP. Statin non-adher ence and residual cardiovascular risk: there is need for substantial improvement. Int J Cardiol 2016; 225: 184-96.

153. Banach M, Rizzo M, Toth P, et al. Statin intolerance - an attempt at a unified definition. Position paper from an International Lipid Expert Panel. Arch Med Sci 2015; 11: 1-23.

154. Banach M, Rizzo M, Obradovic M, et al. PCSK9 inhibition - a novel mechanism to treat lipid disorders? Curr Pharm Des 2013; 19: 3869-77.

155. Mikhailidis DP, Lawson RW, McCormick AL, et al. Comparative efficacy of the addition of ezetimibe to statin vs statin titration in patients with hypercholesterolaemia: systematic review and meta-analysis. Curr Med Res Opin 2011; 27: 1191-210.

156. Banach M, Mikhailidis DP. Statin intolerance: some practical hints. Cardiol Clin 2018; 36: 225-31.

157. Banach M, Penson PE, Fras Z, et al.; FH Europe and the International Lipid Expert Panel (ILEP). Brief recommendations on the management of adult patients with familial hypercholesterolemia during the COVID-19 pandemic. Pharmacol Res 2020; 158: 104891.

158. Banach M, Mikhailidis DP. Statin therapy and new-onset diabetes: an attempt at recommendations. Exp Rev Endocrinol Metab 2013; 8: 213-6.

159. Cholesterol Treatment Trialists' Collaboration (CTT). Efficacy and safety of more intensive lowering of LDL cholesterol: a meta-analysis of data from 170000 participants in 26 randomised trials. Lancet 2010; 376: 1670-81.

160. Garcia-Calvo M, Lisnock J, Bull HG. The target of ezetimibe is Niemann-Pick C1-like 1 (NPC1L1). Proc Natl Acad Sci USA 2005; 102: 8132-7. 
161. Knopp RH, Gitter H, Truitt T, et al. Effects of ezetimibe, a new cholesterol absorption inhibitor on plasma lipids in patients with primary hypercholesterolemia. Eur Heart J 2003; 24: 729-41.

162. Simon JS, Karnoub MC, Devlin DJ, et al. Sequence variation in NPC1L1 and association with improved LDL-cholesterol lowering in response to ezetimibe treatment. Genomic 2005; 86: 648-56.

163. Dujovne CA, Ettinger MP, McNeer JF, et al. Efficacy and safety of a potent new selective cholesterol absorption inhibitor, ezetimibe, in patients with primary hypercholesterolemia. Am J Cardiol 2002; 90: 1092-7.

164. Awad K, Mikhailidis DP, Katsiki N, Muntner P, Banach M; Lipid and Blood Pressure Meta-Analysis Collaboration (LBPMC) Group. Effect of ezetimibe monotherapy on plasma lipoprotein(a) concentrations in patients with primary hypercholesterolemia: a systematic review and meta-analysis of randomized controlled trials. Drugs 2018; 78: 453-62.

165. Sahebkar A, Simental-Mendía LE, Pirro M, et al. Impact of ezetimibe on plasma lipoprotein(a) concentrations as monotherapy or in combination with statins: a systematic review and meta-analysis of randomized controlled trials. Sci Rep 2018; 8: 17887.

166. Tsimikas S, Gordts PLSM, Nora C, Yeang C, Witztum JL. Statin therapy increases lipoprotein(a) levels. Eur Heart J 2020; 41: 2275-84.

167. Banach M, Penson PE. Statins and Lp(a): do not make perfect the enemy of excellent. Eur Heart J 2020; 41: 190-1.

168. Lee J, Hwang YC, Lee WJ, et al. Comparison of the efficacy and safety of rosuvastatin/ezetimibe combination therapy and rosuvastatin monotherapy on lipoprotein in patients with type 2 diabetes: multicenter randomized controlled study. Diabetes Ther 2020; 11: 859-71.

169. Dyrbus K, Gasior M, Desperak P, Nowak J, Osadnik T, Banach M. Characteristics of lipid profile and effectiveness of management of dyslipidaemia in patients with acute coronary syndromes - data from the TERCET registry with 19,287 patients. Pharmacol Res 2019; 139: 460-6.

170. Katsiki N, Mikhailidis DP, Banach M. Lipid-lowering agents for concurrent cardiovascular and chronic kidney disease. Expert Opin Pharmacother 2019; 20: 2007-17.

171. Serban MC, Banach M, Mikhailidis DP. Clinical implications of the IMPROVE-IT trial in the light of current and future lipid-lowering treatment options. Expert Opin Pharmacother 2016; 17: 369-80.

172. Bays H. Ezetimibe. Expert Opin Investig Drugs 2002; 11: 1587-604.

173. Dragan S, Serban MC, Banach M. Proprotein convertase subtilisin/kexin 9 inhibitors: an emerging lipidlowering therapy? J Cardiovasc Pharmacol Ther 2015; 20: 157-68.

174. Abifadel $M$, Varret $M$, Rabès JP, et al. Mutations in PCSK9 cause autosomal dominant hypercholesterolemia. Nat Genet 2003; 34: 154-6.

175. Blumenthal DM, Maddox TM, Aragam K, Sacks CA, Virani SS, Wasfy JH. Predictors of PCSK9 (proprotein convertase subtilisin/kexin type 9) inhibitor prescriptions for secondary prevention of clinical atherosclerotic cardiovascular disease. Circ Cardiovasc Qual Outcomes 2021 Aug 18:CIRCOUTCOMES120007237. doi: 10.1161/CIRCOUTCOMES.120.007237.

176. Sabatine MS, Giugliano RP, Keech AC, et al.; FOURIER Steering Committee and Investigators. Evolocumab and clinical outcomes in patients with cardiovascular disease. N Engl J Med 2017; 376: 1713-22.

177. Schwartz GG, Steg PG, Szarek M, et al.; ODYSSEY OUTCOMES Committees and Investigators. Alirocum$\mathrm{ab}$ and cardiovascular outcomes after acute coronary syndrome. N Engl J Med 2018; 379: 2097-107.

178. Macchi C, Ferri N, Sirtori CR, Corsini A, Banach M, Ruscica M. Proprotein convertase subtilisin/kexin type 9: a view beyond the canonical cholesterol-lowering impact. Am J Pathol 2021; 191: 1385-97.

179. Koskinas KC, Windecker S, Pedrazzini G, et al. Evolocumab for early reduction of LDL cholesterol levels in patients with acute coronary syndromes (EVOPACS). J Am Coll Cardiol 2019; 74: 2452-62.

180. Leucker TM, Blaha MJ, Jones SR, et al. Effect of evolocumab on atherogenic lipoproteins during the periand early postinfarction period: a placebo-controlled, randomized trial. Circulation 2020; 142: 419-21.

181. Trankle CR, Wohlford G, Buckley LF, et al. Alirocumab in acute myocardial infarction: results from the Virginia Commonwealth University Alirocumab Response Trial (VCU-AlirocRT). J Cardiovasc Pharmacol 2019; 74: 266-9.

182. Banach M, Rizzo M, Nikolic D, Howard G, Howard V, Mikhailidis D. Intensive LDL-cholesterol lowering therapy and neurocognitive function. Pharmacol Ther 2017; 170: 181-91.

183. Giugliano RP, Mach F, Zavitz K, et al.; EBBINGHAUS Investigators. Design and rationale of the EBBINGHAUS trial: a phase 3, double-blind, placebo-controlled, multicenter study to assess the effect of evolocumab on cognitive function in patients with clinically evident cardiovascular disease and receiving statin background lipid-lowering therapy-A cognitive study of patients enrolled in the FOURIER trial. Clin Cardiol 2017; 40: 59-65.

184. Giugliano RP, Mach F, Zavitz K, et al.; EBBINGHAUS Investigators. cognitive function in a randomized trial of evolocumab. N Engl J Med 2017; 377: 633-43.

185. Nikolic D, Castellino G, Banach M, et al. PPAR agonists, atherogenic dyslipidemia and cardiovascular risk. Curr Pharm Des 2017; 23: 894-902.

186. Keech A, Simes RJ, Barter P, et al. Effects of long-term fenofibrate therapy on cardiovascular events in 9795 people with type diabetes mellitus (the FIELD study): a randomised controlled study. Lancet 2005; 366: 1849-61.

187. ACCORD Study Group. Ginsberg HM, Lovato LC, et al. Effects of combination lipid therapy in type 2 diabetes mellitus. N Engl J Med 2010; 362: 1563-74.

188. Elam MB, Ginsberg HN, Lovato LC, et al.; ACCORDION Study Investigators. Association of fenofibrate therapy with long-term cardiovascular risk in statin-treated patients with type 2 diabetes. JAMA Cardiol 2017; 2: 370-80.

189. Klempfner R, Erez A, Sagit BZ, et al. Elevated triglyceride level is independently associated with increased all-cause mortality in patients with established coronary heart disease: twenty-two-year follow-up of the bezafibrate infarction prevention study and registry. Circ Cardiovasc Qual Outcomes 2016; 9: 100-8.

190. Araki E, Yamashita S, Arai H, et al. Efficacy and safety of pemafibrate in people with type 2 diabetes and elevated triglyceride levels: 52-week data from the PROVIDE study. Diabetes Obes Metab 2019; 21: 1737-44.

191. Pradhan AD, Paynter NP, Everett BM, et al. Rationale and design of the Pemafibrate to Reduce Cardiovascular Outcomes by Reducing Triglycerides in Patients 
M. Banach, P. Burchardt, K. Chlebus, P. Dobrowolski, D. Dudek, K. Dyrbuś, M. Gąsior, P. Jankowski, J. Jóźwiak, L. Kłosiewicz-Latoszek, I. Kowalska, M. Małecki, A. Prejbisz, M. Rakowski, J. Rysz, B. Solnica, D. Sitkiewicz, G. Sygitowicz, G. Sypniewska, T. Tomasik, A. Windak, D. Zozulińska-Ziółkiewicz, B. Cybulska

with Diabetes (PROMINENT) study. Am Heart J 2018; 206: 80-93.

192. Budoff MJ, Muhlestein JB, Bhatt DL, et al. Effect of icosapent ethyl on progression of coronary atherosclerosis in patients with elevated triglycerides on statin therapy: a prospective, placebo-controlled randomized trial (EVAPORATE): interim results. Cardiovasc Res 2021; 117: 1070-7.

193. Manson JE, Cook NR, Lee IM, et al.; VITAL Research Group. Marine n-3 fatty acids and prevention of cardiovascular disease and cancer. N Engl J Med 2019; 380: 23-32.

194. Nicholls SJ, Lincoff AM, Garcia M, et al. Effect of highdose omega-3 fatty acids vs corn oil on major adverse cardiovascular events in patients at high cardiovascular risk: the STRENGTH randomized clinical trial. JAMA 2020; 324: 2268-80.

195. Mazidi M, Mikhailidis DP, Banach M. Omega-3 fatty acids and risk of cardiovascular disease: systematic review and meta-analysis of randomized controlled trials with 127,447 individuals and a mendelian randomization study. Circulation 2019; 140: e965-1011.

196. Tadic M, Sala C, Grassi G, et al. Omega-3 fatty acids and coronary artery disease: more questions than answers. J Clin Med 2021; 10: 2495.

197. Ooi CP, Loke SC. Colesevelam for type 2 diabetes mellitus: an abridged Cochrane review. Diabet Med 2014; 31: 2-14.

198. The Lipid Research Clinics Coronary Primary Prevention Trial results. I. Reduction in incidence of coronary heart disease. JAMA 1984; 251: 351-64.

199. The Lipid Research Clinics Coronary Primary Prevention Trial. Results of 6 years of post-trial follow-up. The Lipid Research Clinics Investigators. Arch Intern Med 1992; 152: 1399-410.

200. He L, Wickremasingha P, Lee J, et al. Lack of effect of colesevelam $\mathrm{HCl}$ on the single-dose pharmacokinetics of aspirin, atenolol, enalapril, phenytoin, rosiglitazone, and sitagliptin. Diabetes Res Clin Pract 2014; 104 401-9.

201. Kamanna VS, Kashyap ML. Mechanism of action of niacin. Am J Cardiol 2008; 101: 20B-6B.

202. Bruckert E, Labreuche J, Amarenco P. Meta-analysis of the effect of nicotinic acid alone or in combination on cardiovascular events and atherosclerosis. Atherosclerosis 2010; 210: 353-61.

203. AIM-HIGH Investigators; Boden WE, Probstfield JL, Anderson $\mathrm{T}$, et al. Niacin in patients with low HDL choles terol levels receiving intensive statin therapy. $\mathrm{N}$ Engl J Med 2011; 365: 2255-67.

204. HPS2-THRIVE Collaborative Group; Landray MJ, Haynes R, Hopewell JC, et al. Effects of extended-release niacin with laropiprant in high-risk patients. N Engl J Med 2014; 371: 203-12.

205. De Backer G, Jankowski P, Kotseva K, et al.; EUROASPIRE $V$ collaborators. Management of dyslipidaemia in patients with coronary heart disease: Results from the ESC-EORP EUROASPIRE $V$ survey in 27 countries. Atherosclerosis 2019; 285: 135-46.

206. Baumgartner A, Drame K, Geutjens S, et al. Does the polypill improve patient adherence compared to its individual formulations? A systematic review. Pharma ceutics 2020; 12: 190.

207. Selak V, Webster R, Stepien S, et al. Reaching cardiovascular prevention guideline targets with a polypill-based approach: a meta-analysis of randomised clinical trials. Heart 2019; 105: 42-8.
208. Katzmann JL, Sorio-Vilela F, Dornstauder E, et al. Non-statin lipid-lowering therapy over time in veryhigh-risk patients: effectiveness of fixed-dose statin/ ezetimibe compared to separate pill combination on LDL-C. Clin Res Cardiol 2020; doi: 10.1007/s00392020-01740-8.

209. Pappa E, Rizos CV, Filippatos TD, et al. Emerging fixeddose combination treatments for hyperlipidemia. J Cardiovasc Pharmacol Ther 2019; 24: 315-22.

210. Ballantyne CM, Laufs U, Ray KK, et al. Bempedoic acid plus ezetimibe fixed-dose combination in patients with hypercholesterolemia and high CVD risk treated with maximally tolerated statin therapy. Eur J Prev Cardiol 2020; 27: 593-603.

211. Laufs U, Parhofer KG, Ginsberg HN, et al. Clinical review on triglycerides. Eur Heart J 2020; 41: 99-109.

212. Vallejo-Vaz AJ, Corral P, Schreier L, Ray KK. Triglycerides and residual risk. Curr Endocrinol Diabetes Obes 2020; 27: 95-103.

213. Gallo A, Beliard S, D’Erasmo L, Bruckert E. Familial chylomicronemia syndrome (FCS). Recent data on diagnosis and treatment. Curr Atheroscler Rep 2020; 22: 63.

214. Chait A, Brunzell JD. Chylomicronemia syndrome. Adv Intern Med 1992; 37: 249-73.

215. Vitztum JL, Gaudet D, Freedman SD, et. al. Volanesorsen and triglyceride levels in familial chylomicronemia syndrome. N Engl J Med 2019; 381: 531-42.

216. Ruscica M, Banach M, Sahebkar A, Corsini A, Sirtori CR. ETC-1002 (Bempedoic acid) for the management of hyperlipidemia: from preclinical studies to phase 3 trials. Expert Opin Pharmacother 2019; 20: 791-803.

217. Ballantyne CM, Banach M, Mancini GBJ, et al. Efficacy and safety of bempedoic acid added to ezetimibe in statin-intolerant patients with hypercholesterolemia: a randomized, placebo-controlled study. Atherosclerosis 2018; 277: 195-203.

218. Ray KK, Bays HE, Catapano AL, et al.; CLEAR Harmony Trial. Safety and efficacy of bempedoic acid to reduce LDL cholesterol. N Engl J Med 2019; 380: 1022-32.

219. Laufs U, Banach M, Mancini GBJ, et al. Efficacy and safety of bempedoic acid in patients with hypercholesterolemia and statin intolerance. J Am Heart Assoc 2019; 8: e011662.

220. Goldberg AC, Leiter LA, Stroes ESG, et al. Effect of bempedoic acid vs placebo added to maximally tolerated statins on low-density lipoprotein cholesterol in patients at high risk for cardiovascular disease: the CLEAR wisdom randomized clinical trial. JAMA 2019; 322: 1780-8.

221. Banach M, Duell PB, Gotto AM Jr, et al. Association of bempedoic acid administration with atherogenic lipid levels in phase 3 randomized clinical trials of patients with hypercholesterolemia. JAMA Cardiol 2020; 5: 1124-35.

222. Cicero AFG, Fogacci F, Hernandez AV, Banach M; Lipid and Blood Pressure Meta-Analysis Collaboration (LBPMC) Group and the International Lipid Expert Panel (ILEP). Efficacy and safety of bempedoic acid for the treatment of hypercholesterolemia: a systematic review and meta-analysis. PLoS Med 2020; 17: e1003121.

223. Banach M, Penson PE. Lipid-lowering therapies: better together. Atherosclerosis 2021; 320: 86-8.

224. Dyrbuś K, Gąsior M, Penson P, Ray KK, Banach M. Inclisiran - new hope in the management of lipid disorders? J Clin Lipidol 2020; 14: 16-27.

225. Kosmas CE, Muñoz Estrella A, Skavdis A, et al. Inclisiran for the treatment of cardiovascular disease: a short 
review on the emerging data and therapeutic potential. Ther Clin Risk Manag 2020; 16: 1031-7.

226. Ciccarelli G, D’Elia S, De Paulis M, et al. Lipid target in very high-risk cardiovascular patients: lesson from PCSK9 monoclonal antibodies. Diseases 2018; 6: 22.

227. Raal FJ, Kallend D, Ray KK, et al. Inclisiran for the treatment of heterozygous familial hypercholesterolemia. N Engl J Med 2020; 382: 1520-30.

228. Ray KK, Wright RS, Kallend D, et al. Two phase 3 trials of inclisiran in patients with elevated LDL cholesterol. N Engl J Med 2020; 382: 1507-19.

229. Khan SA, Naz A, Masoo MQ, et al. Meta-analysis of inclisiran for the treatment of hypercholesterolemia. Am J Cardiol 2020; 134: 69-73.

230. Cordero A, Santos-Gallego CG, Fácila L, et al. Estimation of the major cardiovascular events prevention with Inclisiran. Atherosclerosis 2020; 313: 76-80.

231. Nikolic D, Rizzo M, Mikhailidis DP, Wong NC, Banach M. An evaluation of RVX-208 for the treatment of atherosclerosis. Expert Opin Investig Drugs 2015; 24 : 1389-98.

232. Nicholls SJ, Ray KK, Johansson JO, et al. Selective BET protein inhibition with apabetalone and cardiovascular events: a pooled analysis of trials in patients with coronary artery disease. Am J Cardiovasc Drugs 2018; 18: 109-15.

233. Ray KK, Nicholls SJ, Buhr KA, et al. Effect of apabetalone added to standard therapy on major adverse cardiovascular events in patients with recent acute coronary syndrome and type 2 diabetes: a randomized clinical trial. JAMA 2020; 323: 1565-73.

234. Kalantar-Zadeh K, Schwartz GG, Nicholls SJ, et al.; BETonMACE Investigators. Effect of apabetalone on cardiovascular events in diabetes, CKD, and recent acute coronary syndrome: results from the BETonMACE randomized controlled trial. Clin J Am Soc Nephrol 2021; 16: 705-16.

235. Rocha NA, East C, Zhang J, et al. ApoCIII as a cardiovascular risk factor and modulation by the novel lipid-lowering agent volanesorsen. Curr Atheroscler Rep 2017; 19: 62.

236. Sahebkar A, Simental-Mendía LE, Katsiki N, et al. Effect of fenofibrate on plasma apolipoprotein C-III levels: a systematic review and meta-analysis of randomised placebo-controlled trials. BMJ Open 2019; 8: e021508.

237. Gouni-Berthold I, Alexander V, Digenio A, et al. Apolipoprotein C-III inhibition with volanesorsen in patients with hypertriglyceridemia (COMPASS): a randomized, double-blind, placebo-controlled trial. Atherosclerosis Suppl 2017; 28: e1-2.

238. Witztum JL, Daniel Gaudet D, Freedman SD, et al. Volanesorsen and triglyceride levels in familial chylomicronemia syndrome. N Engl J Med 2019; 381: 531-42.

239. Gouni-Berthold I, Alexander VJ, Yang Q, et al.; COMPASS study group. Efficacy and safety of volanesorsen in patients with multifactorial chylomicronaemia (COMPASS): a multicentre, double-blind, randomised, placebo-controlled, phase 3 trial. Lancet Diabetes Endocrinol 2021; 9: 264-75.

240. Raal FJ, Rosenson RS, Reeskamp LF, et al. Evinacumab for Homozygous familial hypercholesterolemia. N Engl J Med 2020; 383: 711-20.

241. Rosenson RS, Burgess LJ, Ebenbichle CF, et al. Evinacumab in patients with refractory hypercholesterolemia. N Engl J Med 2020; 383: 2307-19.

242. Ahmad Z, Pordy R, Rader DJ, et al. Inhibition of angiopoietin-like protein 3 with evinacumab in subjects with high and severe hypertriglyceridemia. J Am Coll Cardiol 2021; 78: 193-5.

243. Miname MH, Rocha VZ, Santos RD. The role of RNA-targeted therapeutics to reduce ASCVD risk: what have we learned recently? Curr Atheroscler Rep 2021; 23: 40.

244. Gaudet D, Karwatowska-Prokopczuk E Baum SJ, et al. Vupanorsen, an $\mathrm{N}$-acetyl galactosamine-conjugated antisense drug to ANGPTL3 mRNA, lowers triglycerides and atherogenic lipoproteins in patients with diabetes, hepatic steatosis, and hypertriglyceridaemia. Eur Heart J 2020; 41: 3936-45.

245. Parham JS. Mipomersen and its use in familial hypercholesterolemia. Expert Opin Pharmacother 2019; 20: 127-31.

246. Shah NP, Pajidipati NJ, McGarrah RW, et al. Lipoprotein (a): an update on a marker of residual risk and associated clinical manifestations. Am J Cardiol 2020; 126: 94-102.

247. Gencer B, Mach F. Potential of lipoprotein(a)-lowering strategies in treating coronary artery disease. Drugs 2020; 80: 229-39.

248. O’Donoghue ML, Morrow DA, Tsimikas S, et al. Lipoprotein(a)for risk assessment in patients with established coronary artery disease. J Am Coll Cardiol 2014; 63: 520-7.

249. Wilson DP, Jacobson TA, Jones PH, et al. Use of lipoprotein(a)whose time has come. Ascientific statement from National Lipid Association. J Clin Lipidol 2019; 13 : 374-98.

250. Langsted A, Nordestgaard BG. Lipoprotein(a): is it more, less or equal to LDL as a causal factor for cardiovascular disease and mortality? Curr Opin Lipidol 2020; 31: 125-31.

251. Grundy SM, Stone NJ, Bailey AL, et al. 2018 AHA/ACC/ AACVPR/AAPA/ABC/ACPM/ADA/AGS/APhA/ASPC/ NLA/PCNA guideline on the management of blood cholesterol. Circulation 2019; 139: e1082-143.

252. O’Donoghue ML, Fazio S, Giugliano RP, Stroes ESG. Lipoprotein(a), PCSK9 inhibition, and cardiovascular risk. Insights from FOURIER trial. Circulation 2019; 139: 1483-92.

253. Bittner V, Szarek M, Aylward P, et al. Lipoprotein(a) lowering by alirocumab contributes to event reduction independent of low-density lipoprotein cholesterol in the ODYSSEY OUTCOMES trial. J Am Coll Cardiol 2020; 75: 133-44.

254. Szarek M, Bittner VA, Aylward P, et al. Lipoprotein(a) lowering by alirocumab reduces the total burden of cardiovascular events independent of low-density lipoprotein cholesterol lowering: ODYSSEY OUTCOMES trial. Eur Heart J 2020; 41: 4245-55.

255. Burgess S, Ference BA, Staley JR, et al. Association of LPA variants with risk of coronary disease and the implications for lipoprotein(a)-lowering therapies: a mendelian randomization analysis. JAMA Cardiol 2018; 3: 619-27.

256. Araszkiewicz A, Bandurska-Stankiewicz E, Budzyński A, et al. 2020 Guidelines on the management of diabetic patients. A position of Diabetes Poland. Clin Diabetol 2020; 9: 1-101.

257. Seferovic PM, Coats AJS, Ponikowski P, et al. European Society of Cardiology/Heart Failure Association position paper on the role and safety of new glucose-lowering drugs in patients with heart failure. Eur Heart J 2020; 22: 196-213.

258. Cuchel M, Bruckert E, Ginsberg HN, et al. Homozygous familial hypercholesterolemia: new insights and guid- 
M. Banach, P. Burchardt, K. Chlebus, P. Dobrowolski, D. Dudek, K. Dyrbuś, M. Gąsior, P. Jankowski, J. Jóźwiak, L. Kłosiewicz-Latoszek, I. Kowalska, M. Małecki, A. Prejbisz, M. Rakowski, J. Rysz, B. Solnica, D. Sitkiewicz, G. Sygitowicz, G. Sypniewska, T. Tomasik, A. Windak, D. Zozulińska-Ziółkiewicz, B. Cybulska

ance for clinicians to improve detection and clinical management. A position paper from the Consensus Panel on Familial Hypercholesterolemia of the European Atheroslcerosis Society. Eur Heart J 2014; 35: 2146-57.

259. Stefanutti C, Julius U. Lipoprotein apheresis: state of the art and novelties. Atheroscler Suppl 2013; 14: 19-27.

260. Schuff-Werner P, Fenger S, Kohkschein P. Role of lipid apheresis in changing times. Clin Res Cardiol Suppl 2012; 7 Suppl 1: 7-14.

261. Thompson GR, Barbir M, Davies D, et al. Recommendations for the use of LDL apheresis. Atherosclerosis 2008; 98: 247-55.

262. Harada-Shiba M, Arai H, Oikawa S, et al. Guidelines for the management of familial hypercholesterolemia. J Arterioscler Thromb 2012; 19: 1043-60.

263. Goldberg AC, Hopkins PN, Toth PP, et al. National Lipid Association Expert Panel on Familial Hypercholesterolemia. Familial hypercholesterolemia: screening, diagnosis and management of pediatric and adult patients: clinical guidance from the National Lipid Association Expert Panel on Familial Hypercholesterolemia. J Clin Lipidol 2011; 5 (3 Suppl): S1-8.

264. Cuchel M, Bruckert E, Ginsberg HN, et al.; European Atherosclerosis Society Consensus Panel on Familial Hypercholesterolaemia. Homozygous familial hypercholesterolaemia: new insights and guidance for clinicians to improve detection and clinical management A position paper from the Consensus Panel on Familial Hypercholesterolaemia of the European Atherosclerosis Society. Eur Heart J 2014; 35: 2146-57.

265. Raal FJ, Honarpour N, Blom DJ, et al.; TESLA Investigators. Inhibition of PCSK9 with evolocumab in homo zygous familial hypercholesterolaemia (TESLA Part B) a randomised, double-blind, placebo-controlled trial. Lancet 2015; 385: 341-50.

266. Raal, FJ, Hovingh GK, Blom D, et al. Long-term treatment with evolocumab added to conventional drug therapy, with or without apheresis, in patients with homozygous familial hypercholesterolaemia: an interim subset analysis of the open-label TAUSSIG study. Lancet Diabetes Endocrinol 2017; 5: 280-90.

267. Moriarty PM, Parhofer KG, Babirak SP, et al. Alirocum$\mathrm{ab}$ in patients with heterozygous familial hypercholesterolaemia undergoing lipoprotein apheresis: the ODYSSEY ESCAPE trial. Eur Heart J 2016; 37: 3588-95.

268. https://ptnefro.pl/index.php/sekcje_i_grupy_robocze

269. Rawla P, Sunkara T, Thandra KC, Gaduputi V. Hypertriglyceridemia-induced pancreatitis: updated review of current treatment and preventive strategies. Clin J Gastroenterol 2018; 11: 441-8.

270. Ewald N, Hardt PD, Kloer HU. Severe hypertriglyceridemia and pancreatitis: presentation and management. Curr Opin Lipidol 2009; 20: 497-504.

271. Song X, Shi D, Cui Q, et al. Intensive insulin therapy versus plasmapheresis in the management of hypertriglyceridemia-induced acute pancreatitis (Bi-TPAI trial): study protocol for a randomized controlled trial. Trials 2019; 20: 365

272. Schettler VJJ, Neumann CL, Peter C, et al.; Scientific Board of GLAR for the German Apheresis Working Group. Lipoprotein apheresis is an optimal therapeutic option to reduce increased Lp(a) levels. Clin Res Cardiol Suppl 2019; 14 (Suppl 1): 33-8.

273. Schettler VJJ, Neumann CL, Peter C, et al.; Scientific Board of GLAR for the German Apheresis Working Group. The German Lipoprotein Apheresis Registry
(GLAR) - almost 5 years on. Clin Res Cardiol Suppl 2017; 12 (Suppl 1): 44-9.

274. Vogt A. Lipoprotein(a)-apheresis in the light of new drug developments. Atheroscler Suppl 2017; 30: 38-43.

275. Bianconi V, Banach M, Pirro M; International Lipid Expert Panel (ILEP). Why patients with familial hypercholesterolemia are at high cardiovascular risk? Beyond LDL-C levels. Trends Cardiovasc Med 2021; 31: 205-15.

276. Beheshti SO, Madsen CM, Varbo A, Nordestgaard BG. Worldwide prevalence of familial hypercholesterolemia: meta-analyses of 11 million subjects. J Am Coll Cardiol 2020; 75: 2553-66.

277. Nordestgaard BG, Chapman MJ, Humphries SE, et al.; European Atherosclerosis Society Consensus Panel. Familial hypercholesterolaemia is underdiagnosed and undertreated in the general population: guidance for clinicians to prevent coronary heart disease: consensus statement of the European Atherosclerosis Society. Eur Heart J 2013; 34: 3478-90.

278. Chlebus K, Cybulska B, Gruchała M, et al. Prevalence, diagnosis, and treatment of familial hypercholesterolaemia in outpatient practices in Poland. Kardiol Pol 2018; 76: 960-7.

279. Pająk A, Szafraniec K, Polak M, et al. Prevalence of familial hypercholesterolemia: a meta-analysis of six large, observational, population-based studies in Poland. Arch Med Sci 2016; 12: 687-96.

280. Banach M, Wojtowicz E, Mastej M, Chrusciel P, Jozwiak J; LIPIDOGRAM studies. Prevalence of familial hypercholesterolemia in Poland in the LIPIDOGRAM2004 and 2006 population-based surveys. Eur Heart J 2017; 38 Suppl 1: P5304.

281. Leigh SE, Foster AH, Whittall RA, et al. Update and analysis of the University College London low density lipoprotein receptor familial hypercholesterolemia database. Ann Hum Genet 2008; 72: 485-98.

282. Trinder M, Francis GA, Brunham LR. Association of monogenic vs polygenic hypercholesterolemia with risk of atherosclerotic cardiovascular disease. JAMA Cardiol 2020; 5: 390-9.

283. Brown EE, Sturm AC, Cuchel M, et al. Genetic testing in dyslipidemia: a scientific statement from the National Lipid Association. J Clin Lipidol 2020; 14: 398-413.

284. Thompson GR, Blom DJ, Marais AD, Seed M, Pilcher GJ, Raal FJ. Survival in homozygous familial hypercholesterolaemia is determined by the on-treatment level of serum cholesterol. Eur Heart J 2018; 39: 1162-8.

285. De Ferranti SD, Rodday AM, Mendelson MM, Wong JB, Leslie LK, Sheldrick RC. Prevalence of familial hypercholesterolemia in the 1999 to 2012 United States National Health and Nutrition Examination Surveys (NHANES). Circulation 2016; 133: 1067-72.

286. Myśliwiec M, Walczak M, Małecka-Tendera E, et al. Po stępowanie $\mathrm{w}$ rodzinnej hipercholesterolemii u dzieci i młodzieży. Stanowisko Forum Ekspertów Lipidowych. Kardiol Pol 2013; 71: 1099-105.

287. Lewek J, Konopka A, Starostecka E, Penson PE, Maciejewski M, Banach M. Clinical features of familial hypercholesterolemia in children and adults in EAS-FHSC Regional Centre for Rare Diseases in Poland. J Clin Med 2021; 10: 4302.

288. Blom DJ, Harada-Shiba M, Rubba P, et al. Efficacy and safety of alirocumab in adults with homozygous familial hypercholesterolemia. J Am Coll Cardiol 2020; 76: 131-42.

289. Blom DJ, Cuchel M, Ager M, Phillips H. Target achieve ment and cardiovascular event rates with lomitapide in homozygous familial hypercholesterolaemia. Orphanet J Rare Dis 2018; 13: 96. 
290. Rawshani A, Rawshani A, Franzen S, et al. Mortality and cardiovascular disease in type 1 and type 2 diabetes. N Engl J Med 2017; 376: 1407-18.

291. Olesen KKW, Madsen M, Egholm G, et al. Patients with diabetes without significant angiographic coronary artery disease have the same risk of myocardial infarction as patients without diabetes in a real-world population receiving appropriate prophylactic treatment. Diabetes Care 2017; 40: 1103-10.

292. Katsiki N, Banach M, Mikhailidis DP. Is type 2 diabetes mellitus a coronary heart disease equivalent or not? Do not just enjoy the debate and forget the patient! Arch Med Sci 2019; 15: 1357-64.

293. Taskinen MR, Boren J. New insights into the pathophysiology of dyslipidemia in type 2 diabetes. Atherosclerosis 2015; 239: 483-95.

294. Cieluch A, Uruska A, Grzelka-Woźniak A, Niedźwiecki P, Flotyńska J, Zozulińska-Ziółkiewicz D. Changes in high-density lipoprotein cholesterol (HDL-C) level and the ratio of triglycerides to $\mathrm{HDL}-\mathrm{C}$ during the first year of type 1 diabetes. The InLipoDiab1 prospective observational study. Pol Arch Intern Med 2019; 129: 598-604.

295. Annuzzi G, lovine C, Mandarino B, et al. Effect of acute exogenous hyperinsulinaemia on very low density lipoprotein subfraction composition in normal subjects. Eur J Clin Invest 2001; 31: 118-24.

296. Fendler W, Rizzo M, Borowiec M, et al. Less but better: cardioprotective lipid profile of patients with GCKMODY despite lower HDL cholesterol level. Acta Diabetol 2014; 51: 625-32.

297. Cannon CP, Blazing MA, Giugliano RP, et al.; IMPROVE-IT Investigators. Ezetimibe added to statin therapy after acute coronary syndromes. N Engl J Med 2015; 372: 2387-97.

298. Sabatine MS, Leiter LA, Wiviott SD, et al. Cardiovascular safety and efficacy of the PCSK9 inhibitor evolocumab in patients with and without diabetes and the effect of evolocumab on glycaemia and risk of new-onset diabetes: a prespecified analysis of the FOURIER randomised controlled trial. Lancet Diabetes Endocrinol 2017; 5: 941-50.

299. Ray KK, Colhoun HM, Szarek M, et al.; ODYSSEY OUTCOMES Committees and Investigators. Effects of alirocumab on cardiovascular and metabolic outcomes after acute coronary syndrome in patients with or without diabetes: a prespecified analysis of the ODYSSEY OUTCOMES randomised controlled trial. Lancet Diabetes Endocrinol 2019; 7: 618-28.

300. Niklas A, Marcinkowska J, Kozela M, et al. Blood pressure and cholesterol control in hypertensive participants with hypercholesterolemia: results from the Polish multicenter national health survey WOBASZ II. Pol Arch Intern Med 2019; 129: 864-73.

301. Tykarski A, Filipiak KJ, Januszewicz A, et al. 2019 Guidelines for the management of hypertension - part 1-7. Arterial Hyperten 2019; 23: 41-87.

302. Williams B, Mancia G, Spiering W, et al. 2018 ESC/ESH Guidelines for the management of arterial hypertension. J Hypertens 2018; 36: 1953-2041.

303. Gupta AK, Arshad S, Poulter NR. Compliance, safety, and effectiveness of fixed-dose combinations of antihypertensive agents: a meta-analysis. Hypertension 2010; 55: 399-407.

304. Dobrowolski P, Klisiewicz A, Florczak E, et al. Independent association of obstructive sleep apnea with left ventricular geometry and systolic function in resistant hypertension: the RESIST-POL study. Sleep Med 2014; 15: $1302-8$.

305. Prejbisz A, Dobrowolski P, Kosinski P, et al. Management of hypertension in pregnancy: prevention, diagnosis, treatment and longterm prognosis. Kardiol Pol 2019; 77: 757-806.

306. Tykarski A, Filipiak KJ, Januszewicz A, et al. 2019 guidelines for the management of hypertension - part 8-9. Arterial Hypertens 2019; 23: 203-39.

307. Awad K, Mikhailidis DP, Toth PP, et al.; Lipid and Blood Pressure Meta-analysis Collaboration (LBPMC) Group. Efficacy and safety of alternate-day versus daily dosing of statins: a systematic review and meta-analysis. Cardiovasc Drugs Ther 2017; 31: 419-31.

308. Bonaca MP, Nault P, Giugliano RP, et al. Low-density lipoprotein cholesterol lowering with evolocumab and outcomes in patients with peripheral artery disease: insights from the FOURIER trial (Further Cardiovascular Outcomes Research With PCSK9 Inhibition in Subjects With Elevated Risk). Circulation 2018; 137: 338-50.

309. Nissen SE, Stroes E, DentAcosta RE, et al.; Gauss3 Investigators. Efficacy and tolerability of evolocumab vs ezetimibe in patients with musclerelated statin intolerance: the GAUSS3 randomized clinical trial. JAMA 2016; 315: 1580-90.

310. Wong ND, Shapiro MD. Interpreting the findings from the recent PCSK9 monoclonal antibody cardiovascular outcomes trials. Front Cardiovasc Med 2019; 6: 14.

311. Mendieta G, Ben-Aicha S, Gutiérrez M, et al. Intravenous statin administration during myocardial infarction compared with oral post-infarct administration. J Am Coll Cardiol 2020; 75: 1386-402.

312. Dyrbus K, Gasior M, Witkowski A, Dudek D, Banach M. Leczenie zaburzeń lipidowych $u$ chorych z przewlekłym zespołem wieńcowym i z ostrym zespołem wieńcowym. Kardiol Pol 2020; Suppl V: 98-132.

313. Taylor F, Huffman MD, Macedo AF, et al. Statins for the primary prevention of cardiovascular disease. Cochrane Database Syst Rev 2013; 2013: CD004816.

314. Aung PP, Maxwell HG, Jepson RG, et al. Lipid-lowering for peripheral arterial disease of the lower limb. Cochrane Database Syst Rev 2007; 2007: CD000123.

315. Szarek M, Steg PG, DiCenso D, et al. Alirocumab reduces total hospitalizations and increases days alive and out of hospital in the ODYSSEY OUTCOMES Trial. Circ Cardiovasc Qual Outcomes 2019; 12: e005858.

316. Awad K, Mohammed M, Zaki MM, et al.; Lipid and Blood Pressure Meta-analysis Collaboration (LBPMC) Group and the International Lipid Expert Panel (ILEP). Association of statin use in older people primary prevention group with risk of cardiovascular events and mortality: a systematic review and meta-analysis of observational studies. BMC Med 2021; 19: 139.

317. Banach M, Shekoohi N, Mikhailidis DP, Lip GYH, Hernandex AV, Mazidi M. Relationship between low-density lipoprotein cholesterol, lipid lowering agents and the risk of stroke: a meta-analysis of observational studies and randomized controlled trials. J Am Coll Cardiol 2020; 75 (11 Suppl 1): 2080.

318. Preiss D, Campbell RT, Murray HM, et al. The effect of statin therapy on heart failure events: a collaborative meta-analysis of unpublished data from major randomized trials. Eur Heart J 2015; 36: 1536-46.

319. Liu G, Zheng XX, Xu YL, et al. Meta-analysis of the effect of statins on mortality in patients with preserved ejection fraction. Am J Cardiol 2014; 113: 1198-204. 
M. Banach, P. Burchardt, K. Chlebus, P. Dobrowolski, D. Dudek, K. Dyrbuś, M. Gąsior, P. Jankowski, J. Jóźwiak, L. Kłosiewicz-Latoszek, I. Kowalska, M. Małecki, A. Prejbisz, M. Rakowski, J. Rysz, B. Solnica, D. Sitkiewicz, G. Sygitowicz, G. Sypniewska, T. Tomasik, A. Windak, D. Zozulińska-Ziółkiewicz, B. Cybulska

320. Bielecka-Dabrowa A, Bytyçi I, Von Haehling S, et al. Association of statin use and clinical outcomes in heart failure patients: a systematic review and meta-analysis. Lipids Health Dis 2019; 18: 188.

321. Deo SV, Rababa'h A, Altarabsheh SE, et al. Statin therapy improves long-term survival in non-ischaemic cardiomyopathy: a pooled analysis of 4500 patients. Heart Lung Circ 2014; 23: 985-7.

322. Tavazzi L, Maggioni AP, Marchioli R, et al. Effect of rosuvastatin in patients with chronic heart failure (the GISSI-HF trial): a randomised, double-blind, placebo-controlled trial. Lancet 2008; 372: 1231-9.

323. Al-Gobari M, Le HH, Fall M, Gueyffier F, Burnand B. No benefits of statins for sudden cardiac death prevention in patients with heart failure and reduced ejection fraction: a meta-analysis of randomized controlled trials. PLoS One 2017; 12: e0171168.

324. Bonsu KO, Reidpath DD, Kadirvelu A. Lipophilic statin versus rosuvastatin (hydrophilic) treatment for heart failure: a meta-analysis and adjusted indirect comparison of randomised trials. Cardiovasc Drugs Ther 2016; 30: $177-88$

325. Tavazzi L, Maggioni AP, Marchioli R, et al.; GISSI-HF Investigators. Effect of $n-3$ polyunsaturated fatty acids in patients with chronic heart failure (the GISSI-HF trial): a randomised, double-blind, placebo-controlled trial. Lancet 2008; 372: 1223-30.

326. Banach M; Lipid and Blood Pressure Meta-Analysis Collaboration Group. Statins in patients with chronic kidney disease - an attempt at recommendations. Curr Med Res Opin 2013; 29: 1419-22.

327. Tonelli M, Muntner P, Lloyd A, et al; Alberta Kidney Disease Network. Association between LDL-C and risk of myocardial infarction in CKD. J Am Soc Nephrol 2013; 24: 979-86.

328. Cholesterol Treatment Trialists' (CTT) Collaboration; Herrington WG, Emberson J, Mihaylova B, et al. Impact of renal function on the effects of LDL cholesterol lowering with statin-based regimens: a meta-analysis of individual participant data from 28 randomised trials. Lancet Diabetes Endocrinol 2016; 4: 829-39.

329. Barylski M, Nikfar S, Mikhailidis DP, al.; Lipid and Blood Pressure Meta-Analysis Collaboration Group. Statins decrease all-cause mortality only in CKD patients not requiring dialysis therapy: a meta-analysis of 11 randomized controlled trials involving 21,295 partici pants. Pharmacol Res 2013; 72: 35-44.

330. Nikolic D, Nikfar S, Salari P, et al.; Lipid and Blood Pressure Meta-Analysis Collaboration Group. Effects of statins on lipid profile in chronic kidney disease patients: a meta-analysis of randomized controlled trials. Curr Med Res Opin 2013; 29: 435-51.

331. Nikolic D, Banach M, Nikfar S, et al.; Lipid and Blood Pressure Meta-Analysis Collaboration Group. A meta-analysis of the role of statins on renal outcomes in patients with chronic kidney disease. Is the duration of therapy important? Int J Cardiol 2013; 168: 5437-47.

332. Ferro CJ, Mark PB, Kanbay M, et al. Lipid management in patients with chronic kidney disease. Nat Rev Nephrol 2018; 14: 727-49.

333. Palmer SC, Navaneethan SD, Craig JC, et al. HMG CoA reductase inhibitors (statins) for kidney transplant recipients. Cochrane Database Syst Rev 2014; 1: CD005019.

334. Lin YC, Lai TS, Wu HY, et al. Effects and safety of statin and ezetimibe combination therapy in patients with chronic kidney disease: a systematic review and meta-analysis. Clin Pharmacol Ther 2020; 108: 833-43.
335. Baigent C, Landray MJ, Reith C, et al.; SHARP Investigators. The effects of lowering LDL cholesterol with simvastatin plus ezetimibe in patients with chronic kidney disease (Study of Heart and Renal Protection): a randomised placebo-controlled trial. Lancet 2011; 377: 2181-92.

336. Jun M, Zhu B, Tonelli M, et al. Effects of fibrates in kidney disease: a systematic review and meta-analysis. J Am Coll Cardiol 2012; 60: 2061-71.

337. Charytan DM, Sabatine MS, Pedersen TR, et al. Efficacy and safety of evolocumab in chronic kidney disease in the FOURIER Trial. J Am Coll Cardiol 2019; 73: 2961-70.

338. Toth PP, Dwyer JP, Cannon CP, et al. Efficacy and safety of lipid lowering by alirocumab in chronic kidney disease. Kidney Int 2018; 93: 1397-408.

339. Wright RS, Collins MG, Stoekenbroek RM, et al. Effects of renal impairment on the pharmacokinetics, efficacy, and safety of inclisiran: an analysis of the ORION-7 and ORION-1 studies. Mayo Clin Proc 2020; 95: 77-89.

340. KDIGO clinical practice guideline for lipid management in chronic kidney disease. Kidney Int 2014; 85: 1303-9.

341. De Zeeuw D, Anzalone DA, Cain VA, et al. Renal effects of atorvastatin and rosuvastatin in patients with diabetes who have progressive renal disease (PLANET I): a randomised clinical trial. Lancet Diabetes Endocrinol 2015; 3: 181-90.

342. Herrera-Gómez F, Chimeno M, Martín-García D, et al. Cholesterol-lowering treatment in chronic kidney disease: multistage pairwise and network meta-analyses. Sci Rep 2019; 9: 8951.

343. Cybulska B, Kłosiewicz-Latoszek L. Komentarz do artykułu „Ocena skuteczności i bezpieczeństwa stosowania statyn u dzieci chorych na rodzinną hipercholesterolemie". Medycyna Praktyczna 2016; http://www. mp.pl/artykuly/26863 (30 June 2016).

344. Myśliwiec M, Walczak M, Małecka-Tendera E, et al. Management of familial hypercholesterolemia in children and adolescents. Position paper of the Polish Lipid Expert Forum. J Clin Lipidol 2014; 8: 173-80.

345. Stolarz-Skrzypek K, Bednarski A, Drożdż D, Czarnecka D. Prewencja miażdżycy u dzieci - rola statyn i kwasu acetylosalicylowego. Przegl Lek 2013; 70: 57-64.

346. Ramaswami U, Humphries SE, Priestley-Barnham L, et al. Current management of children and young people with heterozygous familial hypercholesterolaemia - HEART UK statement of care. Atherosclerosis 2019; 290: 1-8.

347. Peterson AL, McBride PE. A review of guidelines for dyslipidemia in children and adolescents. WMJ 2012; 111: 274-81.

348. Niinikoski H, Viikari J, Rönnemaa T, et al. Prospective randomized trial of low-saturated-fat, low-cholesterol diet during the first 3 years of life. The STRIP baby project. Circulation 1996; 94: 1386-93.

349. Perk J, De Backer G, Gohlke H, et al.; Fifth Joint Task Force of the European Society of Cardiology and Other Societies on Cardiovascular Disease Prevention in Clinical Practice; European Association for Cardiovascular Prevention and Rehabilitation. European Guidelines on cardiovascular disease prevention in clinical practice (version 2012): The Fifth Joint Task Force of the European Society of Cardiology and Other Societies on Cardiovascular Disease Prevention in Clinical Practice (constituted by representatives of nine societies and by invited experts). Atherosclerosis 2012; 223: 1-68.

350. Goldwire M. Screening and treatment of pediatric dyslipidemias. US Pharm 2014; 39: 52-6. 
351. Obarzanek E, Kimm SY, Barton BA, et al.; DISC Collaborative Research Group. Long-term safety and efficacy of a cholesterol-lowering diet in children with elevated low-density lipoprotein cholesterol: seven-year results of the Dietary Intervention Study in Children (DISC). Pediatrics 2001; 107: 256-64.

352. Cameron C, Craig CL, Bull FC, Bauman A. Canada's physical activity guides: has their release had an impact? Can J Public Health 2007; 98 Suppl 2: S161-9.

353. Lamaida N, Capuano E, Pinto L, et al. The safety of statins in children. Acta Paediatr 2013; 102: 857-62.

354. Vuorio A, Kuoppala J, Kovanen PT, et al. Statins for children with familial hypercholesterolemia. Cochrane Database Syst Rev 2019; 2019: CD006401.

355. Raal FJ, Braamskamp MJ, Selvey SL, Sensinger CH, Kastelein JJ. Pediatric experience with mipomersen as adjunctive therapy for homozygous familial hypercholesterolemia. J Clin Lipidol 2016; 10: 860-9.

356. Daniels S, Caprio S, Chaudhari U, et al. PCSK9 inhibition with alirocumab in pediatric patients with heterozygous familial hypercholesterolemia: the ODYSSEY KIDS study. J Clin Lipidol 2020; 14: 322-30.e5.

357. Santos RD, Ruzza A, Hovingh GK, et al.; HAUSER-RCT Investigators. Evolocumab in pediatric heterozygous familial hypercholesterolemia. N Engl J Med 2020; 383: 1317-27.

358. Elkins C, Fruh S, Jones L, Bydalek KJ. Clinical practice recommendations for pediatric dyslipidemia. Pediatr Health Care 2019; 33: 494-504.

359. Shah AS, Wilson DP. Primary hypertriglyceridemia in children and adolescents. J Clin Lipidol 2015; 9 (5 Suppl): S20-8.

360. Shah AS, Wilson DP. Genetic disorders causing hypertriglyceridemia in children and adolescents. In: Endotext [Internet]. Feingold KR, Anawalt B, Boyce A, (eds.). MDText.com, Inc.; South Dartmouth 2000

361. Lewington S, Whitlock G, Clarke R, et al. Blood cholesterol and vascular mortality by age, sex, and blood pressure: a meta-analysis of individual data from 61 prospective studies with 55,000 vascular deaths. Lancet 2007; 370: 1829-39.

362. Reiner Z. Primary prevention of cardiovascular disease with statins in the elderly. Curr Atheroscler Rep 2014; 16: 420 .

363. Cholesterol Treatment Trialists' Collaboration. Efficacy and safety of statin therapy in older people: a metaanalysis of individual participant data from 28 randomised controlled trials. Lancet 2019; 393: 407-15.

364. Gencer B, Marston NA, Im K, et al. Efficacy and safety of lowering LDL cholesterol in older patients: a systematic review and meta-analysis of randomised controlled trials. Lancet 2020; 396: 1637-43.

365. Awad K, Mohammed M, Zaki MM, et al.; Lipid and Blood Pressure Meta-analysis Collaboration (LBPMC) Group and the International Lipid Expert Panel (ILEP). Association of statin use in older people primary prevention group with risk of cardiovascular events and mortality: a systematic review and meta-analysis of observational studies. BMC Med 2021; 19: 139.

366. Cybulska B, Kłosiewicz-Latoszek L. Czy warto leczyć hiperlipidemię u ludzi starszych. In: Zaburzenia lipidowe. Cybulska B, Kłosiewicz-Latoszek L (eds.). Termedia, Poznan 2010; 171-84.

367. Peters MJ, Symmons DP, McCarey D, et al. EULAR evidence-based recommendations for cardiovascular risk management in patients with rheumatoid arthritis and other forms of inflammatory arthritis. Ann Rheum Dis 2010; 69: 325-31.
368. Gladman DD, Ang M, Su L, et al. Cardiovascular morbidity in psoriatic arthritis. Ann Rheum Dis 2009; 68: 1131-5.

369. Liao KP, Playford MP, Frits $M$, et al. The association between reduction in inflammation and changes in lipoprotein levels and HDL cholesterol efflux capacity in rheumatoid arthritis. J Am Heart Assoc 2015; 4: e001588.

370. Konrad E, Güralp O, Shaalan W, et al. Correlation of elevated levels of lipoprotein(a), high-density lipoprotein and low-density lipoprotein with severity of preeclampsia: a prospective longitudinal study. J Obstet Gynaecol 2020; 40: 53-8.

371. Regitz-Zagrosek V, Roos-Hesselink JW, Bauersachs J, et al.; ESC Scientific Document Group. 2018 ESC Guidelines for the management of cardiovascular diseases during pregnancy. Eur Heart J 2018; 39: 3165-241.

372. Vahedian-Azimi A, Makvandi S, Banach M, Reiner Ž, Sahebkar A. Fetal toxicity associated with statins: a systematic review and meta-analysis. Atherosclerosis 2021; 327: 59-67.

373. Botha TC, Pilcher GJ, Wolmarans K, Blom DJ, Raal FJ. Statins and other lipid-lowering therapy and pregnancy outcomes in homozygous familial hypercholesterolaemia: a retrospective review of 39 pregnancies. Atherosclerosis 2018; 277: 502-7.

374. Döbert M, Varouxaki AN, Mu AC, et al. Pravastatin versus placebo in pregnancies at high risk of term preeclampsia. Circulation 2021; 144: 670-9.

375. World Alzheimer Report 2019: Attitudes to dementia. https://www.alz.co.uk/research/world-report-2019.

376. Chu CS, Tseng PT, Stubbs B, et al. Use of statins and the risk of dementia and mild cognitive impairment: a systematic review and meta-analysis. Sci Rep 2018; 8: 5804.

377. Zhang X, Wen J, Zhang Z. Statins use and risk of dementia: a dose-response meta-analysis. Medicine 2018; 97: e11304.

378. Ze-Min K. Effect of combined antihypertensive and lipid-lowering therapies on cognitive function: a new treatment strategy? Cardiol Res Practice 2020; 2020: 1484357.

379. Janik MJ, Urbach DV, van Nieuwenhuizen E, et al. Alirocumab treatment and neurocognitive function according to the CANTAB scale in patients at increased cardiovascular risk: a prospective, randomized, placebo-controlled study. Atherosclerosis 2021; 331: 20-7.

380. Gencer B, Mach F, Guo J, et al.; FOURIER Investigators. Cognition after lowering LDL-cholesterol with evolocumab. J Am Coll Cardiol 2020; 75: 2283-93.

381. Abifadel M, Elbitar S, El Khoury P, et al. Living the PCSK9 adventure: from the identification of a new gene in familial hypercholesterolemia towards a potential new class of anticholesterol drugs. Curr Atheroscler Rep 2014; 16: 439.

382. Marchi C, Adorni MP, Caffarra P, et al. ABCA1- and ABCG1-mediated cholesterol efflux capacity of cerebrospinal fluid is impaired in Alzheimer's disease. J Lipid Res 2019; 60: 1449-56.

383. Lai SW, Liao KF, Lai HC, et al. Statin use and risk of hepatocellular carcinoma. Eur J Epidemiol 2013; 28: 485-92.

384. Vahedian-Azimi A, Shojaie S, Banach M, et al. Statin therapy in chronic viral hepatitis: a systematic review and meta-analysis of nine studies with 195,602 participants. Ann Med 2021; 53: 1227-42.

385. Banach M, Serban MC. Discussion around statin discontinuation in older adults and patients with wast- 
M. Banach, P. Burchardt, K. Chlebus, P. Dobrowolski, D. Dudek, K. Dyrbuś, M. Gąsior, P. Jankowski, J. Jóźwiak, L. Kłosiewicz-Latoszek, I. Kowalska, M. Małecki, A. Prejbisz, M. Rakowski, J. Rysz, B. Solnica, D. Sitkiewicz, G. Sygitowicz, G. Sypniewska, T. Tomasik, A. Windak, D. Zozulińska-Ziółkiewicz, B. Cybulska

ing diseases. J Cachexia Sarcopenia Muscle 2016; 7: 396-9.

386. Frisk G, Bergström H, Helde Frankling M, BjörkhemBergman L. Sex-differences in discontinuation of statin treatment in cancer patients the year before death. Pharmaceuticals 2021; 14: 368.

387. Tjia J, Kutner JS, Ritchie CS, et al. Perceptions of statin discontinuation among patients with life-limiting illness. J Palliat Med 2017; 20: 1098-103.

388. Melzi S, Carenzi L, Cossu MV, et al. Lipid metabolism and cardiovascular risk in HIV-1 infection and HAART: present and future problems. Cholesterol 2010; 2010: 271504.

389. Toribio M, Fitch KV, Sanchez L, et al. Effects of pitavastatin and pravastatin on markers of immune activation and arterial inflammation in HIV. AIDS 2017; 31: 797806.

390. Aberg JA, Sponseller CA, Ward DJ, Kryzhanovski VA Campbell SE, Thompson MA. Pitavastatin versus pravastatin in adults with HIV-1 infection and dyslipidaemia (INTREPID): 12 week and 52 week results of a phase 4, multicentre, randomised, double-blind, superiority trial. Lancet HIV 2017; 4: e284-94.

391. Aberg JA, Gallant JE, Ghanem KG, Emmanuel P, Zingman BS, Horberg MA; Infectious Diseases Society of America. Primary care guidelines for the management of persons infected with HIV: 2013 update by the HIV Medicine Association of the Infectious Diseases Society of America. Clin Infect Dis 2014; 58: e1-34.

392. Hemkens LG, Bucher HC. HIV infection and cardiovascular disease. Eur Heart J 2014; 35: 13731381.

393. Bavinger C, Bendavid E, Niehaus K, et al. Risk of cardiovascular disease from antiretroviral therapy for HIV: a systematic review. PLoS One 2013; 8: e59551.

394. Kutner JS, Blatchford PJ, Taylor HD, et al. Safety and benefit of discontinuing statin therapy in setting of advanced, life-limiting illness. A randomized clinical trial. JAMA Intern Med 2015; 175: 691-700.

395. Nishtala PS, Gnjidie D, Chyou T, Hilmer SN. Discontinuation of statins on population of older New Zealanders with limited life expectancy. Intern Med J 2016; 46: 493-9.

396. Van der Ploeg MA, Floriani C, Achterberg WC, et al. Recommendations for (discontinuation of) statin treatment in older adults: review of guidelines. J Am Geriatr Soc 2020; 68: 417-25.

397. Phelps M, Christensen DM, Gerds T, et al. Cardiovascular comorbidities as predictors for severe COVID-19 infection or death. Eur Heart J Qual Care Clin Outcomes 2021; 7: 172-80.

398. Wang X, Liu Z, Li J, et al. Impacts of type 2 diabetes on disease severity, therapeutic effect, and mortality of patients with COVID-19. J Clin Endocrinol Metabol 2020; 105: dgaa535.

399. Sattar N, McInnes IB, McMurray JJV. Obesity is a risk factor for severe COVID-19 infection. Circulation 2020; 142: 4-6.

400. Kreutz R, Algharably EAE, Azizi M, et al. Hypertension, the renin-angiotensin system, and the risk of lower respiratory tract infections and lung injury: implications for COVID-19. Cardiovasc Res 2020; 116: 1688-99.

401. Fosbol EL, Butt JH, Ostergaard L, et al. Association of angiotensin-converting enzyme inhibitor or angiotensin receptor blocker use with COVID-19 diagnosis and mortality. JAMA 2020; 324: 168-77.

402. Lewek J, Jatczak-Pawlik I, Maciejewski M, Jankowski P, Banach M. COVID-19 and cardiovascular complica- tions - preliminary results of the LATE-COVID study. Arch Med Sci 2021; 17: 818-22.

403. Bhaskar S, Sinha A, Banach M, et al. Cytokine storm in COVID-19-immunopathological mechanisms, clinical considerations, and therapeutic approaches: the REPROGRAM Consortium Position Paper. Front Immunol 2020; 11: 1648.

404. Reiner Ž, Hatamipour M, Banach M, et al. Statins and the COVID-19 main protease: in silico evidence on direct interaction. Arch Med Sci 2020; 16: 490-6.

405. Radenkovic D, Chawla S, Pirro M, Sahebkar A, Banach M. Cholesterol in relation to COVID-19: should we care about it? J Clin Med 2020; 9: 1909.

406. Daniels LB, Sitapati AM, Zhang J, et al. Relation of statin use prior to admission to severity and recovery among COVID-19 inpatients. Am J Cardiol 2020; 136: 149-55.

407. Saeed O, Castagna F, Agalliu I, et al. Statin use and in hospital mortality in diabetics with COVID-19. J Am Heart Assoc 2020; 9: e018475.

408. Vahedian-Azimi A, Mohammadi SM, Heidari Beni F, et al. Improved COVID-19 ICU admission and mortality outcomes following treatment with statins: a systematic review and meta-analysis. Arch Med Sci 2021; 17: 579-95.

409. Penson PE, Banach M. Nocebo/drucebo effect in statin-intolerant patients: an attempt at recommendations. Eur Heart J 2021; doi: 10.1093/eurheartj/ehab358.

410. Penson PE, Mancini GBJ, Toth PP, et al.; Lipid and Blood Pressure Meta-Analysis Collaboration (LBPMC) Group \& International Lipid Expert Panel (ILEP). Introducing the 'Drucebo' effect in statin therapy: a systematic review of studies comparing reported rates of statin-associated muscle symptoms, under blinded and open-label conditions. J Cachexia Sarcopenia Muscle 2018; 9: 1023-33.

411. Bytyci I, Bajraktari G, Sahabkar A, Penson PE, Rysz J, Banach $M$. The prevalence of statin intolerance worldwide: a systematic review and meta-analysis with $4,143,517$ patients. Presentation at the European Society of Cardiology Congress - Digital Experience 2021. 27th August 2021.

412. Rosenson RS, Miller K, Bayliss M, et al. The Statin-Associated Muscle Symptom Clinical Index (SAMS-CI): revision for clinical use, content validation, and inter-rater reliability. Cardiovasc Drugs Ther 2017; 31: 179-86.

413. Michalska-Kasiczak M, Sahebkar A, Mikhailidis DP, et al.; Lipid and Blood Pressure Meta-analysis Collaboration (LBPMC) Group. Analysis of vitamin D levels in patients with and without statin-associated myalgia - a systematic review and meta-analysis of 7 studies with 2420 patients. Int J Cardiol 2015; 178: 111-6.

414. Rosenson RS, Baker S, Banach M, et al. Optimizing cholesterol treatment in patients with muscle complaints. J Am Coll Cardiol 2017; 70: 1290-301.

415. Toth PP, Patti AM, Giglio RV, et al. Management of statin intolerance in 2018: still more questions than answers. Am J Cardiovasc Drugs 2018; 18: 157-73.

416. Patel J, Martin SS, Banach M. Expert opinion: the therapeutic challenges faced by statin intolerance. Expert Opin Pharmacother 2016; 17: 1497-507.

417. Stroes ES, Thompson PD, Corsini A, et. al. Statin associated muscle symptoms: impact of statin therapy European Atherosclerosis Society Consensus Panel Statement on Assessment Actiology and Management. Eur Heart J 2015; 36: 1012-22.

418. Śliż D, Filipiak KJ, Naruszewicz M, Siebert J, Mamcarz A. Differences in achieving treatment goals with statin 
use in various regions of Poland--3ST-POL study results. Ann Agric Environ Med 2016; 23: 116-9.

419. Pajak A, Jankowski P, Kawecka-Jaszcz K, et al. Changes in secondary prevention of coronary artery disease in the post-discharge period over the decade 1997-2007. Results of the Cracovian Program for Secondary Prevention of Ischaemic Heart Disease and Polish parts of the EUROASPIRE II and III surveys. Kardiol Pol 2009; 67: 1353-9.

420. Wisniowska B, Skowron A. Evaluation of patients' adherence to statins in poland. Curr Med Res Opin 2011; 27: 99-105

421. Kardas P, Cieszynski J, Czech M, Banas I, Lewek P. Primary nonadherence to medication and its drivers in poland: Findings from the electronic prescription pilot analysis. Pol Arch Intern Med 2020; 130: 8-16.

422. Zongo A, Simpson S, Johnson JA, Eurich DT. Change in trajectories of adherence to lipid-lowering drugs following non-fatal acute coronary syndrome or stroke. J Am Heart Assoc 2019; 8: e013857.

423. Rodriguez F, Maron DJ, Knowles JW, Virani SS, Lin S, Heidenreich PA. Association of statin adherence with mortality in patients with atherosclerotic cardiovascular disease. JAMA Cardiol 2019; 4: 206-13.

424. Lewey J, Shrank WH, Bowry AD, Kilabuk E, Brennan TA, Choudhry NK. Gender and racial disparities in adherence to statin therapy: a meta-analysis. Am Heart J 2013; 165: 665-78.

425. Mann DM, Woodward M, Muntner P, Falzon L, Kronish I. Predictors of nonadherence to statins: a systematic review and meta-analysis. Ann Pharmacother 2010; 44: 1410-21.

426. Ingersgaard MV, Helms Andersen T, Norgaard $O$, Grabowski D, Olesen K. Reasons for nonadherence to statins - a systematic review of reviews. Patient Prefer Adherence 2020; 14: 675-91.

427. Lemstra M, Blackburn D, Crawley A, Fung R. Proportion and risk indicators of nonadherence to statin therapy: a meta-analysis. Canad J Cardiol 2012; 28: 574-80.

428. Pedro-Botet J, Climent E, Benaiges D. Muscle and statins: from toxicity to the nocebo effect. Expert Opin Drug Saf 2019; 18: 573-9.

429. Kolte D, Aronow WS, Banach M. Polypills for the prevention of cardiovascular diseases. Expert Opin Investig Drugs 2016; 25: 1255-64.

430. Nelson AJ, Puri R, Nissen SE. Statins in a distorted mirror of media. Curr Atheroscler Rep 2020; 22: 37.

431. Matthews A, Herrett E, Gasparrini A, et al. Impact of statin related media coverage on use of statins: interrupted time series analysis with UK primary care data. BMJ 2016; 353: i3283.

432. Jóźwiak J. Czynniki ryzyka - dyslipidemia. In: Ocena wybranych czynników ryzyka sercowo-naczyniowego w ogólnopolskiej 5-letniej prospektywnej obserwacji kohorty pacjentów POZ. Jóźwiak J (Ed.). Wydawnictwo Politechniki Częstochowskiej, Czestochowa 2013.

433. Bell DA, Kirke AB, Barbour R, et al. Can patients be accurately assessed for familial hypercholesterolaemia in primary care? Heart Lung Circ 2014; 23: 1153-7.

434. Vickery AW, Bell D, Garton-Smith J, Kirke AB, Pang J, Watts GF. Optimising the detection and management of familial hypercholesterolaemia: central role of primary care and its integration with specialist services. Heart Lung Circ 2014; 23: 1158-64. 
M. Banach, P. Burchardt, K. Chlebus, P. Dobrowolski, D. Dudek, K. Dyrbuś, M. Gąsior, P. Jankowski, J. Jóźwiak, L. Kłosiewicz-Latoszek, I. Kowalska, M. Małecki, A. Prejbisz, M. Rakowski, J. Rysz, B. Solnica, D. Sitkiewicz, G. Sygitowicz, G. Sypniewska, T. Tomasik, A. Windak,

D. Zozulińska-Ziółkiewicz, B. Cybulska

\section{APPENDIX}

Table I. Detailed information and contact details of the centres forming the PoLA Lipid Clinic Network, being a part of the EAS Lipid Clinic Network

\begin{tabular}{|c|c|c|c|}
\hline Institution & Coordinator & Address & Contact \\
\hline $\begin{array}{l}\text { Regional Centre for } \\
\text { Rare Diseases }\end{array}$ & $\begin{array}{l}\text { Professor Maciej Banach, } \\
\qquad \text { MD, PhD } \\
\text { Ewa Starostecka, MD, PhD }\end{array}$ & $\begin{array}{l}\text { Polish Mother's Memorial } \\
\text { Hospital Research Institute, } \\
\text { Rzgowska 281/289, 93-338 Łódź }\end{array}$ & rccr@iczmp.edu.pl \\
\hline $\begin{array}{l}\text { Department } \\
\text { of Cardiology } \\
\text { and Congenital } \\
\text { Diseases of Adults }\end{array}$ & $\begin{array}{l}\text { Professor Maciej Banach, } \\
\text { MD, PhD } \\
\text { Joanna Lewek, MD, PhD }\end{array}$ & $\begin{array}{l}\text { Polish Mother's Memorial } \\
\text { Hospital Research Institute, } \\
\text { Rzgowska 281/289, 93-338 Łódź }\end{array}$ & Joanna.lewek@iczmp.edu.pl \\
\hline $\begin{array}{l}\text { Cardiology } \\
\text { Outpatient Clinic }\end{array}$ & $\begin{array}{l}\text { Professor Maciej Banach, } \\
\text { MD, PhD } \\
\text { Joanna Lewek, MD, PhD }\end{array}$ & $\begin{array}{c}\text { Polish Mother's Memorial } \\
\text { Hospital Research Institute, } \\
\text { Rzgowska 281/289, 93-338 Łódź }\end{array}$ & Joanna.lewek@iczmp.edu.pl \\
\hline $\begin{array}{l}\text { "Pro Corde" } \\
\text { Cardiology Centre } \\
\text { Ltd. }\end{array}$ & Anna Bieńkiewicz, MD & $\begin{array}{c}\text { "Pro Corde" Cardiology Centre } \\
\text { Nowowiejska 64-66/1A, } \\
\text { 50-315 Wrocław }\end{array}$ & Phone (71) 3226008 \\
\hline $\begin{array}{l}\text { Lipid disorders } \\
\text { clinic kardio. } \\
\text { CLINIC specialist } \\
\text { clinics }\end{array}$ & $\begin{array}{l}\text { Ass. prof. Tadeusz Osadnik, } \\
\text { MD, PhD }\end{array}$ & $\begin{array}{l}\text { Wyszyńskiego 1, } \\
\text { 41-300 Dąbrowa Górnicza }\end{array}$ & $\begin{array}{l}\text { Phone +48664 } 466005 \\
\text { Phone +48789434820 } \\
\text { (lipid clinic coordinator) }\end{array}$ \\
\hline $\begin{array}{l}\text { Lipid disorders } \\
\text { clinic kardio. } \\
\text { CLINIC \& Te-Vita } \\
\text { specialist clinics }\end{array}$ & $\begin{array}{l}\text { Ass. prof. Tadeusz Osadnik, } \\
\text { MD, PhD }\end{array}$ & Szymały 1A, 41-922 Radzionków & $\begin{array}{l}\text { Phone +48790 } 404455 \\
\text { Phone +48789434820 } \\
\text { (lipid clinic coordinator) }\end{array}$ \\
\hline $\begin{array}{l}\text { Metabolic Clinic, } \\
\text { CMUJ Department } \\
\text { of Metabolic } \\
\text { Diseases }\end{array}$ & $\begin{array}{l}\text { Ass. prof. Małgorzata Waluś- } \\
\text { Miarka, MD, PhD }\end{array}$ & $\begin{array}{c}\text { University Hospital in Krakow, } \\
\text { Jakubowskiego 2, } \\
\text { 30-688 Kraków }\end{array}$ & Phone (12) 4002950 \\
\hline Metabolic Clinic & Paweł Rajewski, MD, PhD & $\begin{array}{c}\text { Gizińscy Medical Centre, Leśna } \\
\text { 9A, 85-676 Bydgoszcz }\end{array}$ & $\begin{array}{c}\text { Phone +4852 } 3455080 \\
\text { Phone +48525065757 } \\
\text { rejestracja@gizinscy.pl }\end{array}$ \\
\hline $\begin{array}{l}\text { Department of } \\
\text { Internal Medicine } \\
\text { and Arterial } \\
\text { Hypertension }\end{array}$ & Piotr Kowalczyk, MD, PhD & $\begin{array}{l}\text { Matopat Specialist Hospital, } \\
\text { Storczykowa 8/10, 87-100 Toruń }\end{array}$ & Phone +48566594800 \\
\hline $\begin{array}{l}\text { Lipidology Unit of } \\
\text { the Department } \\
\text { of Paediatrics, } \\
\text { Diabetology and } \\
\text { Endocrinology }\end{array}$ & $\begin{array}{l}\text { Professor Małgorzata } \\
\text { Myśliwiec, MD, PhD }\end{array}$ & $\begin{array}{l}\text { University Clinical Centre, } \\
\text { Dębinki 7, 80-957 Gdańsk }\end{array}$ & Phone (58) 3492898 \\
\hline $\begin{array}{l}\text { Cardiology } \\
\text { Outpatient Clinic/ } \\
\text { Unit of Lipid } \\
\text { Disorders }\end{array}$ & $\begin{array}{l}\text { Professor Paweł Burchardt, } \\
\text { MD, PhD }\end{array}$ & $\begin{array}{l}\text { Jozef Strus Multispecialist City } \\
\text { Hospital with Nursing Home } \\
\text { SPZOZ, Szwajcarska 3, } \\
\text { 61-285 Poznań }\end{array}$ & Phone (61) 8739085 \\
\hline $\begin{array}{l}\text { Department of } \\
\text { Treatment of } \\
\text { Obesity, Metabolic } \\
\text { Disorders and } \\
\text { Clinical Dietetics }\end{array}$ & $\begin{array}{l}\text { Professor Paweł Bogdański, } \\
\text { MD, PhD }\end{array}$ & $\begin{array}{c}\text { Poznan University of Medical } \\
\text { Sciences, Szamarzewskiego 84, } \\
\text { 60-569 Poznań }\end{array}$ & Phone +48 618549742 \\
\hline $\begin{array}{l}\text { Metabolic Clinic } \\
\text { for Children, } \\
\text { Department } \\
\text { of Paediatrics, } \\
\text { Rheumatology, } \\
\text { Immunology, and } \\
\text { Bone Metabolic } \\
\text { Disorders, Medical } \\
\text { University of } \\
\text { Bialystok }\end{array}$ & $\begin{array}{c}\text { Radosław Motkowski, MD, } \\
\text { PhD }\end{array}$ & $\begin{array}{l}\text { Waszyngtona } 17, \\
15-274 \text { Białystok }\end{array}$ & Phone +48 857450624 \\
\hline
\end{tabular}


Table I. Cont.

\begin{tabular}{|c|c|c|c|}
\hline Institution & Coordinator & Address & Contact \\
\hline $\begin{array}{l}\text { Department of } \\
\text { Internal Medicine } \\
\text { and Clinical } \\
\text { Pharmacology, } \\
\text { Medical University } \\
\text { of Lodz }\end{array}$ & $\begin{array}{c}\text { Professor Marlena Broncel, } \\
\text { MD, PhD } \\
\text { Paulina Gorzelak-Pabiś, MD, } \\
\text { PhD }\end{array}$ & $\begin{array}{l}\text { Dr Wladyslaw Bieganski } \\
\text { Provincial Specialist Hospital; } \\
\text { Karola Kniaziewicza 1/5, } \\
\text { 91-347 Łódź }\end{array}$ & $\begin{array}{c}\text { Phone (42) } 2516051 \\
\text { Marlena.broncel@umed. } \\
\text { lodz.pl } \\
\text { Paulina.gorzelak-pabis@ } \\
\text { umed.lodz.pl }\end{array}$ \\
\hline $\begin{array}{l}\text { Department } \\
\text { of Metabolic } \\
\text { Disorders }\end{array}$ & $\begin{array}{c}\text { Professor Bogusław } \\
\text { Okopień, MD, PhD } \\
\text { Marcin Basiak, MD, PhD }\end{array}$ & $\begin{array}{l}\text { Department of Internal Medicine } \\
\text { and Clinical Pharmacology, } \\
\text { Medical University of Silesia in } \\
\text { Katowice; Medyków 14, } \\
\text { 40-752 Katowice }\end{array}$ & Phone +48 322088510 \\
\hline
\end{tabular}

